EDSON HIROSHI WATANABE

\title{
FRAMEWORK PARA AVALIAÇÃO DE DESEMPENHO E SUSTENTABILIDADE DE SISTEMA PRODUTIVO DISPERSO
}

São Paulo

2018 
EDSON HIROSHI WATANABE

FRAMEWORK PARA AVALIAÇÃO DE

DESEMPENHO E SUSTENTABILIDADE DE SISTEMA PRODUTIVO DISPERSO

Tese apresentada à Escola Politécnica da Universidade de São Paulo para obtenção de título de Doutor em Ciências.

São Paulo 
EDSON HIROSHI WATANABE

FRAMEWORK PARA AVALIAÇÃO DE

DESEMPENHO E SUSTENTABILIDADE DE SISTEMA PRODUTIVO DISPERSO

Tese apresentada à Escola Politécnica da Universidade de São Paulo para obtenção de título de Doutor em Ciências.

Área de Concentração: Engenharia de Controle e Automação em Mecânica

Orientador: Prof. Dr. Paulo Eigi Miyagi

São Paulo

2018 
Este exemplar foi revisado e corrigido em relação à versão original, sob responsabilidade única do autor e com a anuência de seu orientador.

São Paulo, de de

Assinatura do autor:

Assinatura do orientador:

Catalogação-na-publicação

\section{Watanabe, Edson Hiroshi}

FRAMEWORK PARA AVALIAÇÃO DE DESEMPENHO E SUSTENTABILIDADE DE SISTEMA PRODUTIVO DISPERSO / E. H. Watanabe -- versão corr. -- São Paulo, 2018.

$162 \mathrm{p}$.

Tese (Doutorado) - Escola Politécnica da Universidade de São Paulo. Departamento de Engenharia Mecatrônica e de Sistemas Mecânicos.

1.SISTEMAS DE PRODUÇÃO 2.SUSTENTABILIDADE (AVALIAÇÃO) 3.REDES DE PETRI 4.INDICADORES DE PRODUTIVIDADE 5.QUALIDADE DO PROCESSO I.Universidade de São Paulo. Escola Politécnica.

Departamento de Engenharia Mecatrônica e de Sistemas Mecânicos II.t. 
Dedico esta Tese aos meus pais Tadasi (In Memoriam) e Mieko, meus irmãos Miriam e Milton, a esposa Ana e aos filhos Rodrigo, Guilherme e Daniel. 


\section{AGRADECIMENTOS}

A Deus em primeiro lugar, pois Ele é o criador e o mantenedor.

Ao meu orientador, Prof. Dr. Paulo Eigi Miyagi, pela paciência e sabedoria nas constantes orientações, permanente disponibilidade e grande incentivo para o desenvolvimento deste trabalho.

Aos meus pais, Tadasi Watanabe (In Memoriam) e Mieko Watanabe que incansavelmente não mediram esforços para ver os filhos alcançarem os seus objetivos.

A minha irmã Miriam, cunhado Milton e sobrinha Cinthia e meu irmão Milton, cunhada Teresa, sobrinhas Natália e Adriane, os quais tenho uma profunda admiração e carinho.

A minha esposa Ana Watanabe que em todos os momentos sempre demonstrou o seu carinho e amor incondicional, e aos filhos Rodrigo Akira Watanabe, Guilherme Yuji Watanabe e Daniel Hiroyuki Watanabe pelo amor e carinho que sempre demonstram, são motivos para eu nunca desistir, admiro-os e amo-os muito.

Aos Profs. Drs. Diolino José dos Santos Filho e Fabrício Junqueira pelas sugestões e contribuições, sempre se colocaram à disposição para uma troca de ideias. O Prof. Dr. Marcos Tsuzuki pelas apresentações dos nossos trabalhos em eventos científicos.

Aos amigos do Laboratório de Sistemas de Automação (LSA) Caio Cezar Fattori, Célia Hanako Kano, Jefferson Afonso Lopes de Souza, Osvaldo Asato, pela companhia, amizade e discussões elucidativas ocorridas ao longo destes anos.

Aos amigos Robson Marinho da Silva e Maurício Fontoura Blos que se tornaram meus conselheiros, incentivando-me e me dando apoio nos momentos difíceis vividos no projeto.

Ao amigo Marcosiris Amorim de Oliveira Pessoa pela amizade e apoio no laboratório.

Às secretárias do PPGEM Marisa da Silva Amado Lara e Regianne Fernandes Augusto do Amaral pelo apoio administrativo.

Aos amigos Akikazu Fukata, Marcos André Pisching e Reinaldo Squillante Jr., pela amizade e pelos momentos especiais que vivemos ao longo desses anos compartilhando discussões sobre a nossa fé. 
A Escola Politécnica da USP, ao Departamento de Engenharia Mecatrônica e de Sistemas Mecânicos e ao LSA, que através da sua infraestrutura didática e de pesquisa disponibilizaram recursos para a obtenção neste trabalho.

Aos amigos do DINTER IFSC-USP: Alencar Migliavacca, Claudio José Weber, Eduardo Makoto Suzuki, Elenira Oliveira Vilela, Julio Cezar Barcellos da Silva e Werther Alexandre de Oliveira Serralheiro, os quais compartilhamos os nossos sonhos e lutas.

A Reitora Profa. Maria Clara Kaschny Schneider e os Profs. Valdir Noll e Mario de Noronha Neto do departamento de pesquisa e inovação do IFSC, e o coordenador pela USP Prof. Gilberto Francisco Martha de Souza, pelo apoio continuo na realização deste projeto.

As agências de fomento à pesquisa: CAPES, CNPq, FAPESP, pelo apoio financeiro para realização do programa do DINTER e de nossas pesquisas e participações em eventos científicos no âmbito nacional e internacional.

A todos aqueles que, mesmo não tem sido citado nominalmente, colaboraram, direta ou indiretamente, de maneira não menos importante, na produção deste trabalho. 
"Disse Deus: Eis que Ihes dou todas as plantas que nascem em toda a terra $e$ produzem sementes, e todas as árvores que dão frutos com sementes. Elas servirão de alimento para vocês. $E$ dou todos os vegetais como alimento a tudo o que tem em si fôlego de vida: a todos os grandes animais da terra, a todas as aves do céu e a todas as criaturas que se movem rente ao chão. E assim foi. E Deus viu tudo o que havia feito, e tudo havia ficado muito bom. ... O Senhor Deus colocou o homem no jardim do Éden para cuidar dele e cultivá-lo." Gênesis 1:29-31;2:15

"Assim, não deverá haver pobre algum no meio de vocês," Deuteronômio 15:4 


\section{RESUMO}

Em geral a avaliação de desempenho dos sistemas produtivos considera critério normalizado de uso eficiente de recursos de transformação tecnológica (como máquinas e matérias-primas), processamento de informações e operações de manuseio/transporte. No entanto, não existem critérios ou regras normalizadas para avaliar o desempenho de um sistema produtivo no contexto da sustentabilidade. Assim, este trabalho introduz uma abordagem para identificar e avaliar os indicadores de desempenho relacionados à sustentabilidade dos sistemas produtivos, especificamente para casos geograficamente dispersos, ou seja, Sistema Produtivo Disperso (SPD), no qual os processos ocorrem de forma distribuída e dispersa. A abordagem proposta baseia-se em um framework destinado a medir os indicadoreschave de desempenho de sustentabilidade (KPIs - Key Performance Indicators) que avaliam a sustentabilidade de um sistema. O framework considera a norma ANSI/ISA95 e os processos produtivos modelados usando a rede de Petri. A metodologia de avaliação de sustentabilidade considera 0 equilíbrio dos indicadores de sustentabilidade, os quais dependem dos aspectos econômicos, ambientais, sociais e tecnológicos, além do comprometimento de todos os colaboradores envolvidos.

Palavras-Chave: Framework, Sistema Produtivo Disperso, Avaliação de Sustentabilidade, Rede de Petri, Indicador de Sustentabilidade. 


\begin{abstract}
In general, the performance evaluation of productive systems considers normalized criteria of the efficient use of technological transformation resources (such as machines and raw materials), information processing and handling/transportation operations. However, there are no normalized criteria or rules to evaluate the performance of a productive system in the context of sustainability. Thus, this paper introduces an approach to identify and to evaluate the performance indicators related to the sustainability of productive systems, specifically for geographically disperse cases, i.e., disperse productive system (DPS), in which the processes are in a distributed and disperse architecture. The proposed approach is based on a framework aimed to measure sustainability key-performance-indicators (KPIs) that evaluate the sustainability of a system. The framework considers the ANSI/ISA-95 standard and productive processes modeled using Petri net. The sustainability assessment methodology considers the balance of sustainability indicators, which depend on economic, environmental, social, and technological aspects, besides the commitment of all the partners involved.
\end{abstract}

Keywords: Framework, Disperse Productive System, Sustainability Evaluation, Petri Net, Sustainability Indicator. 


\section{LISTA DE FIGURAS}

Figura 1 - Ciclo para desenvolvimento da pesquisa 25

Figura 2 - Resumo das principais referências do trabalho 26

Figura 3 - MES (Manufacturing Execution System). 44

Figura 4 - Níveis 1, 2, 3 e 4 de gestão de controle com a ANSI/ISA-95 70

Figura 5 - Módulo SuMS proposto no contexto da ANSI/ISA-95. 72

Figura 6 - Rede de comunicação no contexto da CPS onde os "usuários do sistema" dispersos podem monitorar a sustentabilidade de cada sistema produtivo (SP1, ... SPn) e de todo sistema SPD. 73

Figura 7 - Exemplo de um Sistema produtivo modelado em PFS: (a) movimento do transportador que circula pelas estações de trabalho; (b) modelo PFS do sistema de transporte

Figura 8 - Exemplo de detalhamento do modelo em rede de Petri de uma das atividades do PFS na Figura 7.

Figura 9 - Exemplo de um modelo em rede de Petri com indicação das informações utilizadas para cálculo de indicadores de sustentabilidade 76 Figura 10 - Esquema do SuMS com as funcionalidades a serem consideradas para análise do desempenho de sustentabilidade de um SPD.

Figura 11 - Método de cálculo do índice de sustentabilidade relacionado à infraestrutura do sistema. .90

Figura 12 - Resumo do cálculo da sustentabilidade. 92

Figura 13 - Tabelas para cálculo de sustentabilidade. 93

Figura 14 - Exemplo de visualização dos resultados das avaliações: (a) avaliação de sustentabilidade, (b) índices da infraestrutura do SPD. 94

Figura 15 - Modelo em PFS das funcionalidades do SuMS e a interação com o ERP e MES 96

Figura 16 - Refinamento dos Modelos em PFS das funcionalidades do SuMS 97

Figura 17 - Funcionalidade do submódulo de 'coleta de dados', o processo produtivo na 'Estação de distriguição' do SPD e também o banco dados .99

Figura 18 - Funcionalidade de 'avalição de dados' e de 'comunicação' 100

Figura 19 - Exemplo de sistema produtivo disperso (SPD). 103

Figura 20 - Modelos dos processos no SPD. (a) Modelo PFS geral dos processos. (b) Modelo em rede de Petri do processo na "Estação de Distribuição". 105

Figura 21 - Processo produtivo da "estação de distribuição" e a funcionalidade da "aquisição de dados" do SuMS. 106 
Figura 22 - Resultados da avaliação de sustentabilidade. (a) Resumo da avaliação. (b)

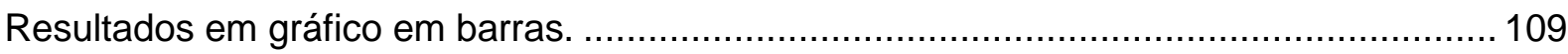

Figura 22 - Placa microprocessada para aquisição de dados. ....................................... 110

Figura 24 - Resultado de leitura de sensor de luminosidade e temperatura......................111

Figura 25 - Resultado da avaliação de sustentabilidade. .............................................. 121

Figura 26 - Resultado da avaliação de sustentabilidade - "pré-fabricação". ..................... 127

Figura 27 - Resultado da avaliação de sustentabilidade - "fabricação". ............................ 127

Figura 28 - Resultado da avaliação de sustentabilidade - "uso". ........................................ 128

Figura 29 - Resultado da avaliação de sustentabilidade - "pós-uso". ................................ 128

Figura 30 - Resultado da avaliação de sustentabilidade no ciclo de vida completo do produto. 129

Figura 31 - Resultado da avaliação de sustentabilidade em fabricação de cabos elétricos. 132

Figura 32 - Resultado da avaliação de sustentabilidade em fabricação mecânica. ............. 135

Figura 33 - Resultado da avaliação de sustentabilidade em fábrica de estamparia. .......... 139 


\section{LISTA DE TABELAS}

Tabela 1 - Indicadores de Sustentabilidade - Aspecto ambiental ...................................... 51

Tabela 2 - Indicadores de Sustentabilidade - Aspecto econômico ….................................... 52

Tabela 3 - Indicadores de Sustentabilidade - Aspecto social ............................................ 52

Tabela 4 - Indicadores de Sustentabilidade - Aspecto tecnológico ....................................53

Tabela 5 - Concentração máxima permitida de dióxido de carbono ......................................53

Tabela 6 - Tempo de decomposição de materiais............................................................... 56

Tabela 7 - Padrão de qualidade do ar ..................................................................... 58

Tabela 8 - Faixa de concentração dos poluentes ........................................................ 59

Tabela 9 - Questionário técnico para levantamento de dados do SPD ............................... 80

Tabela 10 - Questionário técnico para levantamento de dados do aspecto econômico ........80

Tabela 11 - Questionário técnico para levantamento de dados do aspecto ambiental ......... 81

Tabela 12 - Questionário técnico para levantamento de dados do aspecto social ............... 81

Tabela 13 - Questionário técnico para levantamento de dados do aspecto tecnológico....... 82

Tabela 14 - Questões sobre envolvimento no aspecto econômico...................................... 82

Tabela 15 - Questões sobre envolvimento no aspecto social.......................................... 83

Tabela 16 - Questões sobre envolvimento no aspecto ambiental .................................... 83

Tabela 17 - Questões sobre envolvimento no aspecto tecnológico ...................................... 84

Tabela 18 - Questões sobre comprometimento com a sustentabilidade ............................. 84

Tabela 19 - Exemplo de indicadores de sustentabilidade - Aspecto Econômico ..................87 87

Tabela 20 - Questionário sobre o Sistema de produção e sua infraestrutura ....................... 89

Tabela 21 - Indicadores de Sustentabilidade de acordo com aspectos econômicos ........... 106

Tabela 22 - Indicadores de Sustentabilidade de acordo com aspectos ambientais ............ 106

Tabela 23 - Indicadores de Sustentabilidade de acordo com aspectos social ................... 107

Tabela 24 - Indicadores de Sustentabilidade de acordo com aspectos tecnológicos .......... 107

Tabela 25 - Indicadores relativos à dimensão econômica e seus pesos (adaptado de GARBIE, 2014)

Tabela 26 - Avaliação de sustentabilidade utilizando o framework considerando os indicadores econômicos

Tabela 27 - Indicadores relativos à dimensão social e seus pesos (adaptado de GARBIE, 2014)

Tabela 28 - Avaliação de sustentabilidade utilizando o framework considerando os indicadores sociais

Tabela 29 - Indicadores relativos à dimensão ambiental e seus pesos (adaptado de GARBIE, 2014) 
Tabela 30 - Avaliação de sustentabilidade utilizando o framework considerando os indicadores ambientais 119

Tabela 31 - Entrada de peso de cada aspecto de sustentabilidade e sua influência.......... 120

Tabela 32 - Resultado da avaliação de sustentabilidade ............................................. 120

Tabela 33 - Avaliação de sustentabilidade considerando o ciclo de vida do produto (adaptado de JAYAL et al., 2010)

Tabela 34 - Avaliação de sustentabilidade na "pré-fabricação" utilizando o framework considerando os indicadores ambientais 123

Tabela 35 - Avaliação de sustentabilidade na "pré-fabricação" utilizando o framework considerando os indicadores sociais.

Tabela 36 - Avaliação de sustentabilidade na "pré-fabricação" utilizando o framework considerando os indicadores econômicos. 124

Tabela 37 - Avaliação de sustentabilidade na "fabricação" utilizando o framework considerando os indicadores ambientais

Tabela 38 - Avaliação de sustentabilidade na "fabricação" utilizando o framework considerando os indicadores sociais

Tabela 39 - Avaliação de sustentabilidade na "fabricação" utilizando o framework considerando os indicadores econômicos.

Tabela 40 - Avaliação de sustentabilidade no "uso" utilizando o framework considerando os indicadores ambientais 125

Tabela 41 - Avaliação de sustentabilidade no "uso" utilizando o framework considerando os indicadores ambientais

Tabela 42 - Avaliação de sustentabilidade no "uso" utilizando o framework considerando os indicadores econômicos

Tabela 43 - Avaliação de sustentabilidade no "pós-uso" utilizando o framework considerando os indicadores ambientais 126

Tabela 44 - Avaliação de sustentabilidade no "pós-uso" utilizando o método framework considerando os indicadores sociais 126

Tabela 45 - Avaliação de sustentabilidade no "pós-uso" utilizando o framework considerando os indicadores econômicos 126

Tabela 46 - Resultado da avaliação de sustentabilidade na fase de "pré-fabricação" ......... 127

Tabela 47 - Resultado da avaliação da sustentabilidade na "fase de fabricação" .............. 127

Tabela 48 - Resultado da avaliação da sustentabilidade na fase de "uso" 128

Tabela 49 - Resultado da avaliação da sustentabilidade na fase de "pós-uso" 128

Tabela 50 - Resultado da avaliação da sustentabilidade no ciclo de vida completo do produto 
Tabela 51 - Modelo para avaliação de desempenho ambiental da fabricação de materiais elétricos (adaptado de GEST e PROD, 2010). 130

Tabela 52 - Avaliação de sustentabilidade utilizando o framework considerando os indicadores ambientais 131

Tabela 53 - Resultado da avaliação de sustentabilidade utilizando o método proposto considerando os indicadores econômicos.

Tabela 54 - Modelo para avaliação de desempenho ambiental da fabricação mecânica (adaptado de GEST e PROD, 2010) 133

Tabela 55 - Avaliação de sustentabilidade utilizando o framework considerando os indicadores ambientais 134

Tabela 56 - Resultado da avaliação de sustentabilidade utilizando o framework considerando os indicadores ambientais 134

Tabela 57 - Modelo para avaliação de desempenho ambiental da operação de estamparia (adaptado de GEST e PROD, 2010) 136

Tabela 58 - Avaliação de sustentabilidade utilizando o framework considerando os indicadores ambientais 137

Tabela 59 - Resultado da avaliação de sustentabilidade utilizando o framework considerando os indicadores ambientais 138 


\section{LISTA DE ABREVIATURAS E SIGLAS}

ABNT - Associação Brasileira de Normas Técnicas

AGV - Automated Guided Vehicles

AHP - Analytic Hierarchy Process

ANSI/ISA-95 -American National Standards Institute/The International Society of Automation

BM\&F/BOVESPA - Bolsa de Mercadorias e Futuros/Bolsa de Valores de São Paulo CAPES - Coordenação de Aperfeiçoamento de Pessoal de Nível Superior CGSDI - Consultative Group on Sustainable Development Indicators CNPq - Conselho Nacional de Desenvolvimento Científico e Tecnológico CONAMA - Conselho Nacional do Meio Ambiente

CPS - Cyber-Physical System

DES - Data Encryption Standard

DJSI - Dow Jones Sustainability Indexes

EC - Economia Circular

EEACSI - European Environmental Agency Core Set of Indicator

EMAS - Environmental Management and Audit Scheme

EPE - Environment Performance Evaluation

Epfl - Environmental Performance Index

EPI - Equipamentos de Proteção Individual

EPrl - Environmental Pressure Indicators for European Union

EPRII - Environmental Performance Resource Impact Indicator

ERP - Enterprise Resource Planning

ESI - Environmental Sustainability Index

FAPESP - Fundação de Amparo à Pesquisa do Estado de São Paulo

Ford PSI - Ford Product Sustainability Index

GEE - Gases de Efeito Estufa

GRI - Global Reporting Initiative

HPSim - Hybrid Petri Simulator

HVAC - Heating, ventilation, and air conditioning

IBrX-50 - Índice Brasil 50

$\mathrm{ICO}^{2}$ - Índice Carbono Eficiente 
IEC - International Electrotechnical Commission

IOPT - Input Output Place Transition

IoT - Internet of Things

IPCC - Intergovernmental Panel on Climate Change

IQA - Índice de Qualidade do Ar

ISA - International Society of Automation

ISI - Intelligence and Security Informatics

ISO - International Organization for Standardization

KPI - Key Performance Indicators

LCA - Life-Cycle Assessment

MATLab - MATrix Laboratory

MCDA - Multiple Criteria Decision Aid

MDL - Mecanismo de Desenvolvimento Limpo

MES - Manufacturing Execution System

MFA - Material Flow Analysis

MGA - Média Geométrica Anual

MIT - Massachusetts Institute of Technology

MMA - Média aritmética Anual

MSM - Metrics for Sustainable Manufacturing

MTBF - Mean Time Between Failures

MTTR - Mean Time To Repair

NBR - Norma Brasileira

NIST - National Institute of Standards and Technology

NISTEP - Japan National Institute of Science and Technology Policy

OECD - Organization for Economic Co-operation and Development

OMAC - Organization for Machine Automation and Control

OMS - Organização Mundial da Saúde

ONG - Organizações Não Governamentais

OPC - OLE (Object Linking and Embedding) for Process Control

P\&D - Pesquisa e Desenvolvimento

PFS - Production Flow Schema

PI - Partículas Inaláveis

PIPE - Platform Independent Petri Net

PRTR - Pollutant Release and Transfer Registries 
QBL - Quadruple Bottom Line

RCE - Redução Certificada de Emissão

RdP - Rede de Petri

SED - Sistemas a Eventos Discretos

SP - Sistema Produtivo

SPD - Sistema Produtivo Disperso

SuKPI - Sustainability Key-Performance-Indicators

SuMS - Sustainability Management System

SWOT - Strengths, Weaknesses, Opportunities and Threats

TBL - Triple Bottom Line

$\mathrm{TI}$ - Technology of Information

TPI - Total Performance Indicator

UNCED - United Nations Conference on Environment and Development

UNCSD - United Nations Indicators of Sustainable Development

URSS - União das Repúblicas Socialistas Soviéticas

USB - Universal Serial Bus

USP - Universidade de São Paulo

VSM - Value Stream Mapping

Walmart Qs - Walmart Sustainability Product Index

WCED - World Commission on Environment and Development

WEB - World Wide Web

WebServer - Internet Server

4R - Reduce, reuse, recycle, recover

$6 \mathrm{R}$ - Reduce, reuse, recycle, recover, redesign and remanufacture 


\section{LISTA DE UNIDADES ESPECÍFICAS}

PM10 - Particulate Material Inhalable

PP - Pontos Percentuais

PPM - Partículas Por Milhão

PTS - Partículas Totais em Suspensão

t $\mathrm{CO}_{2} \mathrm{e}$ - Toneladas de dióxido de carbono equivalente 


\section{SUMÁRIO ESTRUTURADO DA TESE}

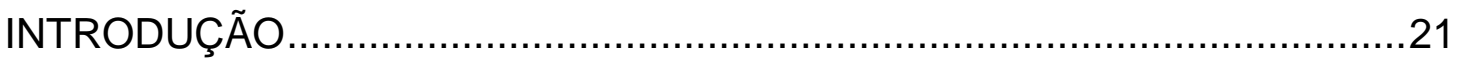

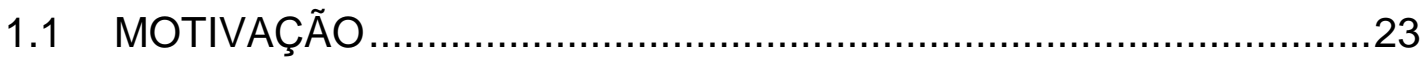

1.2 OBJETIVO

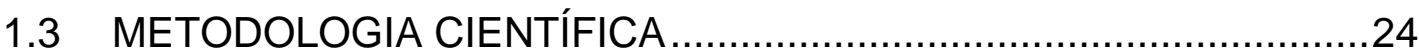

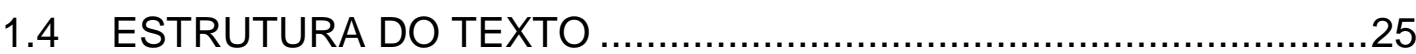

2 SUSTENTABILIDADE, INDICADORES E FERRAMENTAS DE AVALIAÇÃO ...

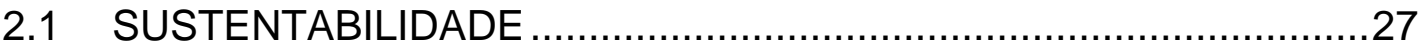

2.2 INDICADORES DE SUSTENTABILIDADE .......................................34

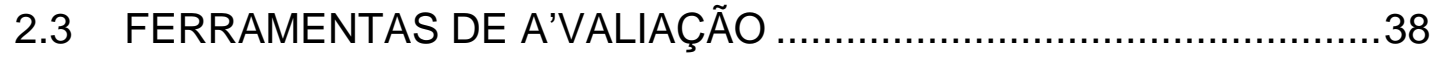

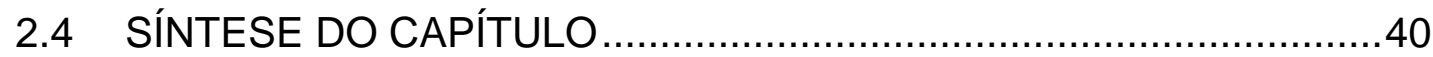

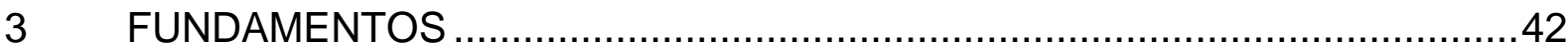

3.1 SUSTENTABILIDADE DE SISTEMA PRODUTIVO …......................42

3.2 ANÁLISE DE DESEMPENHO DA PRODUÇÃO …...........................43

3.3 SISTEMA PRODUTIVO DISPERSO COMO SISTEMA A EVENTOS DISCRETOS .45

3.4 SISTEMA PRODUTIVO SUSTENTÁVEL.......................................46

3.5 INDICADORES DE SUSTENTABILIDADE DE SISTEMAS PRODUTIVOS.

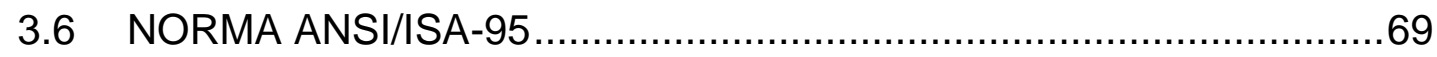

3.7 CYBER PHYSICAL SYSTEM E TECNOLOGIA DA INFORMAÇÃO..71

3.8 TÉCNICAS DE MODELAGEM DE PROCESSOS ….........................73

3.9 SÍNTESE DO CAPÍTULO ………………….............................

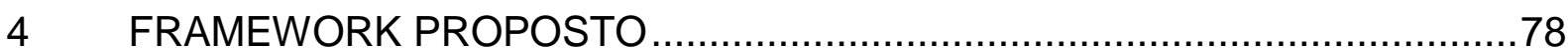

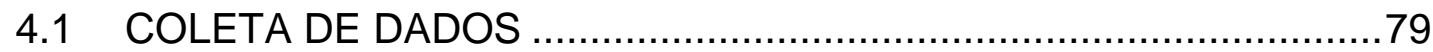

4.1.1 Levantamento de dados do SPD............................................79 
4.1.2 Definição dos indicadores de sustentabilidade

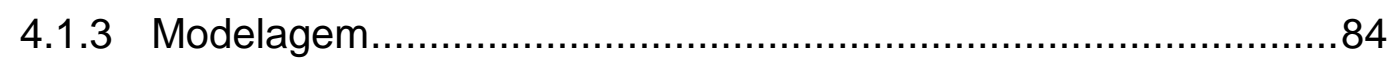

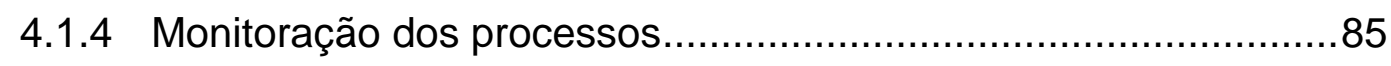

4.2 AVALIAÇÃO DOS DADOS - PROCESSAMENTO DOS DADOS DE SUSTENTABILIDADE .86

4.3 COMUNICAÇÃO COM O NÍVEL DE DECISÕES ESTRATÉGICAS..95

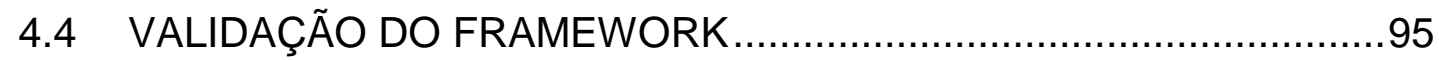

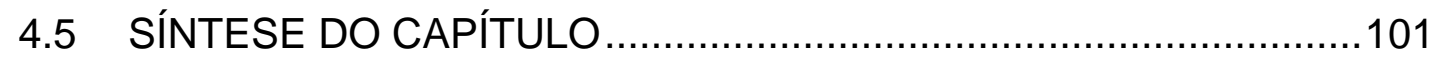

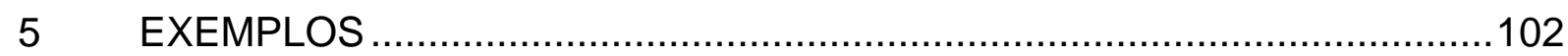

5.1 IMPLEMENTAÇÃO DO FRAMEWORK ……................................102

5.1.1 PROTÓTIPO DE UM SISTEMA DE AQUISIÇÃO DE DADOS..........108

5.2 APLICAÇÃO DE MÉTOdOS DE AVALIAÇÃO DE

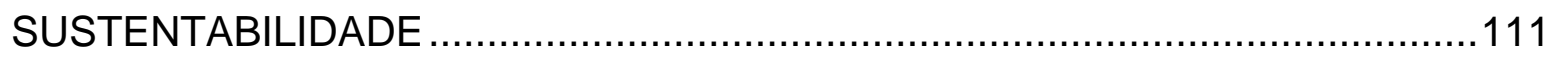

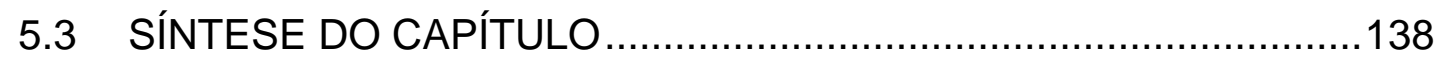

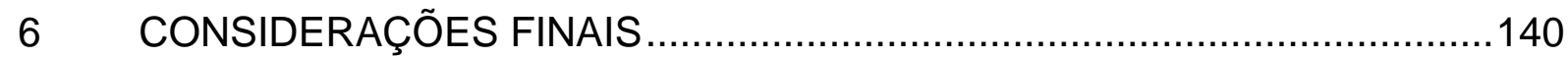

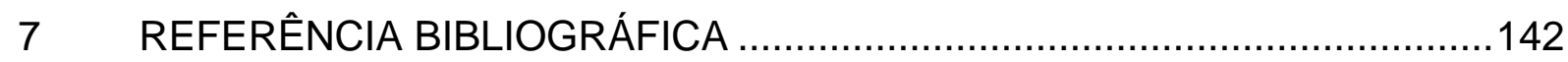

ANEXO

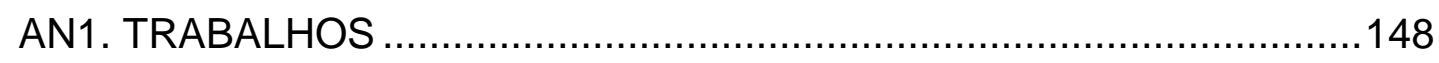

AN1.1 ACEITOS E APRESENTADOS EM EVENTOS TÉCNICO-

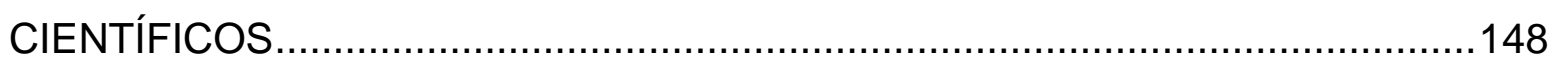

AN1.2. TRABALHOS PUBLICADOS EM PERIÓDICOS CIENTÍFICOS....150

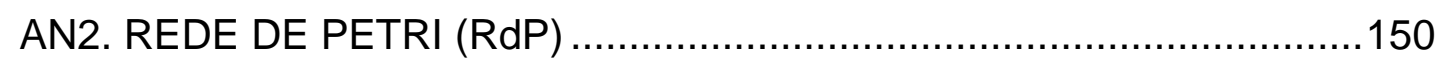

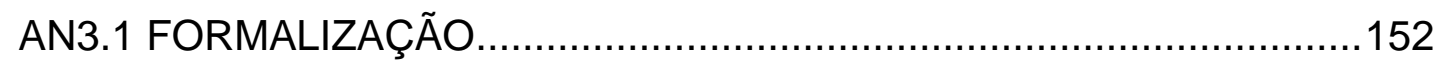

AN3.2 CARACTERÍSTICAS DOS SEDS MODELADOS EM RDP ............153

AN4. PRODUCTION FLOW SCHEMA (PFS) ……………………....157

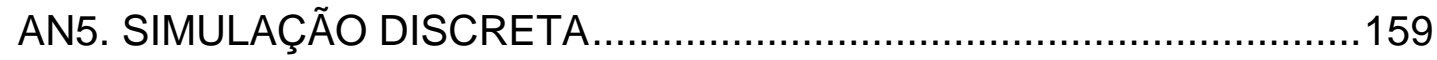




\section{INTRODUÇÃO}

Os sistemas produtivos podem ser entendidos como uma classe de sistemas caracterizados por uma rede de empresas, fornecedores de produtos e serviços e demais recursos, isto é, entidades que podem estar distribuídas geograficamente para explorar melhor os recursos e as vantagens sócio econômicas de diferentes regiões. Para melhor caracterizar esta classe de sistemas utiliza-se o termo sistema produtivo disperso (SPD). Assegurar o desempenho de um SPD é fundamental sob o aspecto econômico. Entretanto, desde meados da década de 80 , devido à crescente escassez de matéria-prima, organizações não governamentais, como o Roman Club, advertiam sobre a necessidade de incluir requisitos de sustentabilidade ambiental na concepção e operação do SPD (SENGE e PORTER, 2001; MCDONOUGH e BRAUNGART, 1998). Assim, surgiram iniciativas das Nações Unidas, como a Comissão Mundial sobre Meio Ambiente e Desenvolvimento (WCED, 1987) e eventos como Rio 92, Kyoto 97, Doha 2012, Paris 2015 e mais recentemente Marrakesh 2016. Neste contexto, existe a proposta de que SPDs deveriam considerar não apenas os parâmetros convencionais de produtividade como o aumento de número de produtos produzidos e redução de custos, mas também aspectos associadas à sustentabilidade, como a redução de impactos ambientais negativos dos processos envolvidos, a conservação e uso de recursos naturais, as práticas para garantir a segurança de funcionários, comunidades e consumidores, as práticas de viabilidade e rentabilidade dos negócios, de tal forma que se garanta a utilização eficiente e segura dos recursos de produção. Além disso, trabalhos como de Amrina e Yusof (2011); Cannata e Taisch (2010); Chen et al. (2014) e Kondoh et al. (2008) também discutem a sustentabilidade como um fator essencial para a avaliação de desempenho de um SPD.

Neste sentido, trabalhos como de Verrier et al. (2013) identificam que:

- Existem propostas de indicadores-chave de desempenho (KPIs) de sistemas produtivos, embora estes não abordem parâmetros específicos de sustentabilidade;

- Cada empresa procura criar suas próprias métricas e KPIs para análise e tomada de decisões, o que é positivo de um lado, mas que dificulta avaliações comparativas entre empresas; 
- Não existe um procedimento sistematizado que considere a sustentabilidade como um critério para a seleção e cálculo dos KPls;

- Apesar de normas como a ANSI/ISA-95 (2005) estabelecerem uma estrutura de gestão e controle dos processos em sistemas produtivos convencionais, não foi identificado na literatura soluções para a monitoração de KPIs de SPDs aderentes ao novo paradigma de aprimoramento contínuo da sustentabilidade desses sistemas.

Por sua vez, observa-se tentativas como a proposta em Jayal et al. (2010) sobre um novo modelo de negócios que considera a sustentabilidade como um guia de atividades produtivas, assim como para (i) melhoria nas relações comerciais, relações de emprego e envolvimento com a comunidade local, (ii) aprimoramento da política ambiental e (iii) fomento da inovação tecnológica. Ainda, do ponto de vista tecnológico, um SPD deve ser desenvolvido considerando também a padronização de produtos e processos, a personalização de produtos e a capacidade de reconfiguração de produtos e processos (GOLDSTONE et al., 2002; BAGHERI et al., 2015), isto é, as normas industriais existentes, como o ANSI/ISA-95, não podem ser ignoradas, principalmente pelo fato de que empresas existentes já organizarem seus sistemas de gestão e controle de acordo com estas normas.

Para a representação de sistemas complexos como é um SPD, isto é, com grande número de elementos e/ou interações entre estes elementos, uma ferramenta formal se faz necessária para a realização de uma análise estrutural e funcional, como o uso de técnica de modelagem em rede de Petri para sua validação. Além disso, considerando a natureza distribuída e dispersa de SPDs, para a infraestrutura de comunicação e processamento de informações deve-se considerar a disponibilidade de sistemas ciber-físicos e ambiente computacional, como WEB (World Wide Web), nuvem e outros, para o acesso sob demanda a uma coleção compartilhada de recursos produtivos diversificados e distribuídos para formar linhas e produção temporárias e reconfiguráveis (WU et al., 2015).

Portanto, entende-se que é necessária uma solução, isto é, um conjunto de funcionalidades devidamente estruturado para avaliar o desempenho de SPD com base em indicadores de sustentabilidade com as seguintes características:

i. Considera a estrutura de gestão e controle de sistemas industriais estabelecida na norma ANSI/ISA-95, mas com uma revisão das funções 
de gestão e controle da mesma, incluindo as funções de processamento de informações para os indicadores de sustentabilidade;

ii. Adota técnicas formais para a modelagem, análise que inclui a verificação e validação dos processos;

iii. Considera a disponibilidade de nova infraestrutura de comunicação e processamento de informações para explorar o acesso sob demanda a recursos de manufatura diversificados e distribuídos para formar linhas de produção temporárias e reconfiguráveis que aumentam a eficiência, reduzem os custos do ciclo de vida do produto e permitem uma alocação otimizada de operações produtivas.

\subsection{MOTIVAÇÃO}

Além da consideração da sustentabilidade como fator estratégico das empresas, trabalhos como de Sarti e Hiratuka (2010) concluem que a reestruturação global da indústria nos últimos 30 anos (i) foi condicionada em grande medida pelas estratégias de internacionalização e de gestão da cadeia de produção, (ii) promoveu um forte deslocamento do processo produtivo e (iii) redirecionou os fluxos globais de produção. Isto é, se identifica claramente uma tendência para a distribuição geográfica e dispersão dos processos produtivos. Por outro lado, observa-se que:

- Não são identificados trabalhos consolidados sobre implementação de avaliação da sustentabilidade quando se considera a natureza distribuída e dispersa dos atuais sistemas produtivos;

- As normas industriais de sistemas de controle e gestão de processos existentes não considerarem a sustentabilidade de modo explícito e sistemático.

\subsection{OBJETIVO}

Baseado nas discussões da seção anterior, o objetivo deste trabalho é desenvolver um framework que sistematiza a avaliação de desempenho e de sustentabilidade de sistemas produtivos dispersos (SPDs), levando-se em conta os indicadores de sustentabilidade.

Neste trabalho adota-se o termo framework conforme a definição no site do Cambridge Dictionary (CAMBRIDGE, 2107), isto é, "uma estrutura de apoio em torno 
do qual uma 'coisa' pode ser construída". Adaptando para o presente trabalho, entende-se o framework como a estrutura de apoio para a implementação de um sistema de avaliação de desempenho de SPD onde, esta estrutura envolve vários subsistemas físicos e lógicos, i.e., hardware e software com funcionalidades específicas assim como os procedimentos para a inicialização dos dados, desenvolvimento de modelos de processos visando seu controle, manipulação e processamento de informações.

$\mathrm{Na}$ prática, existem normas e padrões internacionais como a ANSI/ISA-95 (2005) que estabelecem uma estruturação do sistema de gerenciamento de sistemas produtivos. Assim, para que o conceito de sustentabilidade seja efetivamente considerado e embutido nos processos de gestão e tomada de decisões num SPD, deve-se assegurar que as diretrizes estabelecidas na ANSI/ISA-95 (2005) são devidamente seguidas. Por outro lado, para a avaliação de um SPD que considera diferentes abordagens e visões dos processos produtivos uma estruturação dos procedimentos deve ser estabelecida. Assim identificam-se duas metas específicas:

- Reinterpretação ${ }^{1}$ e extensão² na norma ANSI/ISA-95 (2005) para considerar a sustentabilidade em processos produtivos dispersos. Com isto, assegura-se que o framework proposto atenda a norma ANSI/ISA-95 (2005).

- Desenvolvimento de um procedimento sistematizado de especificação das funcionalidades para a avaliação de desempenho e da sustentabilidade de SPDs. Com isto, estabelece-se como a implementação das partes que compõem o framework proposto deve ser conduzida.

\subsection{METOdOLOGiA CiENTÍFICA}

Considera-se que a pesquisa não tem um final, no sentido de que esta tese é visto aqui como uma contribuição de um trabalho que continua sendo realizado. Neste sentido este trabalho segue a metodologia de projeto apresentada em Jensen (1992) (Figura 1), que envolve três perspectivas diferentes: teoria, ferramentas e aplicações. Eles são tratados de forma cíclica e repetitiva. Este trabalho desenvolve e aperfeiçoa assim as aplicações das teorias, os quais são utilizados para modificar e aperfeiçoar

${ }^{1}$ A norma ANSI/ISA-95 considera sistemas produtivos, mas não foca os casos de processos distribuídos e dispersos geograficamente.

${ }^{2}$ Inserção de módulo para tratar especificamente da sustentabilidade. 
as soluções de casos práticos. Ferramentas são utilizadas ou quando necessárias desenvolvidas para apoiar o avanço de teorias às suas práticas por meio das aplicações.

Figura 1 - Ciclo para desenvolvimento da pesquisa

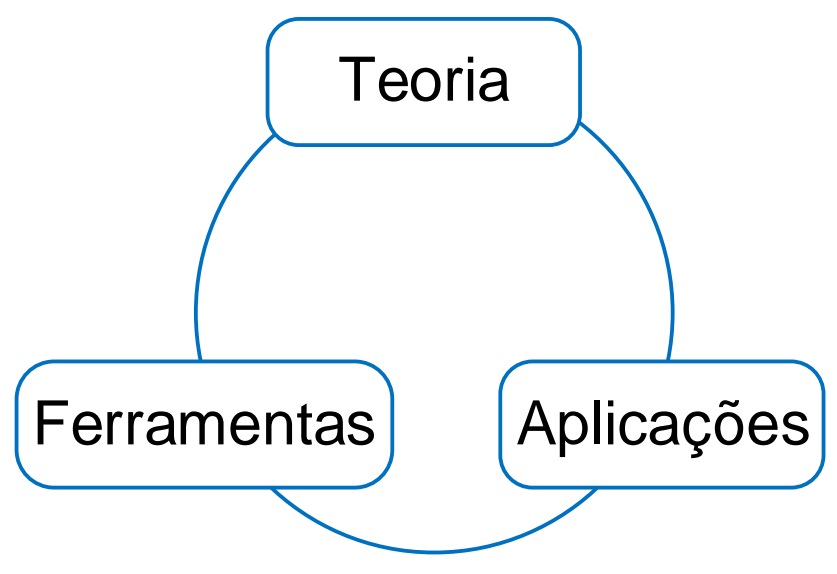

Fonte: Adaptado de Jensen (1992)

Este método de pesquisa e desenvolvimento é uma abordagem eficaz em áreas tecnológicas como a Engenharia que, neste caso, considera os aspectos formais associados à definição de sistemas, modelos, métodos de análise aplicáveis por meio de ferramentas computacionais existentes e, as aplicações em processos industriais como meio de desenvolvimento de novos paradigmas. Os trabalhos de pesquisa sob as três perspectivas identificadas em Jensen (1992) evoluem simultaneamente, condicionando-se mutuamente. Os desenvolvimentos nas três perspectivas identificadas se beneficiam das sinergias resultantes. A Figura 2 sintetiza as principais referências do presente trabalho.

\subsection{ESTRUTURA DO TEXTO}

O texto está estruturado com os seguintes tópicos: o Capítulo 2 apresenta o estado da arte de sustentabilidade, dos indicadores e ferramentas de avaliação de sustentabilidade. O Capítulo 3 apresenta os fundamentos e as premissas adotadas. O Capítulo 4 apresenta o framework proposto para avaliar o desempenho e a sustentabilidade de um SPD. O Capítulo 5 descreve exemplos de implementação. $O$ Capítulo 6 apresenta as conclusões e sugere trabalhos futuros. O anexo lista os 
trabalhos derivados desta tese, fundamentos da técnica de modelagem de processos sistemas adotados, isto é, rede de Petri e Production Flow Schema e informações sobre simulação discreta que foi a técnica usada para complementar a verificação e validação do framework e dos modelos dos processos.

Figura 2 - Resumo das principais referências do trabalho

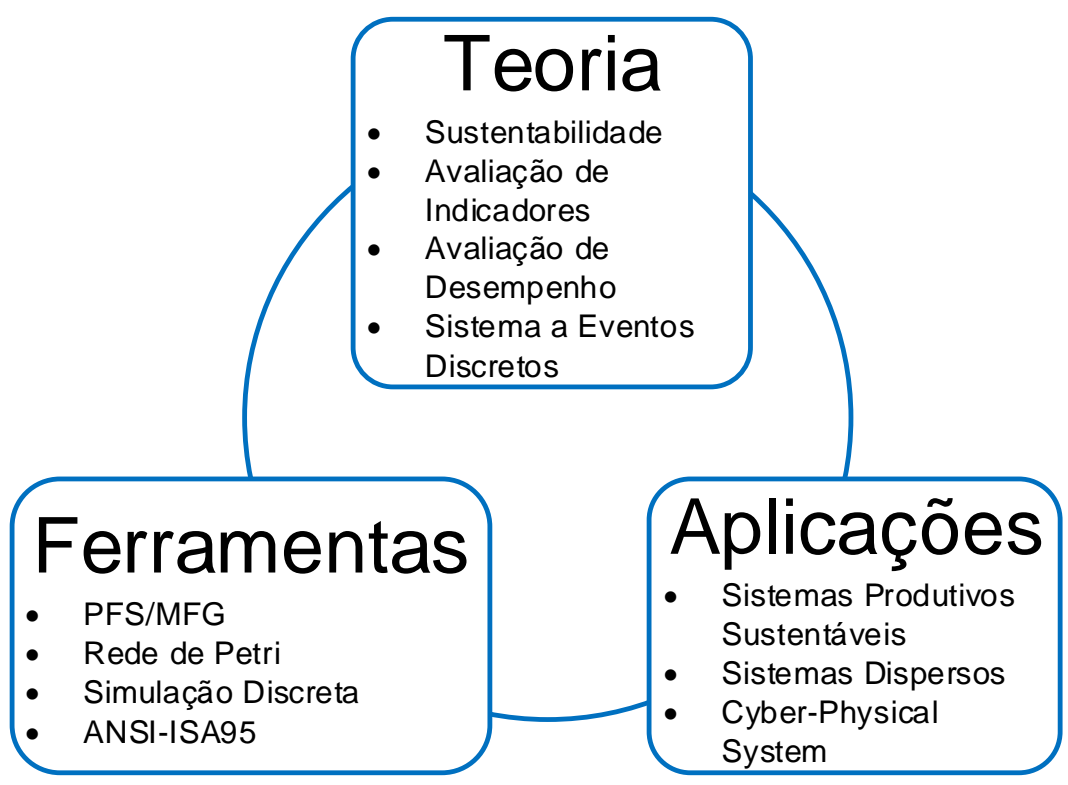

Fonte: $\mathrm{O}$ autor 


\section{SUSTENTABILIDADE, INDICADORES E FERRAMENTAS DE AVALIAÇÃo}

Este capítulo apresenta os conceitos relativos à sustentabilidade e a sua evolução cronológica. Mostra um estudo sobre os indicadores de desempenho e sustentabilidade em sistemas produtivos e também aborda uma análise sobre ferramentas de avaliação.

\subsection{SUSTENTABILIDADE}

O estudo deste assunto teve início em pesquisas multidisciplinares na década de 60, desde então muitas barreiras (culturais, sociais, econômicas e políticas) já foram vencidas e atualmente a sustentabilidade é considerada uma realidade para a construção de um mundo melhor. Porém, ainda existem inúmeras dificuldades para sua implementação.

A seguir é mostrada uma cronologia da discussão sobre a sustentabilidade no mundo:

\section{8 - Clube de Roma}

Fundada em 1968, o Clube de Roma (COLOMBO, 2011) é uma organização internacional não governamental dedicada ao estudo da problemática mundial relacionada com desenvolvimento sustentável que é o termo que cunhou para descrever os problemas políticos, sociais, culturais, ambientais e tecnológicos de um mundo, multidisciplinar e com perspectiva de longo prazo. Reúne cientistas, pesquisadores, empresários e chefes de estado de todos os continentes, incluindo pessoas como o ex-presidente da URSS Mikhail Gorbachev e Rigoberta Menchú Tum, laureada do Prêmio Nobel da Paz de 1992, em reconhecimento ao seu trabalho em justiça social e reconhecimento dos direitos dos povos indígenas (QUEBEC, 2017). Ao longo dos anos, o Clube de Roma produziu um grande número de relatórios, incluindo The Limits to Growth (MEADOWS et al., 1972). 


\section{2 - Lançamento de The Limits to Growth}

Em 1972, o Clube de Roma publicou um relatório sobre os limites para o crescimento (MEADOWS et al., 1972), escrito a seu pedido por uma equipe de pesquisadores do Massachusetts Institute of Technology (MIT). Este relatório foi um dos primeiros documentos de importância publicado sobre os limites ecológicos ao crescimento econômico e demográfico. Explica os resultados de simulações matemáticas realizadas no crescimento demográfico e econômico correlacionadas com a exploração de recursos naturais. O relatório apresenta previsões até 2100 .

A maioria da equipe do MIT concebeu um modelo do mundo especificamente para investigar cinco grandes tendências de preocupação global:

- $\quad$ Aceleração da industrialização global;

- $\quad$ Crescimento rápido da população mundial;

- Desnutrição generalizada causada pela pobreza;

- Dependência de recursos não renováveis e seu esgotamento acelerado;

- Deterioração do ambiente.

A principal conclusão extraída pelos pesquisadores foi que, se as tendências de crescimento na população mundial e industrialização continuassem inalteradas, os limites do modelo para o crescimento seriam alcançados em algum momento dentro dos cem anos seguintes (em torno de 2072), sendo o resultado mais provável bastante abrupto e com declínio incontrolável em capacidade populacional e industrial para atender às necessidades.

Eles propuseram substituir o crescimento pelo equilíbrio do modo a estabilizar a atividade econômica e o crescimento demográfico. Os pesquisadores do MIT apresentaram um modelo de desenvolvimento que não estava mais focado no progresso definido em termos de crescimento econômico - com o crescimento entendido como o impulso para a acumulação infinita de riquezas em um mundo em que os recursos são limitados - mas na compreensão do conceito de progresso como uma melhoria da nossa aptidão para assegurar o bem-estar das comunidades humanas enquanto respeitamos os equilíbrios ecológicos que sustentam a vida.

Além da controvérsia levantada pelas conclusões do The Limits to Growth, o relatório tem colaborado ao longo dos anos na direção de uma definição dos fundamentos de um modo de desenvolvimento que se qualifica hoje como sustentável. (QUEBEC, 2017) 


\section{2 - Conferência das Nações Unidas sobre o Meio Ambiente Humano}

A Conferência das Nações Unidas sobre o Meio Ambiente Humano ocorreu no verão de 1972 em Estocolmo (NAÇÕES UNIDAS, 2017). Provavelmente, pela primeira vez, questões de natureza ecológica foram adicionadas à lista de preocupações internacionais. Um dos principais resultados deste encontro histórico foi a adoção pelos participantes de uma declaração de princípios e um plano de ação para combater a poluição.

Foi nesse encontro que o Programa das Nações Unidas para o Meio Ambiente foi fundado (QUEBEC, 2017).

\section{4 - Comissão Mundial do Meio Ambiente e do Desenvolvimento (Comissão Brundtland)}

Em 1984, a Assembleia das Nações Unidas concedeu à Gro Harlem Brundtland (NAÇÕES UNIDAS, 2017), então primeira-ministra da Noruega, o mandato de formar e presidir a Comissão Mundial sobre Meio Ambiente e Desenvolvimento, hoje reconhecido por ter promovido os valores e os princípios do desenvolvimento sustentável.

O objetivo da Comissão era principalmente recomendar como a comunidade internacional deve preservar o meio ambiente por meio de uma melhor cooperação entre países em desenvolvimento e os chamados países desenvolvidos, considerando as relações existentes entre os povos, os recursos disponíveis, o meio ambiente saudável e o desenvolvimento sócio-econômico dos países. A Comissão elaborou assim um perfil de questões ambientais e, finalmente, apresentou um plano de ação que definia as metas da comunidade internacional em questões relacionadas ao desenvolvimento e à proteção ambiental (NAÇÕES UNIDAS, 2017; QUEBEC, 2017).

No final dos trabalhos da Comissão, Brundtland declarou que: “... quando os termos de referência de nossa Comissão foram originalmente discutidos em 1982, havia aqueles que queriam que suas considerações se limitassem apenas a 'questões ambientais'. Mas isso teria sido um grave erro. O ambiente não existe como uma esfera separada das ações, ambições e necessidades humanas, e as tentativas de defendê-lo isoladamente das preocupações humanas deram a própria palavra 'ambiente' uma conotação de ingenuidade em alguns círculos políticos. A palavra 
'desenvolvimento' também foi estreitada por alguns em um foco muito limitado, ao longo das linhas de o que as nações pobres deveriam fazer para se tornarem mais ricas e, novamente, é automaticamente descartado por muitos na arena internacional como sendo uma preocupação de especialistas, das pessoas envolvidas em questões de ajuda ao desenvolvimento". (Gro Harlem Brundtland, no prefácio de Our Common Future, 1987)

Destaca-se ainda que durante o trabalho da Comissão Mundial sobre Meio Ambiente e Desenvolvimento ocorreram duas grandes catástrofes ambientais e humanas que hoje fazem parte da nossa história: a catástrofe em Bhopal, Índia em 1984, causada por um vazamento de gás tóxico em uma planta de pesticidas e resultando na morte de milhares de pessoas e ferimentos de milhares de outros, bem como a explosão de quatro reatores da central nuclear de Tchernobyl na Ucrânia em1986. O impacto radioativo desse acidente teve e continuará a ter efeitos negativos sobre a saúde das populações e ecossistemas afetados (NAÇÕES UNIDAS, 2017; QUEBEC, 2017).

O trabalho da Comissão levou ao lançamento em 1987 do relatório Our Common Future.

\section{7 - Lançamento do Our Commom Future}

O relatório Our Commom Future, também é chamado de relatório Brundtland e popularizou o termo "desenvolvimento sustentável" (NAÇÕES UNIDAS, 2017; QUEBEC, 2017).

O relatório apresenta um programa abrangente de mudanças que expõe os vínculos entre o crescimento econômico ilimitado, o uso inconsequente dos recursos naturais, a pobreza, e a degradação ambiental. Em consonância com o relatório Limits to Growth publicado pelo Clube de Roma em 1972, o relatório Our Common Future identifica os problemas de escala mundial que comprometem a saúde e a segurança da humanidade e, mais fundamentalmente, o equilíbrio ecológico de que a vida depende. O documento também estabelece objetivos gerais para reverter as tendências atuais. Essencialmente, o relatório confirma a habilidade da humanidade de mudar o curso da história, tomando um caminho de desenvolvimento diferente que desta vez seria sustentável (NAÇÕES UNIDAS, 2017; QUEBEC, 2017). 


\section{2 - Cúpula da Terra}

A cidade do Rio de Janeiro foi o cenário da Cúpula da Terra, também chamada de Conferência das Nações Unidas para o Meio Ambiente e o Desenvolvimento (UNCED). Os participantes definiram os princípios fundamentais e estabeleceram um programa de ação denominado Agenda $21^{3}$, no qual se baseiam hoje diversas iniciativas de desenvolvimento sustentável (NAÇÕES UNIDAS, 2017; QUEBEC, 2017).

Reunindo cerca de 200 representantes de vários governos e um grande número de ONGs, a Cúpula da Terra deu origem à Declaração do Rio sobre Meio Ambiente e Desenvolvimento, um documento chave reafirmando o compromisso internacional com os princípios do desenvolvimento sustentável.

Outros documentos que foram discutidos nesta reunião são:

- $\quad$ Convenção sobre biodiversidade;

- Convenção-quadro sobre mudanças climáticas (e seu corolário, o Protocolo de Kyoto);

- Convenção de combate à desertificação;

- Declaração de princípios sobre gestão, conservação e desenvolvimento sustentável das florestas.

Na sequência desta reunião, foram criadas instituições internacionais para realizar os compromissos assumidos pelas nações presentes. Entre essas instituições, desde 1992 a Comissão das Nações Unidas para o Desenvolvimento Sustentável tem promovido os princípios e práticas associados ao desenvolvimento sustentável no nível internacional (NAÇÕES UNIDAS, 2017, QUEBEC, 2017).

\footnotetext{
${ }^{3} \mathrm{~A}$ Agenda 21 é um plano abrangente de ação para os princípios estabelecidos na Declaração do Rio sobre Meio Ambiente e Desenvolvimento. Ela aborda os problemas globais, que são agrupados em 39 temas envolvendo desenvolvimento social e econômico, proteção ambiental, gerenciamento de recursos, participação da sociedade civil no processo de tomada de decisão e os meios para implementar o desenvolvimento sustentável. Adotada por 179 nações, o programa é um documento de referência de classe mundial.
} 


\section{Declaração do Rio sobre Meio Ambiente e Desenvolvimento}

De acordo com a Declaração do Rio, os países signatários concordaram que a proteção do meio ambiente e o desenvolvimento social e econômico são fundamentais para alcançar o desenvolvimento sustentável. Esta declaração marca um passo significativo no estabelecimento de prioridades de desenvolvimento sustentável no nível internacional (NAÇÕES UNIDAS, 2017; QUEBEC, 2017).

\section{7 - Conferência de Kyoto}

$\mathrm{Na}$ conferência de Kyoto os organismos internacionais tomaram uma nova posição com relação às questões ambientais, embora houvesse um conflito entre União Europeia e Estados Unidos. Nessa conferência foi criado o Protocolo de Kyoto. Um documento que sugere a redução de gases do efeito estufa (cujas metas são de $5,2 \%$ com referência aos níveis de 1990 e têm um prazo final para cumprir a meta: entre 2008 e 2012). Para que fosse aprovado, os países desenvolvidos deveriam aceitar o acordo, pois eles são responsáveis pela maior parte das emissões de gases poluentes da atmosfera. Assim, com a criação do protocolo surge o MDL (Mecanismo de Desenvolvimento Limpo), também conhecido como mercado de créditos de carbono, e os certificados de carbono (NAÇÕES UNIDAS, 2017).

\section{2 - Cúpula Mundial sobre Desenvolvimento Sustentável}

Em 2002, a Cúpula Mundial sobre Desenvolvimento Sustentável foi realizada em Johanesburgo, para que os participantes renovassem seu compromisso com os princípios definidos na Declaração do Rio e os objetivos da Agenda 21 e também quanto ao progresso nesse sentido priorizando certos objetivos. Isso incluiu a eliminação da pobreza, as mudanças nos padrões de consumo e a produção não viável, e a proteção e gestão dos recursos naturais. Os participantes abordaram também a questão da globalização e dos laços que ligam questões de saúde e desenvolvimento. Os representantes dos governos presentes aguardavam a proposição de estratégias nacionais de desenvolvimento sustentável a serem implementadas antes de 2005. Desde então, alguns governos, organizações internacionais e comunidades adotaram e implementaram estratégias, planos de ação 
e programas decorrentes das instruções descritas na reunião (NAÇÕES UNIDAS, 2017, QUEBEC, 2017).

\section{1 - Conferência em Durban (África do Sul)}

Nesta conferência foram colocados vários desafios em pauta como: definir quais medidas seriam tomadas com relação às mudanças climáticas e também qual seria o próximo passo, após a expiração do prazo estabelecido no Protocolo de Kyoto. Alguns países aceitaram a criação de um novo acordo ou protocolo com força legal para diminuir os efeitos negativos das mudanças climáticas e também para que futuramente todos os países participassem da diminuição dos gases. No novo texto os seguintes pontos foram discutidos:

- $\quad$ Existência de uma lacuna entre a proposta de redução dos gases estufa e a contenção do aquecimento médio do planeta em $2^{\circ} \mathrm{C}$;

- Formação de um grupo para criar um novo instrumento internacional legal até 2015, com implementação a partir de 2020 (processo chamado de Plataforma Durban para Ação Aumentada);

- O relatório do IPCC (Intergovernamental Panel on Climate Change) deverá ser levado em consideração, para que sejam tomadas medidas mais severas para conter o aquecimento global;

- $\quad$ Surgimento de uma nova etapa para o Protocolo de Kyoto, estendido até 2017.

Outros assuntos debatidos foram o funcionamento do Fundo Verde Climático, a aprovação da criação de um Centro de Tecnologia do Clima (NAÇÕES UNIDAS, 2017).

\section{2 - Conferência no Brasil (Rio +20)}

A Conferência da ONU sobre o Desenvolvimento Sustentável mais conhecida como Rio +20 aconteceu na cidade do Rio de Janeiro, após vinte anos de realização da conferência sobre meio ambiente e desenvolvimento sustentável, a Rio-92. O objetivo dessa conferência foi garantir e renovar o compromisso entre os políticos para o desenvolvimento sustentável (NAÇÕES UNIDAS, 2017). 


\section{5 - Acordo de Paris}

O Acordo de Paris, que é destinado a substituir o Protocolo de Kyoto, é o primeiro pacto universal para tentar combater a mudança climática. Ele tem como objetivo manter o aumento da temperatura média mundial "abaixo de $2^{\circ} \mathrm{C}$ ", e "reúne esforços para limitar o aumento de temperatura a $1,5^{\circ} \mathrm{C}$ ", em relação dos níveis préindustriais (NAÇÕES UNIDAS, 2017).

Muitos entendem que o sucesso do cumprimento de metas e a reversão do quadro de descontrole do uso dos recursos naturais dependem do envolvimento de toda a sociedade mundial. E nesse contexto ainda existem muitas posições diferentes pois, mesmo pensadores como Adam Smith e Karl Marx que são mencionados como exemplo de visões distintas sobre a evolução da sociedade, tinham a mesma idéia de que os recursos naturais eram de alguma forma inesgotáveis, assim, nenhum deles aborda explicitamente a sustentabilidade em suas teorias.

\subsection{INDICADORES DE SUSTENTABILIDADE}

Existem inúmeros repositórios de artigos técnico-científicos relacionados com indicadores de sustentabilidade de sistemas produtivos com acesso via internet e neste caso considerou-se as bases de dados do Scopus, ISI e IEEEXplore. As principais palavras chaves compostas para busca foram: "sustainable manufacturing" AND "performance metrics", e "sustainable manufacturing" AND "performance indicators". No presente levantamento considerou-se os últimos 15 anos. Deste levantamento, são destacados os seguintes trabalhos:

- Chen et al. (2014) detectam a falta de ferramentas de fácil uso para monitoração e avaliação do estado de sustentabilidade de empresas de manufatura baseados em indicadores de desempenho e para 0 estabelecimento das prioridades para melhorias sistemáticas. Assim o trabalho propõe desenvolver uma ferramenta baseada em informações de sustentabilidade, avaliar as empresas sob um olhar holístico e ajudá-las a tomar decisões necessárias para melhorias do meio ambiente. Devido à complexidade de um sistema produtivo o trabalho de Chen et al. (2014) confirma que não deve existir apenas um único critério de sustentabilidade. 
- Joung et al. (2012) relatam que devido às pressões por vezes da sociedade e também pelos grupos de ambientalistas em todo mundo, muitos fabricantes de produtos têm considerado a introdução em seus processos de algum tipo de mudança em prol da sustentabilidade. Esta situação, de acordo com os autores, tem desafiado as empresas a desenvolverem e implementarem técnicas e ferramentas de avaliações de sistemas de manufatura sustentáveis. Assim, para medir o nível de sustentabilidade são criadas métricas e indicadores para monitoração, avaliação e tomada de decisões. Porém, os autores acrescentam que isso tem gerado confusões entre as empresas para se definir qual é o conjunto de indicadores a ser utilizado e como interpretar os resultados. Os autores revisam um conjunto de indicadores disponíveis publicamente e fornecem uma categorização destes indicadores as quais são quantificáveis e claramente relacionados com o tipo de atividade produtiva, o seu uso e, também como funcionaria um repositório de indicadores de sustentabilidade com mais de 200 dados para facilitar as empresas e os acadêmicos a buscarem essas informações. A categorização está baseada na similaridade de indicadores em relação à: gestão ambiental, crescimento econômico, bemestar social, avanço tecnológico e gerenciamento de desempenho.

- Verrier et al. (2013) analisam trabalhos anteriores e práticas de 21 indústrias asiáticas para avaliar como funcionam as ações relacionadas ao conceito de produção enxuta e ações consideradas ecológicas e, como estas podem ser melhoradas quando usadas juntas. Os autores reforçam que o sistema produtivo enxuto é fruto das práticas que auxiliam as empresas a identificarem e eliminarem desperdícios por meio de implementações de melhorias. Estas práticas identificam basicamente 7 tipos de desperdícios: superprodução, paradas, transporte desnecessário, defeitos, processos inapropriados, estoque desnecessário e movimentações desnecessárias. Esta abordagem ajuda a aumentar a eficiência, diminuir custos, melhorar o tempo de atendimento ao cliente e, contribui para melhorar a qualidade, assegurar maior lucratividade e uma melhor imagem pública. A abordagem ecológica ajuda a reduzir os desperdícios relacionados com: uso desnecessário da energia, consumo desnecessário de matérias primas, uso inadequado de materiais perigosos e, eleva a imagem da empresa como socialmente responsável. Propõem-se assim a criação de um repositório de dados para associar as maturidades das 
ações entre as empresas e também apresentam um questionário quantitativo e outro qualitativo de indicadores para documentar o real consumo e impacto ambiental das empresas participantes do estudo.

- Kondoh et al. (2008) afirmam que para se chegar a uma sociedade sustentável é importante reduzir o impacto ambiental dos processos produtivos, porém para os engenheiros o principal objetivo tem se focado apenas em melhorar a qualidade produtiva. Os autores sugerem que antes da conscientização do desenvolvimento sustentável é necessário rever o conceito de qualidade produtiva. A eco-eficiência é citada como um índice útil para avaliar aspectos econômicos e ambientais simultaneamente, mas os autores argumentam que a eco-eficiência não pode avaliar cada componente de um produto ou cada seguimento de um processo produtivo. A solução se encontra em um novo indicador de eficiência chamado "indicador de desempenho total" (TPI - Total Performance Indicator). O TPI é descrito como uma poderosa ferramenta para determinar estratégias de projeto para produtos ecológicos. No cálculo deste índice são considerados: o tempo de uso do produto, o custo e o impacto ambiental em todo o ciclo de vida do produto. Para avaliar um processo produtivo usa-se a mesma ideia aplicada ao produto.

- Cannata e Taisch (2010) argumentam que o consumo de energia é um dos principais fatores que impactam o desenvolvimento humano identificados com base em 3 pilares: econômico, ambiental e social. Os autores confirmam que em pesquisas recentes as atividades de produção respondem pela maior parcela de consumo de energia de um sistema produtivo. Para reagir a esta situação e ir em direção a um sistema eficiente energicamente, relatam que diversas ações devem ser realizadas. Entretanto, observam que o planejamento da produção e as políticas de controle da produção que são usados para otimizar os processos produtivos não levam em consideração a eficiência energética. Neste artigo, os autores investigam os indicadores de desempenho da eficiência energética e também o planejamento da produção para um caso prático.

- Amrina e Yusof (2011) consideram que a indústria automobilística é estratégica e uma das mais importantes do setor produtivo e, devido à grande movimentação de matérias primas e recursos naturais é geradora de um grande impacto ambiental. Portanto, estes pesquisadores entendem que é de 
suma importância a avaliação de desempenho sustentável em suas linhas produtivas e em seus processos. Os autores propõem definir um conjunto inicial de "indicadores chave de desempenho" (KPIs - Key Performance Indicators) para avaliar a produção sustentável apropriada para a indústria automotiva. Este conjunto consiste de três fatores divididos em nove dimensões e um total de 41 sub-dimensões. O levantamento foi dirigido para confirmar a adaptabilidade dos indicadores para as práticas da indústria existente. Os KPls foram derivados de uma integração de indicadores de desempenho de produção e indicadores de produção sustentável. Os autores adotaram as 3 dimensões da sustentabilidade: econômico, ambiental e social e os seguintes indicadores de fabricação: qualidade, custo, distribuição e flexibilidade, os quais foram incorporados nos KPIs como dimensão econômica.

A análise do estado-da-arte sobre indicadores de desempenho e de sustentabilidade em sistemas produtivos baseado no levantamento realizado identificam os seguintes pontos:

- $\quad$ Existem trabalhos focados em avaliação de sustentabilidade de produtos e de empresas, mas, em geral, associadas a um único processo produtivo;

- Não existe um critério único de abordagem da sustentabilidade de sistemas produtivos;

- Cada empresa tem criado suas métricas e indicadores para monitoração, avaliação e tomada de decisões e isto resulta na impossibilidade de definir qual conjunto de indicadores devem ser utilizados e como interpretar os resultados para comparar os processos característicos de cada empresa;

- $\quad$ O índice de eco-eficiência não é suficiente para avaliar cada componente de um produto ou cada seguimento de um processo produtivo composto por processos de diferentes empresas, isto é, o TPI apresenta resultados relevantes, mas o seu cálculo deve ser revisto para o caso de SPDs;

- $\quad$ o processo de avaliação de sistemas produtivos sustentáveis é relativamente complexo, assim uma solução sistematizada é necessária;

- Os procedimentos para levantamento dos indicadores de sustentabilidade e para avaliação do desempenho da sustentabilidade de sistemas produtivos não estão estruturados. 


\subsection{FERRAMENTAS DE AVALIAÇÃO}

A avaliação é uma das partes mais importantes do desenvolvimento sustentável, pois por meio da medição e análise de resultados, pode-se acompanhar a evolução do desempenho sustentável do sistema produtivo e seus processos de produção, para assim promover melhorias no sistema e nos processos. Existem muitas pesquisas feitas, com diversas abordagens aplicadas para o desenvolvimento de métodos e ferramentas de avaliação. Moldavska e Welob (2015) identificaram ferramentas de avaliação de sustentabilidade com aplicação em sistemas produtivos. A avaliação das ferramentas é feita com base na informação fornecida pelos desenvolvedores de cada ferramenta e, também nos resultados dos estudos de casos apresentados nos relatos publicados. A confiabilidade do procedimento de avaliação, bem como os dados coletados por meio da lista de indicadores são discutidas. Com a utilização do método AHP (Analytic Hierarchy Process) para ponderar os indicadores ou a técnica de comparação em pares, concluiu-se que o resultado da avaliação pode conter um nível relativamente alto de incerteza. Outros resultados de ferramentas incluem incertezas devido a opiniões subjetivas de especialistas utilizados na avaliação. Algumas ferramentas fornecem resultados significativos apenas ao fazer comparação com base em determinado período de tempo (MONEIM et al., 2013; KRAJNC e GLAVI, 2005; AMRINA e YUSOF, 2011). Algumas outras ferramentas apresentam o resultado no nível do indicador e não utilizam a agregação, normalização e ponderação dos indicadores. Quando a ferramenta tem muitos indicadores, o resultado é difícil de ser analisado. No entanto, pode-se evitar incertezas com a normalização e ponderação. Uma ferramenta pode apresentar o resultado como índice de valor agregado ou índice sem valor agregado. Isso não se refere à taxa de sustentabilidade; no entanto, atividades sem valores agregados podem mostrar onde as melhorias são necessárias. O tipo de dados coletados define a visão adotada pela avaliação de sustentabilidade. É por isso que os conjuntos de indicadores usados por cada ferramenta devem ser considerados. Algumas ferramentas utilizam apenas indicadores qualitativos, outras ferramentas utilizam indicadores quantitativos. Outras utilizam a combinação de indicadores qualitativos e quantitativos. A utilização de apenas um tipo de indicador (qualitativo ou quantitativo) pode reduzir a representatividade da avaliação. 
Quão bem uma ferramenta de avaliação aborda o contexto do caso da empresa depende da combinação de indicadores utilizados pela ferramenta. A lista padrão de indicadores pode não abranger todos os aspectos da fabricação específica (por exemplo, substâncias perigosas, inovação). No entanto, um conjunto de indicadores padrão permite a redução do tempo de avaliação, uma vez que elimina a necessidade de identificação de indicadores para empresa (MONEIM et al., 2013; VELEVA e ELLENBECKER, 2001; WINFIELD et al., 2010; GAUDREAU e GIBSON, 2010). A maioria das ferramentas analisadas inclui o conjunto padrão de indicadores, de modo que a aplicabilidade a uma configuração específica da empresa fica limitada. Algumas das ferramentas, no entanto, incluem a lista padrão de indicadores com a opção de adicionar indicadores específicos que levem em consideração o contexto do caso da empresa. As ferramentas, com base no mapeamento de fluxo de valor (VSM - Value Stream Mapping), incluem o conjunto padrão de indicadores aplicado a cada processo de fabricação, em comparação com a maioria das outras ferramentas que aplicam indicadores a um caso específico de empresa (por exemplo, consumo de água doce, uso de energia). Uma ferramenta de avaliação deve utilizar um conjunto padrão de indicadores atribuídos a diferentes elementos de fábrica. Embora a ferramenta não permita expandir a lista de indicadores, ele deve fornecer o conjunto de indicadores mais abrangente possível. De acordo com os autores, esses indicadores abrangem o contexto de casos de empresas (SINGH et al., 2014; PAJU et al., 2010; MONEIM et al., 2013; VELEVA e ELLENBECKER, 2001; KRAJNC e GLAVI, 2005).

Várias ferramentas apontam problemas apenas no nível social, econômico e ambiental. Além disso, essas ferramentas apresentam o resultado como uma pontuação geral, que pode ser usada para rastrear a taxa de sustentabilidade ao longo de um período de tempo. Outras ferramentas são capazes de identificar problemas mais específicos, como disponibilidade de água, qualidade da água, qualidade das oportunidades de subsistência; consumo de água, uso de matérias-primas, consumo de energia; fontes de resíduos; atividades com ou sem valor agregado; terra, água doce, saúde, educação. Além disso, o projeto de uma ferramenta eficaz permite a identificação do elemento de fábrica em que acontece a ameaça à sustentabilidade (CHEN et al., 2014; FAULKNER e BADURDEEN, 2014; BROWN et al., 2014; SPARKS e BADURDEEN, 2014).

A maioria das ferramentas consomem muito tempo para avaliação devido à necessidade de coleta de dados ou devido à necessidade de envolver entrevistas de 
especialistas para o procedimento de ponderação. Além disso, algumas ferramentas de avaliação requerem conhecimento sobre AHP, ou combinação de LCA (Life-Cycle Assessment), VSM e DES (Data Encryption Standard) (PAJU et al.,2010; MONEIM et al., 2013; KRAJNC e GLAVI, 2005; FAULKNER e BADURDEEN, 2014; YUSOF et al., 2013).

Pelo que foi levantado nos trabalhos acima mencionados, não existe ainda uma ferramenta que identifica problemas e soluções específicas na empresa com base em informações confiáveis em tempo limitado e com recursos limitados e que aborda os principais pilares da sustentabilidade com procedimentos de normalização, ponderação e agregação de dados dos processos envolvidos (MOLDAVSKA e WELOB, 2015).

Outro resultado desta revisão é que, embora as ferramentas baseadas em questionários (indicadores qualitativos) exijam menos tempo e recursos em comparação com outras ferramentas de avaliação, as incertezas do resultado são altas devido à natureza subjetiva dos questionários (MOLDAVSKA e WELOB, 2015). Ferramentas baseadas em VSM ou ferramentas baseadas na abordagem de Gibson e Hassan (2005) são relativamente dispendiosas. O VSM aborda o contexto de fabricação e aponta problemas específicos e, Gibson e Hassan (2005) abordam interligações entre os principais pilares de sustentabilidade, ao contrário de outras ferramentas.

\subsection{SÍNTESE DO CAPÍTULO}

Foram apresentados dados históricos sobre a sustentabilidade no contexto mundial e as iniciativas para reverter ou postergar os efeitos negativos do desenvolvimento industrial para a humanidade se o problema da sustentabilidade não for efetivamente enfrentado planejando e adotando estratégias globais para cuidar dos recursos ainda existentes. Nem sempre nos dados e trabalhos estudados os SPDs foram citados, mas entende-se que são um foco de grande atenção.

Considerando o objetivo deste trabalho, foi apresentado um estudo sobre os indicadores de sustentabilidade nas indústrias, sobre dados que refletem o estado da arte dos indicadores, e como as empresas os estão utilizando. Deriva-se que apesar de existirem diversas propostas, uma abordagem mais sistêmica deve ser considerada para organizar e estruturar os indicadores de modo a serem efetivamente 
úteis para avaliação de SPDs e aprimoramento contínuo da sustentabilidade dos sistemas e processos.

Com base em informações e trabalhos correlatos apresentou-se também uma discussão sobre as ferramentas de avaliação de sustentabilidade existentes. Esta discussão é assumida como uma forma de balizamento para a identificação de metodologias, métodos, procedimentos e técnicas a serem exploradas para que os objetivos da tese sejam alcançados.

Assim, no próximo capítulo são descritos os fundamentos, isto é, as metodologias, métodos, procedimentos e técnicas adotadas no desenvolvimento do presente trabalho. 


\section{FUNDAMENTOS}

Os conceitos aqui apresentados são os fundamentos para a determinação do escopo do trabalho desenvolvido com formulação das hipóteses, visões de sistemas e técnicas de modelagem adotadas. São apresentados os indicadores de sustentabilidade existentes e normas industriais relacionadas à gestão e controle de processos, assim como uma discussão da disponibilidade e aplicação de novas tecnologias de informação e comunicação.

\subsection{SUSTENTABILIDADE DE SISTEMA PRODUTIVO}

A World Commission in Environment and Development (WCED, 1987) define o desenvolvimento sustentável como um processo que atende as necessidades atuais sem comprometer a capacidade das futuras gerações de alcançar as suas próprias necessidades. Portanto, o desenvolvimento sustentável procura melhorar a eficiência de processos produtivos em todos os aspectos, a fim de reduzir os impactos ambientais, manter a equidade social e a viabilidade do negócio. De acordo com a Organização para Cooperação e Desenvolvimento Econômico - Organization for Economic Co-operation and Development (OECD, 2011), sustentabilidade é um termo sistêmico, isto é, inclui um conjunto de fatores ou aspectos que são responsáveis pela manutenção de um sistema para este executar processos de maneira sustentável. Neste contexto, a sustentabilidade pode ser abordada de diferentes formas, sendo que tradicionalmente se considera três aspectos: (i) econômico; (ii) ambiental; (iii) social, chamados Triple Bottom Line (TBL) por Elkington (1997). Entende-se que estes aspectos derivam do fato de que os impactos resultantes da ausência de sustentabilidade num sistema são mais visíveis segundo estes aspectos.

Entretanto, do ponto de vista de sistema produtivo, existe a necessidade de consideração do aspecto tecnológico. Isto é, a revisão de conceitos e procedimentos que proporcionam a inovação tecnológica é um aspecto tão relevante para a sustentabilidade de sistemas quanto os outros anteriormente citados. Assim, neste trabalho, a abordagem adotada considera indicadores de acordo com quatro aspectos 
de sustentabilidade: (i) ambiental; (ii) econômico; (iii) social e (iv) tecnológico 4 . Nesta nova configuração, a sustentabilidade é baseada em quatro pilares, de modo que estas definem o Quadruple Bottom Line (QBL).

Considera-se assim que a sustentabilidade $\boldsymbol{S}_{\text {ust }}$ de um sistema produtivo depende do equilíbrio dos quatro aspectos, de modo que ela é expressa pela Eq. (1).

$$
\boldsymbol{S}_{\text {ust }}=f\left(I_{E c o}, I_{E n v}, I_{S o c}, I_{T e c}\right)
$$

onde:

$\boldsymbol{I}_{\boldsymbol{E} \boldsymbol{c} \boldsymbol{}}=$ Indicador do aspecto econômico;

$\boldsymbol{I}_{\boldsymbol{E n v}}=$ Indicador do aspecto ambiental;

$I_{\text {Soc }}=$ Indicador do aspecto social;

$\boldsymbol{I}_{\text {Tec }}=$ Indicador do aspecto tecnológico.

Assume-se inicialmente que os indicadores são calculados com base em parâmetros definidos por especialistas, com base na infraestrutura e nos processos do sistema produtivo.

\subsection{ANÁLISE DE DESEMPENHO DA PRODUÇÃO}

A norma ANSI/ISA-95 (2005) define a atividade de análise de desempenho da produção onde as informações sobre a produção são estudadas e comparadas com os valores dedados pré-estabelecidos e/ou esperados. De acordo com a estrutura hierárquica de gestão e controle dos processos estabelecido pela norma, entende-se que as seguintes informações são tratadas no nível de supervisão dos processos produtivos: tempo de ciclo de produção, utilização de recursos, utilização de equipamentos, desempenho de equipamentos, eficiência de processos de acordo com os KPIs e variabilidade da produção. O resultado desta análise é enviado para o nível superior de gestão e planejamento da produção para processamento e tomada de decisões estratégicas.

${ }^{4} \mathrm{O}$ aspecto tecnológico é perceptível ao longo da operação do sistema produtivo, por meio da evolução dos resultados atingidos pelo sistema, por meio de implementações de melhorias tecnológicas e atualizações de software e hardware no processo. 
O gerenciamento de desempenho envolve um conjunto de atividades que sistematicamente captura e processa a informação de desempenho dos processos produtivos. Isto também envolve ações de correção que afetam a parte operacional do sistema. O gerenciamento de desempenho de um sistema produtivo envolve:

- Monitoração dos parâmetros para assegurar a visibilidade dos KPls;

- $\quad$ Processamento das informações dos KPIs;

- $\quad$ Análise das causas que afetam os KPIs; e

- $\quad$ Previsão de valores futuros dos KPIs.

A Figura 3 apresenta as principais informações (relativos ao rastreamento de produtos, recursos disponíveis, produtos nas linhas de produção e parâmetros operacionais do sistema) que devem ser consideradas para a análise de desempenho da produção. O resultado desta análise é a identificação de problemas e possíveis mudanças que estes podem apontar. Observa-se que o contexto na norma considera apenas o uso eficiente das máquinas sob a visão de custo e qualidade dos produtos e $o$ atendimento aos prazos estabelecidos.

Figura 3 - MES (Manufacturing Execution System)

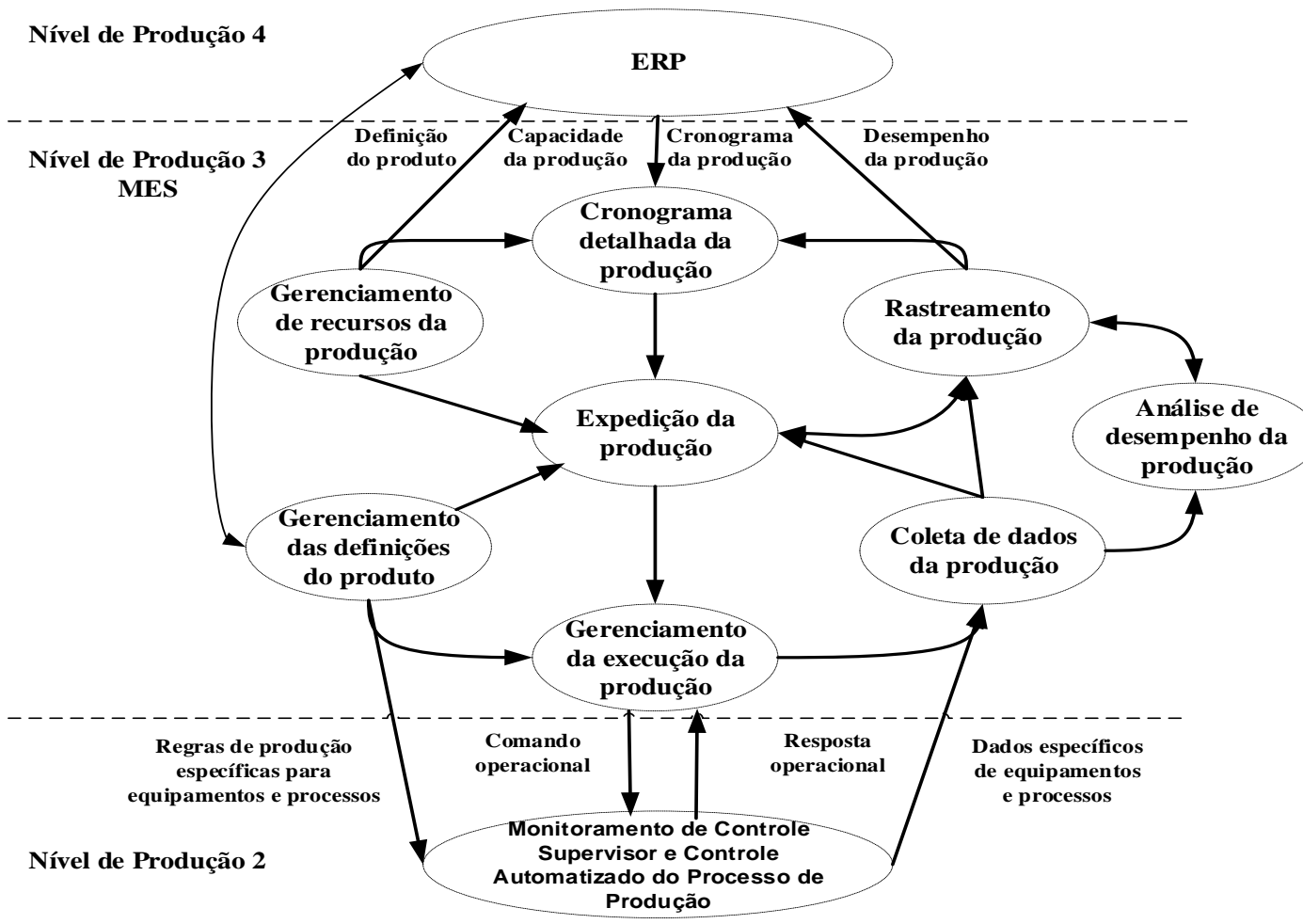

Fonte: Adaptado de ANSI/ISA-95 (2005)

Conforme a norma ANSI/ISA-95 (2005), a tarefa de análise de desempenho da produção inclui: 
- $\quad$ Produzir relatórios de desempenho e custo;

- Avaliar limites para a capacidade das máquinas e qualidade dos produtos;

- Realizar testes de desempenho para determinar as capacidades relacionadas;

- Comparar diferentes linhas de produção e calcular as diferenças em relação aos objetivos operacionais;

- Comparar diferentes operações produtivas e delimitar as interações se for o caso;

- Identificar operações produtivas com desempenho fora do normal;

- Determinar porque o desempenho de algumas operações produtivas é anormal;

- Comparar operações produtivas similares;

- $\quad$ Fornecer dados para mudanças de processos e procedimentos visando melhoramento contínuo do processo;

- $\quad$ Prever resultados de uma operação produtiva, baseado no desempenho atual e passado;

- Gerar os indicadores de produção.

\subsection{SISTEMA PRODUTIVO DISPERSO COMO SISTEMA A EVENTOS DISCRETOS}

Os sistemas produtivos dispersos (SPDs) podem ser tratados do ponto de vista de teoria de sistemas como Sistemas a Eventos Discretos (SEDs) (CASSANDRAS e LAFORTUNE, 2010), isto é, um sistema com estados discretos que variam em função da ocorrência de eventos vistos como abruptos e instantâneos.

Para o estudo da estrutura e do comportamento funcional de SEDs existem várias técnicas e ferramentas. No caso específico de processos produtivos, a abordagem de SED geralmente é adotada na parte de gestão e otimização dos processos (nível 4 da norma ANSI/ISA-95) de modo que a Engenharia de Produção costuma explorar as técnicas de programação linear, pesquisa operacional e de simulação discreta (MIYAGI, 1996). Quando o enfoque está na especificação dos sinais de instrumentação dos dispositivos de atuação e de detecção (nível 1 e 2 da 
norma ANSI/ISA-95) a Engenharia eletro-eletrônica, pneumática e hidráulica explora mais as técnicas de circuitos seqüenciais e combinatórios (ARATA e MIYAGI, 1991, 2005; CURY, 2001). Entretanto, no caso onde o foco está na parte de execução de funções de gestão SPDs, isto é, onde o cerne são as funcionalidades que estão entre a parte de controle (nível 2 da norma ANSI/ISA-95) dos equipamentos que estão no chão-de-fábrica e a parte que envolve as decisões estratégicas (nível 4 da norma ANSI/ISA-95) da empresa como um todo, técnicas formais de modelagem e análise de SED podem ser exploradas. Assim, uma técnica fundamentada em conceitos genéricos como a rede Petri (RdP) é considerada mais adequada (PETERSON, 1981; MURATA, 1989; SILVA, 2013). Mello, Junqueira e Miyagi (2010), por exemplo, abordam a modelagem de sistemas orientados a serviço em SPDs usando a RdP e comprova sua efetividade. De fato, existe vários trabalhos (MORALES, MELO e MIYAGI , 2007; DA SILVA et al., 2016) que indicam que a RdP é comprovadamente uma técnica efetiva para a modelagem e análise do desempenho de sistemas produtivos.

\subsection{SISTEMA PRODUTIVO SUSTENTÁVEL}

Esmaeilian et al. (2016) descrevem um sistema produtivo como a combinação de processos onde as matérias-primas são convertidas em produtos acabados que por sua vez são colocados no mercado. Estes processos sofrem inovações constantes em função da evolução da tecnologia, criação de novas ferramentas e novos métodos de fabricação. Expandindo essa visão, um sistema produtivo sustentável pode ser entendido como um sistema orientado a produtos, e também a serviços que deve garantir resultados positivos relacionados com o QBL de sustentabilidade (aspectos econômicos, ambientais, sociais e tecnológicos). Na análise da sustentabilidade do sistema, se deve levar em conta todas as etapas da produção e do ciclo de vida do produto, desde a aquisição de matéria prima e recursos de produção até o final do processo de produção e a reciclagem do produto em sua obsolescência.

O sistema produtivo sustentável deve manter o equilíbrio do meio ambiente e também manter a qualidade de vida para as gerações atuais sem causar danos irreparáveis ao ecossistema para as gerações futuras. Por meio de uma monitoração inteligente do QBL é que se procura alcançar este equilíbrio. Este tipo de sistema necessita manter a rentabilidade econômica e com isso a eficiência do processo de 
produção é fundamental. Neste sentido, Zhang et al. (2013) e Jayal et al. (2010) apresentam uma diretriz de projeto de sistemas sustentáveis chamada de $6 \mathrm{R}-$ reduce, reuse, recycle, recover, reprojeto, remanufacture (reduzir, reutilizar, reciclar, recuperar, reprojeto, remanufaturar).

Em muitos países como o Brasil ainda não existe regulamentação sobre a logística reversa associada ao reprojeto ou à remanufatura $\mathrm{e}$, mesmo nos países mais avançados estes são temas ainda em discussão de modo que neste trabalho o foco está numa diretriz 4R (reduzir, reutilizar, reciclar, recuperar) para a análise de sustentabilidade de SPDs.

As definições das diretrizes adotadas são:

- Reduzir a quantidade de resíduos produzidos (por exemplo, por meio da utilização de produtos com maior tempo de vida);

- Reutilizar resíduos quando não for possível reduzir os resíduos;

- Reciclar os produtos e materiais que já não possam ser reutilizados (por exemplo, por meio da separação de materiais componentes que podem ser utilizados em outros produtos e processos);

- Recuperar, sempre que possível, a energia e os materiais utilizados nos produtos e processos.

\subsection{INDICADORES DE SUSTENTABILIDADE DE SISTEMAS PRODUTIVOS}

Veleva, Hart e Greiner, (2001) mencionam que os indicadores de sustentabilidade têm três objetivos principais: (i) aumentar a conscientização e a compreensão do problema; (ii) fornecer informações qualificadas para a tomada de decisões; e (iii) medir o progresso em direção aos objetivos estabelecidos. O'Brien (1999) por sua vez argumenta que os indicadores são dados qualitativos ou quantitativos usados para avaliar os aspectos de sustentabilidade de um sistema. Além disso, de acordo com Amrina e Yusof (2011), existem diferentes abordagens a serem consideradas além da tarefa de obter um conjunto de dados, isto é, também se deve considerar o conjunto de ações para assegurar a medição correta para definir quais indicadores devem ser avaliados. 
Alguns pesquisadores, como Joung et al. (2012) entendem também que a medição de certos dados visa identificar um problema específico para aplicar melhorias relacionadas à sustentabilidade nas atividades do sistema produtivo.

Estes trabalhos indicam que a análise e interpretação dos dados dos sistemas produtivos são fundamentais, mas isso infelizmente não é trivial. Existe a dificuldade derivada da complexidade relacionada com o número de indicadores a serem considerados e o modo de quantificação dos dados (OECD, 2001; OECD, 2011).

Existem organizações que estudam os indicadores de sustentabilidade e os classificam em grupos conforme a área de atuação da empresa. $O$ estabelecimento de critérios padrões na definição de indicadores procura assegurar tanto a confiabilidade como a repetibilidade para se avaliar o nível de sustentabilidade de produtos, processos e recursos. Algumas dessas organizações e suas propostas, conforme Joung et al. (2012) e Tan et al. (2015), são:

a) Indicadores de sustentabilidade para avaliações do meio ambiente

- Consultative Group on Sustainable Development Indicators (CGSDI) promovea cooperação, melhor coordenação e estratégias entre os principais indivíduos e instituições que trabalham na área de desenvolvimento e uso de indicadores de desenvolvimento sustentável. Padroniza o desenvolvimento de indicadores no nível internacional criando produtos como o painel de controle para a sustentabilidade;

- International Organization for Standardization (ISO) Environment Performance Evaluation (EPE) standard (ISO 14031) - estabelece especificações para a organização desenvolver os seus próprios indicadores para medição de desempenho ambiental;

- Wellbeing Index - avalia o nível de sustentabilidade de países em dois principais campos, que são o bem-estar do ser humano e do meio ambiente;

- Enviromental Sustainability Index - consiste de indicadores de qualidade do ar, da água, e solo e análise da biodiversidade. Avalia a redução do impacto no meio ambiente e verifica a poluição do ar, da água, dos ecossistemas, o desperdício e consumo de produtos, e o crescimento populacional, que abrange os riscos ao homem, isto é, a saúde e a sustentabilidade do ser 
humano. Avalia a capacidade social e institucional, abrangendo a ciência e tecnologia, a governança ambiental, responsabilidade do setor privado e eficiência ecológica, que abrange participação e colaboração nos esforços globais na busca por redução dos gases nocivos ao meio ambiente e preservação ambiental;

- Global Scenario Group - examina as perspectivas mundiais e formas de promover um futuro mais sustentável e equitativo, através de criação de cenários, nestes faz-se a análise das forças motrizes, incertezas críticas e tensões nos sistemas sociais e ambientais para cada cenário;

- Ecological Footprint - mede os ativos ecológicos que uma determinada população necessita para produzir os recursos naturais que consome (incluindo alimentos vegetais e produtos de fibras, gado e produtos pesqueiros, madeira e outros produtos florestais, espaço para infra-estrutura urbana) e absorver seus resíduos, especialmente as emissões de carbono.A Pegada Ecológica rastreia o uso de seis categorias de áreas de superfície produtivas: terra cultivável, pastagens, áreas de pesca, área construída, área florestal e demanda de carbono na terra.

- Environmental performance index (Epfl) - avalia do desempenho das políticas do país na redução do impacto no meio ambiente sobre a saúde humana;

- Japan National Institute of Science and Technology Policy (NISTEP) - faz a monitoração de indicadores para cobrir o avanço tecnológico, investiga e analisa o estado e as tendências das atividades de inovação e inovação nas empresas;

- European Environmental Agency Core Set of Indicator (EEACSI) - fornece um conjunto de indicadores gerenciais;

- Environmental Sustainability Indicators (ESI) - faz a medição e administração da avaliação do meio ambiente para regiões e países;

- United Nations Indicators of Sustainable Development (UNCSD) - avalia o grau de desenvolvimento sustentável de um país ou região;

- Organisation for Economic Cooperation and Development (OECD) - faz a monitoração das condições ambientais para o desenvolvimento sustentável dos países; 
- Environmental Pressure Indicators for European Union (EPrl) - lista os indicadores das atividades mais importantes que causam impacto negativo sobre o meio ambiente;

- Pollutant Release and Transfer Registries (PRTR) - acompanha atividades relativas ao controle da emissão de poluentes.

b) Indicadores de sustentabilidade para avaliações empresariais

- Global Report Initiative (GRI) - faz a avaliação de sustentabilidade e acompanhamento da empresa por meio de relatórioscom os impactos econômicos, ambientais e sociais em suas atividades;

- Dow Jones Sustainability Indexes (DJSI) - faz a avaliação do desempenho financeiro e de sustentabilidade;

- Organization for Economic Co-operation and Development (OECD) desenvolveu o OECD Toolkit como um meio de medir a sustentabilidade de empresas;

- General Motors Metrics for Sustainable Manufacturing (MSM) - estuda os indicadores de sustentabilidade existentes e recomenda os mais apropriados para análise de impactos ambientais das atividades produtivas;

- Walmart Sustainability Product Index (Walmart Qs) - faz a avaliação do nível de sustentabilidade de fornecedores do grupo Walmart no nível global;

- Métricas de sustentabilidade da Instituição dos Engenheiros Químicos (IChemE) - avalia do nível de sustentabilidade de processos industriais;

- Wuppertal Sustainability Indicators - avalia o nível de sustentabilidade nas atividades das empresas analisando impactos causados sociedade e 0 atingimento de metas;

- Índice Carbono Eficiente(ICO2) - reporta o nível de emissões de gases causadores do efeito estufa das empresas que compõem o índice IBrX-50. Este índice mede o retorno total de uma carteira teórica composta por 50 ações selecionadas entre as mais negociadas na bolsa de valores de São Paulo;

- Interface EcoMetrics - mede o nível de sustentabilidade de processos produtivos, identificando pontos de melhoria; 
- Environmental performance resource impact indicator (EPRII) - avalia de desempenho ambiental de fornecedores automotivos na África do Sul;

- Ford Product Sustainability Index (Ford PSI) - avalia o nível de sustentabilidade de seus veículos, nas dimensões ambientais, econômicas e sociais;

- Life Cycle Assesment (LCA) - analisa o impacto ambiental gerado por um produto durante todo o seu ciclo de vida;

- Material Flow Analysis (MFA) -analisa as relações entre fluxos de materiais (incluindo energia), atividades humanas (incluindo desenvolvimentos econômicos e comerciais) e mudanças ambientais. Usa o princípio do balanceamento de massa;

- Enviromental Management and Audit Scheme (EMAS) - reporta o desempenho ambiental de produtos e serviços. Fornece um guia para cálculo das emissões de gases responsáveis pelo efeito estufa.

Com foco na diretriz de projeto de sistemas sustentáveis chamada de $4 \mathrm{R}$ (reduzir, reutilizar, reciclar e recuperar) se identificam os indicadores que atendam a necessidade básica dos sistemas produtivos existentes.

Para o presente trabalho se reorganizou e reclassificou os indicadores existentes (TAN et al. (2015)) com base no que tem sido publicado e, o resultado está nas Tabelas 1, 2, 3 e 4, onde se considerou o QBL de sustentabilidade, no sentido de facilitar o processamento dos dados e a análise de sustentabilidade de um SPD. Estas listas são utilizadas na definição dos indicadores após a avalição da arquitetura do SP podendo ser escolhidas toda lista ou parte dela.

Tabela 1 - Indicadores de Sustentabilidade - Aspecto ambiental

\begin{tabular}{|c|c|c|}
\hline $\begin{array}{l}\text { SUB- } \\
\text { CATEGORIA }\end{array}$ & INDICADOR & MÉTODO DE QUANTIFICAÇÃO \\
\hline \multirow{4}{*}{$\begin{array}{l}\text { EMISSÃO E } \\
\text { POLUIÇÃO }\end{array}$} & $\begin{array}{l}\text { Emissão de gás de efeito } \\
\text { estufa }\end{array}$ & Massa de $\mathrm{CO}_{2}$ equivalentes emitidos \\
\hline & Descarte de água residual & Volume de água residual descartada \\
\hline & Resíduos tóxicos & Quantidade de material em kg/produto produzido \\
\hline & Desperdício de material & Quantidade de material descartado \\
\hline \multirow{7}{*}{$\begin{array}{l}\text { CONSUMO DE } \\
\text { RECURSO }\end{array}$} & $\begin{array}{l}\text { Materiais reutilizados ou } \\
\text { Reciclados em produtos }\end{array}$ & Massa de material reusado / reciclado \\
\hline & $\begin{array}{l}\text { Descarte de material de } \\
\text { embalagem }\end{array}$ & Massa de material de embalagem descartadas \\
\hline & $\begin{array}{l}\text { Reuso de material de } \\
\text { embalagem }\end{array}$ & Massa de material de embalagem reutilizada \\
\hline & Consumo total de energia & $\begin{array}{l}\text { Total de energia consumida atribuída no processo de } \\
\text { fabricação (energia consumida / unidade de produto) }\end{array}$ \\
\hline & Consumo de água & Volume de água consumida / unidade de produto \\
\hline & Água reutilizada & Total de volume de água reutilizada \\
\hline & Qualidade do ar & Nível aceitável de pureza do ar \\
\hline
\end{tabular}


Tabela 2 - Indicadores de Sustentabilidade - Aspecto econômico

\begin{tabular}{|c|c|c|}
\hline $\begin{array}{l}\text { SUB- } \\
\text { CATEGORIA }\end{array}$ & INDICADOR & MÉTODO DE QUANTIFICAÇÃO \\
\hline \multirow{6}{*}{$\begin{array}{l}\text { DESEMPENHO } \\
\text { FINANCEIRO }\end{array}$} & $\begin{array}{l}\text { Benefício com } \\
\text { redução de gás } \\
\text { carbono }\end{array}$ & Ganho financeiro com redução de gás carbono \\
\hline & $\begin{array}{l}\text { Economia com reuso } \\
\text { de material }\end{array}$ & Ganho financeiro pela quantidade de matéria reutilizada \\
\hline & $\begin{array}{l}\text { Economia com } \\
\text { descarte de resíduo }\end{array}$ & Ganho financeiro pela quantidade de material descartado \\
\hline & $\begin{array}{l}\text { Economia com } \\
\text { material reciclado }\end{array}$ & Ganho financeiro pela quantidade de material reciclado \\
\hline & $\begin{array}{l}\text { Benefício com } \\
\text { energia renovável }\end{array}$ & $\begin{array}{l}\text { Ganho financeiro pela quantidade de energia tradicional } \\
\text { economizada em relação a renovada }\end{array}$ \\
\hline & $\begin{array}{l}\text { Redução da energia } \\
\text { tradicional }\end{array}$ & $\begin{array}{l}\text { Ganho financeiro por quantidade de energia tradicional } \\
\text { economizada }\end{array}$ \\
\hline \multirow{4}{*}{$\begin{array}{l}\text { CUSTO DE } \\
\text { PRODUÇÃO }\end{array}$} & $\begin{array}{l}\text { Custo de material de } \\
\text { produção }\end{array}$ & Custos de material utilizado em processo de produção \\
\hline & $\begin{array}{l}\text { Custo de energia de } \\
\text { produção }\end{array}$ & Custos de energia utilizada em processo de produção \\
\hline & $\begin{array}{l}\text { Custo de mão de } \\
\text { obras de produção }\end{array}$ & Custos de mão de obra utilizada durante o processo de produção \\
\hline & de capital & $\begin{array}{l}\text { Custos de operação e de capital utilizados durante o processo de } \\
\text { produção }\end{array}$ \\
\hline
\end{tabular}

Tabela 3 - Indicadores de Sustentabilidade - Aspecto social

\begin{tabular}{|c|c|c|}
\hline $\begin{array}{l}\text { SUB- } \\
\text { CATEGORIA }\end{array}$ & INDICADOR & MÉTODO DE QUANTIFICAÇÃO \\
\hline \multirow{4}{*}{ EMPREGADO } & Dia de trabalho perdido & $\begin{array}{l}\text { Número total de dias de trabalho perdido devido a } \\
\text { acidentes }\end{array}$ \\
\hline & Satisfação no trabalho & $\begin{array}{l}\text { levantamento de humor do trabalhador durante o período } \\
\text { de trabalho }\end{array}$ \\
\hline & $\begin{array}{l}\text { Taxa de acidente de } \\
\text { trabalhadores }\end{array}$ & $\begin{array}{l}\text { Número total de ocorrências durante o período de } \\
\text { trabalho }\end{array}$ \\
\hline & $\begin{array}{l}\text { Taxa de produtividade de mão } \\
\text { de obra }\end{array}$ & (Total da receita / Total de custos de mão de obra) \\
\hline \multirow[b]{2}{*}{ EMPREGADO } & $\begin{array}{l}\text { Treinamento do trabalhador } \\
\text { em sustentabilidade }\end{array}$ & $\begin{array}{l}\text { (Empregados treinado sem sustentabilidade / Total de } \\
\text { números de empregados) } \times 100 \%\end{array}$ \\
\hline & $\begin{array}{l}\text { Sugestões de melhoria de } \\
\text { sustentabilidade pelo } \\
\text { trabalhador }\end{array}$ & $\begin{array}{l}\text { Número total de sugestões de empregados a respeito do } \\
\text { melhoramento da sustentabilidade }\end{array}$ \\
\hline CLENTE & Reclamações de clientes & $\begin{array}{l}\text { Número total de reclamações de clientes relativo ao } \\
\text { desempenho de sustentabilidade }\end{array}$ \\
\hline \multirow{3}{*}{ COMUNIDADE } & $\begin{array}{l}\text { Programa de relacionamento } \\
\text { com o cliente }\end{array}$ & $\begin{array}{l}\text { Número total sugestões da comunidade a respeito do } \\
\text { melhoramento de sustentabilidade }\end{array}$ \\
\hline & $\begin{array}{l}\text { Publicação de relatórios de } \\
\text { sustentabilidade }\end{array}$ & $\begin{array}{l}\text { Número total de avaliações e relatórios publicadas e \% } \\
\text { de conclusões destas avaliações de sustentabilidade }\end{array}$ \\
\hline & Prêmio de sustentabilidade & Número total de prêmios ou menções \\
\hline
\end{tabular}

Os indicadores ambientais da Tabela 1 são descritos a seguir:

Emissão de gás de efeito estufa - Este indicador está associado ao nível aceitável de emissão de gases de efeito estufa no local de trabalho para o bem-estar do trabalhador. Uma maneira de quantificar a sua medição é considerando a massa de $\mathrm{CO}_{2}$ equivalente emitida no ambiente de trabalho. 
Organizações e autoridades de todo o mundo estabeleceram recomendações como indicadas na Tabela 5 para a concentração máxima permitida de dióxido de carbono e/ou fluxo mínimo permitido de ar em edifícios ocupados.

Fonte: Co2 Measurement Specialists: http://www.co2meter.com/

\section{Tabela 4 - Indicadores de Sustentabilidade - Aspecto tecnológico}

\begin{tabular}{|c|c|c|}
\hline $\begin{array}{l}\text { SUB- } \\
\text { CATEGORIA }\end{array}$ & INDICADOR & MÉTODO DE QUANTIFICAÇÃO \\
\hline \multirow{2}{*}{ SEGURANÇA } & $\begin{array}{l}\text { Aplicação de política de TI } \\
\text { sustentável }\end{array}$ & $\begin{array}{l}\text { Número total de ações de reclamações relatadas } \\
\text { para o desempenho de sustentabilidade }\end{array}$ \\
\hline & $\begin{array}{l}\text { Equipamentos de proteção e } \\
\text { segurança pessoal }\end{array}$ & $\begin{array}{l}\text { Número total de equipamentos de proteção de } \\
\text { segurança pessoal }\end{array}$ \\
\hline \multirow{3}{*}{ DESEMPENHO } & $\begin{array}{l}\text { Atualização de versão de software } \\
\text { e hardware }\end{array}$ & $\begin{array}{l}\text { Número de atualizações de produtos / Número de } \\
\text { produtos instalados }\end{array}$ \\
\hline & Investimento em inovação e P\&D & $\begin{array}{l}\text { Quantidade total de investimentos em P\&D para } \\
\text { esforco de sustentabilidade }\end{array}$ \\
\hline & $\begin{array}{l}\text { Fornecedores de serviços com } \\
\text { certificação em meio ambiente }\end{array}$ & $\begin{array}{l}\text { (Número de provedores com certificação ambiental / } \\
\text { Número total de provedores) } \times 100 \%\end{array}$ \\
\hline \multirow{5}{*}{$\begin{array}{l}\text { LINHA DE } \\
\text { PRODUÇÃO }\end{array}$} & $\begin{array}{l}\text { Aplicação de política de } \\
\text { manutenção }\end{array}$ & $\begin{array}{l}\text { Número de equipamentos inspecionados / Número } \\
\text { de equipamentos instalados }\end{array}$ \\
\hline & $\begin{array}{l}\text { Evitar parada de linha devido à } \\
\text { preocupação de segurança }\end{array}$ & $\begin{array}{l}\text { Quantidade de pontos monitorados de segurança ao } \\
\text { redor de maquinarias de fabricação }\end{array}$ \\
\hline & Política de sistemas abertos & Número total de produto sistema aberto instalado \\
\hline & Monitoração de energia renovável & $\begin{array}{l}\text { Número total de sistema a energia renovável } \\
\text { instalado }\end{array}$ \\
\hline & $\begin{array}{l}\text { Monitoração do ciclo de operação } \\
\text { de máquinas }\end{array}$ & $\begin{array}{l}\text { Quantidade de pontos monitorados do ciclo de } \\
\text { trabalho de equipamento / desgaste durante o } \\
\text { processo de fabricação }\end{array}$ \\
\hline
\end{tabular}

Tabela 5 - Concentração máxima permitida de dióxido de carbono

\begin{tabular}{|c|c|}
\hline CONCENTRAÇÃO & DESCRIÇÃO \\
\hline 5.000 PPM & $\begin{array}{l}\text { É a concentração de } \mathrm{CO}_{2} \text { máxima durante uma jornada de trabalho de } 8 \text { horas de } \\
\text { acordo com organizações internacionais. }\end{array}$ \\
\hline 2.000 PPM & $\begin{array}{l}\text { De acordo com muitas investigações este nível de } \mathrm{CO}_{2} \text { produz um aumento } \\
\text { significativo na sonolência, cansaço, dor de cabeça e desconforto. }\end{array}$ \\
\hline 1.000 PPM & $\begin{array}{l}\text { É a recomendação de concentração máxima de dióxido de carbono em uma sala } \\
\text { fechada. Corresponde a um fluxo de ar (uma necessidade de ar fresco) de } \\
\text { aproximadamente } 7 \text { litros/segundo por pessoa, que é recomendado como o nível de } \\
\text { conforto máximo em muitos outros países, isto é, Suécia e Japão. }\end{array}$ \\
\hline 800 PPM & $\begin{array}{l}\text { É o máximo nível de } \mathrm{CO}_{2} \text { para empresas de HVAC comerciais. É também } \\
\text { concentração máxima de } \mathrm{CO}_{2} \text { permitida para escritórios na Califórnia. Corresponde a } \\
\text { um fluxo de ar (uma necessidade de ar fresco) de cerca de } 10 \text { litros/segundos por } \\
\text { pessoa. }\end{array}$ \\
\hline 400-800 PPM & $\begin{array}{l}\text { Nesta faixa se considera ventilação excessiva (isto é, demasiado ar fresco implica em } \\
\text { energia desperdiçada). }\end{array}$ \\
\hline 350-450 PPM & ão comum de $\mathrm{CO}_{2}$ ao ar livre. \\
\hline
\end{tabular}

Descarte de água residual - Este indicador está associado ao nível aceitável de águas residuais lançadas ao meio ambiente que prejudica a qualidade de rios e a vida aquática. Toda água descartada pelas atividades domésticas, comerciais ou 
industriais, e a devolução desta água ao meio ambiente deve prever o seu devido tratamento. Águas residuais industriais são soluções aquosas provenientes de instalações utilizadas para todo o tipo de comércio ou indústria, resultantes de processos produtivos. A falta de tratamento das águas residuais acarreta na queda da qualidade da água dos rios, no comprometimento da fauna e flora, da pesca, da navegação, da geração de energia. Redução de descarte de águas residuais pode ser obtida com implantação de processos de tratamento com biofiltros e outros, para reuso de parte delas. Uma maneira de quantificar este indicador é medir o volume de água residual descartada.

Fonte: Fundação Universitária Iberoamericana: https://www.funiber.org.br/engenhariaambiental-tratamento-de-aguas-residuarias-industriais

Resíduos tóxicos - Trata-se da quantidade de resíduos perigosos gerados pela empresa, definidos como Classe $1^{5}$ conforme NBR 10004:2004 da ABNT. Devese relacionar a geração total de resíduos ao desempenho do sistema produtivo como um todo. Trata-se de um indicador de desempenho operacional e de gerenciamento. A quantidade de resíduos perigosos (Classe 1) gerados são fatores estratégicos no custo do destinatário final e indicativo de competitividade. O desafio é a eliminação ou redução da geração destes resíduos aplicando os princípios de produção mais limpa $(\mathrm{P}+\mathrm{L})$ resultando em redução dos custos operacionais e adequação da capacidade de suporte ambiental. No caso da não eliminação de resíduos perigosos, a destinação final adequada é essencial para evitar risco ambiental. Uma maneira de quantificar este indicador é medir a quantidade de resíduos gerados por produto. Uma maneira de quantificar este indicador é medir a quantidade de resíduos tóxicos gerados em $\mathrm{kg} /$ produto produzido.

Fonte: Companhia Ambiental do Estado de São Paulo: http://cetesb.sp.gov.br/camarasambientais/wp-content/uploads/sites/21/2013/12/manual_ind_texteis.pdf

5 Classe 1 (de acordo com a NBR 10.004/2004 são chamados de perigosos): Levando-se em consideração suas características de inflamabilidade, corrosividade, reatividade, toxicidade e patogenicidade, podem apresentar riscos à saúde pública e ao meio ambiente, quando manuseados ou dispostos de forma inadequada; Classe 2 (Não Inertes): são resíduos não classificados como perigosos ou inertes, incluindo-se nesta classificação os resíduos orgânicos em geral, como restos de alimentos; Classe 3 (Inertes): são aqueles resíduos que não apresentam periculosidade ao homem e ao meio ambiente. 
Desperdício de material - Este indicador está relacionado com 0 melhoramento de processos de fabricação para reduzir o volume de materiais desperdiçadas. Reduzir o desperdício de materiais resulta em melhor eficiência dos recursos, minimizando a poluição e gerando benefícios cada vez mais valorizados no atual mercado. Uma maneira de quantificar este indicador é medir a quantidade de material desperdiçado em $\mathrm{kg} /$ quantidade de produto produzido.

Fonte: Companhia Ambiental do Estado de São Paulo: http://cetesb.sp.gov.br/camarasambientais/wp-content/uploads/sites/21/2013/12/manual_ind_texteis.pdf

Materiais reutilizados ou reciclados em produtos - Reciclagem envolve um conjunto de técnicas que têm por finalidade aproveitar os detritos gerados pelo processo produtivo e reutilizá-los no ciclo de produção. É o resultado de uma série de atividades, onde os materiais descartados são desviados, coletados, separados e processados para serem usados como matéria-prima de novos produtos. Uma maneira de quantificar este indicador é pela medição da quantidade de material reusado ou reciclado $\mathrm{kg} / \mathrm{lote}$ de produção.

Fonte: Companhia Ambiental do Estado de São Paulo: http://cetesb.sp.gov.br/camarasambientais/wp-content/uploads/sites/21/2013/12/manual_ind_texteis.pdf

Descarte de material de embalagem - As embalagens, quando consumidas de maneira exagerada e descartadas de maneira regular ou irregular - em lugar de serem encaminhadas para reciclagem - contribuem e muito para o esgotamento de aterros e lixões, dificultam a degradação de outros resíduos, são ingeridos por animais causando sua morte, poluem a paisagem, causam problemas na rede elétrica (sacolas que se prendem em fios de alta tensão), e muitos outros tipos de impactos ambientais menos visíveis ao consumidor final (o aumento do consumo aumenta a demanda pela produção de embalagens, o que consome mais recursos naturais e gera mais resíduos).

Todo esse impacto pode ser diminuído ou eliminado, basicamente, por meio da redução do consumo desnecessário e correta separação e destinação do lixo: comprando somente aquilo que é necessário, reutilizando o que for possível e mandando para reciclagem materiais recicláveis e para a compostagem os resíduos orgânicos, a Tabela 6 mostra o tempo de decomposição de materiais na natureza. 
Tabela 6 - Tempo de decomposição de materiais

DECOMPOSIÇÃO DOS MATERIAIS

\begin{tabular}{l|l}
\hline \multicolumn{1}{c|}{ MATERIAL } & TEMPO DE DECOMPOSIÇÃO NA NATUREZA \\
Papel & De 3 a 6 meses \\
Tecidos & De 6 meses a 1 ano \\
Metal & Mais de 100 anos \\
Alumínio & Mais de 200 anos \\
Plástico & Mais de 400 anos \\
Vidro & Mais de 1000 anos
\end{tabular}

Uma maneira de quantificar este indicador é medir a quantidade de material de embalagem descartada em $\mathrm{kg}$.

Fonte: Ministério do Meio Ambiente: http://www.mma.gov.br/responsabilidadesocioambiental/producao-e-consumo-sustentavel/consumo-consciente-deembalagem/impacto-das-embalagens-no-meio-ambiente

Fonte: Associação Brasileira de Embalagem: http://www.abre.org.br/wpcontent/uploads/2012/08/protocolo_global.pdf

Reuso de material de embalagem - A logística reversa é a área da logística que trata dos aspectos de retornos de produtos, embalagens ou materiais ao seu centro produtivo. Isto é, sua implantação é de um processo de reciclagem, uma vez que os materiais retornam a diferentes centros produtivos em forma de matéria prima. Não voltam para a indústria de uma forma direta, passando por cooperativas de reciclagem e atravessadores. A logística reversa é utilizada em prol da empresa, transformando materiais, que seriam inutilizados, em matéria-prima, reduzindo assim, os custos para a empresa. Uma maneira de quantificar este indicador é medir a quantidade de material de embalagem reutilizadas.

Fonte: Ministério do Meio Ambiente:http://www.mma.gov.br/responsabilidadesocioambiental/producao-e-consumo-sustentavel/consumo-consciente-deembalagem/impacto-das-embalagens-no-meio-ambiente

Fonte: Associação Brasileira de Embalagens: http://www.abre.org.br/descarteseletivo/

Consumo total de energia - Todo processo necessita ter controle do seu consumo de energia para analisar se é possível economizar mais, diminuir o consumo e otimizar o funcionamento dos equipamentos da produção ou até mesmo substituir alguns por outros que utilizem menos energia. Uma maneira de quantificar este indicador é medir o total de energia consumida atribuída no processo de fabricação (energia consumida/unidade de produto). 
Fonte: Companhia Ambiental do Estado de São Paulo: http://cetesb.sp.gov.br/camarasambientais/wp-content/uploads/sites/21/2013/12/manual_ind_texteis.pdf

Consumo de água - $\mathrm{A}$ água é um recurso essencial para qualquer atividade $\mathrm{e}$ é necessário se conscientizar e aplicar medidas internas para evitar o desperdício de água. O uso da água nos processos industriais é feito desde a incorporação do recurso nos produtos até na higiene dos trabalhadores. Uma maneira de quantificar este indicador é medir o volume de água consumida/unidade de produto.

Fonte: Companhia Ambiental do Estado de São Paulo: http://cetesb.sp.gov.br/camarasambientais/wp-content/uploads/sites/21/2013/12/manual_ind_texteis.pdf

Água reutilizada - A quantidade de água fresca disponível tem se restringido, o que afeta seu custo. Além disso, os custos para o descarte da água também estão aumentando. Reutilizar águas residuais resolve dois problemas: reduz o consumo de água fresca e o descarte de efluentes. Uma maneira de quantificar este indicador é medir a porcentagem de água reutilizada.

Fonte: Companhia Ambiental do Estado de São Paulo: http://cetesb.sp.gov.br/camarasambientais/wp-content/uploads/sites/21/2013/12/manual_ind_texteis.pdf

Qualidade do ar - A Organização Mundial da Saúde (OMS) recomenda que na adoção de um padrão de qualidade do ar sejam considerados fatores relacionados tanto aos riscos à saúde, quanto às atividades econômicas, políticas e sociais, dependendo das circunstâncias locais. No Brasil os padrões de qualidade do ar foram estabelecidos pela Resolução CONAMA no 03/1990, divididos em padrões primários (níveis máximos que poderão afetar a saúde da população) e secundários (níveis mínimos de efeito adverso sobre o bem-estar da população, dano à fauna e à flora, aos materiais e ao meio ambiente em geral). Os parâmetros regulamentados pela legislação ambiental são os seguintes: partículas totais em suspensão, fumaça, partículas inaláveis, dióxido de enxofre, monóxido de carbono, ozônio e dióxido de nitrogênio. A mesma resolução estabelece ainda os critérios para episódios agudos de poluição do ar, conforme indicado na Tabela 7.

Uma maneira de quantificar este indicador é pelo Índice de Qualidade do $\mathrm{Ar}$ (IQA), desenvolvido no Canadá e EUA na década de 80. Este índice padroniza todos os poluentes medidos em uma única escala visando facilitar a divulgação dos resultados do monitoramento da qualidade do ar. Por meio do IQA o impacto de um 
certo poluente pode ser comparado com o de outro, porque um mesmo valor de índice significa o mesmo efeito. Os parâmetros contemplados pela estrutura do índice são: dióxido de enxofre $\left(\mathrm{SO}_{2}\right)$, dióxido de nitrogênio $\left(\mathrm{NO}_{2}\right)$, ozônio $\left(\mathrm{O}_{3}\right)$, monóxido de carbono (CO), partículas inaláveis (PI), partículas totais em suspensão (PTS) e fumaça.

Tabela 7 - Padrão de qualidade do ar

Padrões nacionais de qualidade do ar - Resolução $n^{\circ} 3$, de 28/06/1990

\begin{tabular}{|c|c|c|c|c|}
\hline Poluente & $\begin{array}{c}\text { Tempo de } \\
\text { Amostragem }\end{array}$ & $\begin{array}{l}\text { Padrão Primário } \\
\qquad\left(\mu \mathrm{g} / \mathrm{m}^{3}\right)\end{array}$ & $\begin{array}{c}\text { Padrão } \\
\text { Secundário } \\
\left(\mu \mathrm{g} / \mathrm{m}^{3}\right)\end{array}$ & $\begin{array}{l}\text { Método de } \\
\text { Medição }\end{array}$ \\
\hline $\begin{array}{l}\text { Partículas totais } \\
\text { em suspensão - } \\
\text { PTS }\end{array}$ & 24 horas* MGA & $\begin{array}{c}240 \\
80\end{array}$ & $\begin{array}{c}150 \\
60\end{array}$ & $\begin{array}{l}\text { Amostrador de } \\
\text { grandes volumes }\end{array}$ \\
\hline Fumaça & 24 horas* MGA & $\begin{array}{c}150 \\
60\end{array}$ & $\begin{array}{l}100 \\
40\end{array}$ & Refletância \\
\hline $\begin{array}{l}\text { Partículas } \\
\text { inaláveis }\end{array}$ & 24 horas* MGA & $\begin{array}{l}150 \\
60\end{array}$ & $\begin{array}{l}150 \\
50\end{array}$ & $\begin{array}{l}\text { Separação } \\
\text { inercial/filtração }\end{array}$ \\
\hline $\begin{array}{l}\text { Dióxido de } \\
\text { Enxofre }\end{array}$ & 24 horas* MGA & $\begin{array}{c}365 \\
80\end{array}$ & $\begin{array}{c}100 \\
40\end{array}$ & Pararosanilina \\
\hline $\begin{array}{l}\text { Monóxido de } \\
\text { Carbono }\end{array}$ & $\begin{array}{l}1 \text { hora* } \\
8 \text { horas* }\end{array}$ & $\begin{array}{c}40.000 \text { (35 ppm) } \\
10.000(9 \text { ppm) }\end{array}$ & $\begin{array}{c}40.000(35 \text { ppm) } \\
10.000(9 \text { ppm) }\end{array}$ & $\begin{array}{l}\text { Infravermelho não } \\
\text { dispersivo }\end{array}$ \\
\hline Ozônio & 1 hora* & 160 & 160 & Quimiluminscência \\
\hline $\begin{array}{l}\text { Dióxido de } \\
\text { Nitrogênio }\end{array}$ & $\begin{array}{l}1 \text { hora } \\
\text { MMA }\end{array}$ & $\begin{array}{l}320 \\
100\end{array}$ & 190 & Quimiluminscência \\
\hline
\end{tabular}

*Não deve excedido mais de uma vez ao ano

MGA - Média geométrica anual

MMA - Média aritmética anual

Baseado nas concentrações dos poluentes monitorados e nas faixas de concentração definidas para cada poluente, o IQA é calculado para cada poluente monitorado, e a qualidade do ar é classificada a partir do maior índice, ou seja, será determinada pelo poluente que apresentar o pior resultado. O IQA é um valor numérico, compreendido entre 0 e 300. Quanto maior o valor que expressa, maior é a poluição do ar, e consequentemente maior será a preocupação com a saúde, Tabela 8. 
Tabela 8 - Faixa de concentração dos poluentes

\begin{tabular}{|c|c|c|c|c|c|}
\hline Poluentes & \multicolumn{5}{|c|}{ Faixa de Concentração dos Poluentes para o Cálculo do IQA } \\
\hline $\begin{array}{l}\text { Dióxido de enxofre }\left(\mathrm{SO}_{2}\right) \\
\left(\mu \mathrm{g} / \mathrm{m}^{3}\right)\end{array}$ & $0-80$ & $81-365$ & $365-800$ & $801-1600$ & $>1600$ \\
\hline $\begin{array}{l}\text { Monóxido de carbono (CO) } \\
\text { (ppm) }\end{array}$ & $0-4,0$ & $4,1-9,0$ & $9,1-15,0$ & $15,1-30,0$ & $>30,0$ \\
\hline $\begin{array}{l}\text { Material Particulado (PM10) } \\
\left(\mu \mathrm{g} / \mathrm{m}^{3}\right)\end{array}$ & $0-50$ & $51-150$ & $151-250$ & $251-420$ & $>420$ \\
\hline Ozônio $\left(\mathrm{O}_{3}\right)\left(\mu \mathrm{g} / \mathrm{m}^{3}\right)$ & $0-80$ & $81-160$ & $161-200$ & $201-800$ & $>800$ \\
\hline $\begin{array}{l}\text { Dióxido de nitrogênio }\left(\mathrm{NO}_{2}\right) \\
\left(\mu \mathrm{g} / \mathrm{m}^{3}\right)\end{array}$ & $0-100$ & $101-320$ & $321-1130$ & $1131-2260$ & $>2260$ \\
\hline $\begin{array}{l}\text { Índice de Qualidade do Ar } \\
\text { (IQA) }\end{array}$ & $0-50$ & $51-100$ & $101-200$ & $201-300$ & $>300$ \\
\hline Classificação & BOA & REGULAR & INADEQUADA & MÁ & PESSIMA \\
\hline
\end{tabular}

Fonte: Ministério do Meio Ambiente:http://www.mma.gov.br/cidades-sustentaveis/qualidade-doar

Os indicadores econômicos da Tabela 2 são descritos a seguir:

Benefício com a redução de gás carbono - A redução de emissões de Gases de Efeito Estufa (GEE) é medida em toneladas de dióxido de carbono equivalente - $\mathrm{t}$ $\mathrm{CO}_{2} \mathrm{e}$ (equivalente). Cada tonelada de $\mathrm{CO}_{2}$ e reduzida ou removida da atmosfera corresponde a uma unidade emitida pelo Conselho Executivo do projeto Mecanismo do Desenvolvimento Limpo (MDL), ligado ao Ministério do Meio Ambiente, denominada de Redução Certificada de Emissão (RCE). Uma maneira de compensar as emissões é o mercado de crédito de carbono. Nele, uma tonelada de gás carbônico corresponde a um crédito de carbono. Empresas que conseguem diminuir a emissão de gases poluentes obtêm estes créditos, podendo vendê-los nos mercados financeiros nacionais e internacionais. As empresas que conseguem reduzir a emissão dos gases poluentes lucram com a venda destes créditos de carbono. No entanto, essa é uma prática questionável, pois o problema não se resolve com as empresas poluidoras apenas comprando créditos - é necessário que elas reduzam de fato o nível de emissões. Uma maneira de quantificar este indicador é medir ganho financeiro com redução de gás carbono. 
Fonte: Governo Brasileiro: http://www.brasil.gov.br/economia-eemprego/2012/08/empresas-que-cumprirem-metas-de-reducao-na-emissao-degases-receberao-beneficios

Economia com reuso de material - Reutilizar consiste no aproveitamento de produtos sem que estes sofram quaisquer tipos de alterações ou processamento complexos. Antes de um produto ser jogado fora, ele ainda tem muitos usos sem ter que passar por um processo de restauração ou reciclagem. Muitas vezes é preciso ser criativo, inovador, usar um produto de várias maneiras. Uma maneira de quantificar este indicador é medir o ganho financeiro pela quantidade de matéria reutilizada.

Fonte: Senado Legislativo Brasileiro: https://www12.senado.leg.br/emdiscussao/edicoes/ residuos-solidos/mundo-rumo-a-4-bilhoes-de-toneladas-por-ano/como-alguns-paises-tratamseus-residuos

Economia com descarte de lixo - A ideia de que tudo o que se produz pode voltar para a produção em vez de virar lixo ganhou o nome de EC. Nessa economia, não existe desperdício - todos os produtos passam por reaproveitamento, transformação e reciclagem. A chave para que isso ocorra não é a tecnologia da reciclagem, mas sim o design inicial do produto, levando em consideração o que acontece com ele quando perde seu valor de uso. Uma maneira de quantificar este indicador é medir o ganho financeiro pela quantidade de material descartado.

Fonte: Senado Legislativo Brasileiro: https://www12.senado.leg.br/emdiscussao/edicoes/ residuos-solidos/mundo-rumo-a-4-bilhoes-de-toneladas-por-ano/como-algunspaises-tratam-seus-residuos

Fonte: https://www.ufrgs.br/sustentabilidade/?cat=15

Economia com material reciclado - O reaproveitamento e a reciclagem na indústria, que transforma resíduos em matéria-prima ou em novos produtos para utilização em setores diversos da economia, reduz custos da produção, gera receita para as empresas e de novo potencializa os investimentos em ações de sustentabilidade. Mais que cumprir as determinações da legislação e além de responder às demandas da sociedade, que exige contrapartidas sociais e ambientais das organizações, esses investimentos se tornaram parte da alma do negócio. Uma maneira de quantificar este indicador é medir o ganho financeiro pela quantidade de material reciclado. 
Fonte:

http://www.europarl.europa.eu/news/pt/headlines/economy/20151201STO05603/ economia-circular- definicao-importancia-e-beneficios

Benefício com energia renovável - Para as empresas em busca da redução de seus custos fixos, o investimento inicial em soluções com energia renovável muitas vezes é considerado alto. Mas, com base numa análise econômica, a instalação, por exemplo, de painéis fotovoltaicos pode ser um ótimo investimento a longo prazo. A conta de energia elétrica pode diminuir consideravelmente, levando em conta o tipo de instalação e as condições do local. O investimento inicial é amortizado em média entre 4 e 6 anos. Depois desse período toda a energia gerada é contabilizada como economia para a empresa, levando-se em consideração que a vida útil dessas instalações/facilidade pode ultrapassar os 30 anos. Uma maneira de quantificar este indicador é medir o ganho financeiro pela quantidade de energia convencional economizada em relação a renovada.

Fonte: Universidade Federal de Santa Maria: http://repositorio.ufsm.br/handle/1/8488

Redução do consumo da energia tradicional - Em tempos de sustentabilidade, a eficiência energética passa a ser um compromisso de governos e da sociedade civil, especialmente por parte da indústria. Com isso, aumenta a quantidade de fabricantes que correm atrás de eficiência energética. De uma forma geral, o peso da energia nos processos produtivos varia entre $15 \%$ e $20 \%$, podendo atingir $60 \%$ no segmento petroquímico, nos chamados eletro intensivos. Só o gasto com iluminação é responsável por $20 \%$ do consumo mundial de eletricidade e cerca de $6 \%$ das emissões globais de gases de efeito estufa. Uma maneira de quantificar este indicador é medir o ganho financeiro por quantidade de energia tradicional economizada.

Fonte: Universidade Federal de Santa Maria: http://repositorio.ufsm.br/handle/1/8488

Fonte: Federação das Industrias da Bahia: http://www.fieb.org.br/Noticia/1286/reducao-deconsumo-e-prioridade-da-industria-.aspx

Custo de material de produção - a melhoria no manuseio de materiais pode reduzir o custo direto de uma empresa, reduzir o desperdício de materiais resulta em melhor eficiência dos recursos, minimizando a poluição e gerando benefícios cada vez 
mais valorizados no mercado. Uma maneira de quantificar este indicador é medir os custos de material utilizado em processo de produção.

Fonte: Empresa especializada em redução de custos de produção: https://www.e3seriescenter.com/blog-engenharia-eletrica-moderna/custo-de-desperdicioscomo-pode-afetar-sua-producao

Custo de energia de produção - A energia é um dos principais insumos para a indústria, podendo representar mais de $40 \%$ de seus custos de produção. Uma maneira de quantificar este indicador é medir os custos de energia utilizada em processo de produtivo.

Fonte: Empresa de comunicação: http://economia.estadao.com.br/noticias/geral,industriaperde-competitividade-com-aumento-da-tarifa-de-energia,70002105633

Custo de mão de obra de produção - O custo neste caso, compreende não somente os salários, mas todos os encargos de impostos e pacote de benefícios oferecidos ao funcionário. Uma maneira de quantificar este indicador é medir os custos de mão de obra utilizada durante o processo de produção.

Fonte: Scielo: http://www.scielo.br/scielo.php?script=sci_arttext\&pid=S141392511992000300003

Custo operacional e de capital - Os custos operacionais são as despesas ligadas ao funcionamento da atividade empresarial. Podem ser classificadas em três categorias: custos diretos (ex. salários), custos indiretos (ex. reparos) e custos gerais (ex. vendas). Custo de capital é referente aos gastos em investimentos necessários para viabilidade da atividade empresarial (ex. máquinas, construções, ...). Uma maneira de quantificar este indicador é medir os custos de operação e de capital utilizados do processo produtivo.

Fonte: Universidade Federal do Rio Grande do Sul: https://www.lume.ufrgs.br/bitstream/handle/10183/96382/000915913.pdf?sequence=1

Os indicadores sociais da Tabela 3 são descritos a seguir:

Dia de Trabalho Perdido - O absenteísmo no trabalho pode ser claramente conceituado como a ausência do trabalhador do seu posto de trabalho, seja em razão de faltas, seja em decorrência de atrasos ou saídas antecipadas do serviço. Os 
trabalhadores são os responsáveis pela efetivação e pelo aprimoramento de todos os processos empresariais, sejam eles de maior ou menor complexidade. Por isso, a presença desses colaboradores é fundamental para o desenvolvimento e a eficácia dos objetivos de uma organização. As ausências e atrasos comprometem o ciclo de atividades previsto e prejudicam os resultados finais. Uma maneira de quantificar este indicador é medir o número total dessas ocorrências durante o período de trabalho.

Fonte: Unicamp: www.bibliotecadigital.unicamp.br/document/?down=71279

Satisfação no trabalho - A satisfação de colaboradores é um fator fundamental para que os níveis de motivação e de produtividade de uma empresa estejam sempre em alta, quanto maior for o grau de satisfação de um funcionário em relação ao seu trabalho, maior será o seu empenho. O nível de satisfação de colaboradores deve ser medido de forma constante em uma empresa para permitir que o setor de recursos humanos possa elaborar e manter as medidas que deixam o trabalhador satisfeito ou mesmo modificar os elementos que os fazem insatisfeitos com suas funções, posições ou atuações. Uma maneira de quantificar este indicador é medir por meio do levantamento de satisfação/humor do trabalhador durante o período de trabalho.

Fonte: $\quad$ Scielo: $\quad$ http://www.scielo.br/pdf/\%0D/epsic/v7nspe/a03v7esp.pdf http://srvd.grupoa.com.br/uploads/imagensExtra/legado/S/SIQUEIRA_Mirlene_Maria_Matias/Me didas_Do_Comportamento_Organizacional/Liberado/Cap_16_Satisfacao.pdf

Taxa de acidente de trabalhadores - Acidentes no trabalho são considerados como consequências de situações como: exposição do trabalhador em um ambiente com precariedade nas condições de segurança; o trabalhador que se expõe às condições perigosas achando normal aquela condição, submissão voluntária; baixa qualificação; ausência de responsabilidade/disciplina pelo empregado na execução da tarefa, excesso de autonomia. Uma maneira de quantificar este indicador é medir o número total de ocorrências de acidentes durante o período de trabalho.

Fonte: http://ftp.medicina.ufmg.br/osat/arquivos/RelatorioAt_30092014.pdf

Taxa de produtividade da mão de obra - Medir a produtividade significa avaliar a eficiência e a racionalidade das atividades. Nessa medida é definida como a relação entre a saída/entrada ou valor de produção/insumo. Elevar o nível de produtividade significa aumentar o valor de produção (saída), com a mesma 
combinação dos fatores de produção (entrada), ou ainda, manter o nível de produção, realizando economias no insumo dos fatores. Os índices assim obtidos, "valor de produção" ou "volume de produção/número de empregados", permitem uma verificação do estado da empresa, bem como a comparação dos relativos índices, entre as diferentes empresas do mesmo setor. Uma maneira de quantificar este indicador é medir o total da receita em relação e o total de custos de mão de obra e relacioná-los.

Fone: Unicamp: http://repositorio.unicamp.br/bitstream/REPOSIP/264256/1/Coelho_

RonaldoSergiodeAraujo_M.pdf

Treinamento em sustentabilidade - O treinamento ajuda o empregado a entender o objetivo da sustentabilidade e promove a conscientização de seu papel como promotor de responsabilidade social. Uma maneira de quantificar este indicador é medir os empregados treinados em sustentabilidade e o total de números de empregados e relacioná-los.

Fonte: Universidade de São Paulo: http://www.usp.br/agen/?p=97855

Sugestões de melhorias de sustentabilidade pelo trabalhador - É uma maneira de fazer com que todos se envolvam no negócio. Por meio de e-mails e cartazes, os funcionários são incentivados a sugerir melhorias para a empresa. Os criadores das idéias que contribuírem para a sustentabilidade da empresa podem ganhar alguma vantagem. Uma maneira de quantificar este indicador é pelo número total de sugestões de empregados a respeito do melhoramento da sustentabilidade.

Fonte: Ministério do Meio Ambiente: http://www.mma.gov.br/responsabilidadesocioambiental/a3p/eixos-tematicos/qualidade-de-vida-no-ambiente-de-trabalho

Fonte: Scielo: http://www.scielo.br/pdf/gp/v17n1/v17n1a05

Reclamações de clientes - As reclamações dos clientes são manifestações de falta de contentamento em relação a algum aspecto da empresa. Para amenizar seus possíveis efeitos negativos, cada negócio precisa de uma equipe de atendimento que saiba fazer a gestão das críticas e atender aos pedidos de seu público. As reclamações podem ser valiosas informações para a otimização de processos, produtos ou serviços garantindo, assim, melhorias para a empresa e a satisfação de clientes. Uma maneira de quantificar este indicador é pelo número total de reclamações de clientes relativo ao desempenho de sustentabilidade. 
Fonte:

Santander:

https://www.santander.com/csgs/Satellite/CFWCSancomQP01/pt_BR/

Corporativo/Sustentabilidade/Atividade-sustentavel/Clientes-qualidade-esatisfa\%C3\%A7\% C3\%A3o-.html?cidSel=1278689263725

Fonte Itaú: https://ww2.itau.com.br/hotsites/sustentabilidade/_/no-seu-dia-adia/biblioteca-virtual/ materias/mat-satisfacao-clientes.html

Programa de relacionamento com o cliente - Um programa de relacionamento tem como principal objetivo apresentar de forma prática os atributos, benefícios e soluções que os produtos da empresa oferecem, e mostrar interesse pelo bem-estar do consumidor, mantendo assim um canal de comunicação e promovendo eventos sociais à comunidade. Uma maneira de quantificar este indicador é pelo número total sugestões da comunidade à respeito do melhoramento de sustentabilidade.

Fonte: http://www.administradores.com.br/artigos/negocios/acoes-simples-para-lidar-comreclamacoes-de-clientes/74112/

Publicação do relatório de sustentabilidade - É um instrumento de prestação de contas à sociedade, o relatório reflete a autoimagem de empresa, possibilita os ajustes em direção à sustentabilidade de fato. A sua elaboração ajuda a empresa a conhecer melhor os seus próprios pontos fracos, constituindo-se assim como um instrumento de gestão capaz de oferecer mais clareza em relação aos fatores de impacto ambiental e social da empresa. Uma maneira de quantificar este indicador é pelo número total de avaliações e relatórios publicadas e \% de conclusões destas avaliações de sustentabilidade.

Fonte: http://www.scielo.br/pdf/gp/2013nahead/aop_gp0954_ao.pdf

Prêmio de sustentabilidade - A promoção desse tipo de prêmio tem pelo menos duas funções: (i) apoiar iniciativas inovadoras de associações comunitárias, empreendedores sociais, institutos de pesquisa, ONGs e universidades em projetos para melhorias ambientais e sociais; (ii) reconhecer ações e iniciativas inovadoras que promovem o desenvolvimento sustentável. Uma maneira de quantificar este indicador é pelo número total de prêmios ou menções distribuídas ou recebidas.

Fonte: Ethos: http://ethos.org.br/PremiolnovacaoemSustentabilidade/ 
Os indicadores tecnológicos da Tabela 4 são descritos a seguir:

Aplicação de política de TI sustentável - A "TI Verde" é um conjunto de políticas e práticas capazes de garantir que a atividade de uma empresa atinja o menor impacto ambiental possível, viabilizando menores gastos de energia, economia dos recursos e matéria prima por meio da adoção de normas e padrões "verdes". Uma maneira de quantificar este indicador é pelo número total de ações de reclamações relatadas para o desempenho de sustentabilidade.

Fonte: http://www.itautec.com.br/media/652021/af_guia_gestor_sustentabilidade.pdf

Equipamentos de proteção e segurança - $O$ uso do equipamentos de proteção e segurança são fundamentais para garantir a saúde e a proteção do trabalhador para evitar consequências negativas em casos de acidentes de trabalho. Todas as atividades profissionais que envolvam algum tipo de risco físico para o trabalhador devem ser cumpridas com o auxílio de EPIs (Equipamentos de Proteção Individual), que incluem óculos, protetores auriculares, máscaras, mangotes, capacetes, luvas, botas, cintos de segurança, protetor solar e outros itens de proteção. O uso de EPIs pode garantir prevenir doenças ocupacionais, que comprometam a capacidade de trabalho e de vida dos profissionais durante e depois da fase ativa de trabalho. Uma maneira de quantificar este indicador é pelo número total de equipamentos de proteção de segurança pessoal.

Fonte: http://www.ib.unicamp.br/comissoes/node/33

Fonte: 3M: https://www.3m.com.br/3M/pt_BR/epi/

Atualização de versão de software e hardware - manter os softwares e hardwares atualizados traz diversos benefícios, entre eles maior proteção e mais funcionalidade do programa e do equipamento instalado, resultando em maior eficiência na execução das tarefas. Com a rápida evolução da tecnologia a empresa pode ficar com os equipamentos obsoletos, que em geral envolvem gastos não planejados. Uma maneira de quantificar este indicador é pelo número de atualizações de produtos/número de produtos instalados.

Fonte: Fundação CELG:http://eletra.org.br/politica-de-atualizacao-de-hardware-e-software/

Fonte: Unify:https://www.unify.com/br/support/product-lifecycle-policy.aspx

Investimento em inovação e P\&D - A lógica de uma empresa se manter no mercado é ter o seu produto aceito por um bom número de compradores. Para atraí- 
los, o produto deve chamar o interesse deles. Assim, o produto deve ser sempre atrativo e deve atender o conceito de responsabilidade social, o qual a sustentabilidade faz parte. Assim qualquer investimento da empresa deve atender os objetivos da sustentabilidade. Uma maneira de quantificar este indicador é pela quantidade total de investimentos em P\&D para esforço de sustentabilidade.

Fonte: Associação Brasileira da Indústria de Máquinas e Equipamentos: http://www.abimaq.org.br/Arquivos/Html/IPDMAQ/10\%20Inov\%20Tec\%20no\%20Brasil,\%20Aval \%20da\%20Pol\%C3\%ADtica\%20NT\%20-\%20IPEA.pdf

Fonte: Universidade de São Paulo: http://rusp.scielo.br/scielo.php?script=sci_arttext\&pid= S0103-99892011000200018\&lng=pt\&nrm=iso

Fornecedores de serviços com certificação em meio ambiente - A qualificação de fornecedores em relação à sustentabilidade do meio ambiente é importante, pois casos em que existe comprovada relação entre um dano ao meio ambiente e a atividade executada podem gerar um prejuízo de ordem econômica (pagamento de multa) e/ou à imagem da empresa. A ISO 14001 estabelece que a organização deva assegurar que os processos terceirizados sejam controlados ou influenciados, podendo, para tanto, considerar $\mathrm{o}$ atendimento a requisitos legais $\mathrm{e}$ outros requisitos. Tal relevância se deve ao fato de que, ao disseminar a importância da conformidade legal entre seus fornecedores, a organização elimina ou ao menos minimiza os riscos decorrentes de ter de responder solidária ou subsidiariamente por atos praticados por terceiros. Uma maneira de quantificar este indicador é pelo (Número de provedores com certificação ambiental/Número total de provedores) $\mathrm{x}$ $100 \%$.

Fonte: Universidade do Estado de São Paulo: http://www.rc.unesp.br/igce/aplicada/ead/ estudos_ambientais/ea27.html

Fonte: Sebrae: //www.bibliotecas.sebrae.com.br/chronus/ARQUIVOS_CHRONUS/bds/bds.nsf/ be73565de4be0504a3e24759188675e3/\$File/6012.pdf

Fonte: Ministério do Meio Ambiente: http://www.mma.gov.br/informma/item/8411-especialistasanalisam-benef\%C3\%ADcios-da-certifica\%C3\%A7\%C3\%A3o-ambiental

Aplicação de política de manutenção - Possuir uma política de manutenção colabora para a realização dos atendimentos serem com mais eficientes e o estabelecimento de ações para lidar com o descarte dos materiais substituídos. Uma maneira de quantificar este indicador é pelo número de equipamentos inspecionados/Número de equipamentos instalados. 
Fonte: Universidade de São Paulo: http://pro.poli.usp.br/trabalho-de-formatura/planejamentode-politica-de-manutencao-preventiva-com-aplicacao-de-simulacao-computacional/

Evitar parada de linha devido preocupação de segurança - Mesmo com uma gestão eficiente da manutenção, é impossível eliminar $100 \%$ dos casos de problemas técnicos em equipamentos - sem falar dos erros humanos. Entretanto, é possível lidar com essas situações e aprender com elas para evitar que se repitam. $\mathrm{Na}$ análise de um imprevisto ocorrido em determinado equipamento ou processo de produção, um indicador é o custo da hora parada. Por meio de seu cálculo, é possível quantificar o prejuízo causado e compreender quanto isso custa para a empresa, seja em relação a um único equipamento, seja para toda a produção. O conjunto de ações metodológicas para prevenir falhas e quebras é parte fundamental da gestão de manutenção. Uma maneira de quantificar este indicador é pela quantidade de pontos de segurança monitorados ao redor de maquinarias de fabricação.

Fonte: http://www.techoje.com.br/site/techoje/categoria/detalhe_artigo/1226

Política de sistema aberto - O uso de tecnologias de sistemas abertos possibilita trazer ganhos para a empresa e assim ela pode promover melhorias para aumento da produtividade, para o meio ambiente e para os funcionários. Além deste tipo de tecnologia aumentar o acesso dos funcionários à conhecimentos e inovação, a disseminação da responsabilidade social de cada na empresa e na sociedade será em escalas maiores, contribuindo assim efetivamente também para a manutenção da sustentabilidade. Uma maneira de quantificar este indicador é levantar os benefícios (monetário como desenvolvimento pessoal do empregado) trazidos pelo número total de sistemas abertos (código aberto ou sem custo) instalados.

Fonte: Scielo: http://blog.scielo.org/blog/2016/01/14/o-acesso-aberto-como-alternativa-desustentabilidade-na-comunicacao-cientifica/

Fonte: Universidade Federal do Pará: http://www.ufpa.br/amazonia21/publicacoes/sistabertos/des-sust-sist-ab.htm

Monitoração de energia renovável - Diante da importância de mensurar a sustentabilidade surgem como questão estratégica, os indicadores de energia para o desenvolvimento sustentável, sendo estes uma ferramenta importante de planejamento para alcançar o desenvolvimento sustentável. Os indicadores são destinados a fornecer dados para analistas e tomadores de decisão para que possam 
compreender melhor a sua situação e as tendências do consumo de energia na produção. Uma maneira de quantificar este indicador é pela medição da porcentagem de eficiência atingida pelos sistemas de energia monitorados.

Fonte: empresa de tecnológia National Instruments: ftp://ftp.ni.com/pub/branches/latam/brazil/

Tecnologias\%20de\%20Monitoramento\%20e\%20Controle\%20para\%20Aplica\%C3\% A7\%C3\%B5es\%20de\%20Energia\%20Renov\%C3\%A1vel.pdf

Fonte: Schneider Eletric: https://www.schneiderelectric.com.br/pt/work/campaign/innovation/ overview.jsp

Monitoração do ciclo de operação de máquinas - A vida de uma ferramenta pode ser definida como sendo o tempo em que a mesma trabalha efetivamente sem perder sua funcionalidade ou até que se atinja o critério de fim de vida previamente estabelecido. O fim de vida de uma ferramenta pode ser definido pelo grau de desgaste estabelecido. O desgaste afeta a precisão, qualidade e aumenta a ocorrência de problemas. Uma maneira de quantificar este indicador é pela porcentagem alcançada pela monitoração do ciclo de trabalho de equipamento/desgaste durante o processo de fabricação.

Fonte: http://dited.bn.pt/4/4/capaindicesa_86158.pdf

\subsection{NORMA ANSI/ISA-95}

Dentre as várias normas industriais internacionalmente aceitas, a ANSI/ISA-95 (2005) é uma das mais conhecidas e comumente implementadas em sistemas produtivos como é o caso de SPD. Nessa norma, são estabelecidos diferentes níveis hierárquicos de gestão e controle de processos. Nos níveis 1 e 2 tem-se o controle dos equipamentos que realizam as transformações físicas dos processos. No nível 3 , de supervisão, tem-se o Manufacturing Execution System (MES) que processa as informações dos processos produtivos visando a sua operacionalização nas instalações industriais disponíveis (maquinarias e pessoas) e, no nível 4, de negócios, essas informações são utilizadas para a tomada de decisões de caráter estratégico (vide Figura 4 que envolve o planejamento e programação da produção).

$\mathrm{Na}$ Figura 4 também são indicadas as organizações normalizadoras que definem interfaces padrões de comunicação entre os níveis: International Society of 
Automation (ISA), International Organization for Standardization (ISO), International Electrotechnical Commission (IEC), OPC Standart e a Organization for Machine Automation and Control (OMAC).

Figura 4 - Níveis 1, 2, 3 e 4 de gestão de controle com a ANSI/ISA-95

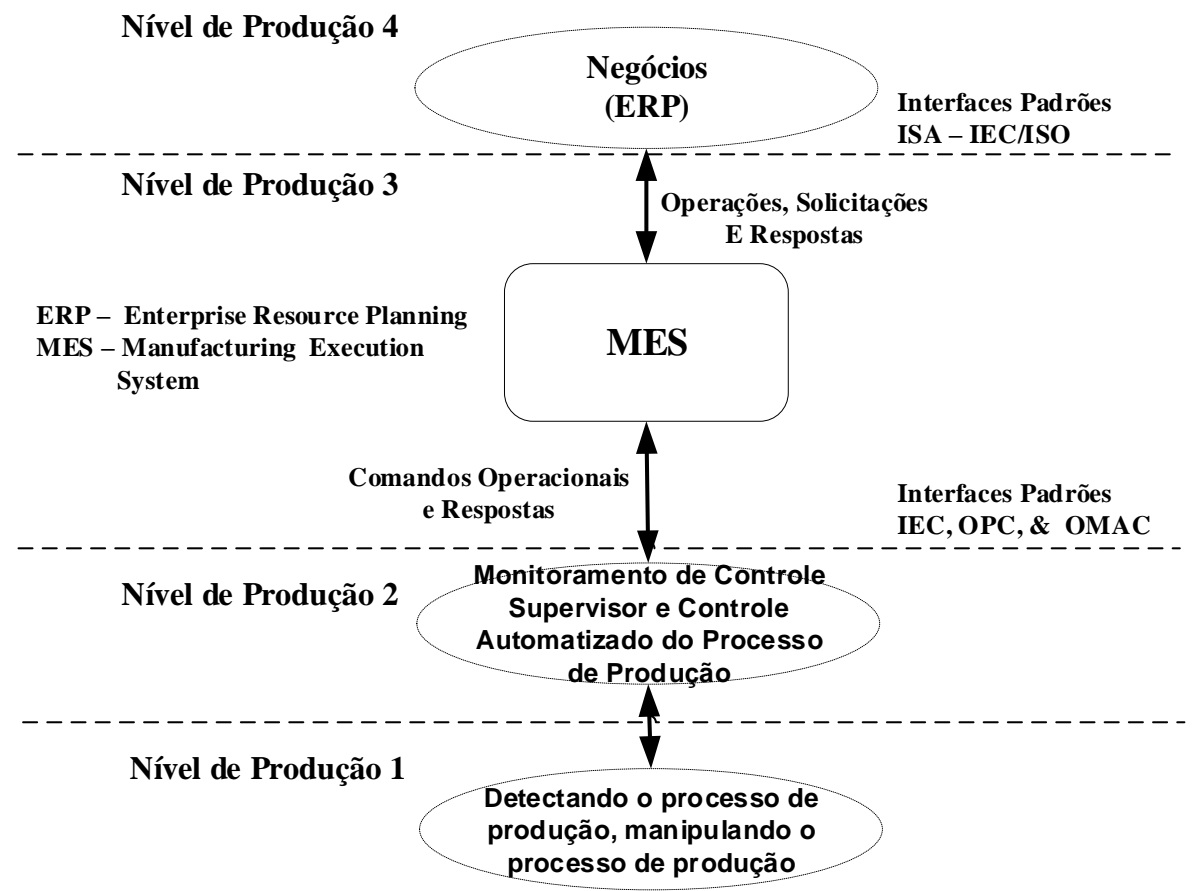

Fonte: Adaptado de ANSI/ISA-95 (2005)

Neste trabalho as funcionalidades do nível 3 são reinterpretadas e estendidas para incluir um módulo para tratar especificamente da sustentabilidade. Este módulo é chamado de Sustainability Management System (SuMS). A proposta é que este módulo calcule e avalie os indicadores de sustentabilidade. A coleta de informações do processo produtivo e do ambiente envolvido ocorre nos níveis 1 e 2, mas para assegurar o tratamento independente dos dados em relação ao sistema de controle básico das operações produtivas, isto é, dos equipamentos da planta produtiva, assume-se que parte dessas informações são recebidas via um sistema de aquisição de dados exclusivo para a avaliação da sustentabilidade.

Depois do processamento das informações coletadas tem-se o cálculo dos indicadores de sustentabilidade. Em caso de discrepância nos dados dos indicadores obtidos, o SuMS deve informar isto ao nível 4 onde são tomadas as decisões estratégicas. O SuMS por outro lado também está continuamente pronto para receber comandos de acordo com os procedimentos de tomada de decisão no nível 4 . Além 
disso, sempre que necessário, o SuMS deve se comunicar (enviar comandos e receber informações) do MES (mesmo nível) e de outros elementos do nível 2.

A Figura 5 mostra o módulo SuMS proposto no contexto da estrutura de gestão e controle de sistemas produtivos da ANSI/ISA (2005). O SuMS funciona independentemente do MES, mas estes podem e devem trocar informações mutuamente para assegurar a operação sustentável do SPD.

O SuMS é composto por sub-módulos que executam as seguintes funcionalidades:

- Coleta de dados: recebe e armazena os dados necessários para o cálculo dos indicadores de sustentabilidade. Uma parte dos dados é recebida de um sistema de aquisição dedicado no nível 2 , enquanto outra parte dos dados dos processos produtivos são recebidos do MES;

- Avaliação de dados:processa os dados de sustentabilidade, faz a conformação dos dados armazenados para colocá-los nos formatos e padrões adequados para o cálculo dos SuKPIs (Indicadores Chave de Desempenho e Sustentabilidade) e faz o cálculo dos SuKPIs;

- Comunicação com o sistema de tomada de decisões estratégicas: faz a interação com o nível superior, mas também realiza uma avaliação preliminar de possíveis discrepâncias com os valores esperados, indicando possíveis causas e/ou possíveis melhorias a serem consideradas.

\subsection{CYBER-PHYSICAL SYSTEM E TECNOLOGIA DA INFORMAÇÃO}

Segundo Colombo et al. (2017), o termo CPS (Cyber-Physical System) foi criado por volta de 2006 para "referir-se à integração de computação com processos físicos". O CPS pode ser descrito como sistemas inteligentes que englobam hardware, software e componentes físicos, integrados e interagindo para detectar e controlar em tempo real os processos que incluem interação com seres humanos por meio de várias formas de dispositivos/interfaces.

Neste sentido, Colombo et al. (2013), Sundmaeker et al. (2013), Miyagi, (1996) Jeong et al., (2014) e Mell e Glance, (2011), declaram o CPS como a base de serviços inteligentes emergentes e futuros, fornecendo a infraestrutura para interação de processos que podem ser geograficamente dispersos. Nesse ambiente, gerentes, 
operadores, fornecedores, clientes e partes interessadas de uma operação do SPD poderiam acessar seus dados de maneira independente (de sua localização física), por exemplo, para monitorar processos, analisar dados e/ou avaliar novos cenários de produção. Ou seja, as informações podem ser acessadas de qualquer lugar via Internet (FERREIRA et al., 2013).

Figura 5 - Módulo SuMS proposto no contexto da ANSI/ISA-95.

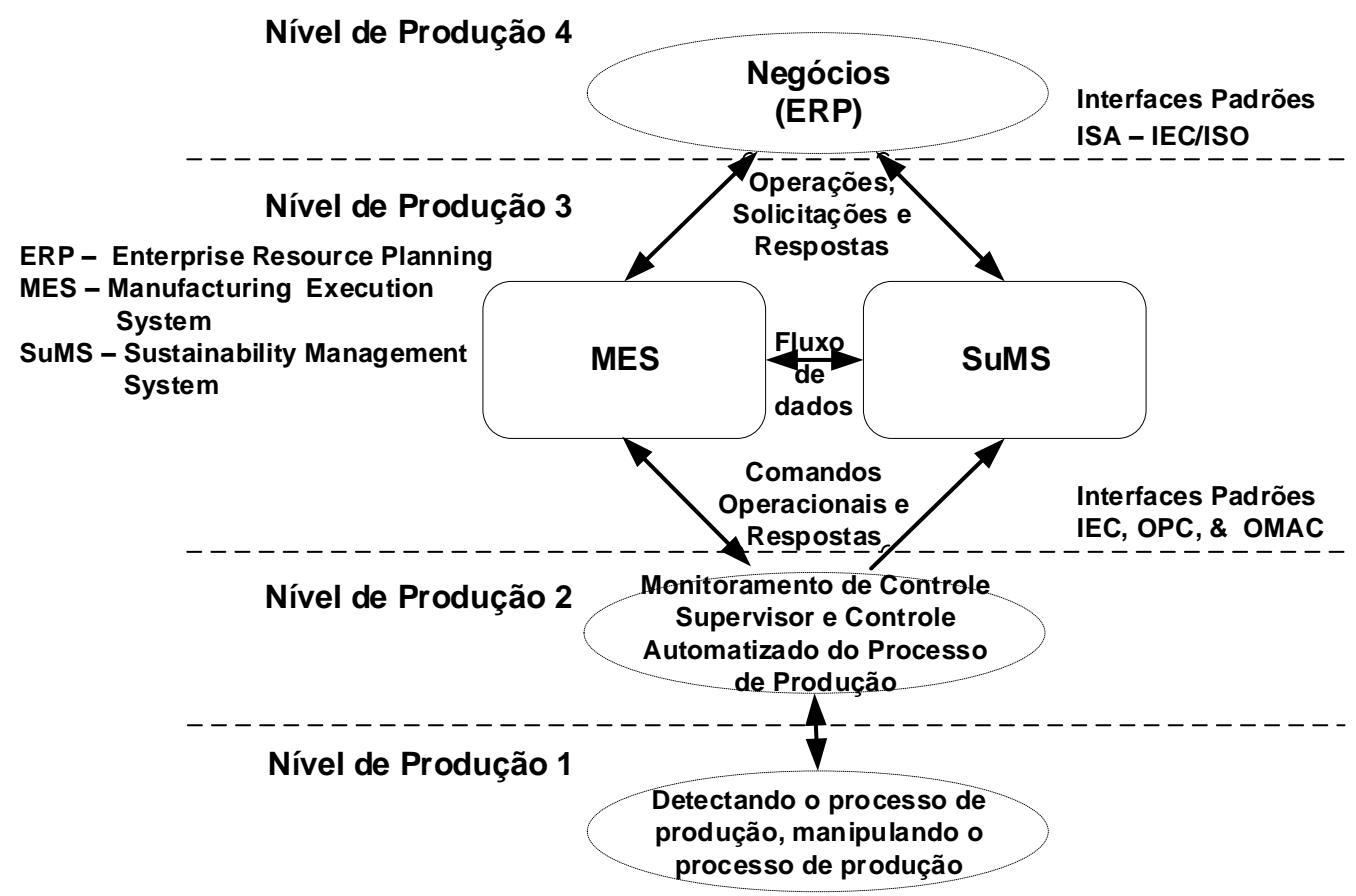

Fonte: $\mathrm{O}$ autor

Apesar de alguns desafios tecnológicos ainda não estarem completamente superados, o CPS e uma infra-estrutura de comunicação da rede de entidades que consideram um nível corporativo (private inter enterprise cloud) e o ambiente público (public cloud) como apresentado em Wollschaeger, Sauter e Jasperneite (2017) também são partes fundamentais da operação de um SPD e de sua gestão de sustentabilidade.

A Figura 6 ilustra como os usuários (gerentes, operadores, fornecedores, clientes, partes interessadas) de um SPD vêem o sistema e interagem com ele independentemente da localização física deles próprios e das plantas (sistemas produtivos) e, portanto, todos os SuMS e suas interfaces (com dispositivos Nível 2 e Nível 4, bem como MES) devem considerar essa infraestrutura. 
Figura 6 - Rede de comunicação no contexto da CPS onde os "usuários do sistema" dispersos podem monitorar a sustentabilidade de cada sistema produtivo (SP1, ... SPn) e de todo sistema SPD

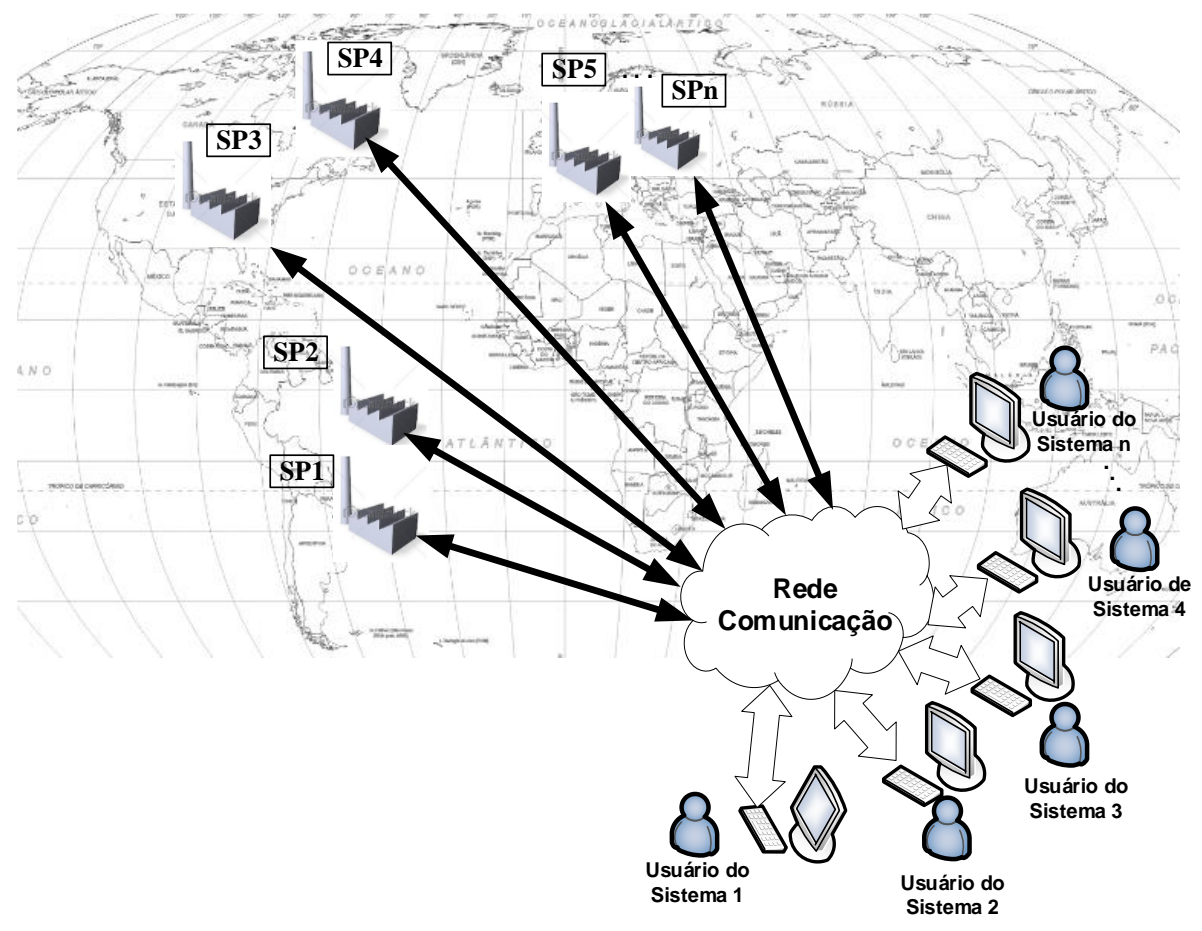

Fonte: $\mathrm{O}$ autor

\subsection{TÉCNICAS DE MODELAGEM DE PROCESSOS}

Processos produtivos reais possuem indeterminações intrínsecas que não permitem uma avaliação puramente analítica, ou seja, não é possível pré-determinar quando certos eventos acontecem como o instante da ocorrência de falha ou o instante de uma operação imprevista acionada por um ser humano. Entretanto podese caracterizar o sistema com base nos estados entre a ocorrência de eventos. Assim, baseado em trabalhos anteriores, assume-se que o SPD pode ser visto como um sistema de eventos discretos (SED); portanto, a rede de Petri pode ser utilizada para modelá-la (MIYAGI, 2001; SILVA, 2013). De fato, a rede de Petri tem sido amplamente utilizada e várias extensões desta técnica foram propostas de acordo com aplicações específicas. Por exemplo, Da Silva et al. (2014) utiliza a técnica do Production Flow Schema (PFS) junto com a rede de Petri lugar/transição para sistematizar o procedimento de modelagem, realizar a análise e a especificação de controle de sistemas produtivos reconfiguráveis. Mello, Junqueira e Miyagi (2010) abordam a orientação a serviços em SPD usando também o PFS e a rede de Petri. Esses 
trabalhos demonstraram que essa combinação permite uma maneira efetiva e relativamente simples e transparente de desenvolver modelos de processos produtivos em rede de Petri. Nesta abordagem combinada, os modelos em PFS são refinados gradualmente e a dinâmica do sistema/processo é descrita apenas no momento em que o modelo em PFS é convertido por um modelo em rede de Petri.

O PFS identifica atividades de um processo e um fluxo de itens (informações, materiais, etc.) entre estas atividades, num nível relativamente alto de abstração. Em um mesmo modelo PFS é possível representar mais de um fluxo. Os fluxos primários indicam as sequencias de $\underline{\text { atividades }}$ principais a serem detalhadas. Os fluxos secundários indicam o envolvimento de recursos ou informações adicionais, de acordo com a interpretação adotada. Nesta representação não há preocupação sobre a evolução dinâmica do sistema

De acordo com Miyagi (1996), em geral, a sistemática para modelagem de sistemas com o PFS deve seguir as seguintes etapas: (1) identificação das principais atividades de transformação de itens (materiais e/ou informações); (2) identificação das inter-atividades que indicam onde os itens são visualizados ou armazenados; (3) definição do fluxo de itens entre as atividades e inter-atividades; (4) introdução dos elementos de controle de recursos e (5) detalhamento dos sinais trocados entre 0 sistema de controle e a planta. Assim, o modelo PFS é gradualmente refinado para os modelos em rede de Petri, relacionando estados, eventos e as dinâmicas dos processos produtivos. A Figura 7 ilustra o exemplo de um sistema produtivo modelado em PFS com destaque no movimento do transportador que circula por estações de trabalho e o modelo do sistema de transporte em PFS. Na Figura 8 tem-se o exemplo do detalhamento do modelo em rede de Petri de uma das atividades do PFS da Figura 7. 
Figura 7 - Exemplo de um Sistema produtivo modelado em PFS: (a) movimento do transportador que circula pelas estações de trabalho; (b) modelo PFS do sistema de transporte

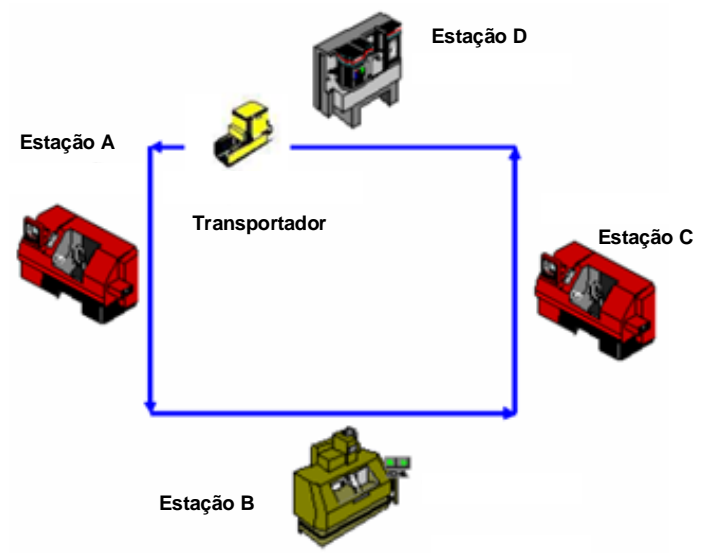

(a)

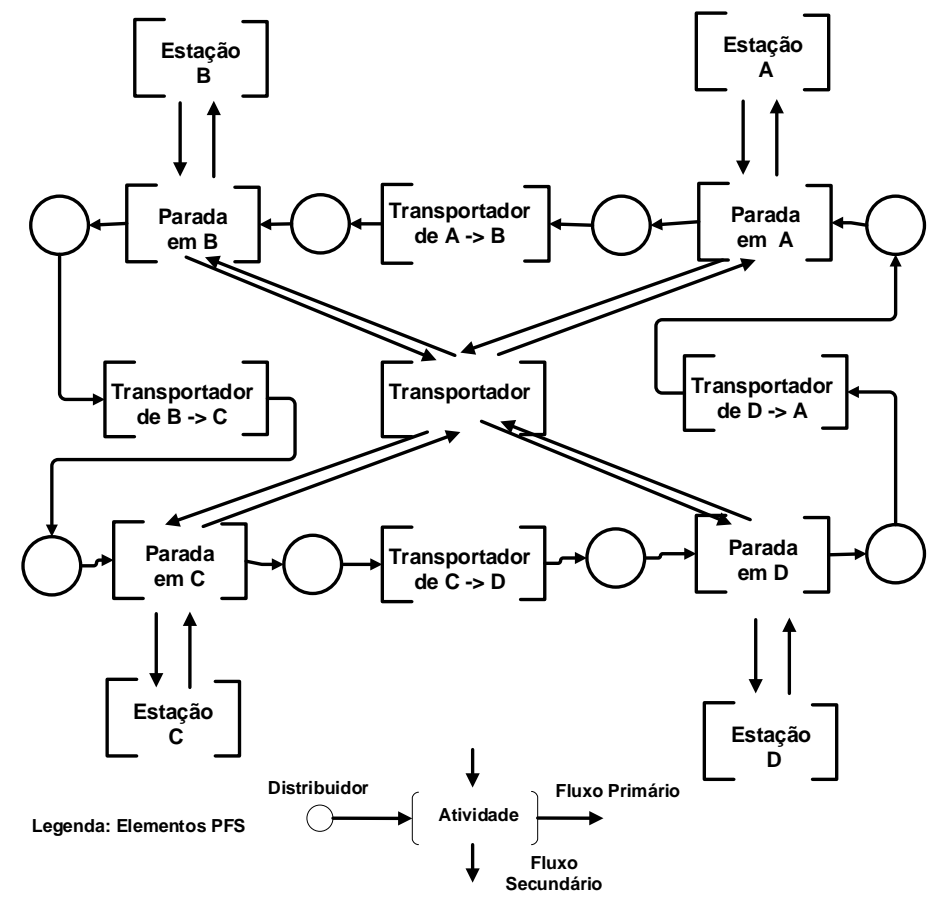

(b)

Fonte: Adaptado de Junqueira e Miyagi, 2009)

A rede de Petri é uma técnica de descrição formal de sistemas que permite a análise de propriedades estruturais e funcionais dos modelos (MURATA, 1989; MELLO, JUNQUIERA e MIYAGI, 2010). Mais detalhes podem ser encontrados no Anexo. 
Figura 8 - Exemplo de detalhamento do modelo em rede de Petri de uma das atividades do PFS na Figura 7.

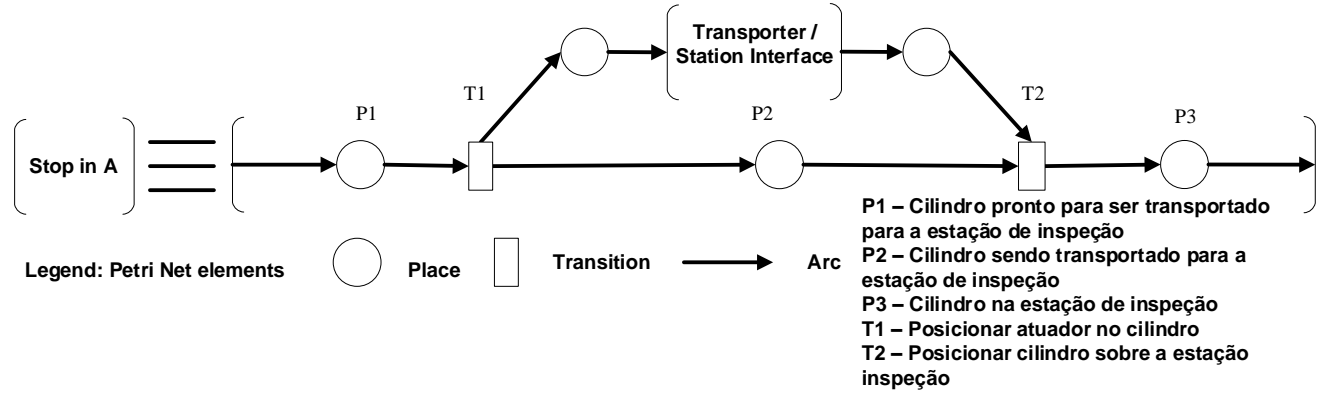

Fonte: Adaptado de Junqueira e Miyagi, 2009)

A Figura 9 ilustra um exemplo de um modelo de um processo produtivo em rede de Petri, no qual as informações para o cálculo de indicadores de sustentabilidade são explicitamente apresentadas. Ou seja, o gráfico indica quais as variáveis que devem ser coletadas e onde e quando essas medidas devem ser levadas em consideração para o cálculo dos SuKPIs. Este modelo usa elementos da rede de Petri designados como arco habilitador e inibidor. Na especificação funcional do SuMS estes elementos são utilizados para representar o intercâmbio de informações necessários para o cálculo dos indicadores de sustentabilidade.

Figura 9 - Exemplo de um modelo em rede de Petri com indicação das informações utilizadas para cálculo de indicadores de sustentabilidade

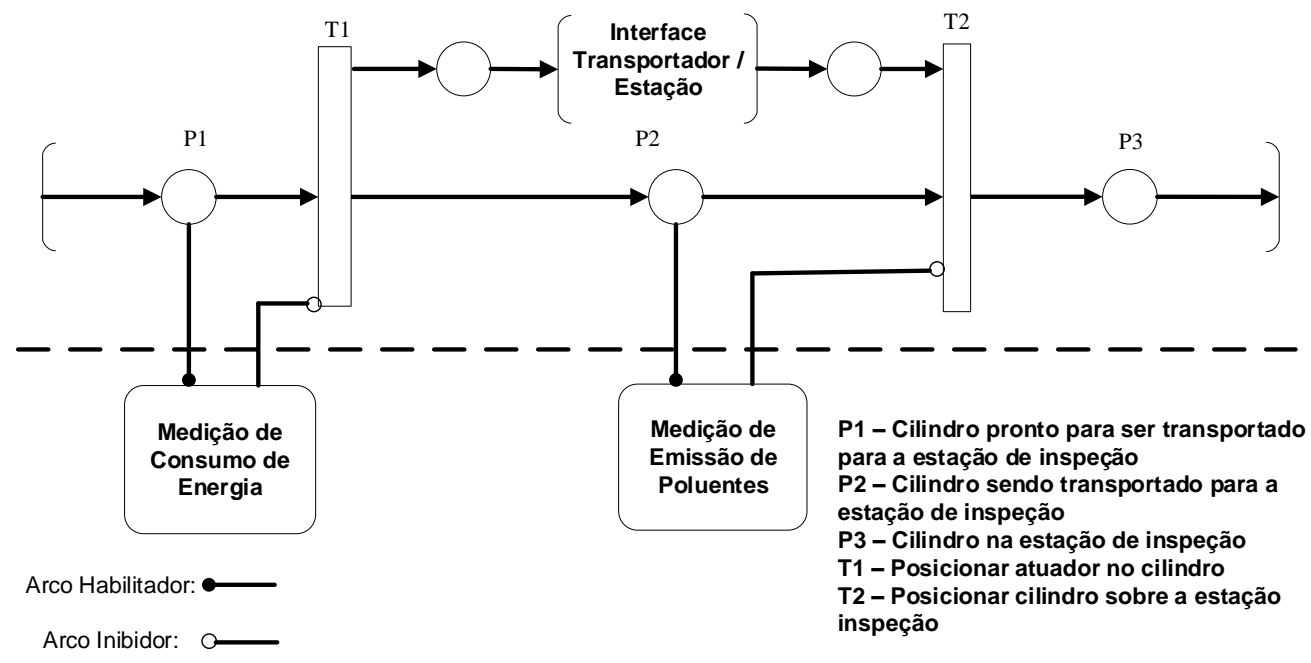

Fonte: $\mathrm{O}$ autor

Para verificar e validar os modelos em rede de Petri dos processos do SPD, além da análise das propriedades dos grafos, explora-se também a técnica de simulação de cenários para estudar as indeterminações intrínsecas relacionadas com o instante da ocorrência de falha e/ou o instante de acionamento de uma operação 
por um ser humano. Para estes casos, a simulação de modelos é uma maneira eficaz de testar situações sob diferentes condições e com isto identificar casos problemáticos e investigar as soluções para superá-los.

Neste trabalho, considera-se que o SuMS tem em seu banco de dados a descrição detalhada de todos os processos do SPD, isto é, o SuMS tem os modelos em PFS e em rede de Petri dos processos de modo que estes podem ser utilizados também para monitorar as informações relativas à sustentabilidade do sistema. Assim o SuMS pode realizar on-line a investigação do nível de discrepância dos indicadores de sustentabilidade, e tem ainda condições de avaliar os seus efeitos para encaminhar as devidas informações para o nível de tomada de decisões estratégicas do SPD.

\subsection{SÍNTESE DO CAPÍTULO}

Foram apresentados os fundamentos relacionados com (i) a sustentabilidade de sistemas produtivos e análise de desempenho desses sistemas, e a opção adotada neste trabalho sob o enfoque de QBL e 4R, e com (ii) a abordagem de sistemas a eventos discretos para o uso de técnicas formais como a rede de Petri para a modelagem e a especificação conceitual e funcional de SPDs.

Foram também apresentados os principais indicadores de sustentabilidade relacionados com sistemas produtivos, e a estrutura de controle e gestão de sistemas industriais segundo as normas industriais existentes e amplamente adotadas no mundo, assim como a reinterpretação e extensão da estrutura prescrita para destacar e incluir explicitamente os parâmetros e funcionalidades necessárias para a avaliação da sustentabilidade de processos no SPD.

Apresentou-se também uma discussão sobre propostas associadas com CPS e novas tecnologias de informação num novo ambiente de comunicação com entidades atuando cooperativamente em que o SPD estará imerso no futuro, e que deve ser considerado no presente trabalho.

Estes fundamentos são a base de um framework para implementar as funcionalidades para a avaliação da sustentabilidade de processos produtivos no SPD e que é introduzido no capítulo seguinte. 


\section{FRAMEWORK PROPOSTO}

Introduzir o conceito de sustentabilidade no SPD não altera a sua natureza de um sistema produtivo, mas a consideração deste conceito desde a fase de projeto do sistema não é trivial (DA SILVA et al., 2016). Para avaliação do desempenho de sustentabilidade de SPD a Figura 10 ilustra as principais funcionalidades que devem ser consideradas. Nesta mesma figura, as setas indicam a relação entre as funcionalidades. Estas funcionalidades derivam de conceitos existentes, métodos e ferramentas que foram desenvolvidos com base na experiência de projetistas e trabalhos de pesquisadores e, que foram aqui devidamente adaptadas para o framework proposto para avaliação da sustentabilidade nos processos produtivos.

Figura 10 - Esquema do SuMS com as funcionalidades a serem consideradas para análise do desempenho de sustentabilidade de um SPD.

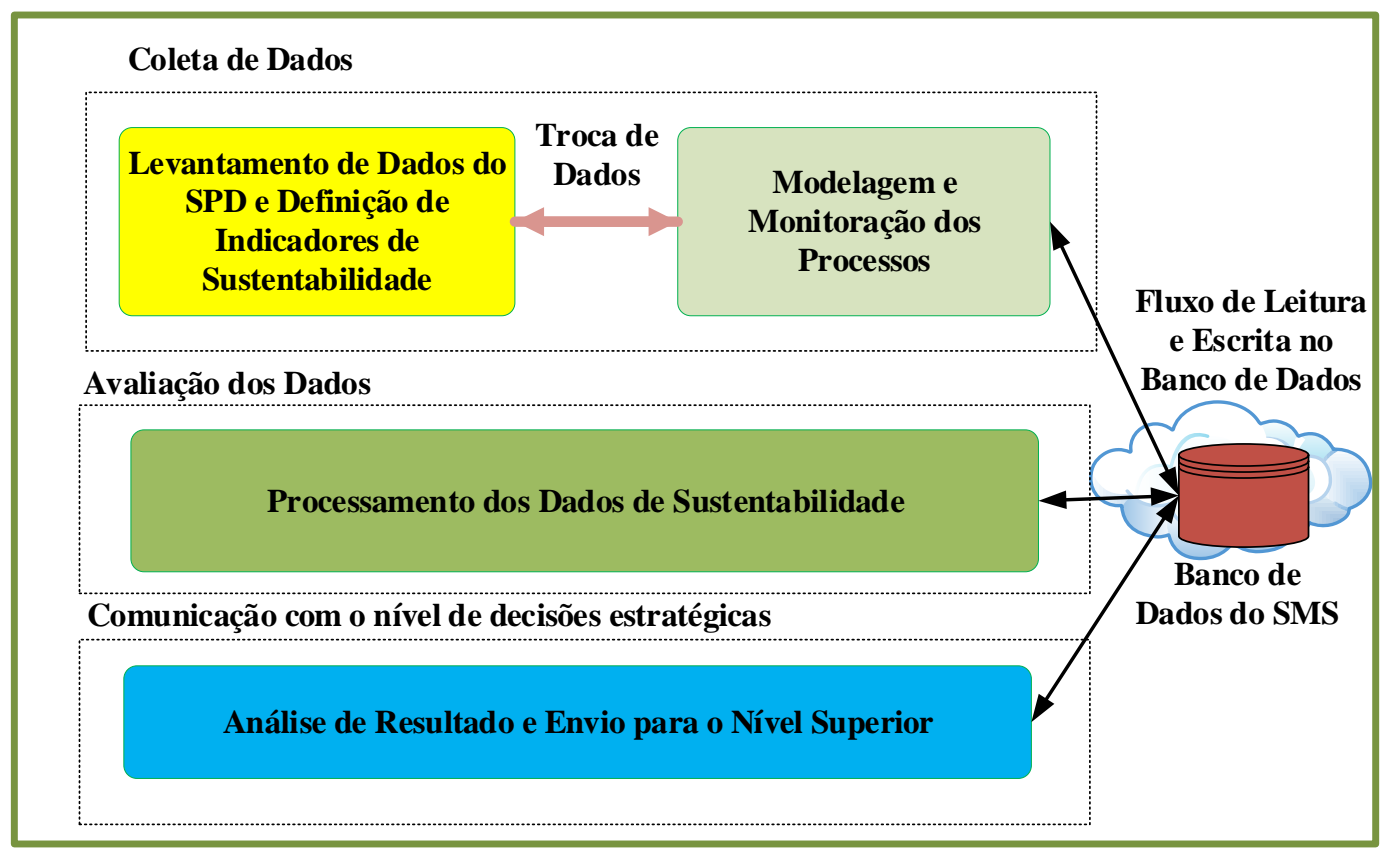

Fonte: $\mathrm{O}$ autor

A Figura 10 mostra as funcionalidades a serem implementadas por hardware e software de acordo com a estrutura revisada de gerenciamento e controle da ANSI/ISA-95 mostrada na Figura 5. As funcionalidades correspondem exatamente aos submódulos SuMS. O banco de dados SuMS é o repositório de dados de processo (modelos em RdP usados para monitorar processos produtivos) e informações de 
sustentabilidade do SPD. As informações do processo produtivo relacionadas especificamente à operação do sistema estão em um banco de dados gerenciado pelo MES. No entanto, existem dados exclusivamente relacionados à sustentabilidade, que podem/devem ser tratados de forma independente, exigindo assim um banco de dados SuMS.

As funcionalidades são detalhadas a seguir:

\subsection{COLETA DE DADOS}

Esta funcionalidade está associada ao levantamento das informações do sistema de produção (parâmetros funcionais e operacionais) para definir e calcular os indicadores de sustentabilidade e, para registro dessas informações no banco de dados do SuMS. Consideram-se aqui quatro atividades principais a seguir descritas:

\subsubsection{Levantamento de dados do SPD}

Na fase de inicialização de dados do SuMS, esta atividade é responsável pelo levantamento de informações do SPD como um todo, isto é, dados sobre a estrutura dos processos envolvidos, as interações entre os processos, os recursos envolvidos, as relações de interdependência e restrições envolvidas.

O levantamento de dados é realizado com base nos documentos de projeto e de operação dos sistemas produtivos e complementados com informações coletadas via questionários. As Tabelas (1, 2, 3 e 4) apresentadas na seção anterior listam a família de indicadores que é a base para a escolha dos indicadores específicos para o SPD. As Tabelas 9 a 18 apresentam as perguntas pré-formatadas para completar este levantamento. Estes questionários foram baseados em Garbie e Al-Hosni (2014) e adaptados para a aplicação em SPDs.

As Tabelas 9 a 13 referem-se às questões técnicas da infraestrutura de produção e aspectos de sustentabilidade. 
Tabela 9 - Questionário técnico para levantamento de dados do SPD

\begin{tabular}{|c|c|c|c|c|}
\hline \multicolumn{3}{|c|}{ QUESTIONÁRIO SOBRE A PRODUÇÃO E A INFRA-ESTRUTURA DO SISTEMA } & \multicolumn{2}{|c|}{ RESULTADO } \\
\hline ITEM & Informação & Descrição & Sim & Não \\
\hline \multirow{5}{*}{1} & \multirow{5}{*}{$\begin{array}{l}\text { Como a produção } \\
\text { pode ser } \\
\text { classificada? }\end{array}$} & Tradicional & & \\
\hline & & Flexível & & \\
\hline & & Enxuto & & \\
\hline & & Ecológico & & \\
\hline & & Sustentável & & \\
\hline \multirow{5}{*}{2} & \multirow{5}{*}{$\begin{array}{l}\text { Como o tamanho } \\
\text { da produção é } \\
\text { classificado? }\end{array}$} & Menos de 50 empregados & & \\
\hline & & até 50 empregados & & \\
\hline & & Entre 50 e 100 empregados & & \\
\hline & & Entre 100 e 1000 empregados & & \\
\hline & & Mais de 1000 empregados & & \\
\hline \multirow{5}{*}{3} & \multirow{5}{*}{$\begin{array}{l}\text { Que tipo de } \\
\text { configuração da } \\
\text { produção é } \\
\text { adotado? }\end{array}$} & Não identificado & & \\
\hline & & Células & & \\
\hline & & Processo & & \\
\hline & & Autonomia & & \\
\hline & & Posicional & & \\
\hline \multirow{5}{*}{4} & \multirow{5}{*}{$\begin{array}{l}\text { Que tipo de } \\
\text { sistema de } \\
\text { transporte da } \\
\text { produção é } \\
\text { utilizado? }\end{array}$} & Nenhum & & \\
\hline & & Empilhadeira & & \\
\hline & & Esteira & & \\
\hline & & AGV & & \\
\hline & & Robô manipulador & & \\
\hline \multirow{5}{*}{5} & \multirow{5}{*}{$\begin{array}{l}\text { Que tipo de } \\
\text { sistema de } \\
\text { gerência integrada } \\
\text { éadotada? }\end{array}$} & Nenhum & & \\
\hline & & Sistema de supervisão local (nível 1, 2) & & \\
\hline & & Sistema de supervisão e controle (nível 3) & & \\
\hline & & Sistema de gerencial central (nível 4) & & \\
\hline & & Data center externo (Cloud, WebServer) & & \\
\hline
\end{tabular}

Tabela 10 - Questionário técnico para levantamento de dados do aspecto econômico

QUESTIONÁRIO SOBRE A PRODUÇÃO E A INFRA-ESTRUTURA DO SISTEMA PRODUTIVO - ASPECTO ECONÔMICO

RESULTADO

\begin{tabular}{|c|c|c|c|c|}
\hline ITEM & Informação & Descrição & Sim & Não \\
\hline \multirow{6}{*}{1} & \multirow{11}{*}{$\begin{array}{l}\text { Quais benefícios } \\
\text { econômicos são } \\
\text { alcançados pela } \\
\text { produção após a } \\
\text { inclusão da } \\
\text { sustentabilida- } \\
\text { de? } \\
\text { Quais custos de } \\
\text { fabricação são } \\
\text { monitorados } \\
\text { para não } \\
\text { ultrapassar o } \\
\text { orçamento } \\
\text { planejado? }\end{array}$} & Benefício com o programa Pegado de Carbono & & \\
\hline & & Benefício com reuso de recursos & & \\
\hline & & Benefício com descarte de lixo & & \\
\hline & & Benefício com reciclagem de materiais & & \\
\hline & & Benefício com energia renovável & & \\
\hline & & Benefício com redução da energia tradicional & & \\
\hline \multirow{5}{*}{2} & & Custo de materiais & & \\
\hline & & Custo de energia & & \\
\hline & & Custo de mão de obras & & \\
\hline & & Custo operacional e de capital & & \\
\hline & & Custo com descarte de materiais & & \\
\hline \multirow{8}{*}{3} & \multirow{8}{*}{$\begin{array}{l}\text { Quais áreas da } \\
\text { empresa têm } \\
\text { recebido } \\
\text { investimentos? }\end{array}$} & $\begin{array}{l}\text { Inovação tecnológica em redução de consumo de } \\
\text { energia }\end{array}$ & & \\
\hline & & Geração de energias renováveis & & \\
\hline & & Benefício aos funcionários & & \\
\hline & & Desenvolvimento de reuso de materiais & & \\
\hline & & Monitoração do meio ambiente & & \\
\hline & & Processo de descarte de materiais & & \\
\hline & & Monitoração de Clientes & & \\
\hline & & $\begin{array}{l}\text { Projeto com a comunidade } \\
\text { Comunicação com cliente e comunidade }\end{array}$ & & \\
\hline
\end{tabular}


Tabela 11 - Questionário técnico para levantamento de dados do aspecto ambiental

\begin{tabular}{|c|c|c|c|c|}
\hline & \multicolumn{2}{|c|}{$\begin{array}{l}\text { QUESTIONÁRIO SOBRE A PRODUÇÃO E A INFRA-ESTRUTURA } \\
\text { DO SISTEMA PRODUTIVO - ASPECTO AMBIENTAL }\end{array}$} & \multicolumn{2}{|c|}{ RESULTADO } \\
\hline \multirow[t]{2}{*}{ ITEM } & Informação & Descrição & Sim & Não \\
\hline & Quais etapas do sistema de & Pontos de coletas definidos & & \\
\hline \multirow[t]{3}{*}{1} & coleta estão em & Sistema de transporte de materiais & & \\
\hline & funcionamento? & Logística de coleta & & \\
\hline & & Sistema de desmonte & & \\
\hline \multirow[t]{4}{*}{2} & Quais etapas do sistema de & Sistema de separação & & \\
\hline & descarte estão em & Sistema de transporte de materiais & & \\
\hline & funcionamento? & $\begin{array}{l}\text { Locais de descartes de materiais } \\
\text { definidos }\end{array}$ & & \\
\hline & & Reconfiguração & & \\
\hline \multirow[t]{6}{*}{3} & & ISO 9.000 implementado & & \\
\hline & Quals soluçoes de & ISO 14.000 implementado & & \\
\hline & $\begin{array}{l}\text { sustentabilidade tem sıdo } \\
\text { imnlantadas? }\end{array}$ & Duplicação da unidade produtiva & & \\
\hline & implantadas? & Máquinas Multifuncionais & & \\
\hline & & Logística Reversa & & \\
\hline & Como a produção pode ser & 2Rs & & \\
\hline \multirow[t]{4}{*}{4} & classificada conforme as & 3Rs & & \\
\hline & seguintes metodologias de & 4Rs & & \\
\hline & $\begin{array}{l}\text { sustentabilidade: (repensar, } \\
\text { recusar, reduzir, reutilizar, } \\
\text { recuperar, reciclar)? }\end{array}$ & $6 \mathrm{Rs}$ & & \\
\hline & & Consumo de água & & \\
\hline \multirow[t]{6}{*}{5} & & Consumo de energia & & \\
\hline & & Desperdício de material & & \\
\hline & O que é monitorado? & Qualidade de ar & & \\
\hline & & Emissão de poluentes & & \\
\hline & & Controle térmico & & \\
\hline & & Emissão de gases tóxicos & & \\
\hline \multirow{3}{*}{6} & & Energia solar & & \\
\hline & energia são utilizadas? & Energia eólica & & \\
\hline & & Energia por biomassa & & \\
\hline
\end{tabular}

Tabela 12 - Questionário técnico para levantamento de dados do aspecto social

QUESTIONÁRIO SOBRE A PRODUÇÃO E A INFRA-ESTRUTURA DO SISTEMA PRODUTIVO - ASPECTO SOCIAL

\begin{tabular}{|c|c|c|c|c|}
\hline \multirow[t]{2}{*}{ ITEM } & Informação & Descrição & Sim & Não \\
\hline & & Gerência de reclamações e criticas & & \\
\hline \multirow[t]{3}{*}{1} & $\begin{array}{l}\text { Quais políticas de tratamento } \\
\text { de clientes estão em }\end{array}$ & $\begin{array}{l}\text { Programa de relacionamento com o } \\
\text { cliente }\end{array}$ & & \\
\hline & funcionamento? & $\begin{array}{l}\text { Participação de clientes com } \\
\text { sugestões de melhorias }\end{array}$ & & \\
\hline & & $\begin{array}{l}\text { Medida de comportamento do } \\
\text { trabalhador }\end{array}$ & & \\
\hline \multirow[t]{7}{*}{2} & & Medida de satisfação & & \\
\hline & O que é monitorado na & Ergonomia & & \\
\hline & estação de trabalho? & Treinamentos em sustentabilidade & & \\
\hline & & Treinamento em segurança & & \\
\hline & & Monitoração de Acidentes & & \\
\hline & & Ponto de sugestões e críticas & & \\
\hline & & $\begin{array}{l}\text { Relatório anual de sustentabilidade } \\
\text { (por ex. GRI - Global Reporting } \\
\text { Initiative) }\end{array}$ & & \\
\hline \multirow[t]{3}{*}{3} & $\begin{array}{l}\text { Quais açoes com a } \\
\text { comunidade estãn em }\end{array}$ & Programa de integração comunitário & & \\
\hline & funcionamento? & $\begin{array}{l}\text { Parceria com escolas locais para } \\
\text { incentivo a capacitação }\end{array}$ & & \\
\hline & & $\begin{array}{l}\text { Projeto de desenvolvimento da } \\
\text { comunidade }\end{array}$ & & \\
\hline
\end{tabular}


Tabela 13 - Questionário técnico para levantamento de dados do aspecto tecnológico

\begin{tabular}{|c|c|c|c|c|}
\hline & \multicolumn{2}{|c|}{$\begin{array}{l}\text { QUESTIONÁRIO SOBRE A PRODUÇÃO E A INFRA-ESTRUTURA } \\
\text { DO SISTEMA PRODUTIVO - ASPECTO TECNOLÓGICO }\end{array}$} & \multicolumn{2}{|c|}{ RESULTADO } \\
\hline ITEM & Informação & Descrição & Sim & Não \\
\hline \multirow{7}{*}{1} & \multirow{7}{*}{$\begin{array}{l}\text { Quais tecnologias estão } \\
\text { sendo utilizadas? }\end{array}$} & $\begin{array}{l}\text { Pesquisa e implantação de fontes } \\
\text { renováveis }\end{array}$ & & \\
\hline & & $\begin{array}{l}\text { Localização por rastreabilidade de } \\
\text { produto }\end{array}$ & & \\
\hline & & $\begin{array}{l}\text { Armazenamento em centro de dados } \\
\text { nas nuvens }\end{array}$ & & \\
\hline & & $\begin{array}{l}\text { Implantação de tecnologia Cyber- } \\
\text { Physical System }\end{array}$ & & \\
\hline & & $\begin{array}{l}\text { Monitoração do bem-estar do } \\
\text { funcionário }\end{array}$ & & \\
\hline & & $\begin{array}{l}\text { Monitoração de segurança interna e } \\
\text { externa }\end{array}$ & & \\
\hline & & $\begin{array}{l}\text { Monitoração continua das } \\
\text { necessidades do cliente e } \\
\text { comunidade }\end{array}$ & & \\
\hline \multirow{7}{*}{2} & \multirow{7}{*}{$\begin{array}{l}\text { O que é adotado para } \\
\text { prognóstico de falhas? }\end{array}$} & Política de manutenção preditiva & & \\
\hline & & Política de manutenção preventiva & & \\
\hline & & Técnica de análise de material & & \\
\hline & & $\begin{array}{l}\text { Monitoração de desempenho de } \\
\text { maquinarias }\end{array}$ & & \\
\hline & & $\begin{array}{l}\text { Monitoração de ciclo de operação de } \\
\text { maquinarias }\end{array}$ & & \\
\hline & & Acompanhamento do índice MTBF & & \\
\hline & & Acompanhamento do índice MTTR & & \\
\hline \multirow{4}{*}{3} & \multirow{4}{*}{$\begin{array}{l}\text { O que é utilizado para } \\
\text { melhorar os sistemas de } \\
\text { controle? }\end{array}$} & Sensores inteligentes & & \\
\hline & & Atuadores inteligentes & & \\
\hline & & $\begin{array}{l}\text { Controladores com gerenciamento de } \\
\text { consumo }\end{array}$ & & \\
\hline & & $\begin{array}{l}\text { Maquinaria com gerenciamento de } \\
\text { segurança e consumo }\end{array}$ & & \\
\hline
\end{tabular}

As Tabelas 14 a 18 são usadas para caracterizar a intensidade do envolvimento da empresa/funcionários com a sustentabilidade do SPD. Este questionário levanta o nível de comprometimento das pessoas com o uso dos recursos e realização dos processos.

Tabela 14 - Questões sobre envolvimento no aspecto econômico QUESTIONÁRIO SOBRE ASPECTO ECONÔMICO DA SUSTENTABILIDADE

RESPOSTA

Itens Sim Não

1 A produção gera retorno financeiro necessário para se manter?

2 É feito re-investimento necessário na empresa para que ela cresça?

3 Há investimento em pesquisa e desenvolvimento de novos produtos e tecnologias?

4 Os custos estão sendo reduzidos por meio de melhorias nos processos produtivos?

5 Questões relacionadas à sustentabilidade afetam o negócio, positivamente (1) ou negativamente $(0)$ ?

6 A empresa tem planos futuros sustentáveis (planos estratégicos) de crescimento para os próximos 5-20 anos?

7 A análise SWOT (ou similar) é uma prática geral para avaliar cada parte da organização?

8 As vendas aumentaram após implantar práticas de sustentabilidade? 
Tabela 15 - Questões sobre envolvimento no aspecto social

\begin{tabular}{|c|c|c|c|}
\hline & $\begin{array}{l}\text { QUESTIONÁRIOSOBRE ASPECTO SOCIAL DA SUSTENTABILIDADE } \\
\text { INDUSTRIAL }\end{array}$ & & STTA \\
\hline & Itens & Sim & Não \\
\hline 1 & É oferecido benefícios aos funcionários, além do que é determinado por lei? & & \\
\hline 2 & $\begin{array}{l}\text { Os funcionários são tratados igualmente e não há preconceito por raça, idade, } \\
\text { sexo ou religião? }\end{array}$ & & \\
\hline 3 & A organização se abre para novas ideias vindas de funcionários? & & \\
\hline 4 & $\begin{array}{l}\text { Existe um programa remunerado de sugestões para melhorias nos processos } \\
\text { produtivos? }\end{array}$ & & \\
\hline 5 & $\begin{array}{l}\text { A empresa tem planos regulares para aumentar a eficiência do processo de } \\
\text { trabalho? }\end{array}$ & & \\
\hline 6 & A formação do pessoal é bem planejada para todos os funcionários? & & \\
\hline 7 & $\begin{array}{l}\text { O ambiente de trabalho é dotado de mecanismos de proteção e de segurança aos } \\
\text { funcionários? }\end{array}$ & & \\
\hline 8 & As reclamações dos clientes são tratadas com devida responsabilidade? & & \\
\hline 9 & Existe algum canal com os clientes para receber sugestões de melhorias? & & \\
\hline 10 & A empresa promove melhorias na comunidade em que está inserida? & & \\
\hline 11 & $\begin{array}{l}\text { O produto/serviço oferecido recebe alguma garantia de não ser prejudicial à } \\
\text { sociedade nem ao meio ambiente? }\end{array}$ & & \\
\hline 12 & Existe algum programa de visitação da comunidade à dependência da empresa? & & \\
\hline 13 & $\begin{array}{l}\text { Existe algum plano vigente ou futuro de investimento na comunidade local para } \\
\text { melhorar/re-fabricar algumas tecnologias? }\end{array}$ & & \\
\hline 14 & $\begin{array}{l}\text { Existem parcerias com as universidades locais no desenvolvimento na pesquisa } \\
\text { acadêmica? }\end{array}$ & & \\
\hline 15 & $\begin{array}{l}\text { É divulgado à comunidade um relatório periódico com os resultados obtidos em } \\
\text { sustentabilidade? }\end{array}$ & & \\
\hline
\end{tabular}

Tabela 16 - Questões sobre envolvimento no aspecto ambiental

\begin{tabular}{|c|c|c|c|}
\hline & $\begin{array}{l}\text { QUESTIONÁRIOASPECTOAMBIENTAL DA SUSTENTABILIDADE } \\
\text { INDUSTRIAL }\end{array}$ & RESF & STTA \\
\hline & Itens & Sim & Não \\
\hline 1 & A empresa soluciona os problemas de poluição ambiental? & & \\
\hline 2 & Existe alguma estratégia para redução de consumo de energia? & & \\
\hline 3 & Tem implantado um novo processo produtivo que consome menos energia? & & \\
\hline 4 & Utiliza fontes de energia renováveis e menos poluentes: solar, eólica ou outras? & & \\
\hline 5 & Procura otimizar o uso de recursos não renováveis na empresa? & & \\
\hline 6 & Tem substituído o uso de recursos não renováveis por recursos renováveis? & & \\
\hline 7 & $\begin{array}{l}\text { Os materiais de escritório e resíduos gerados na produção são encaminhados } \\
\text { para reciclagem ou reutilizados na própria empresa? }\end{array}$ & & \\
\hline 8 & Utiliza material reciclado na embalagem de produto? & & \\
\hline 9 & $\begin{array}{l}\text { Tem se preocupado em desenvolver embalagens que utilizam menor quantidade } \\
\text { de plástico/papelão/etc. }\end{array}$ & & \\
\hline 10 & $\begin{array}{l}\text { Acha viável o reuso de material vindo de produtos obsoletos da empresa que } \\
\text { estão no mercado (logística reversa)? }\end{array}$ & & \\
\hline 11 & $\begin{array}{l}\text { Pensa em implantar um sistema de coleta, pontos de coleta, de produtos } \\
\text { obsoletos de clientes. }\end{array}$ & & \\
\hline 12 & $\begin{array}{l}\text { Existem controles de gerenciamento de resíduos (ou seja, controle de emissões, } \\
\text { plano de redução de } \mathrm{CO}_{2} \text {, regulamentos de queima)? }\end{array}$ & & \\
\hline 13 & Existe implantado uma política de descarte de subprodutos não utilizados? & & \\
\hline
\end{tabular}

Os dados levantados são a seguir armazenadas no banco de dados do SuMS e devidamente processados para a definição dos indicadores de sustentabilidade do SPD. Neste instante, valores são atribuídos a cada indicador conforme as informações levantadas do SPD, por especialista de sustentabilidade. Assim, estes valores serão os de referência para o cálculo da sustentabilidade. 
Tabela 17 - Questões sobre envolvimento no aspecto tecnológico

\begin{tabular}{|c|c|c|c|}
\hline & $\begin{array}{l}\text { QUESTIONÁRIOASPECTOTECNOLÓGICO DA SUSTENTABILIDADE } \\
\text { INDUSTRIAL }\end{array}$ & RES & STA \\
\hline & Itens & Sim & Não \\
\hline 1 & A empresa investe em novas tecnologias? & & \\
\hline 2 & A empresa treina pessoal para se familiarizar com a tecnologia mais recente? & & \\
\hline 3 & A empresa possui seu próprio know-how tecnológico? & & \\
\hline 4 & A empresa tem planos de melhoria para a segurança das pessoas nas operações? & & \\
\hline 5 & Existem registros de acompanhamento de segurança de produção? & & \\
\hline 6 & $\begin{array}{l}\text { A empresa segue o sistema de manutenção preventiva para os equipamentos da } \\
\text { planta? }\end{array}$ & & \\
\hline 7 & $\begin{array}{l}\text { A empresa segue um sistema de manutenção preditiva para os equipamentos da } \\
\text { planta? }\end{array}$ & & \\
\hline
\end{tabular}

Tabela 18 - Questões sobre comprometimento com a sustentabilidade

\begin{tabular}{|c|c|c|c|}
\hline & $\begin{array}{l}\text { QUESTIONÁRIO COMPROMETIMENTO COM A SUSTENTABILIDADE } \\
\text { INDUSTRIAL }\end{array}$ & RESF & STA \\
\hline & Itens & Sim & Não \\
\hline 1 & $\begin{array}{l}\text { Todos na empresa estão comprometidos com os aspectos econômicos da } \\
\text { sustentabilidade industrial }\end{array}$ & & \\
\hline 2 & $\begin{array}{l}\text { Todos na empresa estão comprometidos com os aspectos sociais da } \\
\text { sustentabilidade industrial? }\end{array}$ & & \\
\hline 3 & $\begin{array}{l}\text { Todos na empresa estão comprometidos com os aspectos ambientais da } \\
\text { sustentabilidade industrial? }\end{array}$ & & \\
\hline 4 & $\begin{array}{l}\text { Todos na empresa estão comprometidos com os aspectos tecnológicos da } \\
\text { sustentabilidade industrial. }\end{array}$ & & \\
\hline 5 & $\begin{array}{l}\text { Todos na empresa estão comprometidos com os aspectos econômicos, ambiental, } \\
\text { social e tecnológico da sustentabilidade industrial? }\end{array}$ & & \\
\hline
\end{tabular}

Depois que os indicadores de sustentabilidade do SPD são definidos, esses levantamentos devem ser periodicamente revisados para acompanhar a evolução do sistema, levando em consideração uma política de avaliação de sustentabilidade implementada e a dinâmica das mudanças no sistema de produção.

\subsubsection{Definição dos indicadores de sustentabilidade}

Os critérios utilizados para definição dos indicadores de sustentabilidade devem considerar a relevância dos indicadores escolhidos, com base nas informações de sustentabilidade levantadas dos processos e da infraestrutura da empresa. Consideram-se as Tabelas 1, 2, 3 e 4 as quais foram elaboradas com base nos indicadores mais utilizados nos sistemas produtivos, levando em consideração o QBL (econômico, ambiental, social e tecnológico).

\subsubsection{Modelagem}

$\mathrm{Na}$ fase de inicialização de dados do SuMS, a modelagem e a análise dos processos do SPD visam desenvolver representações com um grau de precisão 
adequado do sistema real em relação aos parâmetros relacionados com sua sustentabilidade. Inicialmente isso é realizado com o levantamento das especificações dos processos de produção, identificando as 'atividades' e 'inter-atividades' envolvidas, para desenvolver assim uma representação gráfica e conceitual dos processos com base na técnica do PFS.

Os processos são inicialmente modelados em PFS e, são objetos de refinamentos até se chegar a um modelo funcional em rede de Petri para a análise da dinâmica dos processos. Isto é, deriva-se um modelo onde se estuda as características funcionais dos processos como as relações de paralelismo, concorrência, assincronismo e não-determinismo, assim como quando e onde nos processos os sinais de sensores (especificamente relacionados ao SuMS) são considerados coletados e processados.

\subsubsection{Monitoração dos processos}

Os modelos resultantes em rede de Petri são desenvolvidos para a análise funcional dos sistemas e processos envolvidos. Os aspectos estruturais e comportamentais dos processos são analisados com base na teoria que fundamenta a rede de Petri, isto é, pela verificação de propriedades do grafo. De acordo com Cardoso e Valete (1997), essas propriedades podem-se dividir em comportamentais (vivacidade, limitabilidade e reversibilidade) e estruturais (componentes conservativos e repetitivos).

Existem, entretanto, aspectos comportamentais dos processos e suas interações cuja análise é mais eficaz via simulação. Assim, diferentes cenários são considerados e simulados de modo a, num primeiro instante, analisar os modelos e, numa segunda fase, obter informações sobre o comportamento dos dados que são utilizados para o cálculo dos indicadores de sustentabilidade.

$\mathrm{Na}$ fase de inicialização dos dados do SuMS, a modelagem e a análise dos processos do SPD visam desenvolver representações com um grau de precisão adequado do sistema real em relação aos parâmetros relacionados com sua sustentabilidade.

$\mathrm{Na}$ fase de operação do SPD os modelos desenvolvidos são usados para acompanhar a evolução dos processos em tempo real, isto é, para monitoração dos indicadores de sustentabilidade. Considera-se que o MES tem, em algum formato, os 
dados relacionados com a produtividade do SPD e com o estado atual dos processos que são trabalhados junto com as informações necessárias para o cálculo dos indicadores de sustentabilidade do sistema e que são disponíveis do banco de dados do SuMS.

Note-se que sistemas de suporte para desenvolvimento de modelos em rede de Petri como PIPE, HPSim, IOPT Tools (DA SILVA et al., 2016), etc., já estão disponíveis. Estes integram ferramentas para edição gráfica de modelos em Petri net e para sua análise, incluindo recursos para realizar simulações de modelo. Esses sistemas de suporte podem ser usados também para coletar e processar dados SPD para que os modelos de processo (em rede de Petri) exibidos em uma tela indiquem on-line a evolução do sistema e dos indicadores de sustentabilidade.

\subsection{AVALIAÇÃO DOS DADOS - PROCESSAMENTO DOS DADOS DE SUSTENTABILIDADE}

Na fase de inicialização de dados do SuMS, diferentes cenários são analisados e situações são estudados para definir os indicadores-chave de desempenho de sustentabilidade (SuKPIs), assim como para definir os valores de referência que na prática são definidos pela equipe ou pessoa responsável especificamente pela sustentabilidade do sistema. Posteriormente esses são armazenados no banco de dados do SuMS.

Na definição da Eq. (1) na seção 3.1 a sustentabilidade do SPD é função dos indicadores nos QBL. Isso envolve vários parâmetros de modo que a importância relativa de cada um deve ser devidamente considerada.

Os dados para o cálculo dos indicadores de sustentabilidade sob os diferentes

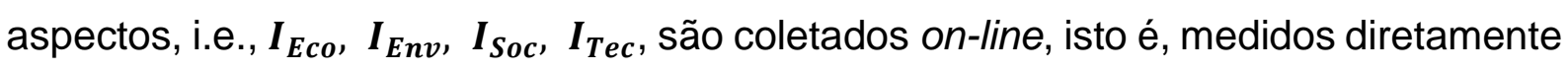
com o sistema produtivo em funcionamento. Os resultados são então comparados com os valores de referência e armazenados na base de dados do SuMS.

Com base nos trabalhos já publicados (por ex.: TRACEY et al., 1999), é adotado aqui um critério de avaliação dos indicadores, no qual o valor medido deve alcançar ao menos $70 \%$ do valor de referência (definido anteriormente por especialista de sustentabilidade), este limite é adotado neste trabalho para que o indicador seja considerado sustentável, pode-se ainda considerar uma margem de tolerância como sendo o limite mínimo de sustentabilidade. Importante observar que para cada caso 
de aplicação deve ser analisada a criticidade dos indicadores para definir os valores limites. Este tipo de critério ajuda na clara identificação da condição do indicador avaliado e também viabiliza a adoção de uma classificação binária do resultado. Existem métodos de avaliação como os que são citados no Capítulo 5 que consideram médias aritméticas dos valores dos indicadores, porém o resultado não deixa claro as contribuições de cada indicador. Assim, no critério aqui adotado fica evidente a participação de cada indicador.

O resultado desta comparação é expresso por meio de um número inteiro no intervalo $[0,1]$, conforme as seguintes relações:

- 0 = fora do espaço de valor esperado;

- 1 = dentro do espaço de valor esperado.

Os pesos de sustentabilidade $\left(\boldsymbol{w}_{E c o(k)}, \boldsymbol{w}_{E n v(k)}, \boldsymbol{w}_{\operatorname{Soc}(\boldsymbol{k})}, \boldsymbol{w}_{T e c(k)}\right)$ são definidos considerando sua relevância no sistema, conforme o seguinte:

- 1 = muito pouco importância;

- 2 = pouco importante;

- 3 = importante;

- 4 = muito importante;

- 5 = fortemente importante.

Na Tabela 19, que é derivada da Tabela 2, tem-se um exemplo de cálculo de indicadores de sustentabilidade sob o aspecto econômico.

Tabela 19- Exemplo de indicadores de sustentabilidade - Aspecto Econômico

\begin{tabular}{|c|c|c|c|c|c|c|}
\hline ITEM & INDICADORES ECONÔMICOS & $\begin{array}{c}\text { VALOR } \\
\text { MEDI } \\
\text { DO }\end{array}$ & $\begin{array}{c}\text { VALOR DE } \\
\text { REFERÊNCIA }\end{array}$ & $\begin{array}{c}\text { ÍNDICES } \\
\text { ALCANÇA } \\
\text { DOS }\end{array}$ & $\begin{array}{c}\text { PESO POR } \\
\text { IMPORTÂN } \\
\text { CIA }\end{array}$ & $\begin{array}{c}\text { NÍVEL DE } \\
\text { IMPORTÂN } \\
\text { CIA }\end{array}$ \\
\hline 1 & $\begin{array}{l}\text { Benefício com redução de gás } \\
\text { carbono }\end{array}$ & 58 & 100 & 0 & 0,08 & 3 \\
\hline 2 & Economia com reuso de material & 70 & 100 & 1 & 0,08 & 3 \\
\hline 3 & Economia com descarte de lixo & 83 & 100 & 1 & 0,08 & 3 \\
\hline 4 & Economia com material reciclado & 45 & 100 & 0 & 0,08 & 3 \\
\hline 5 & Benefício com energia renovável & 33 & 100 & 0 & 0,11 & 4 \\
\hline 6 & Redução da energia tradicional & 156 & 100 & 1 & 0,14 & 5 \\
\hline 7 & Custo de material & 75 & 100 & 1 & 0,11 & 4 \\
\hline 8 & Custo de energia & 80 & 100 & 1 & 0,11 & 4 \\
\hline 9 & Custo de mão de obras & 72 & 100 & 1 & 0,11 & 4 \\
\hline 10 & Custo operacional e de capital & 81 & 100 & 1 & 0,08 & 3 \\
\hline
\end{tabular}


Os índices alcançados são calculados conforme a Eq. (2):

se $\left\{\frac{v m_{k}}{v r_{k}}\right\} \times 100 \geq$ limite, então $i d_{\text {alcançado }}=1$; senão $i d_{\text {alcançado }}=0$

onde:

$$
\begin{aligned}
& \text { id }_{\text {alcançado }(k)} \text { = índice alcançado; } \\
& \mathbf{v m}=\text { valor medido; } \\
& \boldsymbol{v} \boldsymbol{r}=\text { valor de referência; } \\
& \boldsymbol{k}=\text { sequência de indicadores; }
\end{aligned}
$$

limite $=$ é o valor de $70 \%$ do valor de referência e uma margem de tolerância.

Por exemplo, o índice alcançado referente ao indicador "Benefício com energia renovável" para a sustentabilidade do sistema é calculado como:

$$
\left\{\frac{33}{100}\right\} \times 100 \text { é }<70 \% \text { do vr(100) então, id alcaçado (Benefício com energia renovável) }=0
$$

O peso por importância de cada aspecto de sustentabilidade é calculado conforme a Eq. (3):

$$
\boldsymbol{w}_{\boldsymbol{k}}=\left\{\frac{\boldsymbol{N}_{i m p(k)}}{\sum_{i=1}^{4} \boldsymbol{N}_{\operatorname{Imp}(i)}}\right\}
$$

onde:

$N_{i m p(k)}=$ nível de importância do indicador no aspecto de sustentabilidade (entre1 a 5);

$\boldsymbol{k}=$ aspecto de sustentabilidade;

$\boldsymbol{i}=$ quantidade de indicadores considerados.

Para o exemplo relacionado com a Tabela 19, o peso por importância do indicador "Benefício com energia renovável" para a sustentabilidade do sistema é calculado como:

$$
w_{a m b}\left(\text { Benefício com energia renovável) }=\left\{\frac{4}{36}\right\}=0,11\right.
$$

Aplicando-se uma soma ponderada dos valores da Tabela 19 tem-se:

$$
\begin{gathered}
\boldsymbol{I D}_{\boldsymbol{E c o}}=\left\{\frac{\sum_{\boldsymbol{k}=\mathbf{1}}^{n}\left(\boldsymbol{i}_{\boldsymbol{E c o}(\boldsymbol{k})} \times \boldsymbol{w}_{\boldsymbol{E c o}(\boldsymbol{k})}\right)}{\sum_{\boldsymbol{k}=\mathbf{1}}^{\boldsymbol{n}} \boldsymbol{w}_{\boldsymbol{E} \boldsymbol{c o}(\boldsymbol{k})}}\right\} \\
\boldsymbol{I}_{\boldsymbol{E} \boldsymbol{c o}}=\left\{\frac{(0 \times 0,08)+(1 \times 0,08)+(1 \times 0,08)+(0 \times 0,08)+(0 \times 0,11)+(1 \times 0,14)+(1 \times 0,11)+((1 \times 0,11)+(1 \times 0,11)+(1 \times 0,08)}{(0,08+0,08+0,08+0,08+0,11+0,14+0,11+0,11+0,11+0,08)}\right\}
\end{gathered}
$$




$$
I D_{E c o}=0,72
$$

O resultado do índice econômico $\left(I D_{E c o}\right)$ indica que $72 \%$ dos seus componentes (sub-indicadores/parâmetros) que o compõem são sustentáveis, i.e., alcançaram o limite estabelecido. Assim, se identifica quais os sub-indicadores/parâmetros necessitam serem melhorados, isto é, neste exemplo são os itens 1, 4 e 5 da Tabela 19.

O framework proposto evidentemente pode adotar outras abordagens e procedimentos para avaliar a sustentabilidade de um SPD, como segue.

\subsubsection{Sustentabilidade considerando questionário de infraestrutura}

As informações referentes à infraestrutura do SPD neste caso são processadas com base nos dados das Tabelas 9 a 18. Cada item (questão) dessas tabelas é analisado e se define uma pontuação e um peso de acordo com o nível de influência direta de cada indicador no processo produtivo.

Por exemplo, a Tabela 20 ilustra os dados coletados para as questões da Tabela 9.

Tabela 20- Questionário sobre o Sistema de produção e sua infraestrutura

\begin{tabular}{|c|c|c|c|c|}
\hline \multicolumn{3}{|c|}{$\begin{array}{l}\text { QUESTIONÁRIO SOBRE A PRODUÇÃO E A INFRAESTRUTURA DO SISTEMA } \\
\text { PRODUTIVO }\end{array}$} & \multicolumn{2}{|c|}{ RESULTADO } \\
\hline ITEM & Informação & Descrição & Sim & Não \\
\hline \multirow{5}{*}{1} & \multirow{5}{*}{$\begin{array}{c}\text { Como a produção } \\
\text { pode ser } \\
\text { classificada? }\end{array}$} & Tradicional & & \\
\hline & & Flexível & $X$ & \\
\hline & & Enxuto & & \\
\hline & & Ecológico & & \\
\hline & & Sustentável & & \\
\hline \multirow{5}{*}{2} & \multirow{5}{*}{$\begin{array}{l}\text { Como o tamanho } \\
\text { da produção é } \\
\text { classificado? }\end{array}$} & Menos de 50 empregados & & \\
\hline & & até 50 empregados & & \\
\hline & & Entre 50 e 100 empregados & $\mathrm{X}$ & \\
\hline & & Entre 100 e 1000 empregados & & \\
\hline & & Mais de 1000 empregados & & \\
\hline \multirow{5}{*}{3} & \multirow{5}{*}{$\begin{array}{l}\text { Que tipo de } \\
\text { configuração da } \\
\text { produção é } \\
\text { adotado? }\end{array}$} & Não identificado & & \\
\hline & & Células & $\mathrm{X}$ & \\
\hline & & Processo & & \\
\hline & & Autonomia & & \\
\hline & & Posicional & & \\
\hline \multirow{5}{*}{4} & \multirow{5}{*}{$\begin{array}{l}\text { Que tipo de } \\
\text { sistema de } \\
\text { transporte da } \\
\text { produção é } \\
\text { utilizado? }\end{array}$} & Nenhum & & \\
\hline & & Empilhadeira & $\mathrm{X}$ & \\
\hline & & Esteira & & \\
\hline & & AGV & & \\
\hline & & Robô manipulador & & \\
\hline \multirow{5}{*}{5} & \multirow{5}{*}{$\begin{array}{c}\text { Que tipo de } \\
\text { sistema de } \\
\text { gerência integrada } \\
\text { é adotada? }\end{array}$} & Nenhum & & \\
\hline & & Sistema de supervisão local (nível 1, 2) & $\mathrm{X}$ & \\
\hline & & Sistema de supervisão e controle (nível 3) & & \\
\hline & & Sistema de gerencial central (nível 4) & & \\
\hline & & Data center externo (Cloud, WebServer) & & \\
\hline
\end{tabular}


Após o preenchimento das Tabelas 9 a 18 se tem o cálculo de indicadores, onde uma tabela como a apresentada na Figura 9 pode ser usada.

Por exemplo, a Tabela 20 representa dados correspondentes à infraestrutura do sistema produtivo, os quais são os parâmetros para calcular o IDISP (Índice da Infraestrutura do Sistema Produtivo). Cada item recebe uma avaliação e se calcula uma média de todos os itens da tabela. O resultado é mostrado na Figura 9. Nesta figura, os indicadores também são classificados por sua influência no sistema e com isso, o peso por importância é calculado (Eq. 3). Assim, se procede do mesmo modo para com as informações das outras tabelas (Tabelas 10 a 18). Os resultados de cada tabela são transportados para a tabela da Figura 9, onde:

$\boldsymbol{S P}=$ Indicador da infraestrutura derivado de dados da Tabela 9;

$\boldsymbol{A}_{e c o}=$ Indicador de aspectos econômicos da infraestrutura derivado de dados da Tabela10;

$\boldsymbol{A}_{e n v}=$ Indicador de aspectos ambiental da infraestrutura derivado de dados da Tabela 11 ;

$\boldsymbol{A}_{\text {soc }}=$ Indicador de aspectos social da infraestrutura derivado de dados da Tabela 12; $\boldsymbol{A}_{t e c}=$ Indicador de aspectos tecnológico da infraestrutura derivado de dados da Tabela13;

Comprometimento $=$ Indicador de comprometimento dos empregados usando a infraestrutura derivado de dados das Tabelas 14 a 18.

Figura 11 - Método de cálculo do índice de sustentabilidade relacionado à infraestrutura do sistema.

\begin{tabular}{|c|ccc|}
\hline $\begin{array}{c}\text { INDICADORES DE } \\
\text { INFRAESTRUTURA }\end{array}$ & $\begin{array}{c}\text { ÍNDICES } \\
\text { ALCANÇADOS }\end{array}$ & $\begin{array}{c}\text { PESO POR } \\
\text { IMPORTÂNCIA }\end{array}$ & $\begin{array}{c}\text { NÍVEL DE } \\
\text { IMPORTÂNCIA }\end{array}$ \\
\hline SP & 0,50 & 0.17 & 5 \\
$\boldsymbol{A}_{E C O}$ & 0,60 & 0.17 & 5 \\
$\boldsymbol{A}_{A M B}$ & 0,55 & 0.17 & 5 \\
$\boldsymbol{A}_{\text {SSOC }}$ & 0,40 & 0.17 & 5 \\
$\boldsymbol{A}_{T E C}$ & 0,60 & 0.17 & 5 \\
COMPROMETIMENTO & 0,60 & 0.17 & \\
IDISP & 0,54 & & \\
\hline
\end{tabular}

Fonte: $\mathrm{O}$ autor

A Figura 11 mostra uma tabela para avaliar os indicadores de cada tabela correspondente ao levantamento dos elementos que define o IIPS.

$$
\boldsymbol{I} \boldsymbol{D}_{\text {ISP }}=\left\{\frac{(0.50 \times 0.17)+(0.60 \times 0.17)+(0.55 \times 0.17)+(0.40 \times 0.17)+(0.60 \times 0.17)+(0.60 \times 0.17)}{(0.17+0.17+0.17+0.17+0.17+0.17)}\right\}
$$




$$
I D_{I S P}=0,54
$$

\subsubsection{Sustentabilidade considerando QBL}

Os valores medidos no SPD são comparados com os valores de referência e o resultado da comparação é armazenado no banco de dados SuMS.

Os índices resultantes são usados para preencher os itens da planilha da Figura 12, juntamente com os pesos apropriados, calculados de acordo com a relevância de cada índice.

Como já mencionado, as definições de pesos são feitas por especialistas, considerando uma escala de importância de cada indicador na avaliação da sustentabilidade do sistema produtivo. O método matricial é usado para calcular a sustentabilidade e, o método baseado na média ponderada correlaciona os indicadores e os aspectos de sustentabilidade para obter o grau de sustentabilidade do SPD. Assim, no final da avaliação, o sistema produtivo é classificado como um sistema de fabricação sustentável ou não. Consequentemente, com base nessas avaliações, é possível verificar quais processos de produção contribuem para alcançar o objetivo de sustentabilidade e quais devem ser melhorados.

Considerando os itens das Tabelas 1, 2, 3 e 4, cada indicador de sustentabilidade relacionado aos aspectos econômicos, ambientais, sociais e tecnológicos $\left(\boldsymbol{I}_{E c o}, \boldsymbol{I}_{E n v}, \boldsymbol{I}_{S o c}, \boldsymbol{I}_{T e c}\right)$ é calculado usando um procedimento análogo ao caso ilustrado na Tabela 19.

Os resultados são colocados em uma planilha como mostrado na Figura 12. Nesta planilha o peso $\left(w_{k}\right)$ da coluna 4 é calculado de acordo com a Eq. (3). Como exemplo o $w_{E c o}$ é obtido como segue:

$$
\boldsymbol{w}_{\text {Eco }}=\left\{\frac{4}{12}\right\}=0,33
$$

Na última linha da planilha da Figura 12 estão os resultados dos cálculos de sustentabilidade do sistema produtivo em questão. O item de avaliação IDISP (Índice do Indicador de Infraestrutura do Sistema de Produtividade) é recebido da planilha na Figura 11. 
Figura 12 - Resumo do cálculo da sustentabilidade.

\begin{tabular}{|l|ccc|}
\multicolumn{1}{|c|}{ ITEM } & ÍNDICES & NíVEL DE IMPORTÂNCIA & $\begin{array}{c}\text { PESO POR } \\
\text { IMPORÂNCIA }\end{array}$ \\
\hline ECONOMICO & 0,72 & 4 & 0,33 \\
AMBIENTAL & 0,70 & 3 & 0,25 \\
SOCIAL & 0,75 & 2 & 0,17 \\
TECNOLÓGICO & 0,61 & 3 & 0,25 \\
AVALIAÇÃO DO & Avaliação da & Limite Mínimo de & Limite de \\
IDISP & Sustentabilidade & Sustentabilidade \\
0,54 & $\mathbf{0 , 6 9}$ & $\mathbf{0 , 6 0}$ & Sustentabilidade \\
& & $\mathbf{0 , 7 0}$
\end{tabular}

Fonte: $\mathrm{O}$ autor

O cálculo da avaliação de sustentabilidade é feito da seguinte forma:

$$
\begin{aligned}
& \boldsymbol{S}_{\text {ust }}=\left\{\frac{\sum_{i=1}^{n} I_{n} \times W_{n}}{\sum_{i=1}^{n} W_{n}}\right\} \\
& \boldsymbol{S}_{\text {ust }}=\left\{\frac{(0.72 \times 0.33)+(0.70 \times 0.25)+(0.75 \times 0.17)+(0.61 \times 0.25)}{(0.33+0.25+0.17+0.25)}\right\} \\
& S_{\text {ust }}=0.69
\end{aligned}
$$

O 'limite de sustentabilidade' é de $70 \%$ e neste exemplo foi considerado o "limite mínimo de sustentabilidade" de $60 \%$. Assim, para o exemplo do caso avaliado com os valores dos índices alcançados conforme a tabela da Figura 12, o sistema é considerado sustentável.

O framework é proposto considerando os indicadores de sustentabilidade que possam ser comuns no SPD, assim como para cada sistema produtivo que compõe o SPD de modo que possam ser usados para uma análise comparativa. O exemplo apresentado ilustra como o desempenho da sustentabilidade do sistema pode ser detalhado sobre os QBL.

A literatura também menciona que outras formas de avaliação envolvem a sustentabilidade de um produto ou processo durante seu ciclo de vida. O framework proposto também considera essas abordagens para analisar o impacto do ciclo de vida do produto no ambiente (ISO, 2004a; ISO, 2004b). As funcionalidades do framework devem, neste caso, ser aplicadas em cada etapa do ciclo de vida do produto (pré-fabricação, fabricação, uso e pós-uso) e depois se faz uma análise do conjunto de dados. 
Independentemente do propósito, todos os resultados apresentados na Figura 13 são armazenados no banco de dados do SuMS.

Figura 13 - Tabelas para cálculo de sustentabilidade.

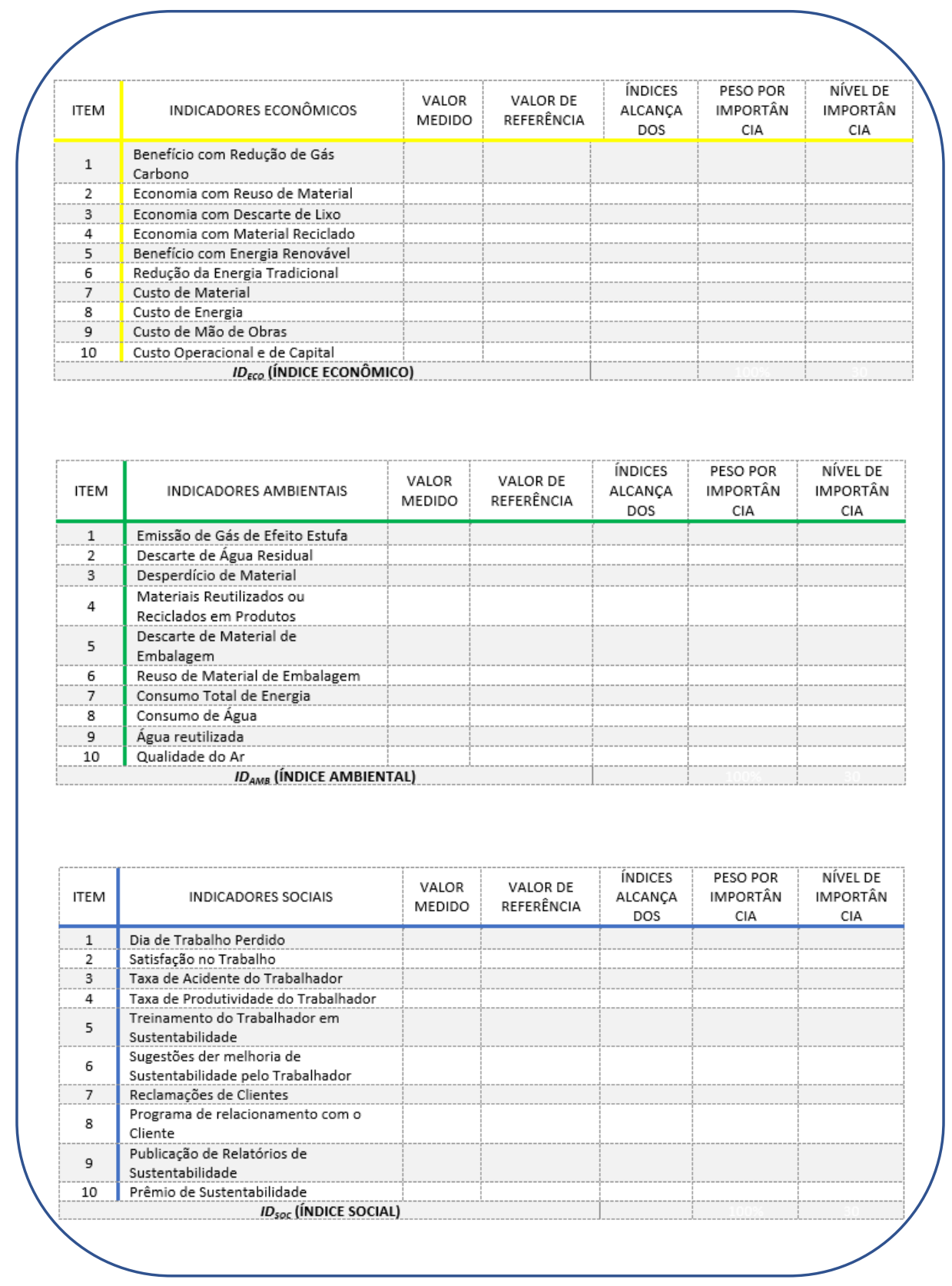

Fonte: $\mathrm{O}$ autor 
Figura 13 - Tabelas para cálculo de sustentabilidade (continuação)

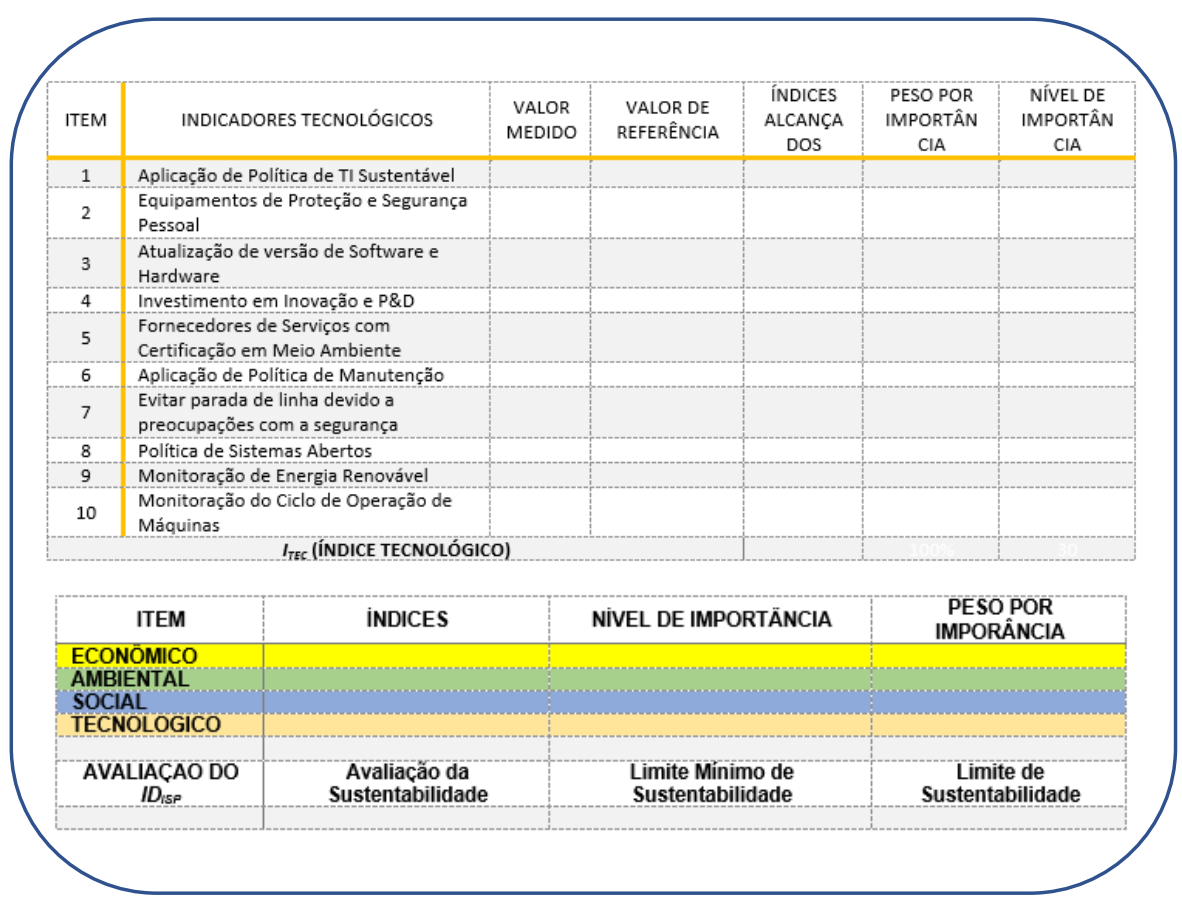

Fonte: $\mathrm{O}$ autor

A Figura 14 apresenta algumas opções de visualização dos resultados da avaliação de sustentabilidade (gráfico à esquerda) e dos índices da infraestrutura do SPD (gráfico à direita).

Figura 14 - Exemplo de visualização dos resultados das avaliações: (a) avaliação de sustentabilidade, (b) índices da infraestrutura do SPD.

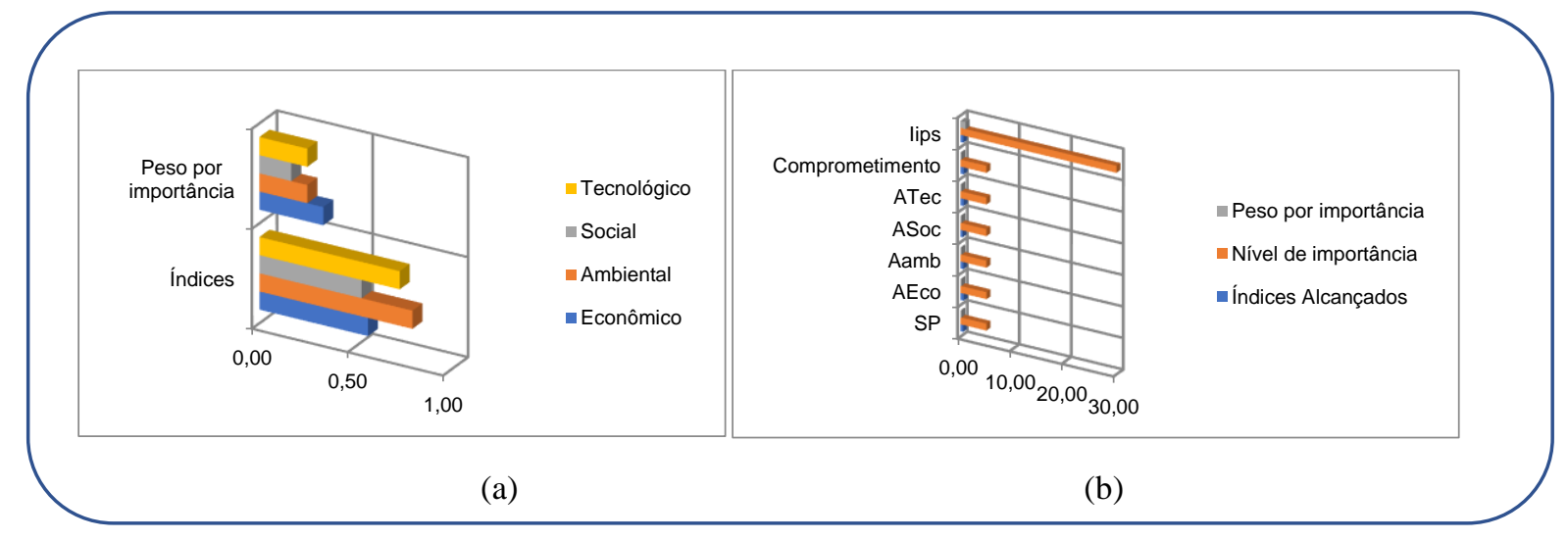

Fonte: $\mathrm{O}$ autor 


\subsection{COMUNICAÇÃO COM O NÍVEL DE DECISÕES ESTRATÉGICAS}

Esta funcionalidade não envolve a inicialização de dados, isto é, é acionada apenas na fase de operação do SPD. Com base nos dados dos indicadores de sustentabilidade e nos parâmetros e variáveis consideradas no cálculo desses indicadores, um relatório é gerado para o nível superior (da estrutura hierárquica da Figura 4). O procedimento básico adotado é que caso haja diferenças entre os valores medidos e os valores esperados, estas diferenças devem ser prontamente reportadas ao nível superior onde as decisões estratégicas são tomadas e nesse transcurso de comunicação esta funcionalidade do SuMS pode atender eventuais solicitações de informações adicionais sobre dados relacionados à sustentabilidade do SPD.

Dependendo do sistema de decisões implantados no nível superior SuMS se pode aplicar um método de aprendizagem.

Entretanto, assumindo o ambiente computacional via servidor WEB e a necessidade de considerar situações reais de problemas de comunicação, se considera que algum método de tomada de decisão deva estar disponibilizado para assegurar a manutenção de certo grau de autonomia do SuMS. Assim, no presente trabalho, o método de decisão MCDA (Multiple Criteria Decision Aid) (BUCHERTA et al., 2015) é utilizado para a tomada de decisão.

\subsection{VALIDAÇÃO DO FRAMEWORK}

A Figura 15 mostra o modelo em PFS das funcionalidades do SuMS e a interação com os módulos ERP e o MES. A Figura 16 mostra um esquema das funcionalidades e procedimentos do SuMS modelados em PFS. Ela indica como implementar o módulo SuMS e os seus submódulos: 'Comunicação', 'Avaliação de Dados', 'Coleta de Dados' e 'Banco de Dados', além de mostrar suas principais atividades. A troca de dados internamente entre os submódulos é representada por meio de arcos habilitadores e arcos inibidores da técnica da rede de Petri (MURATA, 1989; MELLO, JUNQUEIRA e MIYAGI, 2010). As setas entre estes módulos e os blocos indicados por ERP e o MES representam a comunicação para troca de dados com esses sistemas. 
Figura 15 - Modelo em PFS das funcionalidades do SuMS e a interação com o ERP e MES

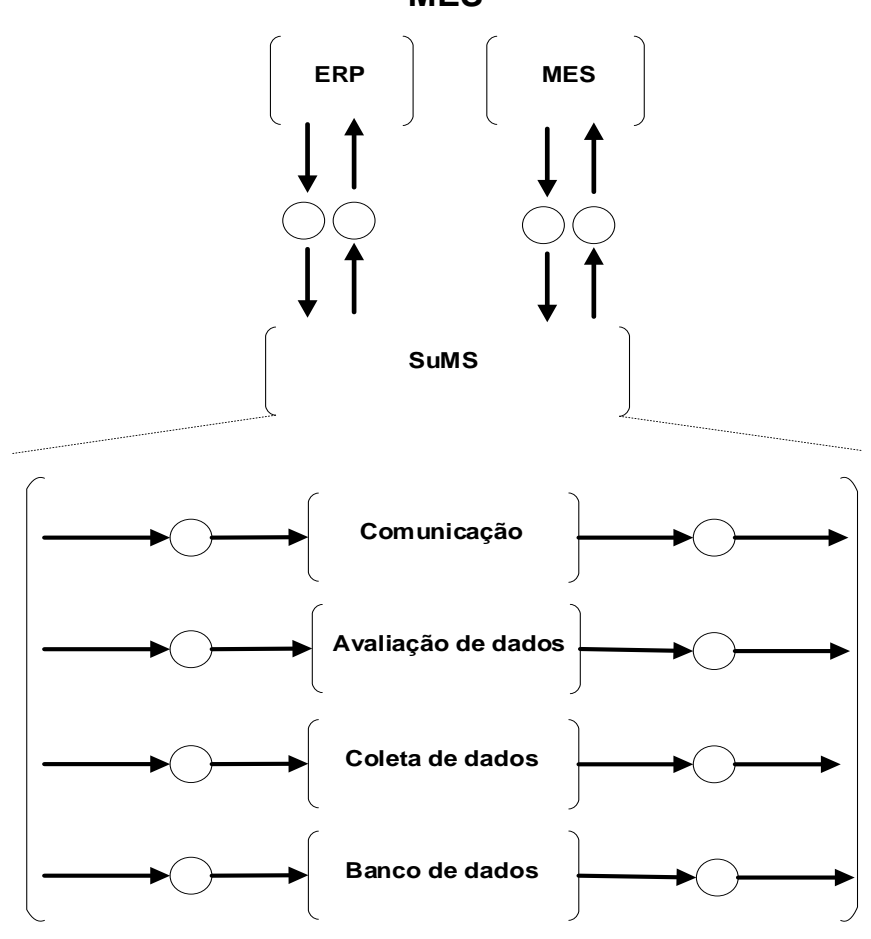

Fonte: $\mathrm{O}$ autor

Os modelos dos módulos são detalhados em rede de Petri para testar e analisar os seus comportamentos dinâmicos. Para este procedimento foi utilizado a ferramenta IOPT (DA SILVA et al., 2016).

Os modelos em rede de Petri derivados dos modelos em PFS da Figura 16 são apresentados na Figura 17 e Figura 18.

Na parte inferior da Figura 17 tem-se o exemplo de um modelo em rede de Petri do processo produtivo de uma estação de trabalho ('Estação de distribuição') e, na parte superior da Figura 17 está o modelo em rede de Petri que descreve o funcionamento do módulo de 'Coleta de dados'. O modelo em rede de Petri do funcionamento do sistema de gerenciamento do 'Banco de dados do SuMS' também está na parte inferior da Figura 17.

Na Figura 18 estão os outros modelos dos módulos de 'Avaliação de dados', e 'Comunicação'.

A Figura 17 mostra o estado inicial de um cenário da 'Estação de distribuição' quando esta recebe uma 'ordem de fabricação, isto é, a transição T1 ativada por um evento externo representa a recepção de uma 'ordem de fabricação', e com isso, a peça chamada de 'cilindro base' deve ser retirada do buffer para iniciar sua passagem por todas as etapas de produção até o finalizar na transição T10. Após esta atividade 
o cilindro é enviado para outra estação de trabalho. Os arcos habilitadores indicados no modelo em rede de Petri do processo produtivo da 'Estação de distribuição' representam os comandos para a execução de operações na planta.

Figura 16 - Refinamento dos Modelos em PFS das funcionalidades do SuMS

SuMS

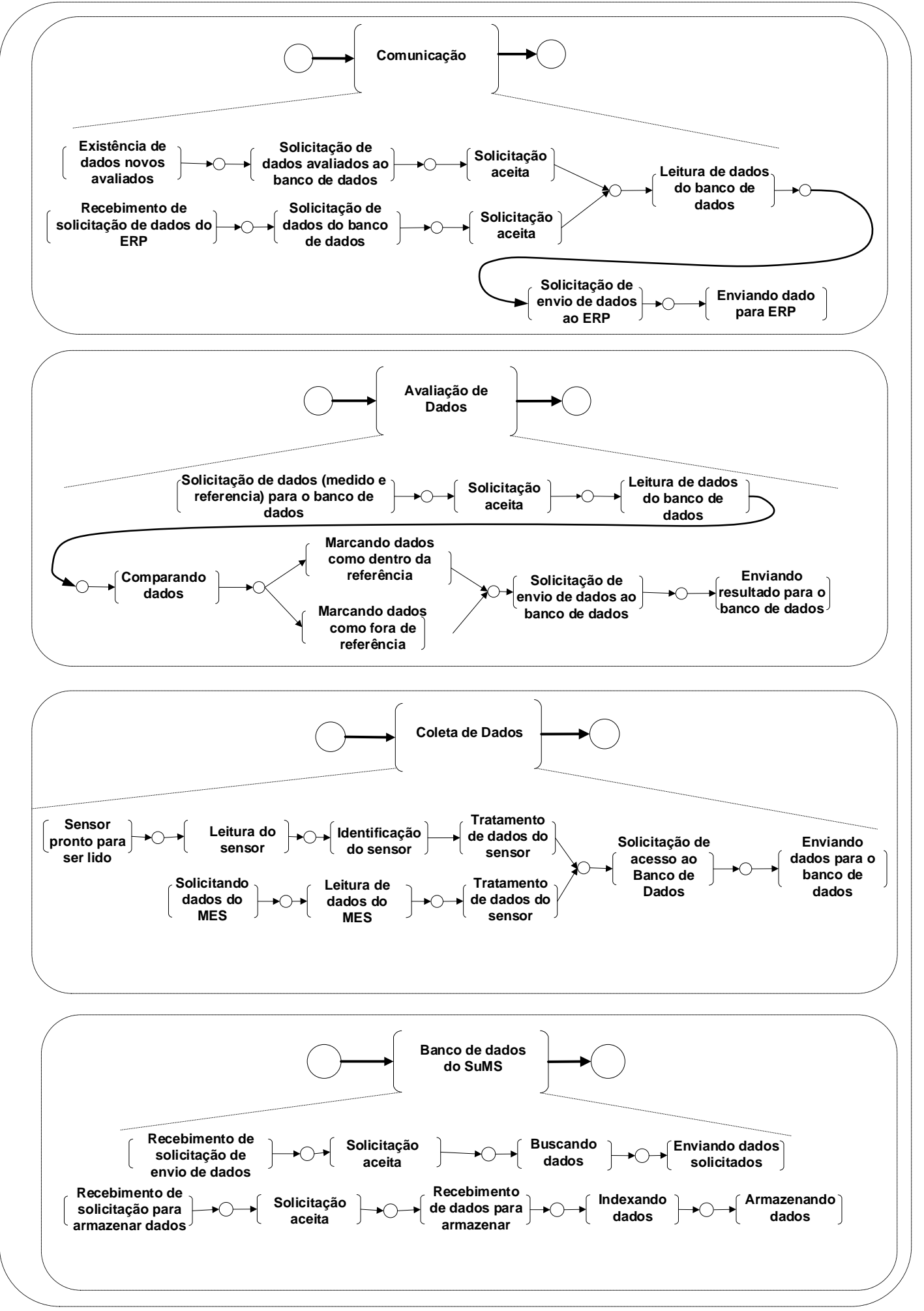

Fonte: $\mathrm{O}$ autor 
No modelo em rede de Petri do módulo de 'Coleta de dados', as transições T11, T12, T13 e T14 representam a aquisição de dados de sensores diretamente da planta, enquanto a transição T21 representa o caso de aquisição de dados do MES. Os arcos habilitadores indicados no modelo em rede de Petri do módulo 'coleta de dados' representam os comandos para a execução de operações no 'Banco de dados do SuMS'.

No modelo em rede de Petri do módulo de 'banco de dados' do SuMS, na Figura 17, as transições T29, T30 e T31 representam as solicitações de envio de dados para o módulo de 'Avaliação de dados e/ou para o módulo de 'Comunicação'. As transições T37, T38 e T39 representam as solicitações para armazenamento de dados de dados do módulo de 'Coleta de dados e o/ou do módulo de 'Avaliação de dados'.

No modelo em rede de Petri do módulo de 'Avaliação de dados', na Figura 18, a transição T45 representa a o início do processo de avaliação de dados para o cálculo dos índices e indicadores relacionados à sustentabilidade do sistema produtivo. Neste processo tem-se uma interação com o 'Banco de dados do SuMS' tanto para utilizar dados dessa base (comando representado pelo arco habilitador que solicita 'leitura de dados para avaliação') como também para armazenar os resultados dos dados processados (comando representado pelo arco habilitador que solicita 'armazenamento dos dados avaliados').

No modelo em rede de Petri do módulo de 'Comunicação', na Figura 18, a transição $T 61$ representa a recepção de novos dados que devem ser encaminhados ao ERP (neste caso entendido como o componente que está num nível superior de tomada de decisões estratégicas do sistema). A transição T77 representa a solicitação de novos dados pelo ERP. Estes processos envolvem a interação com o 'Banco de dados do SuMS' para a leitura de dados dessa base (comando representado pelo arco habilitador que solicita 'leitura de dados') como também com o ERP (comando representado pelos arcos habilitadores para a 'leitura' e 'envio' de dados ao ERP).

Estes modelos são editados usando a ferramenta IOPT (DA SILVA et al., 2016). Com o IOPT se verifica inicialmente as propriedades estruturais dos modelos, isto é, se atendem ao que é definido para uma rede de Petri. A seguir se tem uma análise das propriedades comportamentais de modelos em rede de Petri para confirmar a vivacidade destes, isto é, se os processos modelados não possuem estados mortos e se o comportamento cíclico desejado (desde a ativação do SuMS até o seu eventual 
desligamento) é devidamente alcançado. A validação neste caso é baseada na análise de cenários onde as situações consideradas críticas para o SuMS são simuladas e se procura confirmar que o sistema como um todo se comporta como o desejado.

Figura 17 - Funcionalidade do submódulo de 'coleta de dados', o processo produtivo na 'Estação de distriguição' do SPD e também o banco dados

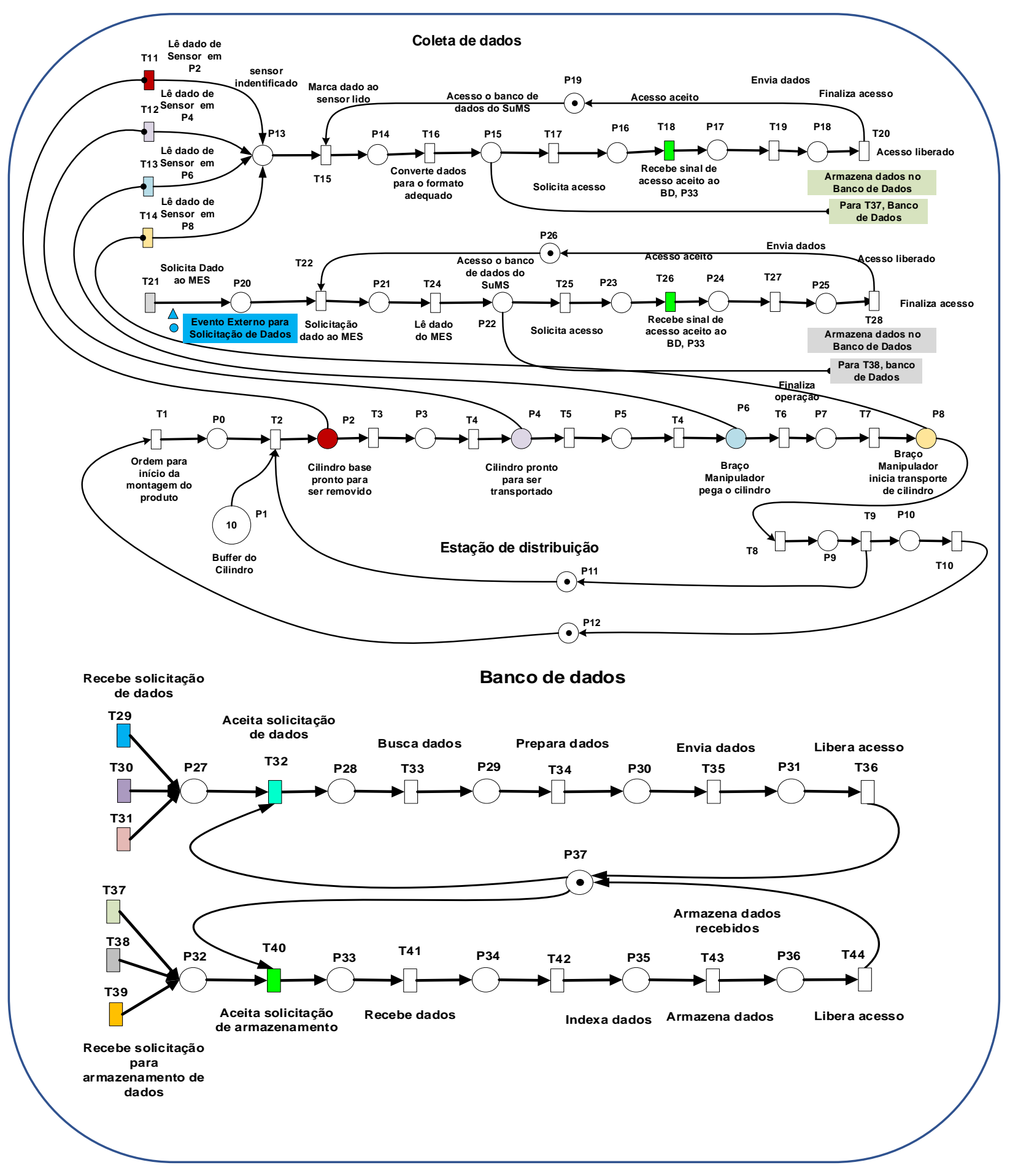

Fonte: $\mathbf{O}$ autor 
Os cenários críticos foram assim simulados e testes foram realizados para confirmar as funcionalidades do framework proposto.

Figura 18 - Funcionalidade de 'avalição de dados' e de 'comunicação'

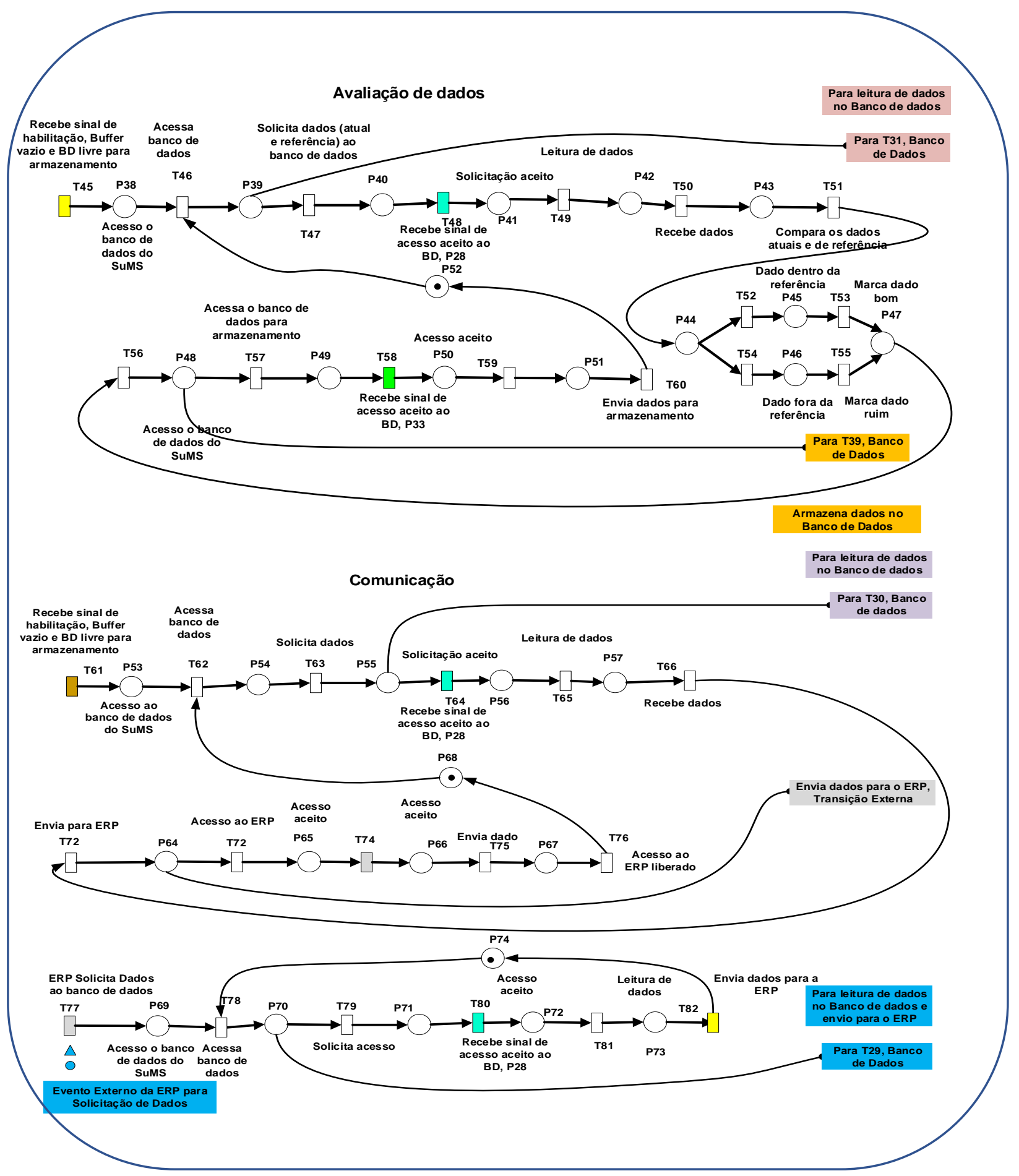

Fonte: $\mathrm{O}$ autor 


\subsection{SÍNTESE DO CAPÍTULO}

O framework proposto foi apresentado com base em suas principais funcionalidades e numa disposição que atende a estrutura hierarquizada de controle e gerenciamento de processos industriais estabelecidas pela norma ANSI/ISA-95.

Foram apresentados alguns casos para explicar os procedimentos de tratamento de dados, assim como foram utilizadas ferramentas e tabelas para a tabulação e cálculo de parâmetros. Entretanto, o foco aqui é caracterizar as funcionalidades, como elas estão relacionadas entre si, e mapear o framework dentro do sistema de controle e gestão de processos de SPD.

Modelos em rede de Petri das funcionalidades do SuMS foram criados para análise de seus comportamentos dinâmicos e foram investigadas a existência de conflitos entre os elementos e no fluxo de dados com aplicação de vários cenários de funcionamento.

Para demonstrar como o framework pode ser a implementado, no capítulo seguinte são apresentados e discutidos exemplos de aplicações. 


\section{EXEMPLOS}

Neste capítulo são mostrados uma implementação do framework proposto em um sistema produtivo disperso e, exemplos de aplicações de outros métodos de avaliação de sustentabilidade utilizando o framework.

\subsection{IMPLEMENTAÇÃO DO FRAMEWORK}

A Figura 19 mostra um sistema produtivo onde o fluxo de produtos segue uma sequência programada de operações de produção em diferentes estações de trabalho. Cada estação de trabalho emula um sistema produtivo independente, isto é, com autonomia para tomar decisões quanto às suas operações produtivas e o conjunto atua como um SPD. Este conjunto de estações de trabalho está instalado e em operação no Departamento de Engenharia Mecatrônica da Escola Politécnica da USP e compõe um sistema que emula as principais características de um SPD e é usado aqui para ilustrar a aplicação do framework proposto para a avaliação do seu desempenho e sustentabilidade.

Neste SPD, o produto final é um conjunto composto por um cilindro base onde um pino, uma mola e uma tampa são acoplados. A "estação de distribuição" tem um tipo de depósito onde os cilindros são empilhados. Os cilindros têm características diversas, como cor e tamanho. Quando uma solicitação (de produto final) é recebida pelo SPD e devidamente aceita, uma "ordem de produção" é encaminhada para a "estação de distribuição". Quando esta "ordem" é aceita pela "estação", um dispositivo é acionado para retirar um dos cilindros da pilha e posicioná-lo numa plataforma para ser encaminhada a "estação de inspeção". Quando a "estação de inspeção" recebe o sinal de que existe um cilindro para ser inspecionado, um braço manipulador é acionado para fazer o transporte do cilindro que está na plataforma da "estação de distribuição" para a "estação de inspeção". Para pegar o cilindro, o braço manipulador possui um dispositivo de suç̧ão como seu end-effector. Assim, o cilindro é posicionado num pedestal onde sua cor e suas dimensões são verificadas. Se determinadas características não são atendidas, o cilindro é considerado reprovado e um dispositivo é acionado para levá-lo ao compartimento de descarte. Se as características são atendidas, o cilindro é considerado aprovado e outro dispositivo é 
acionado para levá-lo a um palete que é movimentado via uma esteira da "estação de transporte".

Figura 19 - Exemplo de sistema produtivo disperso (SPD).

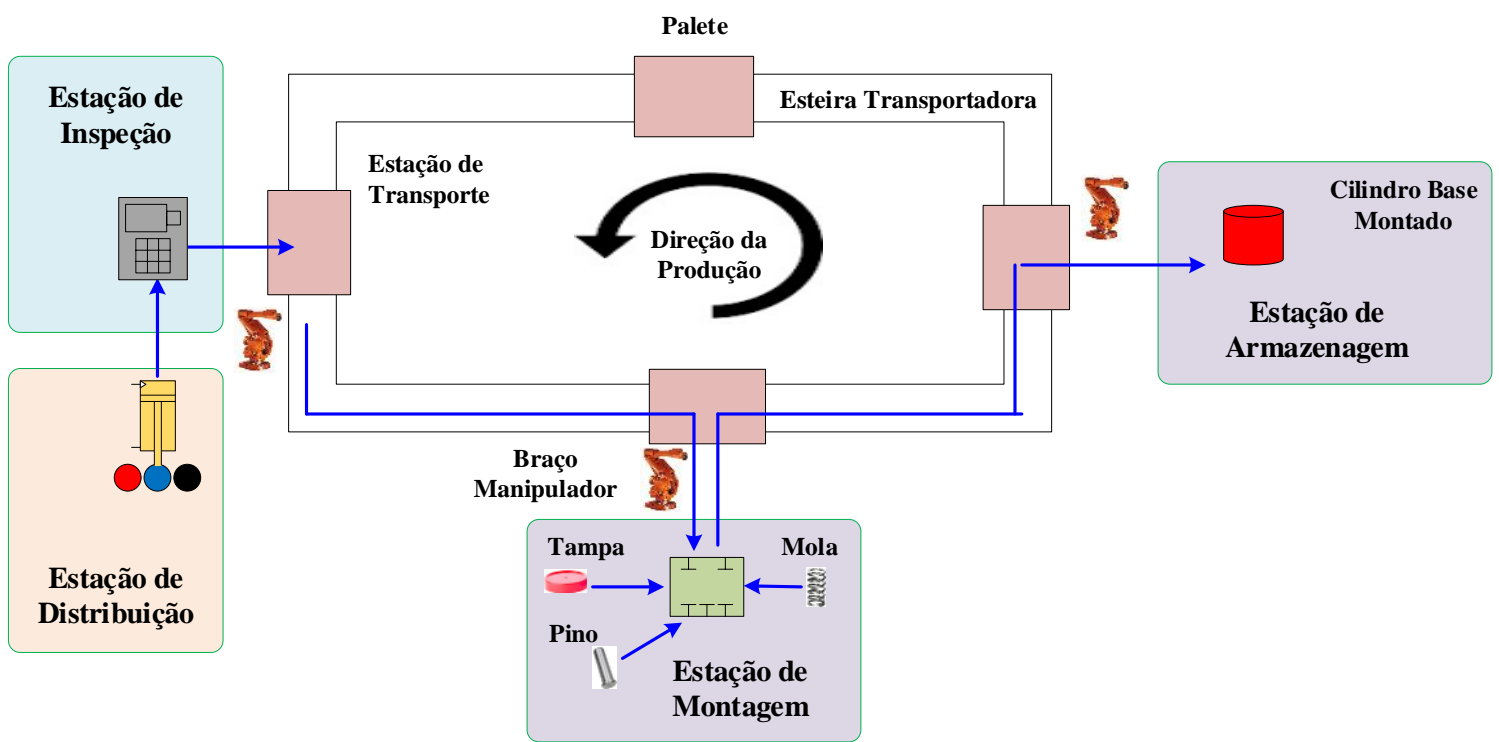

(a) Esquema do SPD

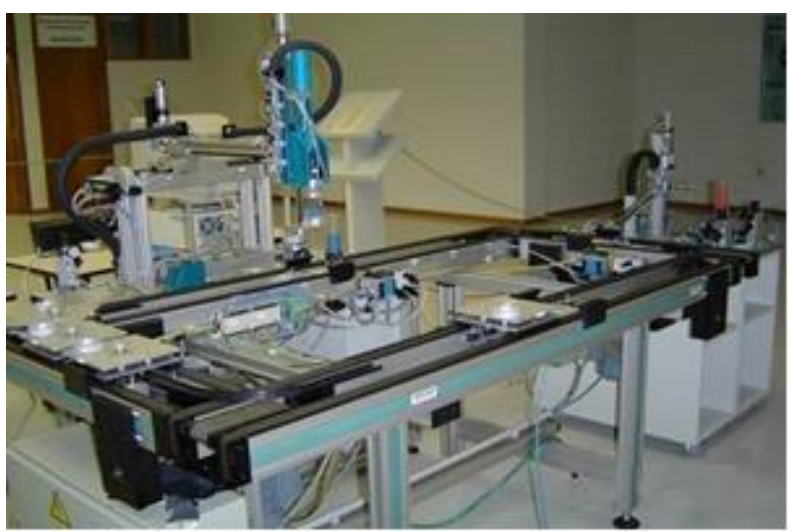

(b) Foto que mostra uma parte da instalação que emula um SPD

Fonte: Adaptado de Junqueira (2006)

A "estação de transporte" realiza a movimentação de paletes entre as estações de trabalho. Quando o palete com o cilindro chega à "estação de montagem", esta aciona outro braço manipulador, com uma garra mecânica como end-effector para retirar o cilindro da esteira e colocá-lo sobre uma bancada de montagem. Em seguida o mesmo braço manipulador, com auxílio de dispositivos especiais de fixação de peças, realiza a colocação de um pino e uma mola no interior do cilindro e em seguida o rosqueamento de uma tampa na sua parte superior. Para finalizar, o braço manipulador coloca o cilindro montado no palete de modo que a "estação de 
transporte" o conduz para a "estação de armazenamento" de produtos, isto é, onde o cilindro montado é retirado do palete e colocado num armazém de produtos acabados.

Por meio destes modelos, o SuMS realiza o monitoramento dos processos SPD. A quantidade de documentos e informações processadas na aplicação do framework proposto para a análise de desempenho de sustentabilidade do SPD é relativamente grande. Assim, apresenta-se aqui apenas a parte mais relevante dos resultados obtidos que confirmam a validade da proposta.

Primeiramente, considera-se a fase de inicialização do SuMS. Assim, de acordo com a seção anterior, analisa-se a arquitetura das funções de controle e gestão do SPD e se preenche as Tabelas 9 e 13 com as informações das características do sistema e dos processos envolvidos. Com base nestas informações são definidos os indicadores de sustentabilidade relevantes para o SPD, utilizando como referência as Tabelas 1, 2, 3 e 4, neste exemplo será considerado todos os indicadores.

O próximo passo envolve técnicas de modelagem de processo SPD. Inicialmente, o modelo conceitual do sistema é desenvolvido usando PFS. Uma vez que estes modelos são verificados, derivam-se os modelos funcionais dos processos envolvidos em rede de Petri. A verificação estrutural e do comportamento dos modelos e as análises dinâmicas do sistema são realizadas. Os modelos são validados com base em simulações de cenários específicos e em dados disponibilizados pelos fabricantes e processos similares.

Os modelos são usados para identificar onde (nos processos) a coleta de dados para o cálculo dos indicadores de sustentabilidade deve ser realizada. Diferentes cenários também são testados para confirmar quais informações são efetivamente viáveis para serem coletadas na prática, avaliando inclusive as restrições de tempo a serem considerados, etc.

A Figura 20 mostra o modelo dos processos produtivos do SPD. A Figura 20a é o modelo PFS do processo geral (note que cada estação de trabalho é modelada como um subsistema relativamente autônomo e a interação entre eles é descrita como um fluxo secundário dos itens) e a Figura 20b mostra o modelo em rede de Petri da "Estação de distribuição" com detalhes funcionais do processo. 
Figura 20 - Modelos dos processos no SPD. (a) Modelo PFS geral dos processos. (b) Modelo em rede de Petri do processo na "Estação de Distribuição".

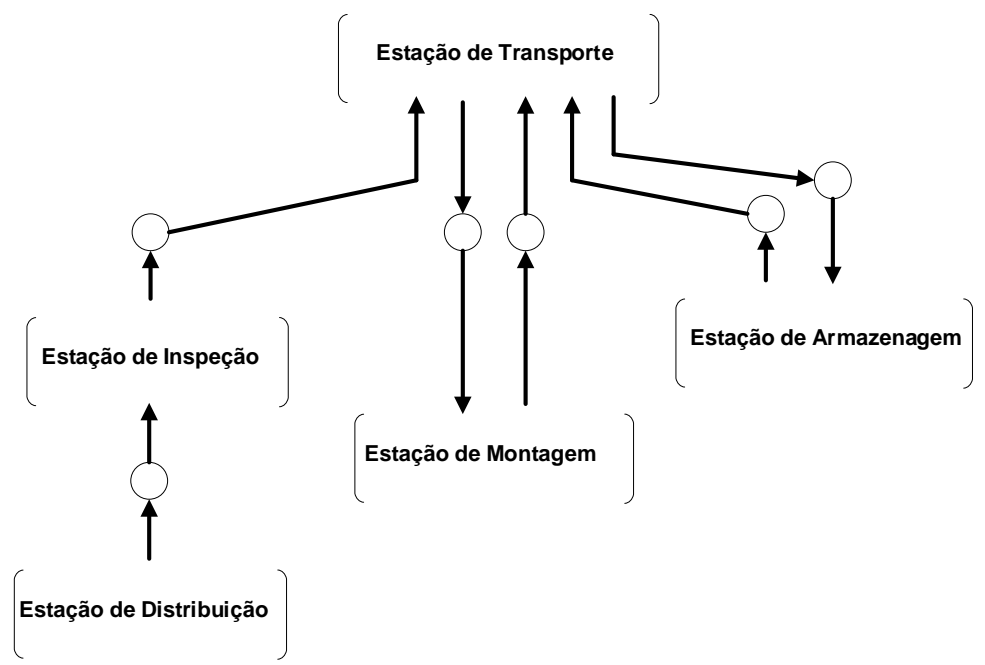

(a)

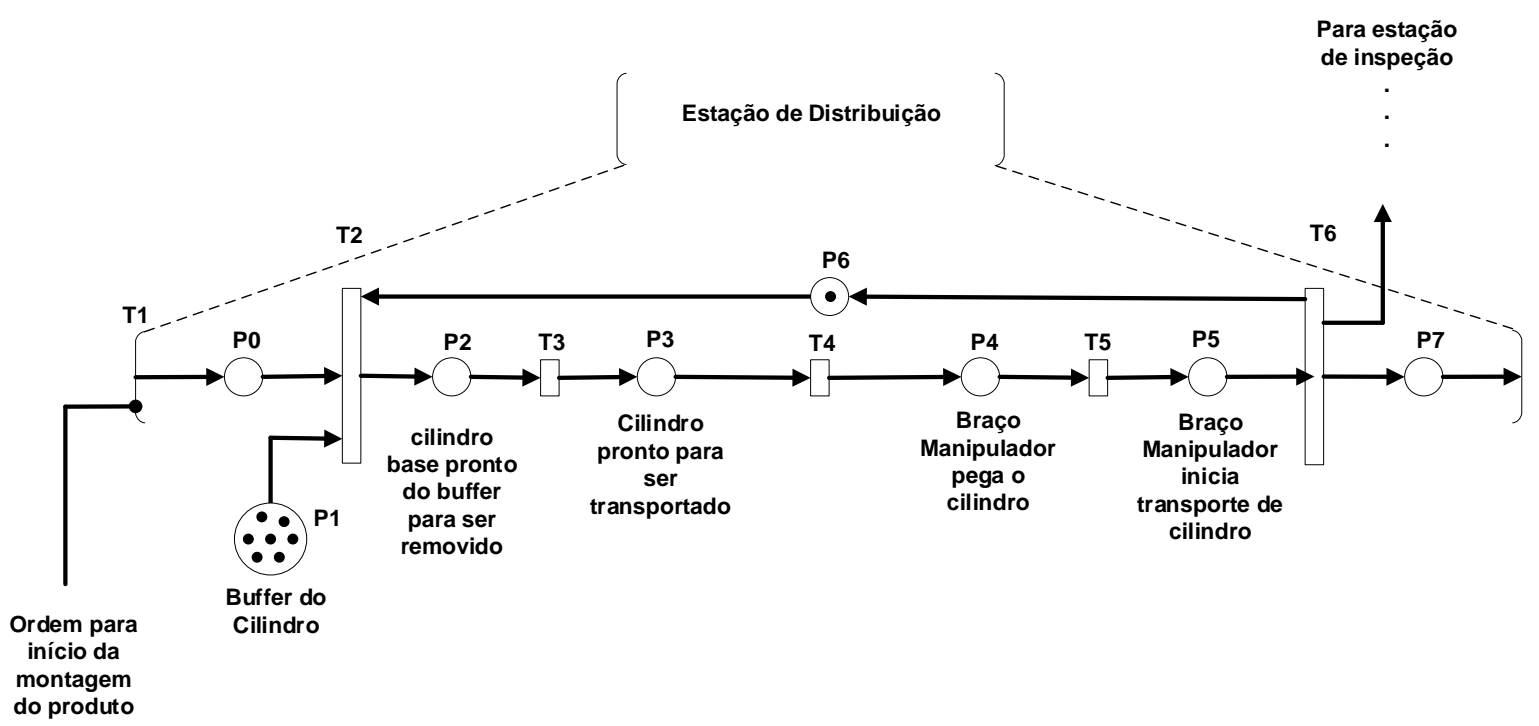

(b)

Fonte: $\mathrm{O}$ autor

A Figura 21 mostra o processo produtivo da "estação de distribuição", ou seja, o modelo em rede de Petri, editado na ferramenta IOPT (DA SILVA et al., 2016). Conforme mencionado anteriormente, uma parte dos dados do processo produtivo para obtenção de informações de sustentabilidade devem ser obtidas como o MES do SPD, mas existem informações não estão disponíveis no MES de modo que um sistema de aquisição de dados foi instalado na planta e, conectado diretamente ao SuMS. Na seção 5.1.1 apresenta-se uma explicação do sistema de aquisição de dados desenvolvido para este exemplo de aplicação. 
Figura 21 - Processo produtivo da "estação de distribuição" e a funcionalidade da "aquisição de dados" do SuMS.

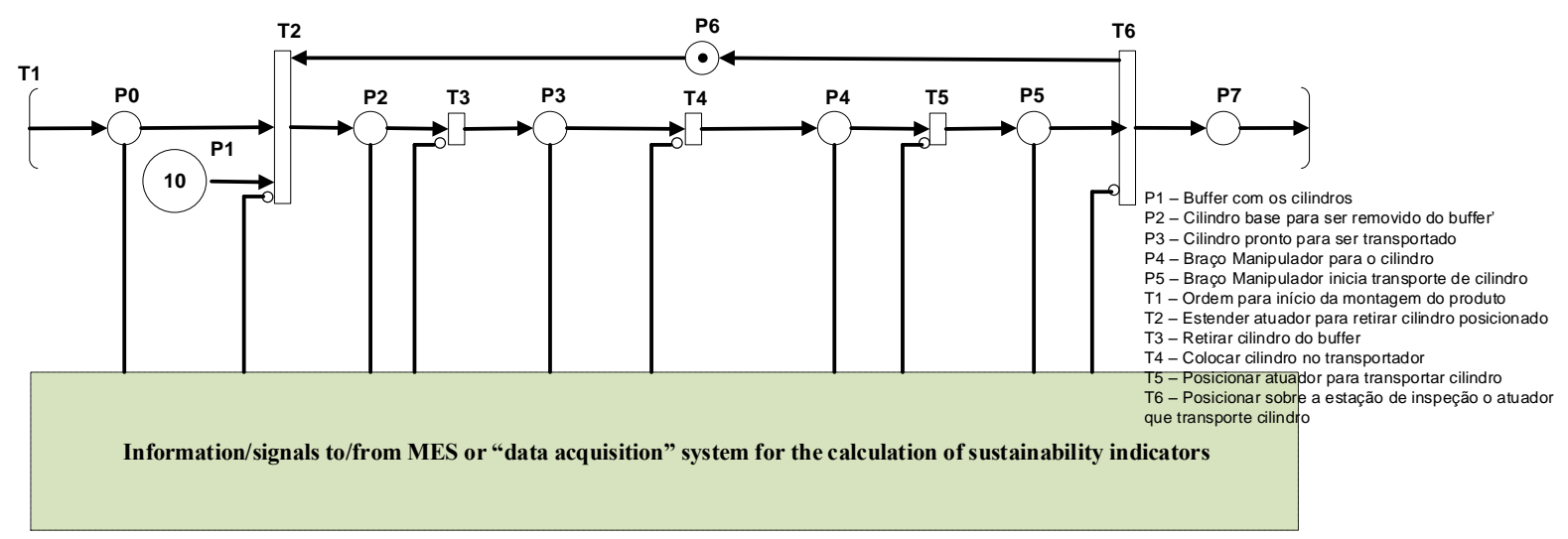

Fonte: $\mathrm{O}$ autor

$\mathrm{Na}$ parte de avaliação de dados, os indicadores são inicializados com a atribuição de valores de referência e as definições dos níveis de importância dos indicadores. Esses valores são usados para calcular o nível de sustentabilidade do SPD. As Tabelas 21 a 24 apresentam os dados resultantes.

Tabela 21- Indicadores de Sustentabilidade de acordo com aspectos econômicos

\begin{tabular}{|c|c|c|c|c|c|c|}
\hline ITEM & INDICADORES ECONÔMICOS & $\begin{array}{l}\text { VALOR } \\
\text { MEDI } \\
\text { DO }\end{array}$ & $\begin{array}{c}\text { VALOR DE } \\
\text { REFERÊNCIA }\end{array}$ & $\begin{array}{c}\text { ÍNDICES } \\
\text { ALCANÇA } \\
\text { DOS }\end{array}$ & $\begin{array}{c}\text { PESO POR } \\
\text { IMPORTÂN } \\
\text { CIA }\end{array}$ & $\begin{array}{c}\text { NÍVEL DE } \\
\text { IMPORTÂN } \\
\text { CIA }\end{array}$ \\
\hline 1 & $\begin{array}{l}\text { Benefício com Redução de Gás } \\
\text { Carbono }\end{array}$ & 58 & 100 & 0 & 0,17 & 5 \\
\hline 2 & Economia com Reuso de Material & 70 & 100 & 1 & 0,10 & 3 \\
\hline 3 & Economia com Descarte de Lixo & 83 & 100 & 1 & 0,10 & 3 \\
\hline 4 & Economia com Material Reciclado & 45 & 100 & 0 & 0,10 & 3 \\
\hline 5 & Benefício com Energia Renovável & 33 & 100 & 0 & 0,13 & 4 \\
\hline 6 & Redução da Energia Tradicional & 400 & 100 & 1 & 0,13 & 4 \\
\hline 7 & Custo de Material & 75 & 100 & 1 & 0,07 & 2 \\
\hline 8 & Custo de Energia & 80 & 100 & 1 & 0,03 & 1 \\
\hline 9 & Custo de Mão de Obras & 72 & 100 & 1 & 0,07 & 2 \\
\hline 10 & Custo Operacional e de Capital & 81 & 100 & 1 & 0,10 & 3 \\
\hline \multicolumn{4}{|c|}{$I D_{E C O}($ ÍNDICE ECONÔMICO) } & 0,57 & & \\
\hline
\end{tabular}

Tabela 22 - Indicadores de Sustentabilidade de acordo com aspectos ambientais

\begin{tabular}{|c|c|c|c|c|c|c|}
\hline ITEM & INDICADORES AMBIENTAIS & $\begin{array}{l}\text { VALOR } \\
\text { MEDI } \\
\text { DO }\end{array}$ & $\begin{array}{c}\text { VALOR DE } \\
\text { REFERÊNCIA }\end{array}$ & $\begin{array}{l}\text { ÍNDICES } \\
\text { ALCANÇA } \\
\text { DOS }\end{array}$ & $\begin{array}{l}\text { PESO POR } \\
\text { IMPORTÂN } \\
\text { CIA }\end{array}$ & $\begin{array}{l}\text { NÍVEL DE } \\
\text { IMPORTÂN } \\
\text { CIA }\end{array}$ \\
\hline 1 & Emissão de Gás de Efeito Estufa & 70 & 100 & 1 & 0,17 & 5 \\
\hline 2 & Descarte de Água Residual & 70 & 100 & 1 & 0,10 & 3 \\
\hline 3 & Desperdício de Material & 70 & 100 & 1 & 0,10 & 3 \\
\hline 4 & $\begin{array}{l}\text { Materiais Reutilizados ou } \\
\text { Reciclados em Produtos }\end{array}$ & 75 & 100 & 1 & 0,10 & 3 \\
\hline
\end{tabular}


Tabela 22 - Indicadores de Sustentabilidade de acordo com aspectos ambientais (continuação)

\begin{tabular}{|c|c|c|c|c|c|c|}
\hline ITEM & INDICADORES AMBIENTAIS & $\begin{array}{l}\text { VALOR } \\
\text { MEDI } \\
\text { DO }\end{array}$ & $\begin{array}{c}\text { VALOR DE } \\
\text { REFERÊNCIA }\end{array}$ & $\begin{array}{l}\text { ÍNDICES } \\
\text { ALCANÇA } \\
\text { DOS }\end{array}$ & $\begin{array}{l}\text { PESO POR } \\
\text { IMPORTÂN } \\
\text { CIA }\end{array}$ & $\begin{array}{l}\text { NÍVEL DE } \\
\text { IMPORTÂN } \\
\text { CIA }\end{array}$ \\
\hline 5 & $\begin{array}{l}\text { Descarte de Material de } \\
\text { Embalagem }\end{array}$ & 33 & 100 & 0 & 0,13 & 4 \\
\hline 6 & Reuso de Material de Embalagem & 90 & 100 & 1 & 0,13 & 4 \\
\hline 7 & Consumo Total de Energia & 72 & 100 & 1 & 0,07 & 2 \\
\hline 8 & Consumo de Água & 73 & 100 & 1 & 0,03 & 1 \\
\hline 9 & Água reutilizada & 63 & 100 & 0 & 0,07 & 2 \\
\hline 10 & Qualidade do Ar & 81 & 100 & 1 & 0,10 & 3 \\
\hline \multicolumn{4}{|c|}{ ID $D_{A M B}$ (ÍNDICE AMBIENTAL) } & 0,80 & & \\
\hline
\end{tabular}

Tabela 23 - Indicadores de Sustentabilidade de acordo com aspectos social

\begin{tabular}{|c|c|c|c|c|c|c|}
\hline ITEM & INDICADORES SOCIAIS & $\begin{array}{l}\text { VALOR } \\
\text { MEDI } \\
\text { DO }\end{array}$ & $\begin{array}{l}\text { VALOR DE } \\
\text { REFERÊNCIA }\end{array}$ & $\begin{array}{l}\text { ÍNDICES } \\
\text { ALCANÇA } \\
\text { DOS }\end{array}$ & $\begin{array}{l}\text { PESO POR } \\
\text { IMPORTÂN } \\
\text { CIA }\end{array}$ & $\begin{array}{l}\text { NÍVEL DE } \\
\text { IMPORTÂN } \\
\text { CIA }\end{array}$ \\
\hline 1 & Dia de Trabalho Perdido & 70 & 100 & 1 & 0,17 & 5 \\
\hline 2 & Satisfação no Trabalho & 72 & 100 & 1 & 0,10 & 3 \\
\hline 3 & Taxa de Acidente do Trabalhador & 73 & 100 & 1 & 0,10 & 3 \\
\hline 4 & Taxa de Produtividade do Trabalhador & 70 & 100 & 1 & 0,10 & 3 \\
\hline 5 & $\begin{array}{l}\text { Treinamento do Trabalhador em } \\
\text { Sustentabilidade }\end{array}$ & 65 & 100 & 0 & 0,13 & 4 \\
\hline 6 & $\begin{array}{l}\text { Sugestões der melhoria de } \\
\text { Sustentabilidade pelo Trabalhador }\end{array}$ & 58 & 100 & 0 & 0,13 & 4 \\
\hline 7 & Reclamações de Clientes & 74 & 100 & 1 & 0,07 & 2 \\
\hline 8 & $\begin{array}{l}\text { Programa de relacionamento com o } \\
\text { Cliente }\end{array}$ & 83 & 100 & 1 & 0,03 & 1 \\
\hline 9 & $\begin{array}{l}\text { Publicação de Relatórios de } \\
\text { Sustentabilidade }\end{array}$ & 75 & 100 & 1 & 0,07 & 2 \\
\hline 10 & Prêmio de Sustentabilidade & 45 & 100 & 0 & 0,10 & 3 \\
\hline \multicolumn{4}{|c|}{ ID $D_{\text {Soc }}$ (ÍNDICESOCIAL) } & 0,53 & & \\
\hline
\end{tabular}

Tabela 24 - Indicadores de Sustentabilidade de acordo com aspectos tecnológicos

\begin{tabular}{|c|c|c|c|c|c|c|}
\hline ITEM & INDICADORES TECNOLÓGICOS & $\begin{array}{l}\text { VALOR } \\
\text { MEDI } \\
\text { DO }\end{array}$ & $\begin{array}{c}\text { VALOR DE } \\
\text { REFERÊNCIA }\end{array}$ & $\begin{array}{l}\text { ÍNDICES } \\
\text { ALCANÇA } \\
\text { DOS }\end{array}$ & $\begin{array}{l}\text { PESO POR } \\
\text { IMPORTÂN } \\
\text { CIA }\end{array}$ & $\begin{array}{l}\text { NÍVEL DE } \\
\text { IMPORTÂN } \\
\text { CIA }\end{array}$ \\
\hline 1 & Aplicação de Política de TI Sustentável & 72 & 100 & 1 & 0,17 & 5 \\
\hline 2 & $\begin{array}{l}\text { Equipamentos de Proteção e } \\
\text { Segurança Pessoal }\end{array}$ & 70 & 100 & 1 & 0,10 & 3 \\
\hline 3 & $\begin{array}{l}\text { Atualização de versão de Software e } \\
\text { Hardware }\end{array}$ & 83 & 100 & 1 & 0,10 & 3 \\
\hline 4 & Investimento em Inovação e P\&D & 75 & 100 & 1 & 0,10 & 3 \\
\hline 5 & $\begin{array}{l}\text { Fornecedores de Serviços com } \\
\text { Certificação em Meio Ambiente }\end{array}$ & 80 & 100 & 1 & 0,13 & 4 \\
\hline 6 & Aplicação de Política de Manutenção & 75 & 100 & 1 & 0,13 & 4 \\
\hline 7 & $\begin{array}{l}\text { Evitar parada de linha devido a } \\
\text { preocupações com a segurança }\end{array}$ & 68 & 100 & 0 & 0,07 & 2 \\
\hline 8 & Política de Sistemas Abertos & 54 & 100 & 0 & 0,03 & 1 \\
\hline 9 & Monitoração de Energia Renovável & 63 & 100 & 0 & 0,07 & 2 \\
\hline
\end{tabular}


Tabela 24 - Indicadores de Sustentabilidade de acordo com aspectos tecnológicos (continuação)

\begin{tabular}{|c|c|c|c|c|c|c|}
\hline ITEM & INDICADORES TECNOLÓGICOS & $\begin{array}{l}\text { VALOR } \\
\text { MEDI } \\
\text { DO }\end{array}$ & $\begin{array}{c}\text { VALOR DE } \\
\text { REFERÊNCIA }\end{array}$ & $\begin{array}{l}\text { ÍNDICES } \\
\text { ALCANÇA } \\
\text { DOS }\end{array}$ & $\begin{array}{l}\text { PESO POR } \\
\text { IMPORTÂN } \\
\text { CIA }\end{array}$ & $\begin{array}{l}\text { NÍVEL DE } \\
\text { IMPORTÂN } \\
\text { CIA }\end{array}$ \\
\hline 10 & $\begin{array}{l}\text { Monitoração do Ciclo de Operação de } \\
\text { Máquinas }\end{array}$ & 40 & 100 & 0 & 0,10 & 3 \\
\hline \multicolumn{4}{|c|}{ ID $D_{T E C}($ ÍNDICE TECNOLÓGICO) } & 0,73 & & \\
\hline
\end{tabular}

A Figura 22 ilustra parte dos resultados da avaliação obtidos neste exemplo. Conforme discutido no capítulo de apresentação do framework adota-se neste exemplo um limite de $70 \%$ para indicação da sustentabilidade do sistema, e foi considerado um limite mínimo de $60 \%$. Os pesos classificam a importância dos indicadores e os valores dos indicadores são calculados a partir dos dados medidos e coletados diretamente da planta do SPD. Conforme ilustrado na Figura 22b, os resultados podem ser apresentados na forma gráfica a partir do qual as melhorias a serem feitas no sistema com relação à sua sustentabilidade são mais facilmente identificadas.

Os dados da Figura 22 indicam que os aspectos econômicos e sociais estão abaixo do valor mínimo considerado como limite. Ao consultar os índices de cada indicador que compõem esses aspectos, se têm os parâmetros que precisam ser melhorados.

Conforme anteriormente mencionado, para o tratamento dos dados, ferramentas de organização e apresentação de dados podem ser usadas. Estas informações são mantidas no banco de dados SuMS e estão disponíveis para o nível de tomada de decisão estratégica do sistema de acordo com a funcionalidade relacionada à comunicação com o nível superior de gerenciamento e controle do SPD.

Este exemplo mostra como as principais funcionalidades do framework proposto podem ser implementadas e servem de prova do conceito, ou seja, que o framework proposto é uma solução efetiva para avaliar a sustentabilidade de um SPD.

\subsubsection{Protótipo de um sistema de aquisição de dados}

O exemplo anterior evidencia que na prática nem todas as informações para o cálculo dos indicadores de sustentabilidade são disponibilizadas pelo MES. De fato, em geral, dados relacionados ao ambiente e à infraestrutura das instalações além de 
em alguns parâmetros específicos dos processos produtivos devem ser coletados diretamente para que sejam processados no SuMS.

Figura 22 - Resultados da avaliação de sustentabilidade. (a) Resumo da avaliação. (b) Resultados em gráfico em barras.

\begin{tabular}{|l|ccc|}
\hline \multicolumn{1}{|c}{ ITEM } & ÍNDICES & NíVEL DE IMPORTÂNCIA & $\begin{array}{c}\text { PESO POR } \\
\text { IMPORTÂNCIA }\end{array}$ \\
\hline ECONÓMICO & 0,57 & 4 & 0,33 \\
AMBIENTAL & 0,80 & 3 & 0,25 \\
SOCIAL & 0,53 & 2 & 0,17 \\
TECNOLOGICO & 0,73 & 3 & 0,25 \\
& & & \\
AVALIAÇÃO DO & Avaliação da & Limite Mínimo de & $\begin{array}{c}\text { Limite de } \\
\text { IDIPS }\end{array}$ \\
Sustentabilidade & Sustentabilidade & Sustentabilidade \\
0,54 & $\mathbf{0 , 6 6}$ & $\mathbf{0 , 6 0}$ & $\mathbf{0 , 7 0}$ \\
\hline
\end{tabular}

(a)

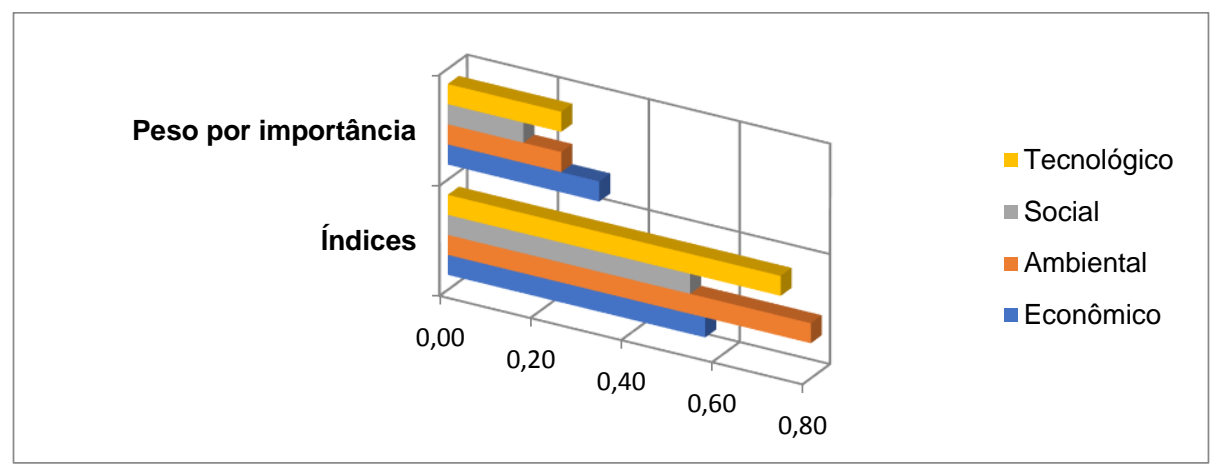

(b)

Fonte: 0 autor

Assim, aqui se apresenta o protótipo de um dispositivo de aquisição de dados ambientais e de consumo de energia. Por meio de sensores e transdutores estes dispositivos transformam grandezas físicas em sinais elétricos que são monitoradas remotamente e processadas no SuMS para comporem os indicadores de sustentabilidade.

O protótipo do dispositivo foi desenvolvido utilizando-se os recursos de uma placa microprocessada padrão (Figura 23) com capacidade de processamento de dados e com entradas analógicas e interface de comunicação com outros dispositivos. Nesta placa são conectados os componentes que captam as informações ambientais (temperatura, ruído e qualidade de ar) e operacionais de equipamentos (consumo de 
energia). Um programa computacional é utilizado para implementar um sistema de monitoração e processamento de informações, e para isto, neste caso foi usado o MATLab (2016) pelas suas características de permitir (i) desenvolvimento relativamente rápido, (ii) facilidade de executar operações de cálculo matemáticos e (iii) armazenamento de resultados em arquivos de formatos padrões.

Figura 23 - Placa microprocessada para aquisição de dados.

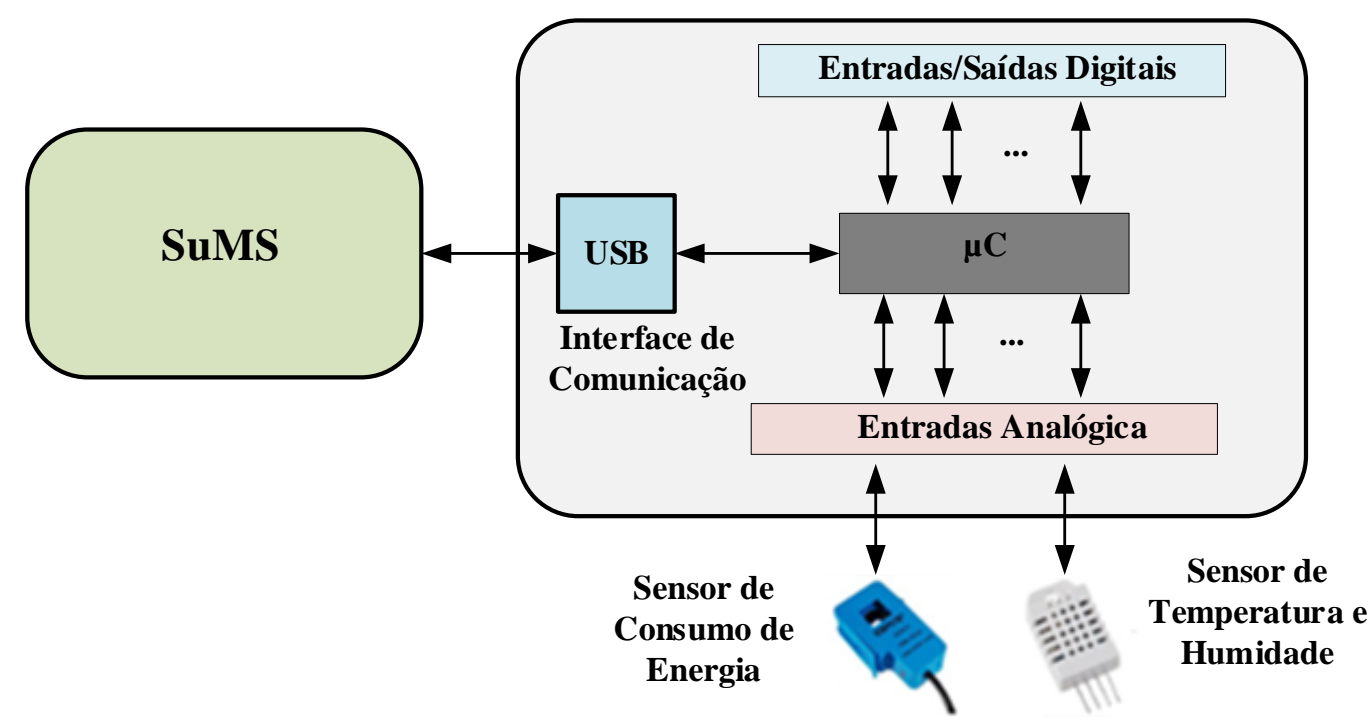

Fonte: $\mathrm{O}$ autor

Um programa de leitura das portas analógicas foi desenvolvido e carregado na placa de aquisição. Foram utilizados a linguagem $C$ e um ambiente de desenvolvimento com ferramentas de edição e depuração de programas do fabricante do microprocessador.

Os transdutores de temperatura e de corrente são conectados nas entradas analógicas da placa de aquisição. Estes transdutores transformam grandezas físicas em tensões elétricas, os quais são lidos por um conversor de sinais analógicos para digitais, codificando-os para valores que são processados por um programa computacional.

Um software assegura que os resultados das medições realizadas na placa sejam armazenados em um arquivo de dados. Este software converte os valores recebidos em parâmetros de conforto térmico do ambiente de trabalho e o de consumo de energia. Executa também uma função de verificador de dados, comparando os dados lidos com os considerados como aceitáveis, monitorando assim o comportamento do sinal ao longo do tempo. 
A Figura 24 mostra alguns resultados dos testes com sensores de luminosidade e de temperatura.

Figura 24 - Resultado de leitura de sensor de luminosidade e temperatura.

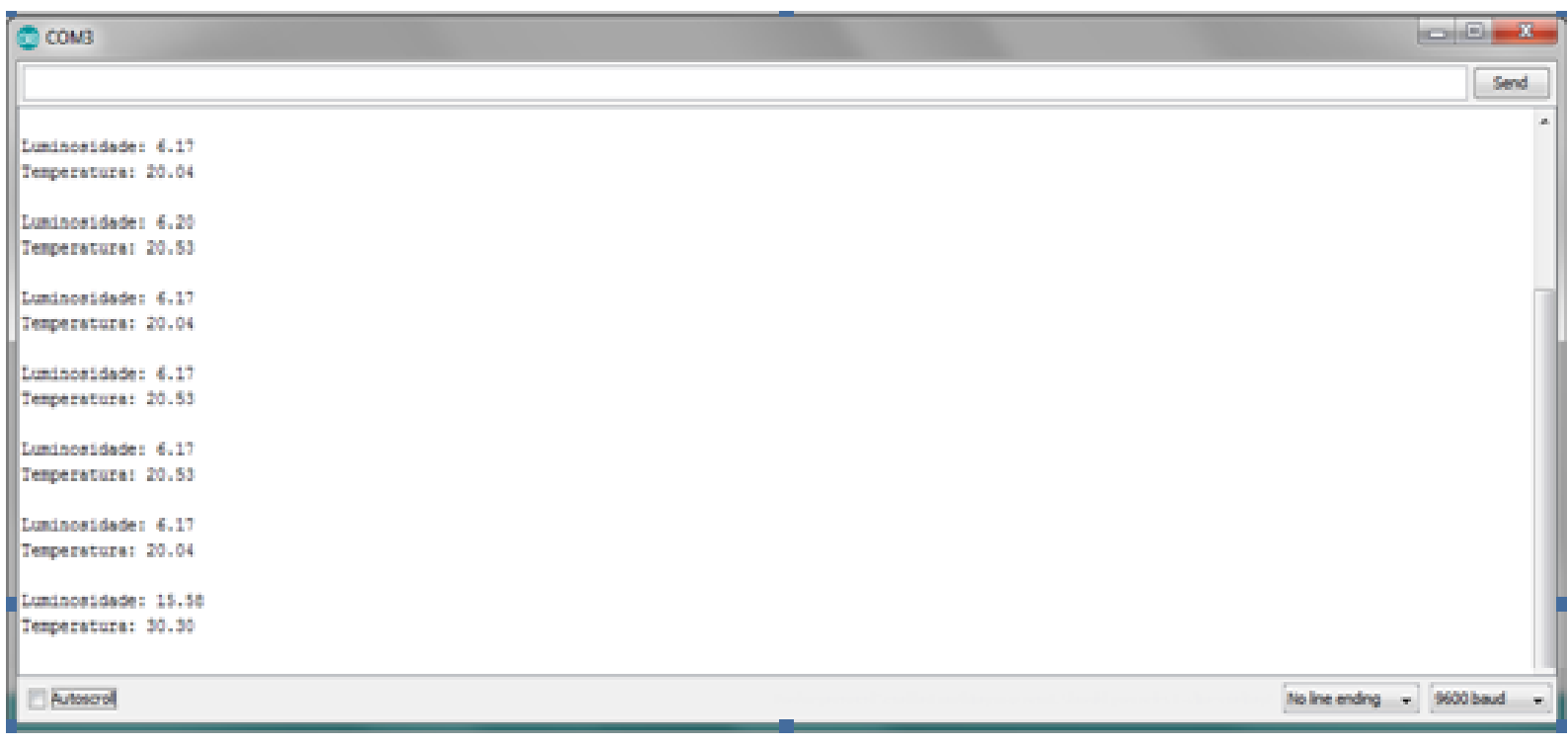

Fonte: $\mathrm{O}$ autor

Este protótipo é apresentado aqui como um exemplo de como implementar o sistema de aquisição de dados para o cálculo da sustentabilidade de SPDs, os quais não estão disponibilizados pelo MES.

\subsection{APLICAÇÃO DE MÉTOdOS DE AVALIAÇÃO DE SUSTENTABILIDADE}

Apresenta-se a seguir outros métodos de avaliação de sustentabilidade que foram aplicados com base no framework proposto.

Cada método adota um formato específico de valores para mensurar o grau de sustentabilidade de um sistema produtivo. Em função disso, os exemplos indicam como estes outros métodos foram incorporados no framework proposto de modo que o foco está na avaliação qualitativa e não nos resultados numéricos. Nestes exemplos se utiliza os dados dos trabalhos onde esses métodos foram apresentados.

\subsubsection{Sustentabilidade de uma empresa de manufatura}

Garbie (2014) apresenta um procedimento para conduzir a integração das medições de sustentabilidade de uma empresa de manufatura. $O$ procedimento é 
usado para estimar a sustentabilidade em três aspectos (econômico, ambiental e social) e as inter-relações entre estes aspectos, e propõe verificar a integração destes aspectos. As métricas de desempenho para cada indicador são derivadas de um caso ilustrativo onde se considera o valor medido $\left(\mathrm{U}_{\mathrm{ij}}\right)$ e o valor esperado $\left(\mathrm{V}_{\mathrm{ij}}\right)$ de diversos parâmetros. A interpretação dos dados depende da natureza deles. Alguns desses parâmetros são quantitativos e outros são qualitativos (onde se adota um mapeamento em graus ou porcentagens). Um programa de computador calcula os pesos relativos entre os grupos de indicadores escolhidos com base em estimativas de especialistas, os quais estabelecem os pesos relativos entre os indicadores. $O$ programa também calcula a sustentabilidade avaliando os indicadores de cada aspecto inserido pelo operador com base em critérios próprios.

\section{a) Resultados obtidos no aspecto econômico}

A avaliação do resultado obtido por Garbie (2014) indica que o valor da sustentabilidade do aspecto econômico está 3,5 vezes fora do valor esperado que é 1, levando a conclusão que existe a necessidade de algum empenho (tempo, custo, recurso e outros) nos aspectos econômico, ambiental e social, para colocá-lo no nível de sustentabilidade que se quer alcançar. Em relação aos principais aspectos que foram calculados, os indicadores reconfiguração, estratégias competitivas e gestão flexível representaram os parâmetros que envolveram maior empenho, isto é, de $8,6513,6,8328$ e 9,1058, respectivamente. Estes valores indicam que esse empenho foi acima do esperado. No que diz respeito às questões de inovação e globalização, foram necessários esforços de 1,6357 e 1,00, respectivamente, o que pode ser considerado dentro do esperado, mas para questões emergentes, e avaliação de desempenho, os valores de 0,0364 e 0,2258, respectivamente, indicam que o empenho foi aquém do desejado. Neste método também são atribuídos pesos aos indicadores.

Os dados do trabalho de Garbie (2014) foram inseridos no framework para o cálculo da sustentabilidade no aspecto econômico da sustentabilidade. Levando-se em consideração os indicadores e respectivos pesos conforme Tabela 25 , esses dados foram transferidos para as colunas 3, 4 e 7 da Tabela 26. Com bases nesses dados, calculou-se o nível de sustentabilidade no aspecto econômica e o resultado obtido foi de $28 \%$, isto é, pelo framework esta empresa não é sustentável neste 
aspecto. Na coluna 5, da Tabela 26, pode-se visualizar os índices de cada indicador. Para este exemplo algumas adaptações foram feitas como: (i) o limite do atendimento do valor de referência foi estabelecido com o valor 1 ou $100 \%$; (ii) os pesos e no nível de importância de cada indicador, no trabalho de Garbie (2014) os indicadores são classificados em 7 níveis de influência, assim como o framework proposto adota 5 níveis, assim agrupou-se 2 níveis entre os 5 mais representativos.

Tabela 25 - Indicadores relativos à dimensão econômica e seus pesos (adaptado de GARBIE, 2014)

\begin{tabular}{|c|c|c|c|c|}
\hline $\begin{array}{c}\text { INDI } \\
\text { CA } \\
\text { DOR }\end{array}$ & $\begin{array}{c}\text { PESOS RELATIVOS AOS INDICADORES ECONÔMICOS DE } \\
\text { SUSTENTABILIDADE }\end{array}$ & $\begin{array}{l}\text { VALOR } \\
\text { MEDIDO (U }\left(U_{\mathrm{IJ}}\right)\end{array}$ & $\begin{array}{l}\text { VALOR DE } \\
\text { REFERÊNCIA }\left(V_{\mathbf{I J}}\right)\end{array}$ & $\begin{array}{l}\text { PESO POR } \\
\text { IMPORTÃNCIA }\end{array}$ \\
\hline E11 & №de paradas causadas pelo fornecedor & 4 & 1 & 0,2264 \\
\hline E12 & Grau ou porcentagem (\%) de usar internet e e-commerce & 80 & 90 & 0,2264 \\
\hline E13 & Unidade monetária / barril & 110 & 70 & 0,2264 \\
\hline E14 & Quantidade de mercados ao redor do mundo & 60 & 90 & 0,2264 \\
\hline E15 & № de novos clientes / ano & 4000 & 5000 & 0,2264 \\
\hline E21 & Grau ou porcentagem (\%) de usar a nova tecnologia & 80 & 95 & 0,1296 \\
\hline E22 & Grau ou porcentagem (\%) de seguir regulamentos & 90 & 95 & 0,1296 \\
\hline E23 & Aumento anual de número de populações $\mathrm{x}$ por região & 3000 & 1000 & 0,1296 \\
\hline E24 & Grau ou porcentagem (\%) de rentabilidade & 70 & 95 & 0,1296 \\
\hline E25 & Percentagem (\%) de utilização de recursos & 80 & 5 & 0,1296 \\
\hline E31 & Grau ou porcentagem (\%) & 80 & 95 & 0,1846 \\
\hline E32 & Grau ou porcentagem (\%) & 80 & 90 & 0,1846 \\
\hline E33 & Porcentagem (\%) do orçamento anual para P\&D & 2 & 5 & 0,1846 \\
\hline E34 & Dias, horas & 25 & 5 & 0,1846 \\
\hline E35 & $\begin{array}{l}\text { Grau ou porcentagem (\%) de flexibilidade dentro de uma } \\
\text { planta }\end{array}$ & 70 & 90 & 0,1846 \\
\hline E36 & $\begin{array}{l}\text { Quantidade de novas regiões relacionadas ao total da } \\
\text { quantidade de regiões }\end{array}$ & 3 & 10 & 0,1846 \\
\hline E37 & $\begin{array}{l}\text { № de novos produtos relacionados ao total do número de } \\
\text { produtos }\end{array}$ & 5 & 10 & 0,1846 \\
\hline E41 & Quantidade de recursos (p.ex., máquinas) & 85 & 75 & 0,1821 \\
\hline E42 & Quantidade de operações diferentes (faixa de flexibilidade) & 1700 & 2000 & 0,1821 \\
\hline E43 & №de equipamentos de manuseio de material & 12 & 15 & 0,1821 \\
\hline E44 & Espaço de armazenamento (metros cúbicos) & 400 & 600 & 0,1821 \\
\hline E45 & $\begin{array}{l}\text { Quantidade de novos sistemas de identificação } \\
\text { comparadosaos existentes }\end{array}$ & 1 & 3 & 0,1821 \\
\hline E46 & Quantidade de localizações da planta ao redor do mundo & 3 & 7 & 0,1821 \\
\hline E47 & № de células focalizadas & 4 & 5 & 0,1821 \\
\hline E51 & Grau ou porcentagem (\%) de complexidade na planta & 80 & 70 & 0,0883 \\
\hline E52 & Valor adicionado (p.ex.., produtividade do funcionário) & 80 & 95 & 0,0883 \\
\hline E53 & Grau ou porcentagem (\%) de agilidade & 75 & 95 & 0,0883 \\
\hline E54 & $\begin{array}{l}\text { № de peças ou componentes pode ser substituído novamente } \\
\text { / produto }\end{array}$ & 5 & 10 & 0,0883 \\
\hline E55 & Porcentagem (\%) do consumo total de peças recicladas & 50 & 95 & 0,0883 \\
\hline E61 & Unidade monetária /unidade & 16 & 12 & 0,1000 \\
\hline E62 & Dias & 11 & 8 & 0,1000 \\
\hline E63 & Unidades / Horas & 20 & 30 & 0,1000 \\
\hline E64 & Utilização (\%) do trabalho manual & 70 & 95 & 0,1000 \\
\hline E65 & Confiabilidade, eficiência do equipamento global (eeg) (\%) & 80 & 95 & 0,1000 \\
\hline
\end{tabular}


Tabela 25 - Indicadores relativos à dimensão econômica e seus pesos (adaptado de GARBIE, 2014) (continuação)

\begin{tabular}{|c|c|c|c|c|}
\hline $\begin{array}{l}\text { INDI } \\
\text { CA } \\
\text { DOR }\end{array}$ & $\begin{array}{c}\text { PESOS RELATIVOS AOS INDICADORES ECONÔMICOS DE } \\
\text { SUSTENTABILIDADE }\end{array}$ & $\begin{array}{l}\text { VALOR } \\
\text { MEDIDO }\left(\bigcup_{I J}\right)\end{array}$ & $\begin{array}{l}\text { VALOR DE } \\
\text { REFERÊNCIA (VIJ) }\end{array}$ & $\begin{array}{l}\text { PESO POR } \\
\text { IMPORTÃNCIA }\end{array}$ \\
\hline E66 & Taxa de reclamações do cliente (unidades / unidade tempo) & 10 & 1 & 0,1000 \\
\hline E71 & Grau de clareza do planejamento estratégico & 70 & 95 & 0,0891 \\
\hline E72 & № de subordinados por supervisor & 10 & 5 & 0,0891 \\
\hline E73 & № da estrutura de organização & 5 & 3 & 0,0891 \\
\hline E74 & Grau ou porcentagem (\%) de liderança & 70 & 95 & 0,0891 \\
\hline E75 & Porcentagem (\%) para acesso ao pessoal qualificado & 30 & 80 & 0,0891 \\
\hline E76 & Porcentagem (\%) de entendimento de culturas estrangeiras & 70 & 90 & 0,0891 \\
\hline
\end{tabular}

Tabela 26 - Avaliação de sustentabilidade utilizando o framework considerando os indicadores econômicos

\begin{tabular}{|c|c|c|c|c|c|c|c|c|}
\hline $\begin{array}{l}\text { INDI } \\
\text { CA } \\
\text { DOR }\end{array}$ & $\begin{array}{c}\text { PESOS RELATIVOS AOS } \\
\text { INDICADORES } \\
\text { ECONÔMICOS DE } \\
\text { SUSTENTABILIDADE }\end{array}$ & $\begin{array}{l}\text { VALOR } \\
\text { MEDI } \\
\text { DO (UIJ) }\end{array}$ & $\begin{array}{l}\text { VALOR } \\
\text { DE REFE } \\
\text { RÊNCIA } \\
\left(V_{I J}\right)\end{array}$ & $\begin{array}{l}\text { ÍNDI } \\
\text { CE } \\
\text { ALCAN } \\
\text { ÇADO }\end{array}$ & $\begin{array}{l}\text { NÍVEL DE } \\
\text { IMPOR } \\
\text { TÂNCIA }\end{array}$ & $\begin{array}{l}\text { PESO POR } \\
\text { IMPOR } \\
\text { TÂNCIA }\end{array}$ & $\begin{array}{l}\text { VALOR } \\
\text { DO } \\
\text { ÍNDI } \\
\text { CE }\end{array}$ & $\begin{array}{l}\text { VALOR DE } \\
\text { SUSTENTABILIDA } \\
\text { DE }\end{array}$ \\
\hline E11 & $\begin{array}{l}\text { № de paradas causadas pelo } \\
\text { fornecedor }\end{array}$ & 4 & 1 & 1 & 5 & 0,2264 & 0,04 & \multirow{23}{*}{$28 \%$} \\
\hline E12 & $\begin{array}{l}\text { Grau ou porcentagem (\%) de } \\
\text { usar internet e e-commerce }\end{array}$ & 80 & 90 & 0 & 5 & 0,2264 & 0,00 & \\
\hline E13 & Unidade monetária / barril & 110 & 70 & 1 & 5 & 0,2264 & 0,04 & \\
\hline E14 & $\begin{array}{l}\text { Quantidade de mercados ao } \\
\text { redor do mundo }\end{array}$ & 60 & 90 & 0 & 5 & 0,2264 & 0,00 & \\
\hline E15 & № de novos clientes / ano & 4000 & 5000 & 0 & 5 & 0,2264 & 0,00 & \\
\hline E21 & $\begin{array}{l}\text { Grau ou porcentagem (\%) de } \\
\text { usar a nova tecnologia }\end{array}$ & 80 & 95 & 0 & 3 & 0,1296 & 0,00 & \\
\hline E22 & $\begin{array}{l}\text { Grau ou porcentagem (\%) de } \\
\text { seguir regulamentos }\end{array}$ & 90 & 95 & 0 & 3 & 0,1296 & 0,00 & \\
\hline E23 & $\begin{array}{l}\text { Aumento anual de número de } \\
\text { populações } x \text { por região }\end{array}$ & 3000 & 1000 & 1 & 3 & 0,1296 & 0,03 & \\
\hline E24 & $\begin{array}{l}\text { Grau ou porcentagem (\%) de } \\
\text { rentabilidade }\end{array}$ & 70 & 95 & 0 & 3 & 0,1296 & 0,00 & \\
\hline E25 & $\begin{array}{l}\text { Percentagem (\%) de utilização } \\
\text { de recursos }\end{array}$ & 80 & 5 & 1 & 3 & 0,1296 & 0,03 & \\
\hline E31 & Grau ou porcentagem (\%) & 80 & 95 & 0 & 4 & 0,1846 & 0,00 & \\
\hline E32 & Grau ou porcentagem (\%) & 80 & 90 & 0 & 4 & 0,1846 & 0,00 & \\
\hline E33 & $\begin{array}{l}\text { Porcentagem }(\%) \text { do } \\
\text { orçamento anual para P\&D }\end{array}$ & 2 & 5 & 0 & 4 & 0,1846 & 0,00 & \\
\hline E34 & Dias, horas & 25 & 5 & 1 & 4 & 0,1846 & 0,03 & \\
\hline E35 & $\begin{array}{l}\text { Grau ou porcentagem (\%) de } \\
\text { flexibilidade dentro de uma } \\
\text { planta }\end{array}$ & 70 & 90 & 0 & 4 & 0,1846 & 0,00 & \\
\hline E36 & $\begin{array}{l}\text { Quantidade de novas regiões } \\
\text { relacionadas ao total da } \\
\text { quantidade de regiões }\end{array}$ & 3 & 10 & 0 & 4 & 0,1846 & 0,00 & \\
\hline E37 & $\begin{array}{l}\text { № de novos produtos } \\
\text { relacionados ao total do } \\
\text { número de produtos }\end{array}$ & 5 & 10 & 0 & 4 & 0,1846 & 0,00 & \\
\hline E41 & $\begin{array}{l}\text { Quantidade de recursos } \\
\text { (p.ex., máquinas) }\end{array}$ & 85 & 75 & 1 & 4 & 0,1821 & 0,03 & \\
\hline E42 & $\begin{array}{l}\text { Quantidade de operações } \\
\text { diferentes (faixa de } \\
\text { flexibilidade) }\end{array}$ & 1700 & 2000 & 0 & 4 & 0,1821 & 0,00 & \\
\hline E43 & $\begin{array}{l}\text { №de equipamentos de } \\
\text { manuseio de material }\end{array}$ & 12 & 15 & 0 & 4 & 0,1821 & 0,00 & \\
\hline E44 & $\begin{array}{l}\text { Espaço de armazenamento } \\
\text { (metros cúbicos) }\end{array}$ & 400 & 600 & 0 & 4 & 0,1821 & 0,00 & \\
\hline E45 & $\begin{array}{l}\text { Quantidade de novos } \\
\text { sistemas de identificação } \\
\text { comparadosaos existentes }\end{array}$ & 1 & 3 & 0 & 4 & 0,1821 & 0,00 & \\
\hline E46 & $\begin{array}{l}\text { Quantidade de localizações da } \\
\text { planta ao redor do mundo }\end{array}$ & 3 & 7 & 0 & 4 & 0,1821 & 0,00 & \\
\hline
\end{tabular}


Tabela 26 - Avaliação de sustentabilidade utilizando o framework considerando os indicadores econômicos (continuação)

\begin{tabular}{|c|c|c|c|c|c|c|c|c|}
\hline $\begin{array}{c}\text { INDI } \\
\text { CA } \\
\text { DOR }\end{array}$ & $\begin{array}{l}\text { PESOS RELATIVOS AOS } \\
\text { INDICADORES } \\
\text { ECONÔMICOS DE } \\
\text { SUSTENTABILIDADE }\end{array}$ & $\begin{array}{l}\text { VALOR } \\
\text { MEDI } \\
\text { DO (UIJ) }\end{array}$ & $\begin{array}{l}\text { VALOR } \\
\text { DE REFE } \\
\text { RÊNCIA } \\
\left(\mathrm{V}_{\text {IJ }}\right)\end{array}$ & $\begin{array}{l}\text { ÍNDICE } \\
\text { ALCAN } \\
\text { ÇADO }\end{array}$ & $\begin{array}{l}\text { NIVEL } \\
\text { DE } \\
\text { IMPOR } \\
\text { TÂNCIA }\end{array}$ & $\begin{array}{l}\text { PESO POR } \\
\text { IMPORTÂN } \\
\text { CIA }\end{array}$ & $\begin{array}{l}\text { VALOR } \\
\text { DO } \\
\text { ÍNDICE }\end{array}$ & $\begin{array}{l}\text { VALOR DE } \\
\text { SUSTENTABILIDA } \\
\text { DE }\end{array}$ \\
\hline E47 & № de células focalizadas & 4 & 5 & 0 & 4 & 0,1821 & 0,00 & \\
\hline E51 & $\begin{array}{l}\text { Grau ou porcentagem (\%) de } \\
\text { complexidade na planta }\end{array}$ & 80 & 70 & 1 & 1 & 0,0883 & 0,01 & \\
\hline E52 & $\begin{array}{l}\text { Valor adicionado (p.ex.., } \\
\text { produtividade do funcionário) }\end{array}$ & 80 & 95 & 0 & 1 & 0,0883 & 0,00 & \\
\hline E53 & $\begin{array}{l}\text { Grau ou porcentagem (\%) de } \\
\text { agilidade }\end{array}$ & 75 & 95 & 0 & 1 & 0,0883 & 0,00 & \\
\hline E54 & $\begin{array}{l}\text { № de peças ou componentes } \\
\text { pode ser substituído } \\
\text { novamente / produto }\end{array}$ & 5 & 10 & 0 & 1 & 0,0883 & 0,00 & \\
\hline E55 & $\begin{array}{l}\text { Porcentagem (\%) do consumo } \\
\text { total de peças recicladas }\end{array}$ & 50 & 95 & 0 & 1 & 0,0883 & 0,00 & \\
\hline E61 & Unidade monetária /unidade & 16 & 12 & 1 & 2 & 0,1000 & 0,02 & \\
\hline E62 & Dias & 11 & 8 & 1 & 2 & 0,1000 & 0,02 & \\
\hline E63 & Unidades / Horas & 20 & 30 & 0 & 2 & 0,1000 & 0,00 & \\
\hline E64 & $\begin{array}{l}\text { Utilização (\%) do trabalho } \\
\text { manual }\end{array}$ & 70 & 95 & 0 & 2 & 0,1000 & 0,00 & \\
\hline E65 & $\begin{array}{l}\text { Confiabilidade, eficiência do } \\
\text { equipamento global (eeg) (\%) }\end{array}$ & 80 & 95 & 0 & 2 & 0,1000 & 0,00 & \\
\hline E66 & $\begin{array}{l}\text { Taxa de reclamações do } \\
\text { cliente (unidades / unidade } \\
\text { tempo) }\end{array}$ & 10 & 1 & 1 & 2 & 0,1000 & 0,02 & \\
\hline E71 & $\begin{array}{l}\text { Grau de clareza do } \\
\text { planejamento estratégico }\end{array}$ & 70 & 95 & 0 & 1 & 0,0891 & 0,00 & \\
\hline E72 & $\begin{array}{l}\text { № de subordinados por } \\
\text { supervisor }\end{array}$ & 10 & 5 & 1 & 1 & 0,0891 & 0,01 & \\
\hline E73 & № da estrutura de organização & 5 & 3 & 1 & 1 & 0,0891 & 0,01 & \\
\hline E74 & $\begin{array}{l}\text { Grau ou porcentagem (\%) de } \\
\text { liderança }\end{array}$ & 70 & 95 & 0 & 1 & 0,0891 & 0,00 & \\
\hline E75 & $\begin{array}{l}\text { Porcentagem (\%) para acesso } \\
\text { ao pessoal qualificado }\end{array}$ & 30 & 80 & 0 & 1 & 0,0891 & 0,00 & \\
\hline E76 & $\begin{array}{l}\text { Porcentagem (\%) de } \\
\text { entendimento de culturas } \\
\text { estrangeiras }\end{array}$ & 70 & 90 & 0 & 1 & 0,0891 & 0,00 & \\
\hline
\end{tabular}

\section{b) Resultados obtidos no aspecto social}

As principais questões da dimensão social levantados no trabalho de Garbie (2014) são: gestão do trabalho; direitos humanos; compromissos sociais; questões dos clientes e; práticas comerciais.

A avaliação do resultado obtido indica que o valor da sustentabilidade do aspecto econômico está 9,5 vezes fora do valor esperado que é 1, levando a conclusão que existe a necessidade de algum empenho (tempo, custo, recurso e outros) nos aspectos econômico, ambiental e social, para colocá-lo no nível de sustentabilidade que se quer alcançar. Em relação aos principais aspectos que foram calculados, os indicadores compromissos sociais e gestão do trabalho representam os parâmetros que envolveram maior empenho, isto é, 35,60 e 2,65, respectivamente. O indicador questões dos clientes com valor 1,28 pode ser considerado dentro do esperado. Os valores indicam que esse empenho foi acima do esperado. Os 
indicadores direitos humanos e práticas comerciais receberam os valores de 0,0116 e 0,2461, respectivamente, indicam que o empenho foi aquém do desejado.

Os dados do trabalho de Garbie (2014) são a seguir utilizados para avaliar a dimensão social da sustentabilidade pelo framework. Consideram-se aqui indicadores e respectivos pesos conforme Tabela 27. Estes dados dos indicadores são transferidos para as colunas 3, 4 e 7 da Tabela 28. Com bases nesses dados o nível de sustentabilidade na dimensão social é calculado e o resultado obtido é $23 \%$, isto é, pelo framework esta empresa não é sustentável neste aspecto. As mesmas adaptações na análise dos dados do aspecto econômico foram feitas neste aspecto.

Tabela 27 - Indicadores relativos à dimensão social e seus pesos (adaptado de GARBIE, 2014)

\begin{tabular}{|c|c|c|c|c|}
\hline $\begin{array}{l}\text { INDI } \\
\text { CA } \\
\text { DOR }\end{array}$ & $\begin{array}{c}\text { PESOS RELATIVOS AOS INDICADORES SOCIAIS DE } \\
\text { SUSTENTABILIDADE }\end{array}$ & $\begin{array}{c}\text { VALOR } \\
\text { MEDIDO (UIJ) }\end{array}$ & $\begin{array}{l}\text { VALOR DE } \\
\left.\text { REFERÊNCIA ( } V_{I J}\right)\end{array}$ & $\begin{array}{l}\text { PESO POR } \\
\text { IMPORTÃNCIA }\end{array}$ \\
\hline S11 & Quantidade de novos empregados por ano & 10 & 30 & 0,1894 \\
\hline S12 & Quantidade de acidentes devido às condições de trabalho & 10 & 1 & 0,1894 \\
\hline S13 & $\begin{array}{l}\text { Grau ou porcentagem (\%) de conversa entre as partes } \\
\text { interessadas }\end{array}$ & 85 & 95 & 0,1894 \\
\hline S14 & Grau ou porcentagem (\%) da segurança social & 80 & 95 & 0,1894 \\
\hline S15 & Quantidade de horas de treinamento / empregado & 10 & 30 & 0,1894 \\
\hline S21 & Grau ou porcentagem (\%) de contratação de crianças & 5 & 1 & 0,3065 \\
\hline S22 & Grau ou porcentagem (\%) de criação de parceria & 70 & 95 & 0,3065 \\
\hline S23 & Grau ou porcentagem (\%) de discriminação & 30 & 2 & 0,3065 \\
\hline S31 & $\begin{array}{l}\text { Grau ou porcentagem (\%) de envolvimento na comunidade } \\
\text { local }\end{array}$ & 75 & 95 & 0,2480 \\
\hline S32 & Média do nível de escolaridade por total de empregado & 50 & 60 & 0,2480 \\
\hline S33 & Grau ou porcentagem (\%) do nível de serviço de saúde & 70 & 85 & 0,2480 \\
\hline S34 & $\begin{array}{l}\text { Quantidade de criação de novos empregos / comunidade } \\
\text { local }\end{array}$ & 150 & 250 & 0,2480 \\
\hline S35 & $\begin{array}{l}\text { Grau ou porcentagem (\%) do orçamento anual ao } \\
\text { investimento na sociedade }\end{array}$ & 3 & 10 & 0,2480 \\
\hline S36 & $\begin{array}{l}\text { Grau ou porcentagem (\%) de tecnologia e cultura em } \\
\text { relação à sociedade }\end{array}$ & 15 & 30 & 0,2480 \\
\hline S41 & Grau ou porcentagem (\%) & 85 & 95 & 0,1422 \\
\hline S42 & Grau ou porcentagem (\%) & 95 & 99 & 0,1422 \\
\hline S43 & Grau ou porcentagem (\%) & 85 & 95 & 0,1422 \\
\hline S51 & Grau ou porcentagem (\%) de corrupção & 20 & 5 & 0,1140 \\
\hline S52 & Grau ou porcentagem (\%) & 70 & 85 & 0,1140 \\
\hline
\end{tabular}

\section{c) Resultados obtidos no aspecto ambiental}

As principais questões do aspecto ambiental levantadas no trabalho de Garbie (2014) são: gestão ambiental; uso dos recursos; poluição; periculosidade e; ambiente natural. 
Tabela 28 - Avaliação de sustentabilidade utilizando o framework considerando os indicadores sociais

\begin{tabular}{|c|c|c|c|c|c|c|c|c|}
\hline $\begin{array}{l}\text { INDI } \\
\text { CA } \\
\text { DOR }\end{array}$ & $\begin{array}{l}\text { PESOS RELATIVOS AOS } \\
\text { INDICADORES SOCIAIS DE } \\
\text { SUSTENTABILIDADE }\end{array}$ & $\begin{array}{l}\text { VALOR } \\
\text { MEDIDO } \\
\left(U_{I J}\right)\end{array}$ & $\begin{array}{l}\text { VALOR DE } \\
\text { REFERÊN } \\
\text { CIA }\left(V_{\mathbf{I J}}\right)\end{array}$ & $\begin{array}{l}\text { ÍNDICE } \\
\text { ALCAN } \\
\text { ÇADO }\end{array}$ & $\begin{array}{l}\text { NÍVEL } \\
\text { DE } \\
\text { IMPOR } \\
\text { TÂNCIA }\end{array}$ & $\begin{array}{l}\text { PESO } \\
\text { POR } \\
\text { IMPOR } \\
\text { TÂNCIA }\end{array}$ & $\begin{array}{l}\text { VALOR } \\
\text { DO } \\
\text { ÍNDICE }\end{array}$ & $\begin{array}{l}\text { VALOR } \\
\text { DE } \\
\text { SUSTEN } \\
\text { TABI- } \\
\text { LIDADE }\end{array}$ \\
\hline $\mathrm{S} 11$ & $\begin{array}{l}\text { Quantidade de novos empregados } \\
\text { por ano }\end{array}$ & 10 & 30 & 0 & 3 & 0,1894 & 0,0000 & \multirow{19}{*}{$23 \%$} \\
\hline $\mathrm{S} 12$ & $\begin{array}{l}\text { Quantidade de acidentes devido às } \\
\text { condições de trabalho }\end{array}$ & 10 & 1 & 1 & 3 & 0,1894 & 0,1894 & \\
\hline S13 & $\begin{array}{l}\text { Grau ou porcentagem (\%) de } \\
\text { conversa entre as partes interessadas }\end{array}$ & 85 & 95 & 0 & 3 & 0,1894 & 0,0000 & \\
\hline S14 & $\begin{array}{l}\text { Grau ou porcentagem (\%) da } \\
\text { segurança social }\end{array}$ & 80 & 95 & 0 & 3 & 0,1894 & 0,0000 & \\
\hline S15 & $\begin{array}{l}\text { Quantidade de horas de treinamento / } \\
\text { empregado }\end{array}$ & 10 & 30 & 0 & 3 & 0,1894 & 0,0000 & \\
\hline $\mathrm{S} 21$ & $\begin{array}{l}\text { Grau ou porcentagem (\%) de } \\
\text { contratação de crianças }\end{array}$ & 5 & 1 & 1 & 5 & 0,3065 & 0,3065 & \\
\hline $\mathrm{S} 22$ & $\begin{array}{l}\text { Grau ou porcentagem (\%) de criação } \\
\text { de parceria }\end{array}$ & 70 & 95 & 0 & 5 & 0,3065 & 0,0000 & \\
\hline $\mathrm{S} 23$ & $\begin{array}{l}\text { Grau ou porcentagem (\%) de } \\
\text { discriminação }\end{array}$ & 30 & 2 & 1 & 5 & 0,3065 & 0,3065 & \\
\hline S31 & $\begin{array}{l}\text { Grau ou porcentagem (\%) de } \\
\text { envolvimento na comunidade local }\end{array}$ & 75 & 95 & 0 & 4 & 0,2480 & 0,0000 & \\
\hline S32 & $\begin{array}{l}\text { Média do nível de escolaridade por } \\
\text { total de empregado }\end{array}$ & 50 & 60 & 0 & 4 & 0,2480 & 0,0000 & \\
\hline S33 & $\begin{array}{l}\text { Grau ou porcentagem (\%) do nível de } \\
\text { serviço de saúde }\end{array}$ & 70 & 85 & 0 & 4 & 0,2480 & 0,0000 & \\
\hline S34 & $\begin{array}{l}\text { Quantidade de criação de novos } \\
\text { empregos / comunidade local }\end{array}$ & 150 & 250 & 0 & 4 & 0,2480 & 0,0000 & \\
\hline S35 & $\begin{array}{l}\text { Grau ou porcentagem (\%) do } \\
\text { orçamento anual ao investimento na } \\
\text { sociedade }\end{array}$ & 3 & 10 & 0 & 4 & 0,2480 & 0,0000 & \\
\hline S36 & $\begin{array}{l}\text { Grau ou porcentagem (\%) de } \\
\text { tecnologia e cultura em relação à } \\
\text { sociedade }\end{array}$ & 15 & 30 & 0 & 4 & 0,2480 & 0,0000 & \\
\hline S41 & Grau ou porcentagem (\%) & 85 & 95 & 0 & 2 & 0,1422 & 0,1422 & \\
\hline S42 & Grau ou porcentagem (\%) & 95 & 99 & 0 & 2 & 0,1422 & 0,0000 & \\
\hline S43 & Grau ou porcentagem (\%) & 85 & 95 & 0 & 2 & 0,1422 & 0,0000 & \\
\hline S51 & $\begin{array}{l}\text { Grau ou porcentagem (\%) de } \\
\text { corrupção }\end{array}$ & 20 & 5 & 1 & 1 & 0,1140 & 0,0000 & \\
\hline S52 & Grau ou porcentagem (\%) & 70 & 85 & 0 & 1 & 0,1140 & 0,0000 & \\
\hline
\end{tabular}

A avaliação do resultado obtido indica que o valor da sustentabilidade do aspecto ambiental está 7,35 vezes fora do valor esperado, que é 1, levando a conclusão que existe a necessidade de algum empenho (tempo, custo, recurso e outros) nos aspectos econômico, ambiental e social, para colocá-lo no nível de sustentabilidade que se quer alcançar. Em relação aos principais aspectos que foram calculados, os indicadores uso dos recursos e gestão ambiental representam os parâmetros que envolveram maior empenho, isto é, 44,95 e 2,56, respectivamente. Os indicadores poluição, periculosidade e ambiente natural alcançaram os valores de 
$0,0003,0,0082$ e 0,0267 , respectivamente, indicam que o empenho foi aquém do desejado.

Os dados do trabalho de Garbie (2014) são a seguir utilizados para avaliar a dimensão ambiental da sustentabilidade pelo framework.

Consideram-se aqui indicadores e respectivos pesos conforme Tabela 29. Estes dados dos indicadores são transferidos para as colunas 3, 4 e 7 da Tabela 30. Com base nesses dados o nível de sustentabilidade na dimensão ambiental é calculado e o resultado obtido é $50 \%$, isto é, pelo framework esta empresa não é sustentável neste aspecto. Consideraram-se as adaptações já adotadas anteriormente.

\section{d) Resultados obtidos no aspecto ambiental}

As principais questões do aspecto ambiental levantadas no trabalho de Garbie (2014) são: gestão ambiental; uso dos recursos; poluição; periculosidade e; ambiente natural.

A avaliação do resultado obtido indica que o valor da sustentabilidade do aspecto ambiental está 7,35 vezes fora do valor esperado, que é 1, levando a conclusão que existe a necessidade de algum empenho (tempo, custo, recurso e outros) nos aspectos econômico, ambiental e social, para colocá-lo no nível de sustentabilidade que se quer alcançar. Em relação aos principais aspectos que foram calculados, os indicadores uso dos recursos e gestão ambiental representam os parâmetros que envolveram maior empenho, isto é, 44,95 e 2,56, respectivamente. Os indicadores poluição, periculosidade e ambiente natural alcançaram os valores de $0,0003,0,0082$ e 0,0267 , respectivamente, indicam que o empenho foi aquém do desejado.

Os dados do trabalho de Garbie (2014) são a seguir utilizados para avaliar a dimensão ambiental da sustentabilidade pelo framework.

Consideram-se aqui indicadores e respectivos pesos conforme Tabela 29. Estes dados dos indicadores são transferidos para as colunas 3, 4 e 7 da Tabela 30. Com base nesses dados o nível de sustentabilidade na dimensão ambiental é calculado e o resultado obtido é $50 \%$, isto é, pelo framework esta empresa não é sustentável neste aspecto. Consideraram-se as adaptações já adotadas anteriormente. 
Para elaborar o quadro resumo dos dados, seguem as Tabelas 31 e 32 . Como Garbie (2014) não considera o aspecto "Tecnológico" na avaliação da sustentabilidade assume-se aqui que este aspecto tem a mesma importância que os outros aspectos (Tabela 31), porém o seu valor é zero (0) (Tabela 32).

Tabela 29 - Indicadores relativos à dimensão ambiental e seus pesos (adaptado de GARBIE, 2014)

\begin{tabular}{|c|c|c|c|c|}
\hline $\begin{array}{l}\text { INDI } \\
\text { CA } \\
\text { DOR }\end{array}$ & $\begin{array}{c}\text { PESOS RELATIVOS AOS INDICADORES AMBIENTAIS DE } \\
\text { SUSTENTABILIDADE }\end{array}$ & $\begin{array}{l}\text { VALOR } \\
\text { MEDIDO }\left(U_{I J}\right)\end{array}$ & $\begin{array}{l}\text { VALOR DE } \\
\text { REFERÊNCIA }\left(V_{I J}\right)\end{array}$ & $\begin{array}{l}\text { PESO POR } \\
\text { IMPORTÃNCIA }\end{array}$ \\
\hline N11 & Unidades monetárias (custo para conformidade com EHS) & 1500 & 2500 & 0,3997 \\
\hline N12 & Grau ou porcentagem (\%) segue a conformidade ISO14001 & 60 & 95 & 0,3997 \\
\hline N13 & Grau ou porcentagem (\%) de avaliação de impacto ambiental & 80 & 95 & 0,3997 \\
\hline N14 & Quantidade de acidentes ambientais por ano & 5 & 0.50 & 0,3997 \\
\hline N21 & $\begin{array}{l}\text { Grau ou porcentagem (\%) de usar energia renovável / energia } \\
\text { total }\end{array}$ & 5 & 15 & 0,1405 \\
\hline N22 & $\begin{array}{l}\text { Grau ou porcentagem (\%) de usar água reciclada / consumo } \\
\text { total de água }\end{array}$ & 20 & 50 & 0,1405 \\
\hline N23 & $\begin{array}{l}\text { Grau ou porcentagem (\%) de usar resíduos reciclados / } \\
\text { resíduos totais }\end{array}$ & 50 & 50 & 0,1405 \\
\hline N31 & $\begin{array}{l}\text { Kg de gases (por exemplo, emissão de dióxido de carbono no } \\
\text { ar) }\end{array}$ & 30 & 5 & 0,1005 \\
\hline N32 & Kg de partículas & 50 & 5 & 0,1005 \\
\hline N33 & $\mathrm{Kg}$ e/ou $\mathrm{m}^{3}$ de partículas necessárias para aterrar & 50 & 15 & 0,1005 \\
\hline N41 & $\mathrm{Kg} \mathrm{e/ou} \mathrm{m}^{3}$ de materiais perigosos & 15 & 5 & 0,1509 \\
\hline N42 & $\mathrm{Kg}$ e/ou $\mathrm{m}^{3}$ de materiais perigosos & 10 & 1 & 0,1509 \\
\hline N43 & $\mathrm{Kg}$ e/ou $\mathrm{m}^{3}$ de resíduos perigosos & 5 & 0.50 & 0,1509 \\
\hline N51 & Nível de porcentagem (\%) de dióxido de carbono na atmosfera & 30 & 5 & 0,2084 \\
\hline N52 & Grau ou porcentagem (\%) da saúde dos ecossistemas & 80 & 95 & 0,2084 \\
\hline N53 & $\mathrm{M}^{2}$ de terra utilizados para a planta & 20000 & 10000 & 0,2084 \\
\hline N54 & $\begin{array}{l}\text { Porcentagem }(\%) \text { do orçamento anual para investimento em } \\
\text { áreas rurais }\end{array}$ & 2 & 10 & 0,2084 \\
\hline
\end{tabular}

Tabela 30 - Avaliação de sustentabilidade utilizando o framework considerando os indicadores ambientais

\begin{tabular}{|c|c|c|c|c|c|c|c|c|}
\hline $\begin{array}{c}\text { INDICA } \\
\text { DOR }\end{array}$ & $\begin{array}{c}\text { PESOS RELATIVOS AOS } \\
\text { INDICADORES AMBINETAIS DE } \\
\text { SUSTENTABILIDADE }\end{array}$ & $\begin{array}{l}\text { VALOR } \\
\text { MEDI } \\
\text { DO (UIJ) }\end{array}$ & $\begin{array}{l}\text { VALOR } \\
\text { DE REFE } \\
\text { RÊNCIA } \\
\left(V_{I J}\right)\end{array}$ & $\begin{array}{l}\text { ÍNDICE } \\
\text { ALCAN } \\
\text { ÇADO }\end{array}$ & $\begin{array}{l}\text { NÍVEL } \\
\text { DE } \\
\text { IMPOR } \\
\text { TÂNCIA }\end{array}$ & $\begin{array}{l}\text { PESO } \\
\text { POR } \\
\text { IMPOR } \\
\text { TÂNCIA }\end{array}$ & $\begin{array}{l}\text { VALOR } \\
\text { DO } \\
\text { ÍNDICE }\end{array}$ & $\begin{array}{l}\text { VALOR } \\
\text { DE } \\
\text { SUSTEN } \\
\text { TABI- } \\
\text { LIDADE }\end{array}$ \\
\hline N11 & $\begin{array}{l}\text { Unidades monetárias (custo para } \\
\text { conformidade com EHS) }\end{array}$ & 1500 & 2500 & 0 & 5 & 0,3997 & 0,00 & \multirow{4}{*}{$50 \%$} \\
\hline N12 & $\begin{array}{l}\text { Grau ou porcentagem (\%) segue a } \\
\text { conformidade ISO14001 }\end{array}$ & 60 & 95 & 0 & 5 & 0,3997 & 0,00 & \\
\hline N13 & $\begin{array}{l}\text { Grau ou porcentagem (\%) de avaliação de } \\
\text { impacto ambiental }\end{array}$ & 80 & 95 & 0 & 5 & 0,3997 & 0,00 & \\
\hline N14 & $\begin{array}{l}\text { Quantidade de acidentes ambientais por } \\
\text { ano }\end{array}$ & 5 & 0.50 & 1 & 5 & 0,3997 & 0,40 & \\
\hline
\end{tabular}


Tabela 30 - Avaliação de sustentabilidade utilizando o framework considerando os indicadores ambientais (continuação)

\begin{tabular}{|c|c|c|c|c|c|c|c|c|}
\hline $\begin{array}{c}\text { INDICA } \\
\text { DOR }\end{array}$ & $\begin{array}{l}\text { PESOS RELATIVOS AOS } \\
\text { INDICADORES AMBINETAIS DE } \\
\text { SUSTENTABILIDADE }\end{array}$ & $\begin{array}{l}\text { VALOR } \\
\text { MEDI } \\
\text { DO } \\
\left(U_{\mathrm{IJ}}\right)\end{array}$ & $\begin{array}{l}\text { VALOR } \\
\text { DE REFE } \\
\text { RÊNCIA } \\
\left(V_{I J}\right)\end{array}$ & $\begin{array}{l}\text { ÍNDICE } \\
\text { ALCAN } \\
\text { ÇADO }\end{array}$ & $\begin{array}{l}\text { NÍVEL } \\
\text { DE } \\
\text { IMPOR } \\
\text { TÂNCIA }\end{array}$ & $\begin{array}{l}\text { PESO } \\
\text { POR } \\
\text { IMPOR } \\
\text { TÂNCIA }\end{array}$ & $\begin{array}{l}\text { VALOR } \\
\text { DO } \\
\text { ÍNDICE }\end{array}$ & $\begin{array}{l}\text { VALOR } \\
\text { DE } \\
\text { SUSTEN } \\
\text { TABILI } \\
\text { DADE }\end{array}$ \\
\hline N21 & $\begin{array}{l}\text { Grau ou porcentagem (\%) de usar energia } \\
\text { renovável / energia total }\end{array}$ & 5 & 15 & 0 & 2 & 0,1405 & 0,00 & \\
\hline N22 & $\begin{array}{l}\text { Grau ou porcentagem (\%) de usar água } \\
\text { reciclada / consumo total de água }\end{array}$ & 20 & 50 & 0 & 2 & 0,1405 & 0,00 & \\
\hline N23 & $\begin{array}{l}\text { Grau ou porcentagem (\%) de usar resíduos } \\
\text { reciclados / resíduos totais }\end{array}$ & 50 & 50 & 1 & 2 & 0,1405 & 0,14 & \\
\hline N31 & $\begin{array}{l}\mathrm{Kg} \text { de gases (por exemplo, emissão de } \\
\text { dióxido de carbono no ar) }\end{array}$ & 30 & 5 & 1 & 1 & 0,1005 & 0,10 & \\
\hline N32 & Kg de partículas & 50 & 5 & 1 & 1 & 0,1005 & 0,10 & \\
\hline N33 & $\begin{array}{l}\mathrm{Kg} \text { e/ou } \mathrm{m}^{3} \text { de partículas necessárias para } \\
\text { aterrar }\end{array}$ & 50 & 15 & 1 & 1 & 0,1005 & 0,10 & \\
\hline N41 & $\mathrm{Kg} \mathrm{e/ou} \mathrm{m}^{3}$ de materiais perigosos & 15 & 5 & 1 & 3 & 0,1509 & 0,15 & \\
\hline N42 & $\mathrm{Kg} \mathrm{e/ou} \mathrm{m}^{3}$ de materiais perigosos & 10 & 1 & 1 & 3 & 0,1509 & 0,15 & \\
\hline N43 & $\mathrm{Kg}$ e/ou $\mathrm{m}^{3}$ de resíduos perigosos & 5 & 0.50 & 1 & 3 & 0,1509 & 0,15 & \\
\hline N51 & $\begin{array}{l}\text { Nível de porcentagem (\%) de dióxido de } \\
\text { carbono na atmosfera }\end{array}$ & 30 & 5 & 1 & 4 & 0,2084 & 0,21 & \\
\hline N52 & $\begin{array}{l}\text { Grau ou porcentagem (\%) da saúde dos } \\
\text { ecossistemas }\end{array}$ & 80 & 95 & 0 & 4 & 0,2084 & 0,00 & \\
\hline N53 & $\mathrm{M}^{2}$ de terra utilizados para a planta & 20000 & 10000 & 1 & 4 & 0,2084 & 0,21 & \\
\hline N54 & $\begin{array}{l}\text { Porcentagem (\%) do orçamento anual para } \\
\text { investimento em áreas rurais }\end{array}$ & 2 & 10 & 0 & 4 & 0,2084 & 0,00 & \\
\hline
\end{tabular}

Usando o framework apresenta-se os dados na forma de percentuais de modo que o avaliador pode ter uma ideia de quão fora o indicador está do valor esperado. O resultado final mostrando todos os aspectos correlacionados é mostrado nas Tabelas 31 e 32 e graficamente na Figura 25. O resultado final do índice de sustentabilidade do sistema como um todo é $25 \%$, isto é, ele não é sustentável.

Tabela 31 - Entrada de peso de cada aspecto de sustentabilidade e sua influência

\begin{tabular}{c|ccccc} 
PESO ESCOLHIDO & ECONÔMICO & AMBIENTAL & SOCIAL & TECNOLÓGICO & TOTAL \\
\hline NÍVEL DE IMPORTÂNCIA & $\mathbf{5}$ & $\mathbf{5}$ & $\mathbf{5}$ & $\mathbf{5}$ & $\mathbf{1 2}$ \\
PESO POR IMPORTÂNCIA & $\mathbf{2 5 \%}$ & $\mathbf{2 5 \%}$ & $\mathbf{2 5 \%}$ & $\mathbf{2 5 \%}$ & $\mathbf{1 0 0 \%}$
\end{tabular}

Tabela 32 - Resultado da avaliação de sustentabilidade

\begin{tabular}{|c|c|c|c|c|c|c|}
\hline ITEM & ECONÔMICO & AMBIENTAL & SOCIAL & TECNOLÓGICO & RESULTADO & LIMITE \\
\hline PESO & $25 \%$ & $25 \%$ & $25 \%$ & $25 \%$ & & \\
\hline ÍNDICES & $28 \%$ & $50 \%$ & $23 \%$ & $0 \%$ & & \\
\hline AVALIAÇÃOO DO IIPS & & & & & $0 \%$ & \\
\hline AVALIAÇÃO DE SUSTENTABILIDADE & & & & & $25 \%$ & \\
\hline LIMITE DE SUSTENTABILIDADE & & & & & & $100 \%$ \\
\hline
\end{tabular}


Figura 25 - Resultado da avaliação de sustentabilidade.

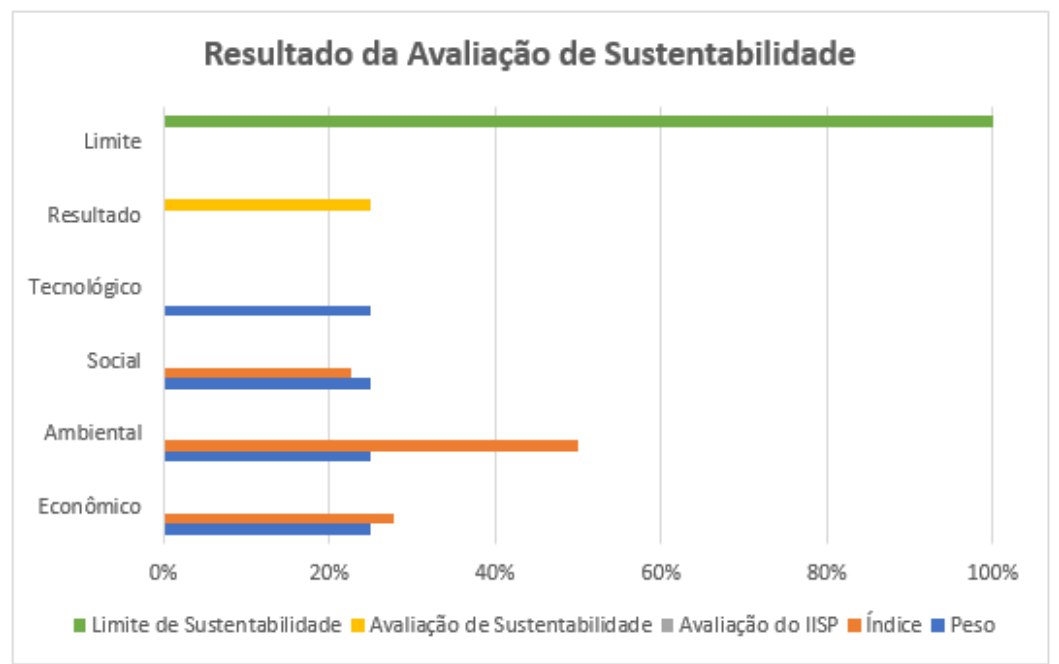

Fonte: $\mathrm{O}$ autor

\subsubsection{Sustentabilidade no ciclo de vida do produto}

Jayal et al. (2010) propuseram um procedimento de avaliação do ciclo de vida (LCA) do produto para quantificar o impacto ambiental e econômico geral, em termos de consumo de material e energia, dióxido de carbono, etc. O ciclo de vida de um produto neste caso é desde a extração de matéria prima até o descarte do produto que seria o final de sua vida.

Considerando os dados apresentados em Jayal et al. (2010) Tabela 33, o framework é aqui aplicado em cada estágio do ciclo de vida do produto considerando os quatro aspectos da sustentabilidade: econômico, ambiental, social e tecnológico. Assim, as Tabelas 34 a 36 correspondem a fase de "pré-fabricação", as Tabelas 37 a 39 a fase de "fabricação", as Tabelas 40 a 42 a fase de "uso" e, as Tabelas 43 a 45 a fase de "pós-uso". Os valores de referência foram definidos com um limite de nível de 0 a 10 para todos os indicadores de cada estágio. O nível de importância de cada indicador também foi aqui estabelecido levando-se em conta os tipos de dados apresentados. O método de Jayal et al. (2010) aplica um fator de influência dos indicadores envolvidos entre os valores de 1 a 10 . Os resultados são obtidos por meio de cálculo de médias aritméticas dos indicadores e consequentemente dos resultados para a obtenção do nível de sustentabilidade de cada aspecto e em cada e também em todo o ciclo. 
Os dados usados como entrada para o sistema proposto são os valores medidos/coletados do processo. As Tabelas 46 a 50 mostram os resultados finais da avaliação e as Figuras 26 a 30 mostram os resultados em formato gráfico.

Os cálculos no framework baseiam-se em dois pontos: (i) na relevância dos indicadores de modo que são designados pesos para cada indicador onde se libera o avaliador para classificar os indicadores pela importância de suas influências; (ii) na definição do limite para o nível de sustentabilidade aceitável, de modo a tornar mais clara a relação dos valores medidos em relação a um valor desejado. Estes dois pontos asseguram a possibilidade de refinar a avaliação quando necessário. Assim, neste exemplo, o framework foi adaptado para testar os valores dos indicadores fornecidos.

Tabela 33 - Avaliação de sustentabilidade considerando o ciclo de vida do produto (adaptado de JAYAL et al., 2010)

FATORES DE INFLUÊNCIAS NOS ESTÁGIOS DO CICLO DE VIDA DO PRODUTO

\begin{tabular}{|c|c|c|c|c|c|c|c|c|c|c|}
\hline $\begin{array}{l}\text { ASPEC } \\
\text { TOS }\end{array}$ & $\begin{array}{c}\text { Pré- } \\
\text { fabricacão }\end{array}$ & & Fabricação & & Uso & & Pós-Uso & & & \\
\hline & & $\begin{array}{c}\text { Pontua } \\
\text { ção até } \\
10\end{array}$ & & $\begin{array}{c}\text { Pontua } \\
\text { ção até } \\
10\end{array}$ & & $\begin{array}{c}\text { Pontua } \\
\text { ção até } \\
10\end{array}$ & & $\begin{array}{c}\text { Pontua } \\
\text { ção até } \\
10\end{array}$ & & \\
\hline \multirow{5}{*}{$\begin{array}{l}\text { AMBI } \\
\text { ENTAL }\end{array}$} & $\begin{array}{l}\text { Extração } \\
\text { de Material }\end{array}$ & 7 & $\begin{array}{l}\text { Energia } \\
\text { Usada na } \\
\text { Produção }\end{array}$ & 7 & Emissões & 9 & Reciclabilidade & 7 & \multirow{5}{*}{\multicolumn{2}{|c|}{ PPSI $_{e m} \quad \mathbf{7 7 , 3}$}} \\
\hline & $\begin{array}{l}\text { Projeto } \\
\text { para o } \\
\text { Meio } \\
\text { Ambiente }\end{array}$ & 8 & $\begin{array}{l}\text { Resíduo } \\
\text { Perigoso } \\
\text { Produzido }\end{array}$ & 9 & $\begin{array}{l}\text { Funcional } \\
\text { idade }\end{array}$ & 8 & $\begin{array}{l}\text { Refabricabilida } \\
\text { de }\end{array}$ & 8 & & \\
\hline & $\begin{array}{l}\text { Processam } \\
\text { ento de } \\
\text { Material }\end{array}$ & 6 & $\begin{array}{l}\text { Uso de } \\
\text { Energia } \\
\text { Renovado }\end{array}$ & 8 & $\begin{array}{l}\text { Resíduos } \\
\text { Perigosos } \\
\text { Gerados }\end{array}$ & 9 & Reprojeto & 7 & & \\
\hline & & & & & & & $\begin{array}{l}\text { Contribuição de } \\
\text { Aterro Sanitário }\end{array}$ & 7 & & \\
\hline & $P S I_{\left(e n \_p m\right)}$ & 70 & $P S I_{\left(e n \_m\right)}$ & 80 & $P S I_{\left(e n \_u\right)}$ & 86,7 & $P S I_{\left(e n \_p u\right)}$ & 72,5 & & \\
\hline \multirow{5}{*}{$\begin{array}{l}\text { SOCl } \\
\mathrm{AL}\end{array}$} & $\begin{array}{l}\text { Saúde do } \\
\text { Trabalhad } \\
\text { or }\end{array}$ & 8 & $\begin{array}{l}\text { Ética no } \\
\text { Trabalho }\end{array}$ & 7 & $\begin{array}{l}\text { Preço dos } \\
\text { Produtos }\end{array}$ & 7 & $\begin{array}{l}\text { Opções de } \\
\text { Recompra }\end{array}$ & 7 & \multirow{5}{*}{$P P S I_{s o}$} & \multirow{5}{*}{73,5} \\
\hline & $\begin{array}{l}\text { Segurança } \\
\text { no } \\
\text { Trabalho }\end{array}$ & 8 & Ergonomia & 7 & $\begin{array}{l}\text { Seguranç } \\
\text { a das } \\
\text { Pessoas }\end{array}$ & 9 & Reuso & 6 & & \\
\hline & Ergonomia & 7 & $\begin{array}{l}\text { Segurança } \\
\text { no Trabalho }\end{array}$ & 8 & $\begin{array}{l}\text { Atualizáv } \\
\text { eis }\end{array}$ & 7 & Recuperação & 7 & & \\
\hline & & & & & $\begin{array}{l}\text { Reclamaç } \\
\text { ões }\end{array}$ & 8 & & & & \\
\hline & $P S I_{\left(s o \_p m\right)}$ & 76,7 & $P S I_{\left(s o \_m\right)}$ & 73,3 & $P S I_{\left(s o \_u\right)}$ & 77,5 & $P S I_{(\text {so_pu })}$ & 66,7 & & \\
\hline
\end{tabular}


Tabela 33 - Avaliação de sustentabilidade considerando o ciclo de vida do produto (adaptado de JAYAL et al., 2010) (continuação)

FATORES DE INFLUÊNCIAS NOS ESTÁGIOS DO CICLO DE VIDA DO PRODUTO

\begin{tabular}{|c|c|c|c|c|c|c|c|c|c|c|}
\hline \multirow[t]{2}{*}{$\begin{array}{l}\text { ASPECT } \\
\text { OS }\end{array}$} & $\begin{array}{c}\text { Pré- } \\
\text { fabricação }\end{array}$ & & Fabricação & & Uso & & Pós-Uso & & & \\
\hline & & $\begin{array}{c}\text { Pont } \\
\text { uaçã } \\
\text { o até } \\
10\end{array}$ & & $\begin{array}{c}\text { Pontua } \\
\text { ção até } \\
10\end{array}$ & & $\begin{array}{c}\text { Pontua } \\
\text { ção até } \\
10\end{array}$ & & $\begin{array}{c}\text { Pontua } \\
\text { ção até } \\
10\end{array}$ & & \\
\hline \multirow[t]{5}{*}{$\begin{array}{l}\text { ECO } \\
\text { NÔMI Co }\end{array}$} & $\begin{array}{l}\text { Custo de } \\
\text { Matéria } \\
\text { Prima }\end{array}$ & 6 & $\begin{array}{l}\text { Custo na } \\
\text { Produção }\end{array}$ & 6 & $\begin{array}{l}\text { Custo de } \\
\text { Manutenç } \\
\text { ão }\end{array}$ & 7 & $\begin{array}{l}\text { Custo de } \\
\text { Reciclagem }\end{array}$ & 7 & $P P S I_{e c}$ & 61,3 \\
\hline & $\begin{array}{l}\text { Custo do } \\
\text { Trabalhado } \\
r\end{array}$ & 3 & $\begin{array}{l}\text { Custo de } \\
\text { Embalagem }\end{array}$ & 7 & $\begin{array}{l}\text { Custo de } \\
\text { Reparo }\end{array}$ & 6 & $\begin{array}{l}\text { Custo de } \\
\text { Desmontagem }\end{array}$ & 8 & & \\
\hline & & & $\begin{array}{l}\text { Custo de } \\
\text { Energia }\end{array}$ & 8 & $\begin{array}{l}\text { Custo } \\
\text { com } \\
\text { Acidentes } \\
\text { do } \\
\text { Consumid } \\
\text { or }\end{array}$ & 8 & $\begin{array}{l}\text { Custo de } \\
\text { Descarte }\end{array}$ & 4 & & \\
\hline & & & $\begin{array}{l}\text { Custo de } \\
\text { Transporte }\end{array}$ & 5 & $\begin{array}{l}\text { Custo de } \\
\text { Garantia } \\
\text { do } \\
\text { Consumid } \\
\text { or }\end{array}$ & 7 & $\begin{array}{l}\text { Custo de } \\
\text { Refabricação }\end{array}$ & 7 & & \\
\hline & $P S I_{\left(e c \_p m\right)}$ & 45,0 & $P S I_{\left(e c \_m\right)}$ & 65,0 & $P S I_{\left(e c \_u\right)}$ & 70,0 & $P S I_{\left(e c \_p u\right)}$ & 65,0 & & \\
\hline
\end{tabular}

Para os níveis de importância dos indicadores usou-se a seguinte conversão: se o fator de influência for 1 ou 2 recebe importância 1; para 3 ou 4 recebe 2; para 5 ou 6 recebe 3; para 7 ou 8 recebe 4 e para 9 ou 10 recebe 5 .

Este exemplo mostra como o framework pode ser utilizado para calcular a sustentabilidade em cada estágio do ciclo de vida do produto.

Tabela 34 - Avaliação de sustentabilidade na "pré-fabricação" utilizando o framework considerando os indicadores ambientais

\begin{tabular}{|c|c|c|c|c|c|c|c|c|}
\hline \multirow{2}{*}{$\begin{array}{l}\text { INDICADOR } \\
\text { AMBIENTAL }\end{array}$} & \multirow{2}{*}{ UNIDADE } & \multicolumn{2}{|c|}{$\begin{array}{c}\text { MEDIDA DE } \\
\text { DESEMPENHO }\end{array}$} & \multirow{2}{*}{$\begin{array}{l}\text { ALCAN } \\
\text { ÇADO }\end{array}$} & \multirow{2}{*}{$\begin{array}{l}\text { NÍVEL DE } \\
\text { IMPOR } \\
\text { TÂNCIA }\end{array}$} & \multirow{2}{*}{$\begin{array}{c}\text { PESO POR } \\
\text { IMPOR } \\
\text { TÂNCIA }\end{array}$} & \multirow{2}{*}{$\begin{array}{l}\text { VALOR } \\
\text { DO } \\
\text { ÍNDICE }\end{array}$} & \multirow{2}{*}{$\begin{array}{c}\text { VALOR DE } \\
\text { SUSTENTABILI } \\
\text { DADE }\end{array}$} \\
\hline & & $\begin{array}{l}\text { Valor } \\
\text { Medido }\end{array}$ & $\begin{array}{c}\text { Valor de } \\
\text { Referência }\end{array}$ & & & & & \\
\hline N1 & $\begin{array}{l}\text { Extração de } \\
\text { Material }\end{array}$ & 7 & 10 & 1 & 4 & 0,36 & 0,36 & \\
\hline N2 & $\begin{array}{l}\text { Projeto para o } \\
\text { Meio Ambiente }\end{array}$ & 8 & 10 & 1 & 4 & 0,36 & 0,36 & $73 \%$ \\
\hline \multirow[t]{2}{*}{ N3 } & $\begin{array}{l}\text { Processamento } \\
\text { de Material }\end{array}$ & 6 & 10 & 0 & 3 & 0,27 & 0,00 & \\
\hline & & & & $P S I_{\left(a m \_p f\right)}$ & & & 0,73 & \\
\hline
\end{tabular}


Tabela 35 - Avaliação de sustentabilidade na "pré-fabricação" utilizando o framework considerando os indicadores sociais

\begin{tabular}{|c|c|c|c|c|c|c|c|c|}
\hline \multirow{2}{*}{$\begin{array}{l}\text { INDICADOR } \\
\text { SOCIAL }\end{array}$} & \multirow{2}{*}{ UNIDADE } & \multicolumn{2}{|c|}{$\begin{array}{c}\text { MEDIDA DE } \\
\text { DESEMPENHO }\end{array}$} & \multirow{2}{*}{$\begin{array}{l}\text { ALCAN } \\
\text { ÇADO }\end{array}$} & \multirow{2}{*}{$\begin{array}{l}\text { NÍVEL DE } \\
\text { IMPORTÂN } \\
\text { CIA }\end{array}$} & \multirow{2}{*}{$\begin{array}{c}\text { PESO POR } \\
\text { IMPORTÂN } \\
\text { CIA }\end{array}$} & \multirow{2}{*}{$\begin{array}{c}\text { VALOR } \\
\text { DO } \\
\text { ÍNDICE }\end{array}$} & \multirow{2}{*}{$\begin{array}{c}\text { VALOR DE } \\
\text { SUSTENTABILI } \\
\text { DADE }\end{array}$} \\
\hline & & $\begin{array}{l}\text { Valor } \\
\text { Medido }\end{array}$ & $\begin{array}{c}\text { Valor de } \\
\text { Referência }\end{array}$ & & & & & \\
\hline S1 & $\begin{array}{l}\text { Saúde do } \\
\text { Trabalhador }\end{array}$ & 8 & 10 & 1 & 4 & 0,33 & 0,33 & \multirow{3}{*}{$100 \%$} \\
\hline S2 & $\begin{array}{l}\text { Segurança no } \\
\text { Trabalho }\end{array}$ & 8 & 10 & 1 & 4 & 0,33 & 0,33 & \\
\hline \multirow[t]{2}{*}{ S3 } & Ergonomia & 7 & 10 & 1 & 4 & 0,33 & 0,33 & \\
\hline & & & & $P S I_{\left(s o \_p f\right)}$ & & & 1,00 & \\
\hline
\end{tabular}

Tabela 36 - Avaliação de sustentabilidade na "pré-fabricação" utilizando o framework considerando os indicadores econômicos

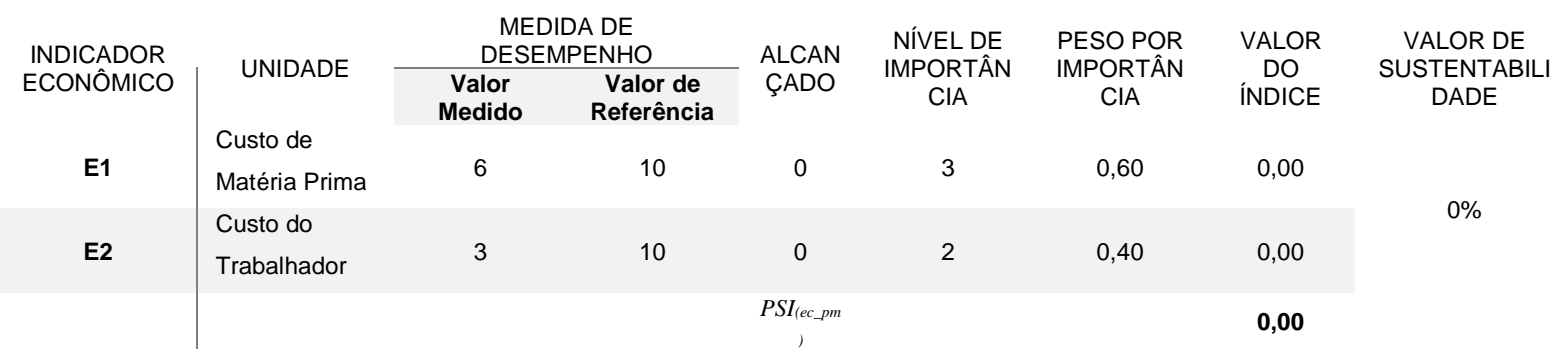

Tabela 37 - Avaliação de sustentabilidade na "fabricação" utilizando o framework considerando os indicadores ambientais

\begin{tabular}{|c|c|c|c|c|c|c|c|c|}
\hline \multirow{2}{*}{$\begin{array}{l}\text { INDICADOR } \\
\text { AMBIENTAL }\end{array}$} & \multirow{2}{*}{ UNIDADE } & \multicolumn{2}{|c|}{$\begin{array}{c}\text { MEDIDA DE } \\
\text { DESEMPENHO }\end{array}$} & \multirow{2}{*}{$\begin{array}{l}\text { ALCAN } \\
\text { ÇADO }\end{array}$} & \multirow{2}{*}{$\begin{array}{l}\text { NÍVEL DE } \\
\text { IMPORTÂN } \\
\text { CIA }\end{array}$} & \multirow{2}{*}{$\begin{array}{l}\text { PESO POR } \\
\text { IMPORTÂN } \\
\text { CIA }\end{array}$} & \multirow{2}{*}{$\begin{array}{l}\text { VALOR } \\
\text { DO } \\
\text { ÍNDICE }\end{array}$} & \multirow{2}{*}{$\begin{array}{l}\text { VALOR DE } \\
\text { SUSTENTABILI } \\
\text { DADE }\end{array}$} \\
\hline & & $\begin{array}{l}\text { Valor } \\
\text { Medido }\end{array}$ & $\begin{array}{l}\text { Valor de } \\
\text { Referência }\end{array}$ & & & & & \\
\hline N1 & $\begin{array}{l}\text { Energia Usada } \\
\text { na Produção }\end{array}$ & 7 & 10 & 1 & 4 & 0,31 & 0,31 & \\
\hline N2 & $\begin{array}{l}\text { Resíduo } \\
\text { Perigoso } \\
\text { Produzido }\end{array}$ & 9 & 10 & 1 & 5 & 0,38 & 0,38 & $100 \%$ \\
\hline \multirow[t]{2}{*}{ N3 } & $\begin{array}{l}\text { Uso de Energia } \\
\text { Renovado }\end{array}$ & 8 & 10 & 1 & 4 & 0,31 & 0,31 & \\
\hline & & & & $P S I_{\left(e n \_m\right)}$ & & & 1,00 & \\
\hline
\end{tabular}

Tabela 38 - Avaliação de sustentabilidade na "fabricação" utilizando o framework considerando os indicadores sociais

\begin{tabular}{|c|c|c|c|c|c|c|c|c|}
\hline \multirow{2}{*}{$\begin{array}{l}\text { INDICADOR } \\
\text { SOCIAL }\end{array}$} & \multirow{2}{*}{ UNIDADE } & \multicolumn{2}{|c|}{$\begin{array}{c}\text { MEDIDA DE } \\
\text { DESEMPENHO }\end{array}$} & \multirow{2}{*}{$\begin{array}{l}\text { ALCAN } \\
\text { ÇADO }\end{array}$} & \multirow{2}{*}{$\begin{array}{l}\text { NÍVEL DE } \\
\text { IMPORTÂN } \\
\text { CIA }\end{array}$} & \multirow{2}{*}{$\begin{array}{l}\text { PESO POR } \\
\text { IMPORTÂN } \\
\text { CIA }\end{array}$} & \multirow{2}{*}{$\begin{array}{l}\text { VALOR } \\
\text { DO } \\
\text { ÍNDICE }\end{array}$} & \multirow{2}{*}{$\begin{array}{c}\text { VALOR DE } \\
\text { SUSTENTABILI } \\
\text { DADE }\end{array}$} \\
\hline & & $\begin{array}{l}\text { Valor } \\
\text { Medido }\end{array}$ & $\begin{array}{c}\text { Valor de } \\
\text { Referência }\end{array}$ & & & & & \\
\hline S1 & $\begin{array}{l}\text { Ética no } \\
\text { Trabalho }\end{array}$ & 7 & 10 & 1 & 4 & 0.33 & 0,33 & \\
\hline S2 & Ergonomia & 7 & 10 & 1 & 4 & 0,33 & 0,33 & $100 \%$ \\
\hline \multirow[t]{2}{*}{ S3 } & $\begin{array}{l}\text { Segurança no } \\
\text { Trabalho }\end{array}$ & 8 & 10 & 1 & 4 & 0,33 & 0,33 & \\
\hline & & & & $P S I_{\left(s o \_m\right)}$ & & & 1,00 & \\
\hline
\end{tabular}


Tabela 39 - Avaliação de sustentabilidade na "fabricação" utilizando o framework considerando os indicadores econômicos

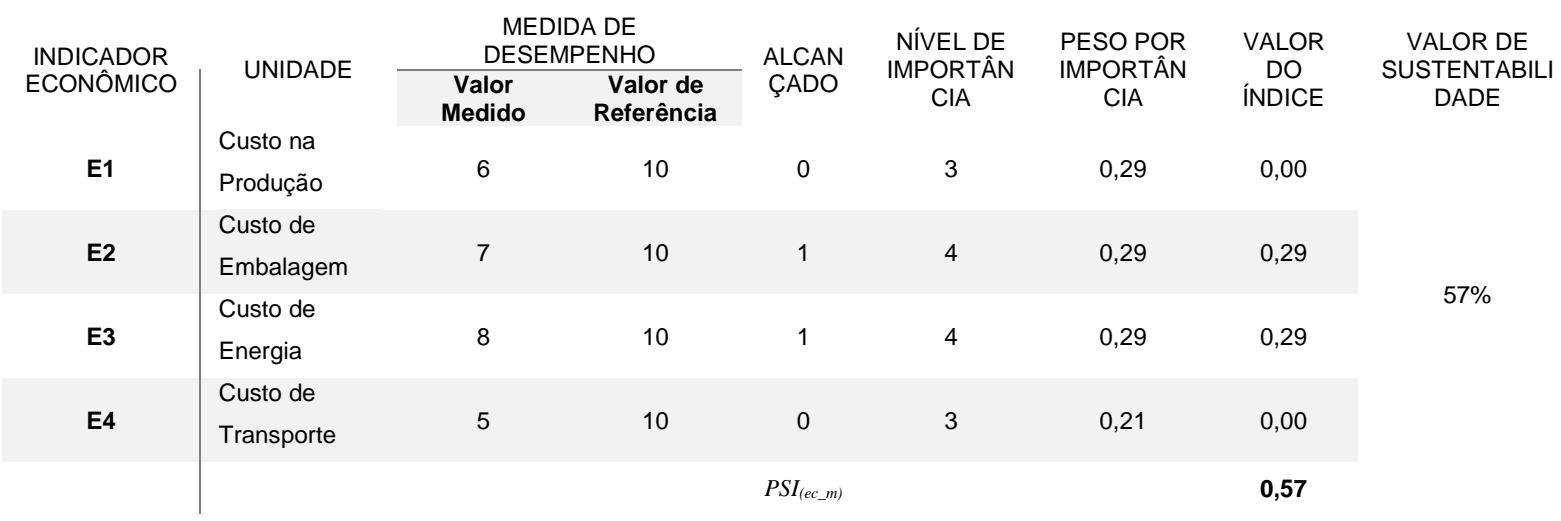

Tabela 40 - Avaliação de sustentabilidade no "uso" utilizando o framework considerando os indicadores ambientais

\begin{tabular}{|c|c|c|c|c|c|c|c|c|}
\hline \multirow{2}{*}{$\begin{array}{l}\text { INDICADOR } \\
\text { AMBIENTAL }\end{array}$} & \multirow{2}{*}{ UNIDADE } & \multicolumn{2}{|c|}{$\begin{array}{c}\text { MEDIDA DE } \\
\text { DESEMPENHO }\end{array}$} & \multirow{2}{*}{$\begin{array}{l}\text { ALCAN } \\
\text { ÇADO }\end{array}$} & \multirow{2}{*}{$\begin{array}{l}\text { NÍVEL DE } \\
\text { IMPORTÂN } \\
\text { CIA }\end{array}$} & \multirow{2}{*}{$\begin{array}{l}\text { PESO POR } \\
\text { IMPORTÂN } \\
\text { CIA }\end{array}$} & \multirow{2}{*}{$\begin{array}{l}\text { VALOR } \\
\text { DO } \\
\text { ÍNDICE }\end{array}$} & \multirow{2}{*}{$\begin{array}{c}\text { VALOR DE } \\
\text { SUSTENTABILI } \\
\text { DADE }\end{array}$} \\
\hline & & $\begin{array}{l}\text { Valor } \\
\text { Medido }\end{array}$ & $\begin{array}{l}\text { Valor de } \\
\text { Referência }\end{array}$ & & & & & \\
\hline N1 & Emissões & 9 & 10 & 1 & 5 & 0,36 & 0,36 & \\
\hline N2 & $\begin{array}{l}\text { Funcionalidad } \\
\text { e }\end{array}$ & 8 & 10 & 1 & 4 & 0,29 & 0,29 & $100 \%$ \\
\hline \multirow[t]{2}{*}{ N3 } & $\begin{array}{l}\text { Resíduos } \\
\text { Perigosos } \\
\text { Gerados }\end{array}$ & 9 & 10 & 1 & 5 & 0,36 & 0,36 & $100 \%$ \\
\hline & & & & $P S I_{(e n u)}$ & & & 1,00 & \\
\hline
\end{tabular}

Tabela 41 - Avaliação de sustentabilidade no "uso" utilizando o framework considerando os indicadores ambientais

\begin{tabular}{|c|c|c|c|c|c|c|c|c|}
\hline \multirow{2}{*}{$\begin{array}{l}\text { INDICADOR } \\
\text { SOCIAL }\end{array}$} & \multirow{2}{*}{ UNIDADE } & \multicolumn{2}{|c|}{$\begin{array}{c}\text { MEDIDA DE } \\
\text { DESEMPENHO }\end{array}$} & \multirow{2}{*}{$\begin{array}{l}\text { ALCAN } \\
\text { ÇADO }\end{array}$} & \multirow{2}{*}{$\begin{array}{l}\text { NÍVEL DE } \\
\text { IMPORTÂN } \\
\text { CIA }\end{array}$} & \multirow{2}{*}{$\begin{array}{c}\text { PESO POR } \\
\text { IMPORTÂN } \\
\text { CIA }\end{array}$} & \multirow{2}{*}{$\begin{array}{l}\text { VALOR } \\
\text { DO } \\
\text { ÍNDICE }\end{array}$} & \multirow{2}{*}{$\begin{array}{c}\text { VALOR DE } \\
\text { SUSTENTABILI } \\
\text { DADE }\end{array}$} \\
\hline & & $\begin{array}{l}\text { Valor } \\
\text { Medido }\end{array}$ & $\begin{array}{c}\text { Valor de } \\
\text { Referência }\end{array}$ & & & & & \\
\hline S1 & $\begin{array}{l}\text { Preço dos } \\
\text { Produtos }\end{array}$ & 7 & 10 & 1 & 4 & 0,24 & 0,24 & \\
\hline S2 & $\begin{array}{l}\text { Segurança } \\
\text { das Pessoas }\end{array}$ & 9 & 10 & 1 & 5 & 0,29 & 0,29 & $100 \%$ \\
\hline S3 & Atualizáveis & 7 & 10 & 1 & 4 & 0,24 & 0,24 & \\
\hline \multirow[t]{2}{*}{ S4 } & Reclamações & 8 & 10 & 1 & 4 & 0,24 & 0,24 & \\
\hline & & & & $P S I_{\left(s o_{-} u\right)}$ & & & 1,00 & \\
\hline
\end{tabular}

Tabela 42 - Avaliação de sustentabilidade no "uso" utilizando o framework considerando os indicadores econômicos

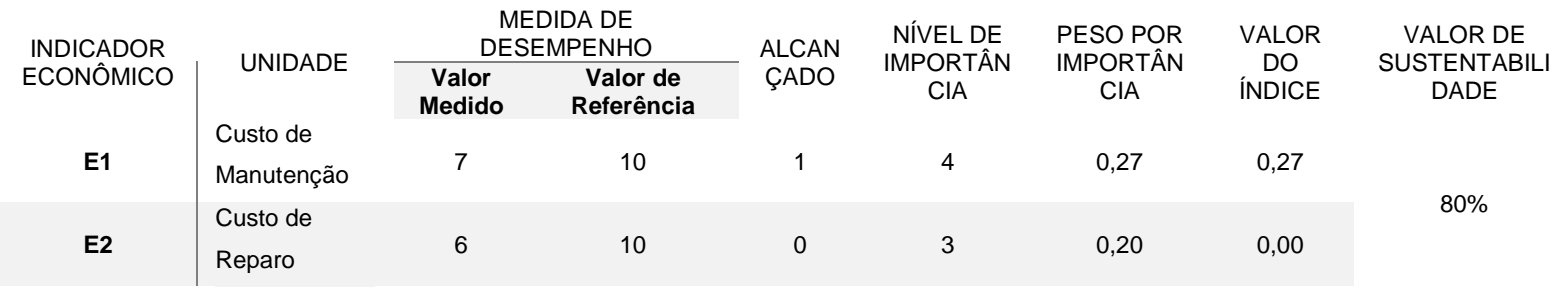


Tabela 42 - Avaliação de sustentabilidade no "uso" utilizando o framework considerando os indicadores econômicos (continuação)

\begin{tabular}{|c|c|c|c|c|c|c|c|c|}
\hline \multirow{2}{*}{$\begin{array}{l}\text { INDICADOR } \\
\text { ECONÔMICO }\end{array}$} & \multirow{2}{*}{ UNIDADE } & \multicolumn{2}{|c|}{$\begin{array}{c}\text { MEDIDA DE } \\
\text { DESEMPENHO }\end{array}$} & \multirow{2}{*}{$\begin{array}{l}\text { ALCAN } \\
\text { ÇADO }\end{array}$} & \multirow{2}{*}{$\begin{array}{l}\text { NÍVEL DE } \\
\text { IMPORTÂN } \\
\text { CIA }\end{array}$} & \multirow{2}{*}{$\begin{array}{l}\text { PESO POR } \\
\text { IMPORTÂN } \\
\text { CIA }\end{array}$} & \multirow{2}{*}{$\begin{array}{l}\text { VALOR } \\
\text { DO } \\
\text { ÍNDICE }\end{array}$} & \multirow{2}{*}{$\begin{array}{c}\text { VALOR DE } \\
\text { SUSTENTABILI } \\
\text { DADE }\end{array}$} \\
\hline & & $\begin{array}{c}\text { Valor } \\
\text { Medido }\end{array}$ & $\begin{array}{c}\text { Valor de } \\
\text { Referência }\end{array}$ & & & & & \\
\hline E3 & $\begin{array}{l}\text { Custo com } \\
\text { Acidentes do } \\
\text { Consumidor }\end{array}$ & 8 & 10 & 1 & 4 & 0,27 & 0,27 & \\
\hline E4 & $\begin{array}{l}\text { Custo de } \\
\text { Garantia do } \\
\text { Consumidor }\end{array}$ & 7 & 10 & 1 & 4 & 0,27 & 0,27 & \\
\hline & & & & $P S I_{\left(e c \_u\right)}$ & & & 0,80 & \\
\hline
\end{tabular}

Tabela 43 - Avaliação de sustentabilidade no "pós-uso" utilizando o framework considerando os indicadores ambientais

\begin{tabular}{|c|c|c|c|c|c|c|c|c|}
\hline \multirow{2}{*}{$\begin{array}{l}\text { INDICADOR } \\
\text { AMBIENTAL }\end{array}$} & \multirow{2}{*}{ UNIDADE } & \multicolumn{2}{|c|}{$\begin{array}{c}\text { MEDIDA DE } \\
\text { DESEMPENHO }\end{array}$} & \multirow{2}{*}{$\begin{array}{l}\text { ALCAN } \\
\text { ÇADO }\end{array}$} & \multirow{2}{*}{$\begin{array}{l}\text { NÍVEL DE } \\
\text { IMPORTÂN } \\
\text { CIA }\end{array}$} & \multirow{2}{*}{$\begin{array}{c}\text { PESO POR } \\
\text { IMPORTÂN } \\
\text { CIA }\end{array}$} & \multirow{2}{*}{$\begin{array}{l}\text { VALOR } \\
\text { DO } \\
\text { ÍNDICE }\end{array}$} & \multirow{3}{*}{$\begin{array}{c}\text { VALOR DE } \\
\text { SUSTENTABILI } \\
\text { DADE }\end{array}$} \\
\hline & & $\begin{array}{l}\text { Valor } \\
\text { Medido }\end{array}$ & $\begin{array}{l}\text { Valor de } \\
\text { Referência }\end{array}$ & & & & & \\
\hline N1 & $\begin{array}{l}\text { Reciclabilida } \\
\text { de }\end{array}$ & 7 & 10 & 1 & 4 & 0,25 & 0,25 & \\
\hline N2 & $\begin{array}{l}\text { Refabricabili } \\
\text { dade }\end{array}$ & 8 & 10 & 1 & 4 & 0,25 & 0,25 & \\
\hline N3 & Reprojeto & 7 & 10 & 1 & 4 & 0,25 & 0,25 & $100 \%$ \\
\hline \multirow[t]{2}{*}{ N4 } & $\begin{array}{l}\text { Contribuição } \\
\text { de Aterro } \\
\text { Sanitário }\end{array}$ & 7 & 10 & 1 & 4 & 0,25 & 0,25 & \\
\hline & & & & $P S I_{\left(e n \_p u\right)}$ & & & 1,00 & \\
\hline
\end{tabular}

Tabela 44 - Avaliação de sustentabilidade no "pós-uso" utilizando o método framework considerando os indicadores sociais

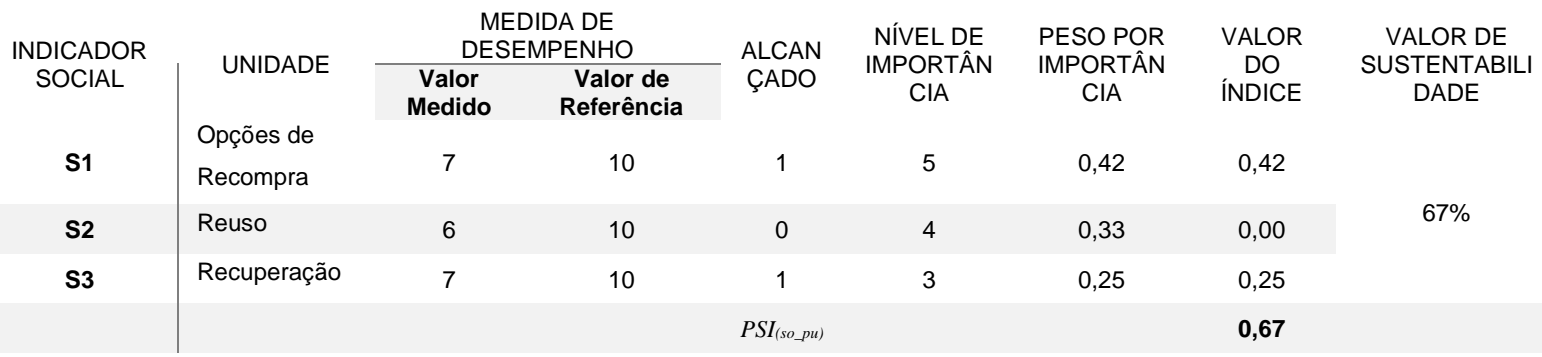

Tabela 45 - Avaliação de sustentabilidade no "pós-uso" utilizando o framework considerando os indicadores econômicos

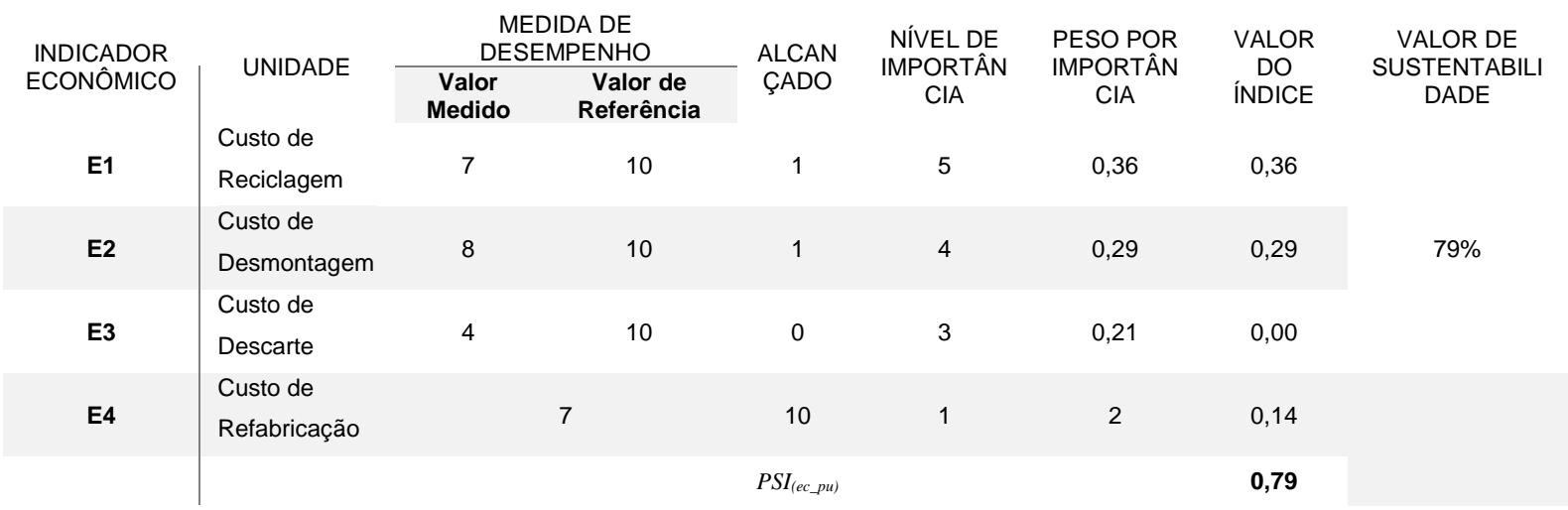


Tabela 46 - Resultado da avaliação de sustentabilidade na fase de "pré-fabricação"

\begin{tabular}{|c|c|c|c|c|c|c|}
\hline ITEM & ECONÔMICO & AMBIENTAL & SOCIAL & TECNOLÓGICO & RESULTADO & LIMITE \\
\hline PESO & $33 \%$ & $27 \%$ & $20 \%$ & $20 \%$ & & \\
\hline ÍNDICES & $0 \%$ & $73 \%$ & $100 \%$ & $0 \%$ & & \\
\hline AVALIAÇÃO DA SUSTENTABILIDADE & & & & & $39 \%$ & \\
\hline LIMITE DE SUSTENTABILIDADE & & & & & & $70 \%$ \\
\hline
\end{tabular}

Figura 26 - Resultado da avaliação de sustentabilidade - "pré-fabricação".

Resultado da Avaliação de Sustentabilidade - PréFabricação

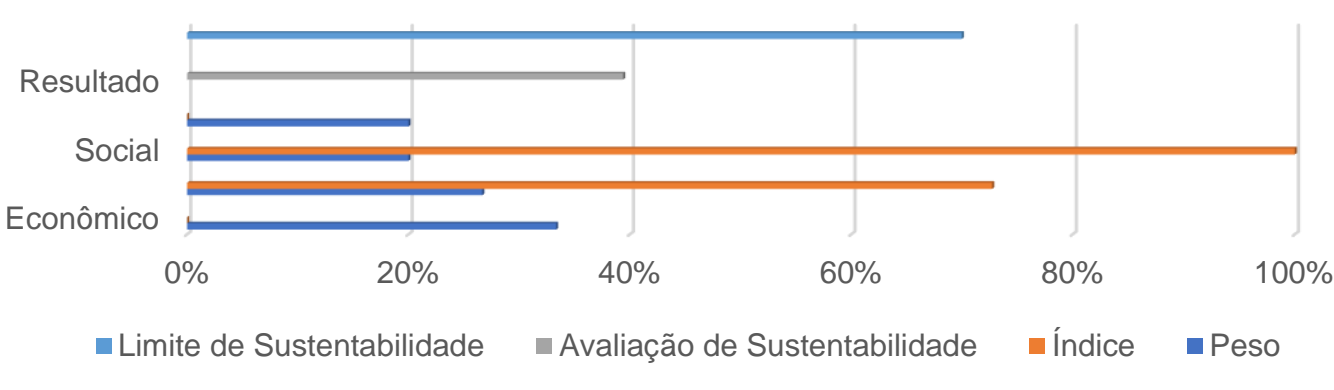

Fonte: $\mathrm{O}$ autor

Tabela 47 - Resultado da avaliação da sustentabilidade na "fase de fabricação"

\begin{tabular}{|c|c|c|c|c|c|c|}
\hline ITEM & ECONÔMICO & AMBIENTAL & SOCIAL & TECNOLÓGICO & RESULTADO & LIMITE \\
\hline PESO & $33 \%$ & $27 \%$ & $20 \%$ & $20 \%$ & & \\
\hline ÍNDICES & $57 \%$ & $100 \%$ & $100 \%$ & $0 \%$ & & \\
\hline AVALIAÇÃO DA SUSTENTABILIDADE & & & & & $86 \%$ & \\
\hline LIMITE DE SUSTENTABILIDADE & & & & & & $70 \%$ \\
\hline
\end{tabular}

Figura 27 - Resultado da avaliação de sustentabilidade - "fabricação".

Resultado da Avaliação de Sustentabilidade Fabricação

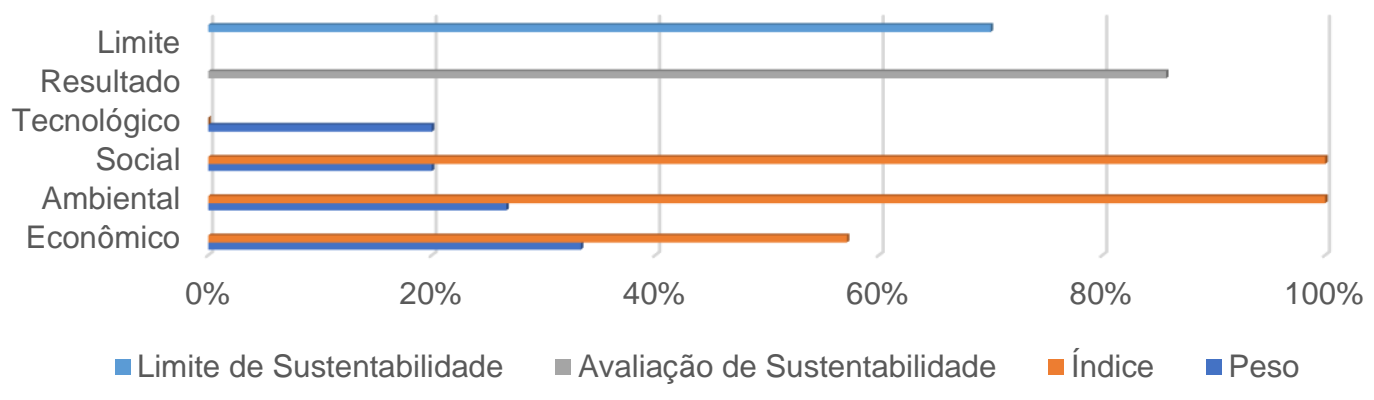

Fonte: $\mathrm{O}$ autor 
Tabela 48 - Resultado da avaliação da sustentabilidade na fase de "uso"

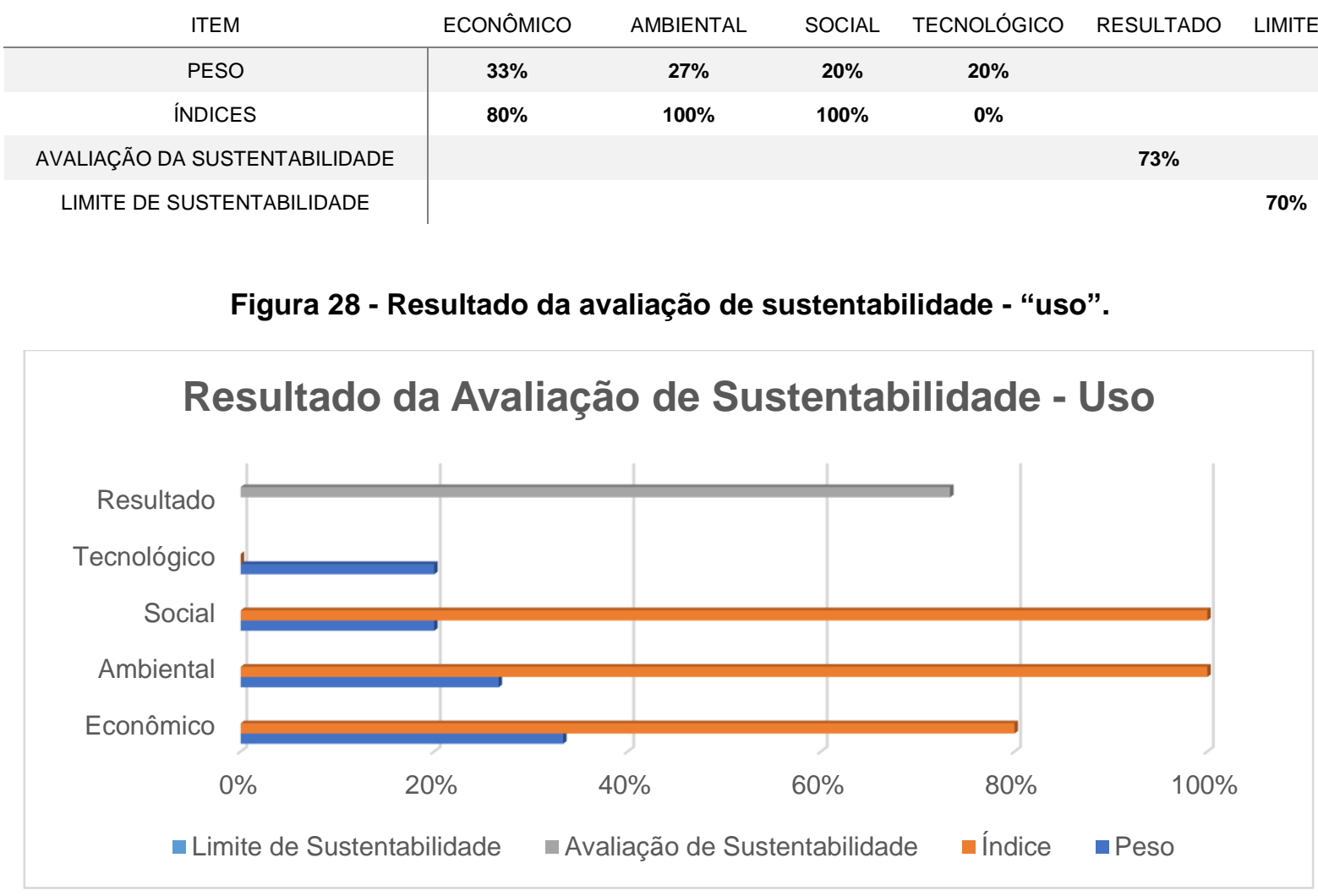

Fonte: $\mathrm{O}$ autor

Tabela 49 - Resultado da avaliação da sustentabilidade na fase de "pós-uso"

\begin{tabular}{c|cccccc}
\hline ITEM & ECONÔMICO & AMBIENTAL & SOCIAL & TECNOLÓGICO & RESULTADO & LIMITE \\
\hline PESO & $36 \%$ & $29 \%$ & $21 \%$ & $14 \%$ & & \\
\hline ÍNDICES & $79 \%$ & $100 \%$ & $67 \%$ & $0 \%$ & & \\
AVALIAÇÃO DA SUSTENTABILIDADE & & & & & $52 \%$ & \\
LIMITE DE SUSTENTABILIDADE & & & & & & $70 \%$
\end{tabular}

Figura 29 - Resultado da avaliação de sustentabilidade - "pós-uso".

\section{Resultado da Avaliação de Sustentabilidade - Pós-Uso}

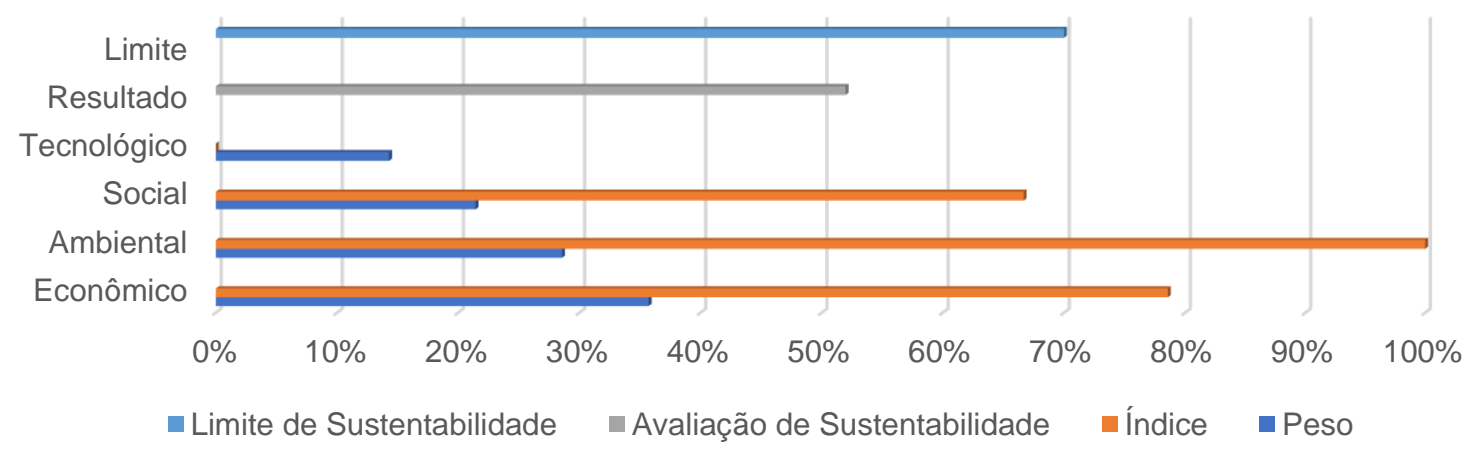

Fonte: $\mathrm{O}$ autor 
Tabela 50 - Resultado da avaliação da sustentabilidade no ciclo de vida completo do produto

\begin{tabular}{|c|c|c|c|c|c|c|}
\hline & PRÉ & FABRICAÇÃO & USO & PÓS-USO & RESULTADO & LIMITE \\
\hline PESO & $25 \%$ & $25 \%$ & $25 \%$ & $25 \%$ & & \\
\hline ÍNDICES & $39 \%$ & $86 \%$ & $73 \%$ & $52 \%$ & & \\
\hline AVALIAÇÃO DA SUSTENTABILIDADE & & & & & $63 \%$ & \\
\hline LIMITE DE SUSTENTABILIDADE & & & & & & $70 \%$ \\
\hline
\end{tabular}

Figura 30 - Resultado da avaliação de sustentabilidade no ciclo de vida completo do produto.

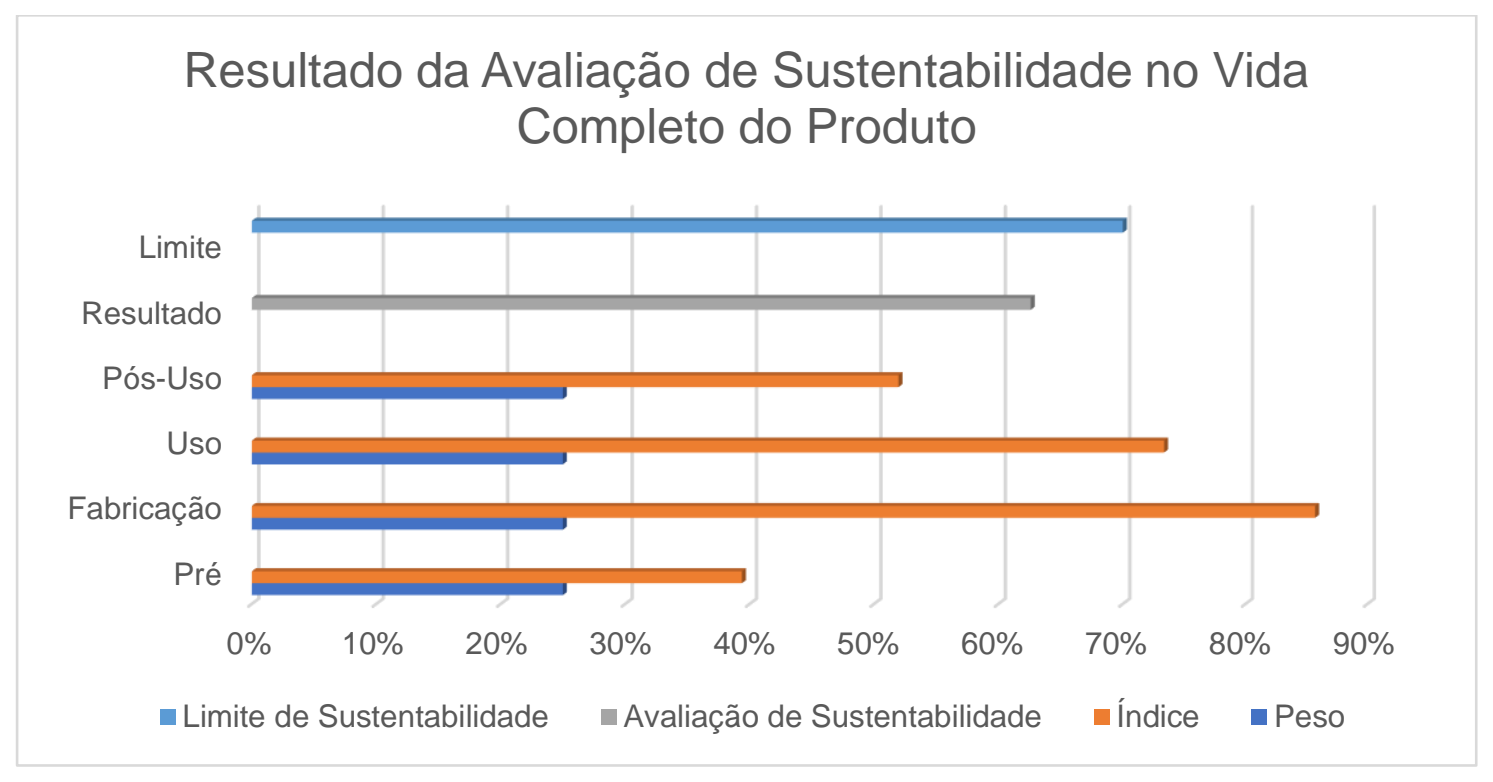

Fonte: $\mathrm{O}$ autor

\subsubsection{Sustentabilidade em operações de fabricação}

Em Gest e Prod (2010) apresenta-se as operações produtivas de uma empresa de manufatura de materiais elétricos, isto é, cabos elétricos, tubos isolantes e resistores elétricos. Especialistas em gestão ambiental estudaram as operações produtivas e junto com um grupo de profissionais e definiram 18 indicadores de sustentabilidade. Participaram da fase de avaliação: gerentes administrativos, comerciais, de engenharia, industriais e supervisores de etapas da produção. $O$ procedimento para o cálculo dos índices de sustentabilidade é sintetizado na Tabela 51.

$\mathrm{Na}$ Tabela 51 observa-se que os maiores desvios foram as emissões atmosféricas com 14,95 pp (pontos percentuais), isto é, faltam 57,5\% para atingir o desejado e, resíduos sólidos com 11,01 , isto é, faltam $50 \%$ para atingir o desejado. Os outros indicadores apresentam desvios inferiores a $8 \mathrm{pp}$. As ações mais recomendadas são em emissão de ácido clorídrico, resíduos de teflon, resíduos de 
silicone e emprego de cobre. As menos relevantes, por já ser rotina, são ações de atendimento à legislação.

Tabela 51 - Modelo para avaliação de desempenho ambiental da fabricação de materiais elétricos (adaptado de GEST e PROD, 2010)

\begin{tabular}{|c|c|c|c|c|c|}
\hline & INDICADOR & $\begin{array}{l}\text { IMPORTÂNCIA } \\
(\%)\end{array}$ & $\begin{array}{c}\text { INDICADOR } \\
\text { (PP = PONTOS } \\
\text { PERCENTUAIS) }\end{array}$ & $\begin{array}{l}\text { RESULTADO } \\
\text { OBTIDO (PP) }\end{array}$ & $\begin{array}{c}\text { DESVIO }(P P)= \\
\text { O QUE FALTA } \\
\text { PARA ATINGIR } \\
\text { O DESEJADO }\end{array}$ \\
\hline EMISSÕES ATMOSFÉRICAS & Emissões de poeira & 8,67 & 5,20 & 11,05 & 14,95 \\
\hline \multirow{2}{*}{$26 \%$} & Emissão de ácido clorídrico & 8,67 & 2,17 & & \\
\hline & $\begin{array}{l}\text { Emissão de gases de } \\
\text { combustão }\end{array}$ & 8,67 & 3,68 & & \\
\hline EfIUENTES LÍQUIDOS & Água de treflação & 4,33 & 3,03 & 8,63 & 4,37 \\
\hline \multirow{2}{*}{$13 \%$} & Água de processo & 4,33 & 3,22 & & \\
\hline & Água de caldeirão & 4,33 & 2,38 & & \\
\hline RESÍDUOS SÓLIDOS & Resíduos de cobre & 3,67 & 3,30 & 10,99 & 11,01 \\
\hline \multirow{4}{*}{$22 \%$} & Resíduos de silicone & 3,67 & 1,65 & & \\
\hline & $\begin{array}{l}\text { Resíduos de PVC (policloreto } \\
\text { de polivinila) }\end{array}$ & 3,67 & 2,01 & & \\
\hline & Resíduos de teflon & 3,67 & 1,47 & & \\
\hline & Resíduos de embalagens & 3,67 & 2,02 & & \\
\hline USO DE RECURSOS & Emprego de energia elétrica & 10,33 & 8,76 & 23,23 & 7,77 \\
\hline \multirow{2}{*}{$31 \%$} & Emprego de água & 10,33 & 7,75 & & \\
\hline & Emprego de cobre & 10,33 & 6,72 & & \\
\hline $\begin{array}{c}\text { GESTÃO E ATENDIMENTO À } \\
\text { LEGISLAÇÃO }\end{array}$ & Atendimento à FEPAM & 2,67 & 2,14 & 6,68 & 1,32 \\
\hline \multirow{2}{*}{$8 \%$} & Atendimento à SMAMM & 2,67 & 2,40 & & \\
\hline & Atendimento ao IBAMA & 2,67 & 2,14 & & \\
\hline $100 \%$ & & 100 & 61 & 61 & 39 \\
\hline
\end{tabular}

Nesse caso para que as emissões atmosféricas apresentem melhoria na sustentabilidade, é necessário que cada indicador atinja o índice estabelecido de $8,67 \%$, da mesma forma que para os resíduos sólidos, os indicadores devem atingir o índice estabelecido de 3,67\%.

Este método tem como principal objetivo avaliar o desvio do indicador com relação ao nível desejado, indicando assim quanto esforço (recursos e tempo) será necessário para atingir a meta estabelecida.

Para a aplicação do framework foi necessário fazer adaptações como: conversão do nível de importância dos indicadores que pode variar de 0 a 10, assim consideramos que: 0-2 nível de importância 1; 3-4, importância 2; 5-6, importância 3; 7-8, importância 4 e 9-10, importância 5. Adotou-se o limite, como aplicado no exemplo, de alcance de $100 \%$ com um desvio de $20 \%$. 
Aplica-se agora o framework com os dados de medidas de desempenho e nível de importância de cada indicador para o seu cálculo. Aqui também, caso o indicador não atenda o limite mínimo de $80 \%$, entende-se que as operações produtivas envolvidas não são consideradas sustentáveis. A Tabela 52 mostra discriminado o estado de cada indicador, onde se indica percentualmente quão longe ou perto se está da meta estabelecida.

Tabela 52 - Avaliação de sustentabilidade utilizando o framework considerando os indicadores ambientais

\begin{tabular}{|c|c|c|c|c|c|c|c|c|c|}
\hline \multirow{2}{*}{$\begin{array}{l}\text { INDICA } \\
\text { DOR } \\
\text { AMBIEN } \\
\text { TAL }\end{array}$} & \multicolumn{2}{|c|}{$\begin{array}{c}\text { MEDIDAS DE } \\
\text { DESEMPENHO }\end{array}$} & \multirow{2}{*}{$\begin{array}{c}\text { LIMITE DE } \\
\text { SUSTENTABILI } \\
\text { DADE }(\%)\end{array}$} & \multirow{2}{*}{$\begin{array}{c}\text { SUSTEN } \\
\text { TABILIDA } \\
\text { DE (\%) }\end{array}$} & \multirow{2}{*}{$\begin{array}{l}\text { AL } \\
\text { CAN } \\
\text { ÇADO }\end{array}$} & \multirow{2}{*}{$\begin{array}{l}\text { NÍVEL DE } \\
\text { IMPORTÂ } \\
\text { NCIA }\end{array}$} & \multirow{2}{*}{$\begin{array}{l}\text { PESO POR } \\
\text { IMPORTÂN } \\
\text { CIA }\end{array}$} & \multirow{2}{*}{$\begin{array}{l}\text { VALOR } \\
\text { DO } \\
\text { ÍNDICE }\end{array}$} & \multirow{2}{*}{$\begin{array}{l}\text { VALOR DE } \\
\text { SUSTENTABI } \\
\text { LIDADE }\end{array}$} \\
\hline & $\begin{array}{c}\text { Valor } \\
\text { medi } \\
\text { do }\end{array}$ & $\begin{array}{c}\text { Valor } \\
\text { deseja } \\
\text { do }\end{array}$ & & & & & & & \\
\hline $\begin{array}{l}\text { EMISSÕES } \\
\text { DE } \\
\text { POEIRA }\end{array}$ & 5,20 & 8,67 & & $60 \%$ & 0 & 4 & $8 \%$ & 0,00 & \\
\hline $\begin{array}{l}\text { EMISSSÃO } \\
\text { DE ÁCIDO } \\
\text { CLORÍDRI } \\
\text { CO }\end{array}$ & 2,17 & 8,67 & & $25 \%$ & 0 & 4 & $8 \%$ & 0,00 & \\
\hline $\begin{array}{l}\text { EMISSÃO } \\
\text { DE GASES } \\
\text { DE } \\
\text { COMBUST } \\
\text { ÃO }\end{array}$ & 3,68 & 8,67 & $100 \%$ & $42 \%$ & 0 & 4 & $8 \%$ & 0,00 & \\
\hline $\begin{array}{l}\text { ÁGUA DE } \\
\text { TREFLAÇ } \\
\text { ÃO }\end{array}$ & 3,03 & 4,33 & & $70 \%$ & 0 & 2 & $4 \%$ & 0,00 & \\
\hline $\begin{array}{l}\text { ÁGUA DE } \\
\text { PROCESS } \\
0\end{array}$ & 3,22 & 4,33 & & $74 \%$ & 0 & 2 & $4 \%$ & 0,00 & \\
\hline $\begin{array}{l}\text { ÁGUA DE } \\
\text { CALDEIRÃ } \\
0\end{array}$ & 2,38 & 4,33 & & $55 \%$ & 0 & 2 & $4 \%$ & 0,00 & \\
\hline $\begin{array}{l}\text { RESÍDUOS } \\
\text { DE COBRE }\end{array}$ & 3,30 & 3,67 & & $90 \%$ & 1 & 2 & $4 \%$ & 0,04 & \\
\hline $\begin{array}{l}\text { RESÍDUOS } \\
\text { DE } \\
\text { SILICONE }\end{array}$ & 1,65 & 3,67 & & $45 \%$ & 0 & 2 & $4 \%$ & 0,00 & \\
\hline $\begin{array}{l}\text { RESÍDUOS } \\
\text { DE PVC }\end{array}$ & 2,01 & 3,67 & Limite Mínimo & $55 \%$ & 0 & 2 & $4 \%$ & 0,00 & $21 \%$ \\
\hline $\begin{array}{l}\text { RESIDUOS } \\
\text { DE EPR }\end{array}$ & 0,55 & 3,67 & $(20 \%)$ & $15 \%$ & 0 & 2 & $4 \%$ & 0,00 & \\
\hline $\begin{array}{l}\text { RESÍ́UOS } \\
\text { DE } \\
\text { TEFLON }\end{array}$ & 1,47 & 3,67 & & $40 \%$ & 0 & 2 & $4 \%$ & 0,00 & \\
\hline $\begin{array}{l}\text { RESÍ́DUOS } \\
\text { DE } \\
\text { EMBALAG } \\
\text { ENS }\end{array}$ & 2,02 & 3,67 & & $55 \%$ & 0 & 2 & $4 \%$ & 0,00 & \\
\hline $\begin{array}{l}\text { EMISSÕES } \\
\text { DE } \\
\text { POEIRA }\end{array}$ & 5,20 & 8,67 & & $60 \%$ & 0 & 4 & $8 \%$ & 0,00 & \\
\hline $\begin{array}{l}\text { EMPREGO } \\
\text { DE } \\
\text { ENERGIA } \\
\text { ELÉTRICA }\end{array}$ & 8,76 & 10,33 & $80 \%$ & $85 \%$ & 1 & 5 & $10 \%$ & 0,10 & \\
\hline $\begin{array}{l}\text { EMPREGO } \\
\text { DE ÁGUA }\end{array}$ & 7,75 & 10,33 & & $75 \%$ & 0 & 5 & $10 \%$ & 0,00 & \\
\hline $\begin{array}{l}\text { EMPREGO } \\
\text { DE COBRE }\end{array}$ & 6,72 & 10,33 & & $65 \%$ & 0 & 5 & $10 \%$ & 0,00 & \\
\hline $\begin{array}{l}\text { ATENDIME } \\
\text { NTO } \AA \\
\text { FEPAM }\end{array}$ & 2,14 & 2,67 & & $80 \%$ & 1 & 1 & $2 \%$ & 0,02 & \\
\hline $\begin{array}{l}\text { ATENDIME } \\
\text { NTO } \dot{A} \\
\text { SMAMM }\end{array}$ & 2,40 & 2,67 & & $90 \%$ & 1 & 1 & $2 \%$ & 0,02 & \\
\hline
\end{tabular}

A Tabela 53 mostra o resumo da avaliação, que no caso estudado considera apenas 0 aspecto ambiental. A Figura 31 mostra o resultado em forma de gráfico. Os 
resultados mostram que as operações produtivas da empresa não são consideradas sustentáveis, pois o índice de sustentabilidade ficou em 46\%, com 6 indicadores aquém do desejado.

Tabela 53 - Resultado da avaliação de sustentabilidade utilizando o método proposto considerando os indicadores econômicos

\begin{tabular}{|c|c|c|c|c|c|c|}
\hline ITEM & ECONÔMICO & AMBIENTAL & SOCIAL & TECNOLÓGICO & RESULTADO & LIMITE \\
\hline PESO & $25 \%$ & $25 \%$ & $25 \%$ & $25 \%$ & & \\
\hline ÍNDICES & $0 \%$ & $21 \%$ & $0 \%$ & $0 \%$ & & \\
\hline AVALIAÇÃO DO IISP & & & & & $0 \%$ & \\
\hline AVALIAÇÃO DE SUSTENTABILIDADE & & & & & $5 \%$ & \\
\hline NÍVEL MÍNIMO DE SUSTENTABILIDADE & & & & & & $80 \%$ \\
\hline LIMITE DE SUSTENTABILIDADE & & & & & & $100 \%$ \\
\hline
\end{tabular}

Em Gest e Prod (2010) apresenta-se também um caso de operações produtivas de uma empresa de fabricação mecânica, isto é, operações envolvidas na fabricação de peças forjadas e usinadas. Seguindo o mesmo procedimento do caso anterior, foram definidos 24 indicadores de sustentabilidade. Os resultados obtidos estão sintetizados na Tabela 54.

Figura 31 - Resultado da avaliação de sustentabilidade em fabricação de cabos elétricos.

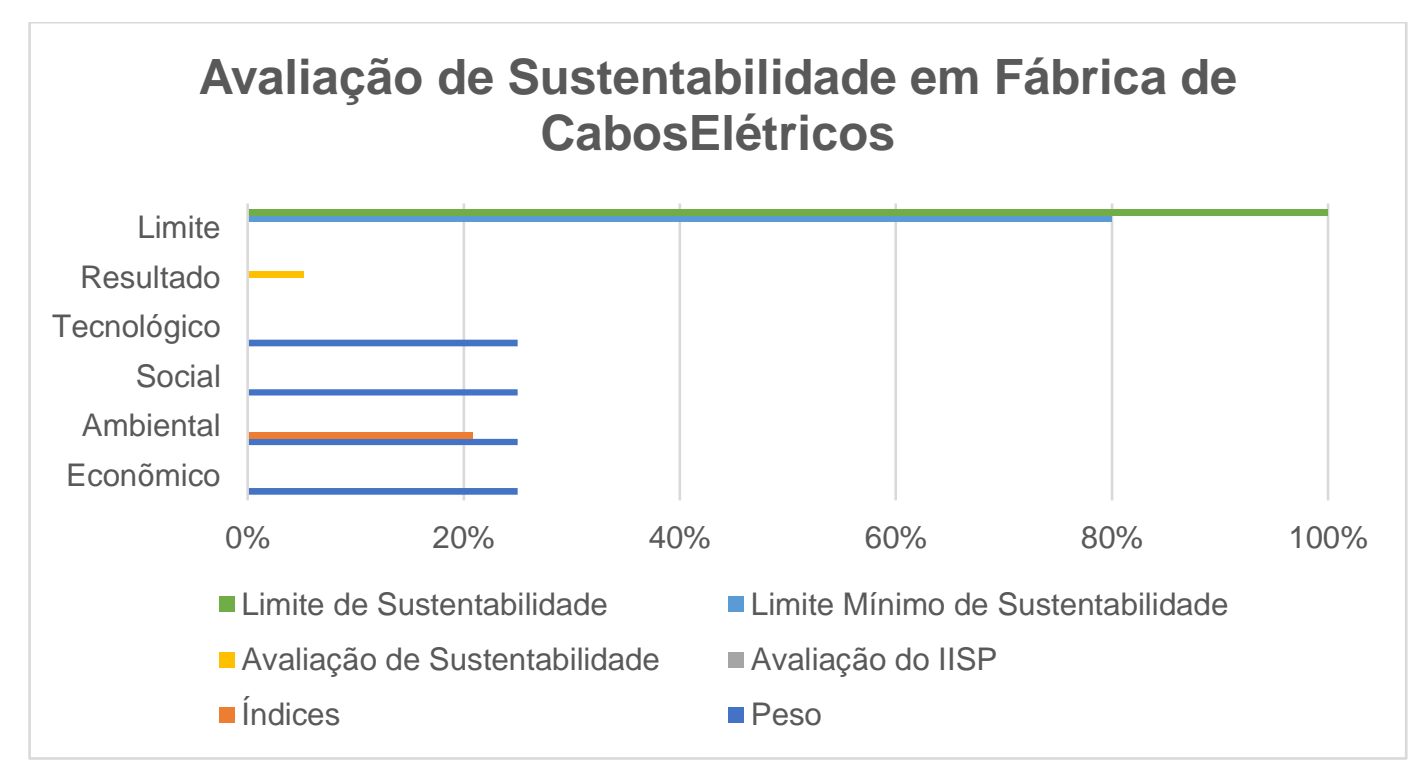

Fonte: $\mathrm{O}$ autor

Neste caso, os maiores desvios estão relacionados com o uso de recursos, com 16,94 pp, isto é, faltam 48,4\% para atingir o desejado e efluentes líquidos, com $9,81 \mathrm{pp}$, isto é, faltam $39 \%$ para atingir o desejado. As ações mais recomendadas 
estão relacionadas com o emprego de água e energia elétrica e tratamento de esgotos e de efluentes do processo de fostatização.

\section{Tabela 54 - Modelo para avaliação de desempenho ambiental da fabricação mecânica (adaptado de GEST e PROD, 2010)}

\begin{tabular}{|c|c|c|c|c|c|}
\hline & INDICADOR & $\begin{array}{c}\text { IMPORTÂNCIA } \\
(\%)\end{array}$ & $\begin{array}{l}\text { INDICADOR } \\
(P P)\end{array}$ & $\begin{array}{l}\text { RESULTADO } \\
\text { OBTIDO (PP) }\end{array}$ & $\begin{array}{c}\text { DESVIO }(\mathrm{PP})= \\
\text { O QUE FALTA } \\
\text { PARA ATINGIR } \\
\text { O DESEJADO }\end{array}$ \\
\hline $\begin{array}{c}\text { EMISSÕES } \\
\text { ATMOSFÉRICAS }\end{array}$ & Emissões de orgânicos voláteis & 3,00 & 1,80 & 9,24 & 5,76 \\
\hline \multirow{4}{*}{$15 \%$} & Emissão de $\mathrm{CO}$ e $\mathrm{CO} 2$ & 3,00 & 1,80 & & \\
\hline & Emissões de matérias-primas armazenadas & 3,00 & 1,95 & & \\
\hline & Emissões de amônia & 3,00 & 1,29 & & \\
\hline & Emissões de gases de solda & 3,00 & 2,40 & & \\
\hline \multirow[t]{2}{*}{$\begin{array}{l}\text { EFLUENTES } \\
\text { LÍQUIDOS }\end{array}$} & Esgoto cloacal & 6,25 & 3,12 & 15,19 & 9,81 \\
\hline & Óleos e graxas & 6,25 & 4,56 & & \\
\hline \multirow[t]{2}{*}{$25 \%$} & Efluentes da fosfatização & 6,25 & 3,12 & & \\
\hline & Emulsões oleosas & 6,25 & 4,37 & & \\
\hline $\begin{array}{l}\text { RESÍDUOS } \\
\text { SÓLIDOS }\end{array}$ & Resíduos de carepa de forjaria & 3,33 & 2,43 & 15,05 & 4,95 \\
\hline $20 \%$ & Resíduos de cavaco de ferro & 3,33 & 2,60 & & \\
\hline \multirow{5}{*}{$20 \%$} & Resíduos de cavaco de ferro & 3,33 & 2,60 & & \\
\hline & Resíduos de manta e borra de retífca & 3,33 & 2,76 & & \\
\hline & Resíduos recicláveis & 3,33 & 2,26 & & \\
\hline & Resíduos de borra de tinta & 3,33 & 2,66 & & \\
\hline & Resíduos de materiais orgânicos & 3,33 & 2,33 & & \\
\hline $\begin{array}{c}\text { USO DE } \\
\text { RECURSOS }\end{array}$ & Emprego de gás natural & 7,00 & 3,85 & 18,06 & 16,94 \\
\hline \multirow{4}{*}{$35 \%$} & Emprego de água & 7,00 & 3,15 & & \\
\hline & Emprego de energia elétrica & 7,00 & 3,15 & & \\
\hline & Emprego de ligas metálicas e aço & 7,00 & 3,71 & & \\
\hline & Emprego de madeira & 7,00 & 4,20 & & \\
\hline $\begin{array}{c}\text { GESTÃO E } \\
\text { ATENDIMENTO }\end{array}$ & Atendimento à legislação do Estado & 1,25 & 0,97 & 3,79 & 2,21 \\
\hline \multirow{2}{*}{$5 \%$} & Atendimento à legislação da União & 1,25 & 0,97 & & \\
\hline & Certificação ISO 14001 & 1,25 & 0,85 & & \\
\hline $100 \%$ & & 98,73 & 60,30 & & \\
\hline
\end{tabular}

Da mesma forma que no primeiro caso, para que os indicadores relacionados com o uso de recursos melhorem a sustentabilidade considera-se que é necessário que eles atinjam o valor de $7 \%$, assim como os indicadores relacionados com efluentes líquidos devem atingir o valor de 6,25\%.

Aplicando agora o framework, onde o limite de 100\% com desvio de $20 \%$ é adotado para considerar como sustentável, os resultados obtidos são apresentados na Tabela 55. A Tabela 56 mostra o resumo da avaliação e a Figura 32 mostra o resultado em forma de gráfico. 
Tabela 55 - Avaliação de sustentabilidade utilizando o framework considerando os indicadores ambientais

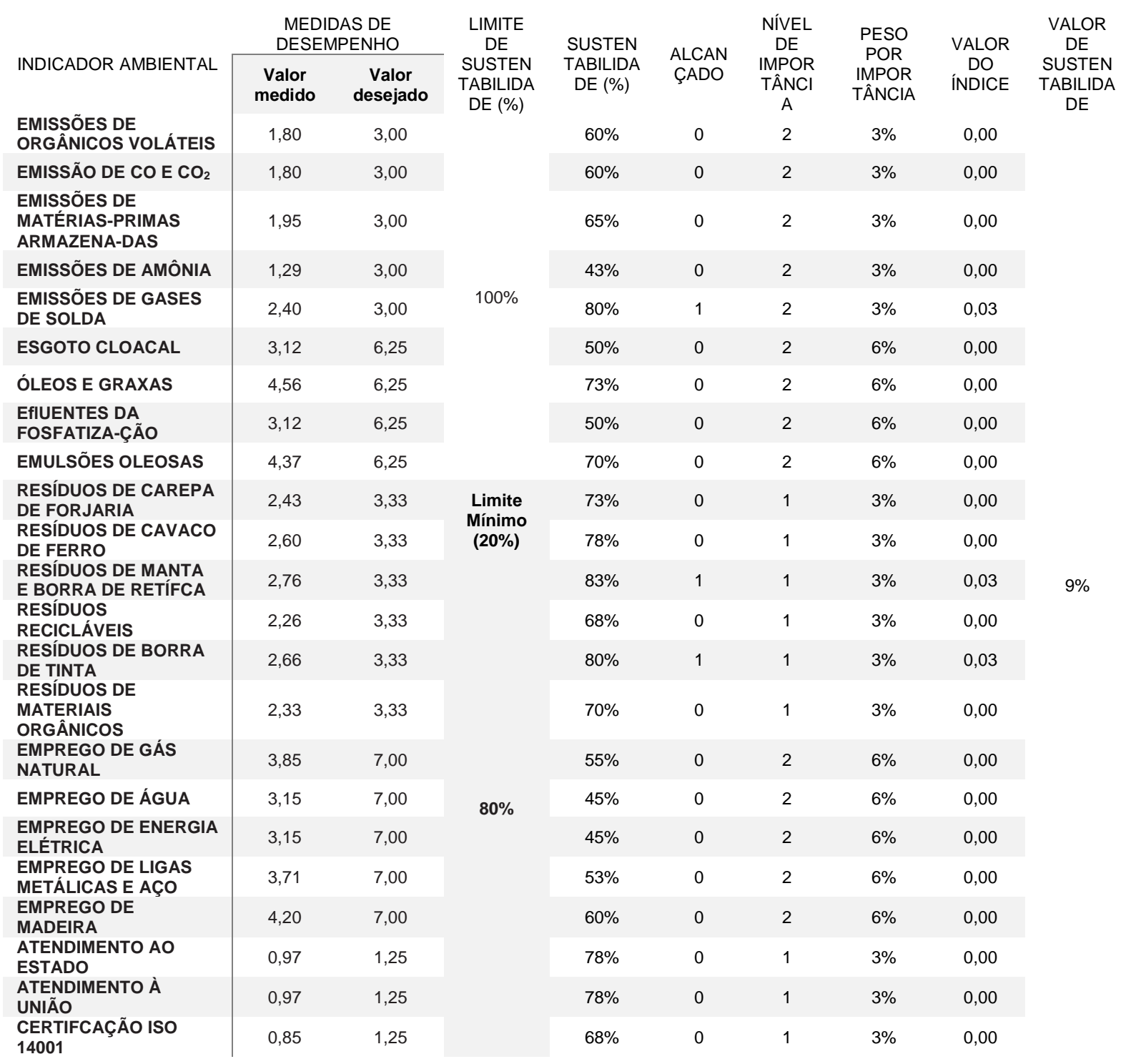

Tabela 56 - Resultado da avaliação de sustentabilidade utilizando o framework considerando os indicadores ambientais

\begin{tabular}{|c|c|c|c|c|c|c|}
\hline ITEM & ECONÔMICO & AMBIENTAL & SOCIAL & TECNOLÓGICO & $\begin{array}{c}\text { RESULTA } \\
\text { DO }\end{array}$ & LIMITE \\
\hline PESO & $25 \%$ & $25 \%$ & $25 \%$ & $25 \%$ & & \\
\hline ÍNDICES & $0 \%$ & $9 \%$ & $0 \%$ & $0 \%$ & & \\
\hline AVALIAÇÃO DO IISP & & & & & $0 \%$ & \\
\hline AVALIAÇÃO DE SUSTENTABILIDADE & & & & & $2 \%$ & \\
\hline $\begin{array}{l}\text { NÍVEL MÍNIMO DE } \\
\text { SUSTENTABILIDADE }\end{array}$ & & & & & & $80 \%$ \\
\hline LIMITE DE SUSTENTABILIDADE & & & & & & $100 \%$ \\
\hline
\end{tabular}

Os resultados da avaliação indicam que a empresa não atingiu o limite mínimo de sustentabilidade, isto é, ela alcançou apenas $46 \%$ de sustentabilidade desejada. Apenas $50 \%$ dos indicadores atingiram o limite mínimo, porém, indicadores com 
relevância alta não atingiram os limites estabelecidos. Os resultados indicam que as operações produtivas devem ser revisadas para melhorar o valor dos indicadores de uso de recursos, emissões atmosféricas e efluentes líquidos.

Figura 32 - Resultado da avaliação de sustentabilidade em fabricação mecânica.

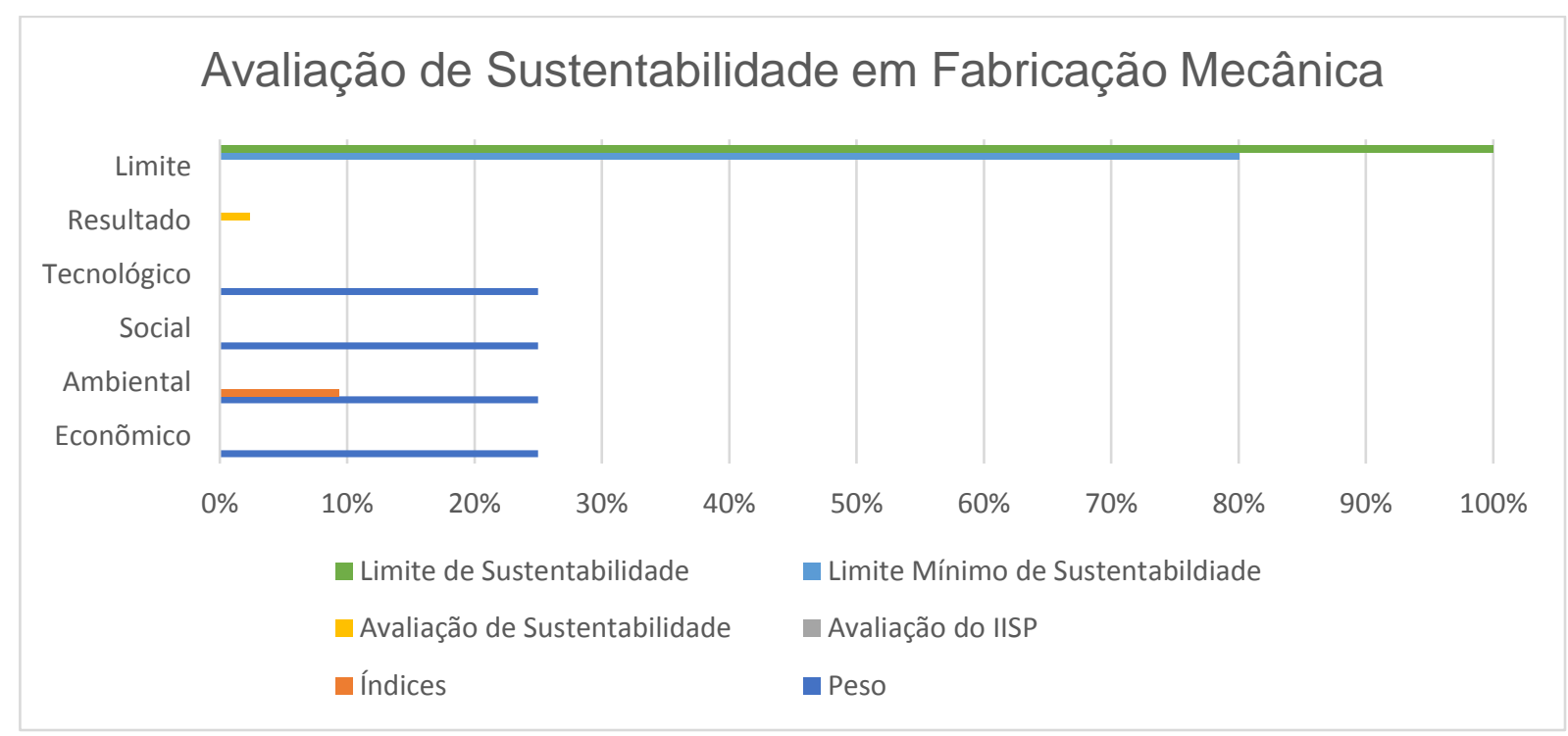

Fonte: $\mathrm{O}$ autor

Ainda em Gest e Prod (2010) tem-se também um caso de operações produtivas de estamparia de chapas para montadoras de veículos e de equipamentos eletromecânicos. Os principais produtos são peças estampadas, conjuntos soldados e cabines para veículos automotores. Seguindo um procedimento do caso anterior, foram definidos 26 indicadores. Os resultados obtidos estão sintetizados na Tabela 57.

Neste caso, os maiores desvios estão relacionados com os efluentes líquidos e os resíduos sólidos. O desvio em relação aos efluentes líquidos foi de 11,21 pp, isto é, faltam 47,5\% para atingir o desejado. O desvio em relação aos resíduos sólidos foi de 5,14 pp, isto é, faltam $15,4 \%$ para atingir o desejado. As ações mais recomendadas estão relacionadas com efluentes sanitários, efluentes de vestiários e óleo de cozinha.

Da mesma forma que no caso anterior, para que os indicadores relacionados com efluentes líquidos indiquem melhoria na sustentabilidade, é necessário que os indicadores atinjam os respectivos índices de 9,44\% (para óleo hidráulico); 7,08\% (para óleo de cozinha); 1,18\% (para efluentes sanitários); 4,72\% (para efluentes de cozinha) e 1,18\% (para efluentes dos vestiários). 
Tabela 57 - Modelo para avaliação de desempenho ambiental da operação de estamparia (adaptado de GEST e PROD, 2010)

\begin{tabular}{|c|c|c|c|c|c|}
\hline CONSTRUTO & INDICADOR & $\begin{array}{l}\text { IMPORTÂNCIA } \\
(\%)\end{array}$ & $\begin{array}{l}\text { INDICADOR } \\
\quad(\mathrm{PP})\end{array}$ & $\begin{array}{l}\text { RESULTADO } \\
\text { OBTIDO (PP) }\end{array}$ & $\begin{array}{c}\text { DESVIO (PP) = O QUE } \\
\text { FALTA PARA ATINGIR O } \\
\text { DESEJADO }\end{array}$ \\
\hline $\begin{array}{l}\text { EMISSÕES } \\
\text { ATMOSFÉRICAS }\end{array}$ & Fumaça preta & 2,08 & 1,04 & 5,63 & (1) \\
\hline $8,34 \%$ & Ruído ambiental & 6,25 & 4,69 & & \\
\hline $\begin{array}{l}\text { EFLUENTES } \\
\text { LÍQUIDOS }\end{array}$ & Óleos hidráulicos & 9,44 & 7,08 & 12,4 & 11,21 \\
\hline \multirow{4}{*}{$23,61 \%$} & Óleo de cozinha & 7,08 & 1,77 & & \\
\hline & Efluentes sanitários & 1,18 & 0,59 & & \\
\hline & Efluentes de cozinha & 4,72 & 2,36 & & \\
\hline & Efluentes vestiários & 1,18 & 0,59 & & \\
\hline $\begin{array}{l}\text { RESÍDUOS } \\
\text { SÓLIDOS }\end{array}$ & Sobras de alimentos & 0,13 & 0 & 28,2 & 5,14 \\
\hline \multirow{9}{*}{$33,34 \%$} & Plástico com óleo & 5,33 & 4 & & \\
\hline & Papelão com óleo & 5,33 & 4 & & \\
\hline & Panos contaminados da ofcina & 3,33 & 2,5 & & \\
\hline & $\begin{array}{l}\text { Resíduos de varrição da } \\
\text { fábrica }\end{array}$ & 1,83 & 0,46 & & \\
\hline & Borra da retífca & 5 & 5 & & \\
\hline & Resíduos de madeiras & 1,67 & 1,67 & & \\
\hline & Sucata metálica & 10 & 10 & & \\
\hline & $\begin{array}{l}\text { Papel, papelão e plásticos de } \\
\text { escritório }\end{array}$ & 0,54 & 0,4 & & \\
\hline & $\begin{array}{l}\text { Cartuchos e resíduos de } \\
\text { impressora }\end{array}$ & 0,17 & 0,17 & & \\
\hline $\begin{array}{l}\text { USO DE } \\
\text { RECURSOS }\end{array}$ & Água & 0,76 & 0,38 & 10,89 & 4,39 \\
\hline \multirow{3}{*}{$15,28 \%$} & Eletricidade & 4,58 & 3,44 & & \\
\hline & $\begin{array}{l}\text { GLP (Gás Liquefeito de } \\
\text { Petróleo) }\end{array}$ & 0,76 & 0,19 & & \\
\hline & Aço & 9,17 & 6,88 & & \\
\hline $\begin{array}{l}\text { GESTÃO E } \\
\text { ATENDIMENTO } \\
\text { À LEGISLAÇÃO }\end{array}$ & $\begin{array}{l}\text { Atendimento à legislação do } \\
\text { Municipal }\end{array}$ & 3,89 & 3,89 & 16,53 & 2,91 \\
\hline
\end{tabular}

Assim o mesmo para os resíduos sólidos, os indicadores devem atingir os respectivos índices de $0,13 \%$ (para sobras de alimentos); 5,33\% (para plástico com óleo); 5,33\% (para papelão com óleo); 3,33\% (para panos contaminados da oficina); 1,83\% (para resíduos de varrição da fábrica); $5 \%$ (para borra da retífica); 1,67\% (para resíduos de madeiras); 10\% (para sucata metálica); 0,54\% (para papel, papelão e plásticos de escritório)e $0,17 \%$ (para cartuchos e resíduos de impressora).

Aplicando agora o framework, onde o limite de 100\% com desvio de $20 \%$ é adotado para considerar como sustentável, os resultados obtidos são apresentados na Tabela 58. A Tabela 59 mostra o resumo da avaliação e a Figura 33 mostra o resultado em forma de gráfico.

Os resultados da avaliação indicam que a empresa não atingiu o limite mínimo de sustentabilidade, isto é, ela alcançou apenas 10\% de sustentabilidade desejada. Assim, uma revisão significativa das atividades deve ser considerada principalmente 
no que afeta os indicadores de efluentes líquidos, uso de recursos e emissões atmosféricas.

Tabela 57 - Modelo para avaliação de desempenho ambiental da operação de estamparia (adaptado de GEST e PROD, 2010 (continuação)

\begin{tabular}{|c|c|c|c|c|c|}
\hline CONSTRUTO & INDICADOR & $\begin{array}{c}\text { IMPORTÂNCIA } \\
(\%)\end{array}$ & $\begin{array}{l}\text { INDICADOR } \\
\text { (PP) }\end{array}$ & $\begin{array}{l}\text { RESULTADO } \\
\text { OBTIDO (PP) }\end{array}$ & $\begin{array}{c}\text { DESVIO }(\mathrm{PP})=\text { O QUE } \\
\text { FALTA PARA ATINGIR O } \\
\text { DESEJADO }\end{array}$ \\
\hline \multirow[t]{4}{*}{$19,44 \%$} & $\begin{array}{l}\text { Atendimento à legislação do } \\
\text { Estadual }\end{array}$ & 3,89 & 3,89 & & \\
\hline & $\begin{array}{l}\text { Atendimento à legislação do } \\
\text { Federal }\end{array}$ & 3,89 & 3,89 & & \\
\hline & $\begin{array}{l}\text { Normas técnicas, normas } \\
\text { regulamentadoras, resoluções, } \\
\text { decretos }\end{array}$ & 3,89 & 3,89 & & \\
\hline & $\begin{array}{l}\text { SGA - Sistema de Gestão } \\
\text { Ambiental do Estado }\end{array}$ & 3,89 & 0,97 & & \\
\hline $100 \%$ & & 99,98 & 74 & 73,65 & 23,65 \\
\hline
\end{tabular}

Tabela 58 - Avaliação de sustentabilidade utilizando o framework considerando os indicadores ambientais

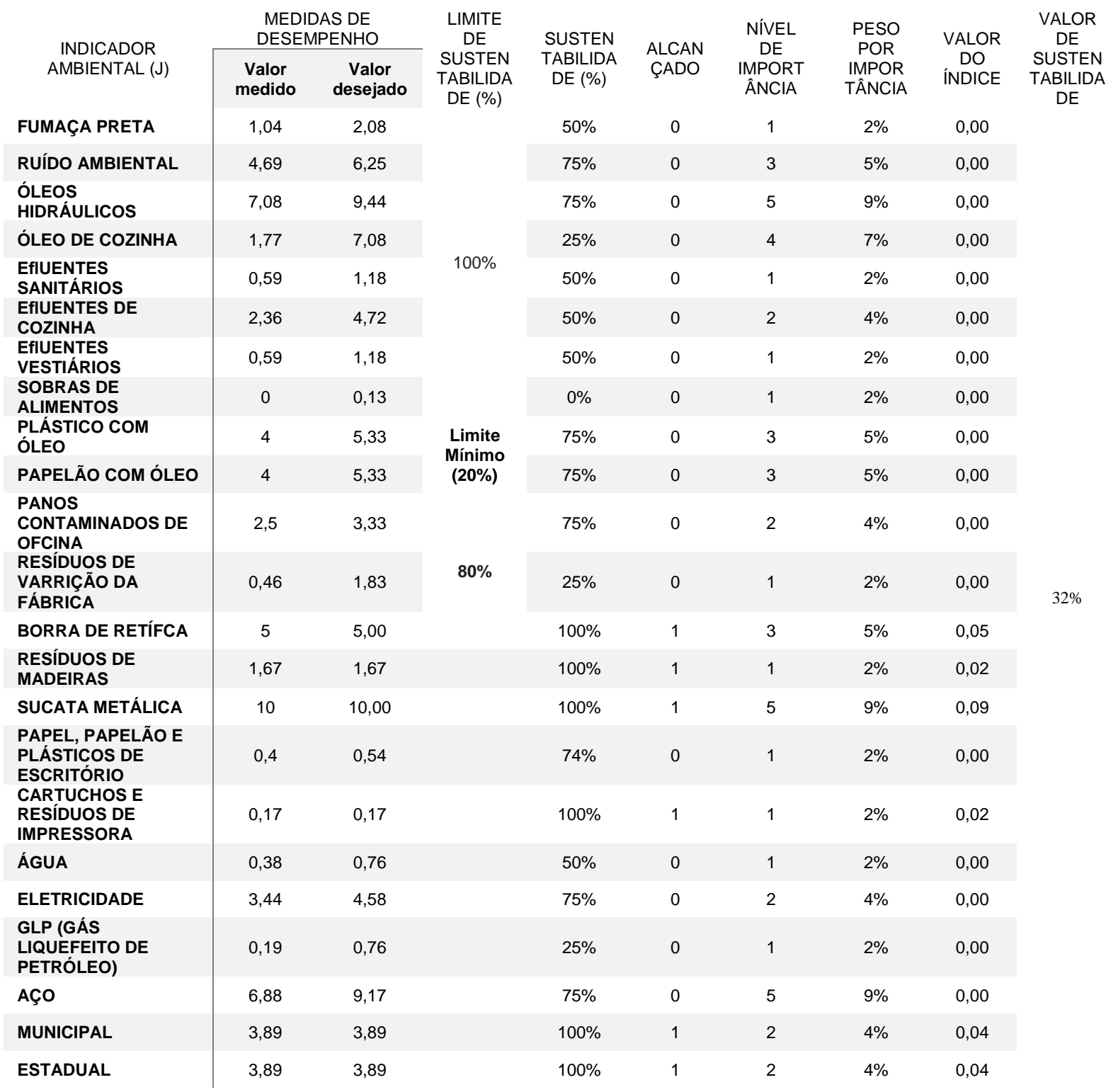


Tabela 58 - Avaliação de sustentabilidade utilizando o framework considerando os indicadores ambientais (continuação)

\begin{tabular}{|c|c|c|c|c|c|c|c|c|c|}
\hline \multirow{2}{*}{$\begin{array}{c}\text { INDICADOR } \\
\text { AMBIENTAL (J) }\end{array}$} & \multicolumn{2}{|c|}{$\begin{array}{c}\text { MEDIDAS DE } \\
\text { DESEMPENHO }\end{array}$} & \multirow{3}{*}{$\begin{array}{l}\text { LIMITE } \\
\text { DE } \\
\text { SUSTEN } \\
\text { TABILIDA } \\
\text { DE }(\%)\end{array}$} & \multirow{2}{*}{$\begin{array}{c}\text { SUSTEN } \\
\text { TABILIDA } \\
\text { DE (\%) }\end{array}$} & \multirow{2}{*}{$\begin{array}{l}\text { ALCAN } \\
\text { ÇADO }\end{array}$} & \multirow{2}{*}{$\begin{array}{l}\text { NÍVEL } \\
\text { DE } \\
\text { IMPORT } \\
\text { ÂNCIA }\end{array}$} & \multirow{2}{*}{$\begin{array}{c}\text { PESO } \\
\text { POR } \\
\text { IMPOR } \\
\text { TÂNCIA }\end{array}$} & \multirow{2}{*}{$\begin{array}{l}\text { VALOR } \\
\text { DO } \\
\text { ÍNDICE }\end{array}$} & \multirow{2}{*}{$\begin{array}{c}\text { VALOR } \\
\text { DE } \\
\text { SUSTEN } \\
\text { TABILIDA } \\
\text { DE }\end{array}$} \\
\hline & $\begin{array}{l}\text { Valor } \\
\text { medido }\end{array}$ & $\begin{array}{c}\text { Valor } \\
\text { desejado }\end{array}$ & & & & & & & \\
\hline FEDERAL & 3,89 & 3,89 & & $100 \%$ & 1 & 2 & $4 \%$ & 0,4 & \\
\hline $\begin{array}{l}\text { NBRS, NRS, } \\
\text { RESOLUÇÕES, } \\
\text { DECRETOS }\end{array}$ & 3,89 & 3,89 & & $100 \%$ & 1 & 2 & $4 \%$ & 0,04 & \\
\hline SGA & 0,97 & 3,89 & & $25 \%$ & 0 & 2 & $4 \%$ & 0,00 & \\
\hline
\end{tabular}

Tabela 59 - Resultado da avaliação de sustentabilidade utilizando o framework considerando os indicadores ambientais

\begin{tabular}{l|cccccc}
\multicolumn{1}{c|}{ ITEM } & ECONÔMICO & AMBIENTAL & SOCIAL & TECNOLÓGICO & RESULTADO & LIMITE \\
\hline PESO & $25 \%$ & $25 \%$ & $25 \%$ & $25 \%$ & & \\
ÍNDICES & $0 \%$ & $32 \%$ & $0 \%$ & $0 \%$ & & \\
AVALIAÇÃO DO IISP & & & & & $0 \%$ & \\
AVALIAÇÃO DE SUSTENTABILIDADE & & & & & $8 \%$ & \\
NÍVEL MíNIMO DE SUSTENTABILIDADE & & & & & & \\
LIMITE DE SUSTENTABILIDADE & & & & & & \\
\hline
\end{tabular}

\subsection{SÍNTESE DO CAPÍTULO}

Foram apresentados exemplos de como o framework proposto pode ser implantado e utilizado com aplicações de diferentes métodos de avaliação da sustentabilidade. Os exemplos também mostram que apesar da subjetividade da análise qualitativa, que intrinsecamente associa incertezas no resultado, o framework considera a inserção de aspectos comportamentais dos colaboradores da empresa na avaliação, os quais são fundamentais para a avaliação da sustentabilidade, pois são estes os principais agentes promotores de mudanças em relação a isso.

Os exemplos mostraram que o framework atende a vários tipos de avaliação de empresa e/ou processos inclusive no ciclo de vida do produto:

- O método de Garbie (2014) e calcula a sustentabilidade de uma empresa utilizando os indicadores nos aspectos econômico, ambiental e social. Neste caso foram consideradas adaptações para uso de pesos para os indicadores.

- O método de Jayal et al. (2010) avalia todo o ciclo de vida do produto (nas fases de pré-fabricação, fabricação, uso e pós-uso). Neste caso 
foram adotadas adaptações como: (i) consideração de valores limites, (ii) valor de referência e (iii) peso dos indicadores.

- O método de Gest e Prod (2010) mostra o valor de certos índices de um grupo de indicadores de um processo produtivo e quanto faltou para eles alcançarem o valor esperado em relação ao aspecto ambiental. Neste caso foram adotadas adaptações na definição de um limite para o cálculo da sustentabilidade e o peso de importância do indicador.

Os casos apresentados exemplificam como o framework incorpora os diferentes métodos de avaliação de sustentabilidade e, comprova sua efetividade para avaliação sistemática de indicadores, identificando os níveis de contribuição de cada indicador no valor da sustentabilidade.

Figura 33 - Resultado da avaliação de sustentabilidade em fábrica de estamparia.

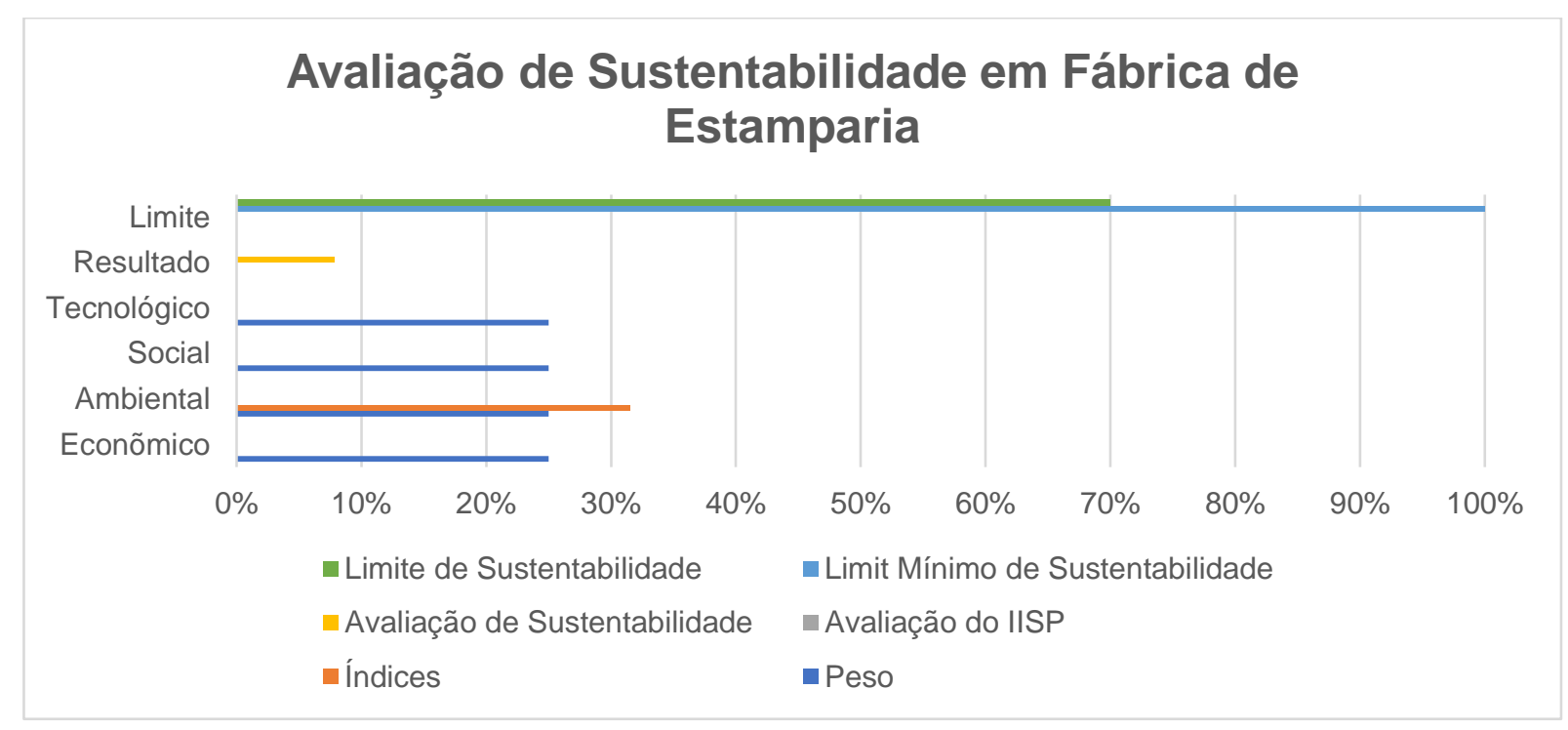

Fonte: $\mathrm{O}$ autor 


\section{CONSIDERAÇÕES FINAIS}

Neste trabalho uma reinterpretação e extensão da norma ANSI/ISA-95 foram introduzidas para caracterizar as funcionalidades necessárias para o cálculo dos indicadores de sustentabilidade num SPD (Sistema Produtivo Disperso), isto é, um módulo chamado de SuMS (Sustainability Management System), específico para o processamento de informações relacionadas com sustentabilidade, é incorporado no nível de gestão e controle do sistema produtivo e atua concomitantemente como o MES (Manufacturing Execution System). Com base nessa abordagem, um framework foi então proposto para orientar o desenvolvimento de um procedimento sistematizado de especificação e implantação das funcionalidades de um sistema para a avaliação de desempenho e da sustentabilidade de SPDs. Estudos de casos foram desenvolvidos e alguns deles apresentados como exemplos foram apresentados neste texto para comprovar e ilustrar como o framework é aplicado e como as suas funcionalidades são implementadas. Diferentes métodos de análise dos indicadores de sustentabilidade também são apresentados nos exemplos para demonstrar a versatilidade do framework já que ainda não existe um consenso de quantos e quais indicadores devem ser considerados para a avaliação do desempenho e da sustentabilidade de SPDs.

O framework mostrou-se efetivo para um primeiro nível de uniformização das abordagens de modo a viabilizar a monitoração e comparação dos indicadores de sustentabilidade de unidades produtivas e de empresas como um todo;

Com o framework se tem um meio eficaz para identificar melhorias potenciais nos processos de produção e sua estrutura permite a adoção de outras abordagens e procedimentos para avaliar a sustentabilidade de um SPD.

Em casos de diferentes métodos de análise dos indicadores de sustentabilidade, com algumas adaptações, o framework comprovou ser efetivo na uniformização dos procedimentos e na análise comparativa de dados.

Hipóteses como as estabelecidas pela norma ANSI/ISA-95 foram assumidas. Entretanto, devido a evoluções tecnológicas, entende-se que as normas atuais necessitam serem revistas assim como novas formas de organização industrial devem ser concebidas.

Este trabalho introduz um novo paradigma considerando o aspecto tecnológico no contexto de sustentabilidade em sistemas produtivos. Isto permite a medida da 
eficiência da execução das atividades produtivas baseado no conceito de inovação tecnológica.

Além disso, baseados nos estudos realizados e resultados obtidos um novo paradigma de sistema produtivo pode ser considerado, isto é, o foco estaria na sustentabilidade como um todo das entidades envolvidas, isto é, com o equilíbrio dos aspectos sociais, tecnológicos, econômicos e ambientais. Sob este enfoque a produtividade e outros aspectos relacionados seriam tratados mais como custos a serem mitigados.

Se este novo paradigma for adotado, todo o planejamento e controle da produção da empresa estariam sujeitos aos indicadores de sustentabilidade e a automação e autonomia dos sistemas garantiriam que as atividades em curso nunca causassem impactos negativos.

Considerando especificamente o framework aqui desenvolvido identifica-se ainda trabalhos que devem ser conduzidos para a especificação da implementação do framework proposto. Entre estes trabalhos cita-se:

- Especificação detalhada das interfaces e das funcionalidades em sistemas em que a sustentabilidade como um todo é necessária;

- Estudo de como os modelos em rede de Petri podem ser explorados para calcular previamente os valores dos indicadores de sustentabilidade e para análise destes em tempo real;

- Estudo da criticidade na seleção dos indicadores que devem fazer parte de uma proposta de um sistema de avaliação de desempenho e sustentabilidade para cada classe de sistemas produtivos;

Por fim, o aspecto tecnológico na sustentabilidade no sistema produtivo destaca também a relevância na investigação do presente trabalho para soluções dentro do contexto de novos ambientes como a Indústria 4.0 (COLOMBO et al., 2017). 


\section{REFERÊNCIA BIBLIOGRÁFICA}

AMRINA, E.; YUSOF, S. Key performance indicators for sustainable manufacturing evaluation in automotive companies. In: IEEE Intern. Conf. on Industrial Engineering and Engineering Management, pp. 1093-1097, 2011, Singapore: IEEE.

ANSI/ISA-95. Enterprise-Control System Integration Part3: Activity Models of Manufacturing Operations Management. ANSI/ISA95.00.03.2005.

ARATA, W.M.; MIYAGI, P.E. Modelagem e análise quantitativa de sistemas de manufatura por redes GSPN. Controle \& Automação, vol.8, no.1, pp.11-20, 1991.

ARATA, W.M.; MIYAGI, P.E. Formal comprehensiveness, uniformity, semantic, and intra/intermodel consistency in the representation of discrete event dynamic system models. In: XVIII COBEM International Congress of Mechanical Engineering, Ouro Preto, MG:ABCM, 2005.

BAGHERI, B.; YANG, S.; KAO, H.-A.; LEE, J. Cyber-physical systems architecture for self-aware machines in Industry 4.0 environment. IFAC-PapersOnLine, vol.48, pp. 1622-1627, 2015.

BROWN, A.; AMUNDSON, J.; BADURDEEN, F. Sustainable value stream mapping (Sus-VSM) in different manufacturing system configurations: application case studies. Journal of Cleaner Production, vol.85, pp.164-179, 2014.

BUCHERT, T.; NEUGEBAUER, S.; SCHENKER, S.; LINDOW, K.; STARK, R. Multicriteria decision making as a tool for sustainable product development - benefits and obstacles. Procedia CIRP, vol. 26, pp. 70 - 75, 2015.

CAMBRIDGE. Acessado em 12/01/2017 do site: http://dictionary.cambridge.org/pt/dicionario/essential-british-english/.

CANNATA, A.; TAISCH, M. (2010). Introducing energy performances in production management: towards energy efficient manufacturing. IFIP Advances in Information and Communication Technology, vol. 338, pp. 168-175, 2010.

CARDOSO, J.; VALLETE, R. Rede de Petri. Florianópolis, Brasil: Editora da UFSC, 1997.

CASSANDRAS, C.G.; LAFORTUNE, S. Introduction to Discrete Event Systems. Springer, New York, 3 edition, 2010.

CHEN, D.; THIEDE, S.; SCHUDELEIT, T.; HERRMANN, C. A holistic and rapid sustainability assessment tool for manufacturing SMEs. CIRP Annals, I.63, no.1, pp. 437-440, 2014.

COLOMBO, U. The Club of Rome and sustainable development. Futures, vol.33, no.1, pp.7-11, 2011. 
COLOMBO, A.; BANGEMANN, T.; KARNOUSKOS, S. A system of systems view on collaborative industrial automation. In: IEEE Intern. Conf. on Industrial Technology. Cape Town, 2013.

COLOMBO, A.W.; KARNOUSKOS, S.; KAYNAK, O.; SHI, Y.; YIN, S. Industrial cyber physical systems - a backbone of the fourth Industrial revolution. IEEE Industrial Electronics Magazine, vol.11, no.1, pp.: 6-16, 2017.

CURY, J.E.R. Teoria de controle supervisório de sistemas a eventos discretos. In: $5^{\mathbf{o}}$ SBAI Simpósio Brasileiro de Automação Inteligente, Canela, RS, 2001.

DA SILVA, R.M.; BLOS, M.F.; JUNQUEIRA, F.; SANTOS FILHO, D.J.; MIYAGI, P.E. A service and holonic control architecture to the reconfiguration of dispersed manufacturing system. IFIP Advances in Information and Communication Technology, vol. 423, pp.111-118, 2014.

DA SILVA, R.M.; JUNQUEIRA, F.; SANTOS FILHO, D.J.; MIYAGI, P.E. Control architecture and design method of reconfigurable manufacturing systems. Control Engineering Practice, vol.49, pp, 87-100, 2016.

ELKINGTON, J. Cannibals with Forks - The Triple Bottom Line of 21st Century Business. Oxford: Capstone Publishing Ltd, 1997.

ESMAEILIAN, B.; BEHDAD, S.A. The evolution and future of manufacturing: a review. Journal of Manufacturing Systems, vol.39, pp. 79-100, 2016.

FAULKNER, W.; BADURDEEN, F. Sustainable Value Stream Mapping (Sus-VSM): methodology to visualize and assess manufacturing sustainability performance. Journal of Cleaner Production, 2014.

FERREIRA, L.; PUTNIK, G.; CUNHA, M.; PUTNIK, Z.; CASTRO, H.; ALVES, C.; VARELA, M. Cloudlet architecture for dashboard in cloud and ubiquitous. Procedia CIRP, vol. 2, pp.366-371, 2013.

GARBIE, I.H.; AL-HOSNI, F.S. New evaluation of petroleum companies based on the agility level in Gulf area. International Journal of Industrial and Systems Engineering, vol.18, no.4, 2014, DOI10.1504/IJISE.2014.065622.

GARBIE, I.H. An analytical technique to model and assess sustainable development index in manufacturing enterprises, International Journal of Production Research, vol. 52, no.16, pp. 4876-4915, 2014, DOI: 10.1080/00207543.2014.893066.

GAUDREAU, K.; GIBSON, R.B. Illustrating integrated sustainability and resilience based assessments: a smallscale biodiesel project in Barbados. Impact Assessment and Project Appraisal, vol. 28, no. 3, pp. 233-43, 2010.

GIBSON, B.; Hassan, S. Sustainability Assessment: Criteria and Processes, 1st Edition, Kindle Edition, 2005.

GOLDSTONE, J. Efflorescences and economic growth in world history: rethinking the "rise of the west" and the industrial revolution. Journal of World History, vol. 13, no.2, pp. 323-389, 2002. 
ISO (2004a). Environmental management - Life cycle assessment - Goal and scope definition and inventory analysis. ISO14041:2004.

ISO (2004b). Environmental mmanagement - Life cycle assessment - Life cycle impact assessment. ISO14042:2004.

ISO (2014a). Automation Systems and Integration - Key Performance Indicator, Part 1: Overview, Concepts and Terminology. ISO22400-1:2014.

ISO (2014b). Automation Systems and Integration - Key Performance Indicator (KPIs), Part 2: Definitions and Descriptions. SO22400-2:2014.

JAYAL, A.; BADURDEEN, F.; DILLON, JR.O.; JAWAHIR, I. Sustainable manufacturing: modeling and optimization challenges at the product,process and system levels. CIRP Journal of Manufacturing Science and Technology, vol. 2, pp.144-152, 2010.

JEONG, H.; PARK, J.; LEE, J. The cloud storage model for manufacturing system in global factory automation. 28th Intern. Conf. on Advanced Information Networking and Applications Workshops, pp. 895-899, 2014. Victoria, BC.

JOUNG, C.; CARREL, J.; SARKAR, P.; FENG, S. Categorization of indicators for sustainable manufacturing. Ecological Indicators, vol. 24, pp.148-157, 2012.

JUNQUEIRA, F. Modelagem e Simulação Distribuída de Sistemas Produtivos. 2006. Biblioteca Digital de Teses e Dissertações da Universidade de São Paulo, São Paulo, 2006. Disponível em: <http://www.teses.usp.br/teses/disponiveis/ 3/3132/tde11122006-150356/>. Acesso em: 20 set. 2015.

JUNQUEIRA, F.; MIYAGI, P. E. Modelagem e simulação distribuída de sistema produtivo baseados em rede de Petri. Sba: Controle \& Automação Sociedade Brasileira de Automatica, v. 20, n. 1, p. 1-19, 2009.

KRAJNC, D.; GLAVI, P. A model for integrated assessment of sustainable development. Resources, Conservation and Recycling, vol. 43, no. 2, pp. 189-208, 2005.

KONDOH, S.; MISHIMA, N.; HOTTA, Y.; WATARI, K.; KURITA, T.; MASUI, K. Evaluation and re-design method of manufacturing processes. 10th International Design Conference, pp. 1167-1174, 2008. Dubrovnik, Croatia.

MATLab Programming Fundamentals (C COPYRIGHT 1984-2016 by The MathWorks, Inc. Retrieved maio 24, 2016, from http://www.mathworks.com/help/pdf_doc/matlab/index.html?s_cid=doc_ftr

MEADOWS, D.H.; MEADOWS, D.L.; RANDERS, J.; BEHRENS II, W.W. The Limits to Growth, A Report for The Club of Rome's Project on the Predicament of Mankind, Potomac Associates Book, Universe Books: New York, 1972.

MCDONOUGH, W.; BRAUNGART, M. The nextindustrial revolution. The Atlantic Monthly, vol. 282, no. 4, pp. 82-92, 1998. 
MELL, P.; GLANCE, T. Definition of Cloud Computing - U.S. Department of Commerce. Special Publication, pp. 800-145, 2011.

MELLO, J.I.; JUNQUEIRA, F.; MIYAGI, P.E. Towards modular and coordinated manufacturing systems oriented to services. Dyna, vol. 77, no. 163, pp.201-210, 2010.

MORALES, R.A.G.; MELO, J.I.; MIYAGI, P.E. Diagnosis and treatment of faults inproductive systems based on Bayesian networks and Petri net. IEEE International Conferenceon Automation Science and Engineering, pp. 357-362, 2007. DOI:10.1109/COASE.2007.4341823.

MIYAGI, P.E. Controle Programável - Fundamentos do Controle de Sistemas a Eventos Discretos. 1를 Edição, 1996, São Paulo - Brasil: Edgard Blücher.

MOLDAVSKA, A.; WELOB T. On the applicability of sustainability assessment tools in manufacturing. The 22nd CIRP conference on Life Cycle Engineering. Procedia CIRP, vol. 29, pp. 621-626, 2015.

MONEIM, A.F.A.; GALAL, N.M.; SHAKWY, M.E. Sustainable Manufacturing Indicators. In: Global Climate Change. Biodiversity and Sustainability. Egypt, 2013.

MURATA, T. Petri nets - properties, analysis and applications. Proceedings of the IEEE, vol. 77, 1989.

NAÇÕES UNIDAS. Retrieved 02.2017, from site das Nações Unidas: https://nacoesunidas.org/acao/meio-ambiente/;

O'BRIEN, C. Sustainable production - a new paradigm for a new millennium. International Journal of Production Economics, vol. 60-61, pp.1-7, 1999.

OECD Sustainable Development: Critical Issues. Organization for Economic Cooperation and Development, 2001.

OECD Sustainable Manufacturing Toolkit - Seven Steps to Environmental Excellence, Start-up Guide. Organization for Economic Co-operation and Development, 2011.

PAJU, M.; HEILALA, J.; HENTULA, M.; HEIKKIL, A.; JOHANSSON, B.; LEONG, S.; LYONS, K. Framework and indicators for a sustainable manufacturing mapping methodology. In: Winter Simulation Conference. Baltimore, Maryland, 2010.

PETERSON, J.L. Petri Net Theory and the Modeling of Systems, Prentice Hall, Inc. (ISBN: 0136619835), 1981.

QUEBEC Retrieved 02.2017, from site Sustainable development: historical markers: http://www.mddelcc.gouv.qc.ca/developpement/reperes_en.htm\#1972;

SARTI, F.; HIRATUKA, C. Indústria mundial: mudanças e tendências recentes. IE/UNICAMP n. 186, 2010. ISSN 0103-9466.

SENGE, P.C.; PORTER, P. Innovating Our Way to the Next Industrial Revolution. MIT Sloan Management Review, vol.24, 2001. 
SILVA, M. Half a century after Carl Adam Petri's PhD thesis: a perspective on the field. Annual Reviews in Control, vol.37, no.2, pp.191-219, 2013.

SINGH, S.; OLUGU, E.; FALLAHPOUR, A. Fuzzy-based sustainable manufacturing assessment model for SMEs. Clean Techn. Environ. Policy, vol. 16, no.5, pp. 84760, 2014.

SPARKS, D.; BADURDEEN, F. Combining sustainable value stream mapping and simulation to assess supply chain performance. In: Industrial and Systems Engineering Research Conference. Montreal, Canada, 2014.

SUNDMAEKER, H.; GUILLEMIN, P.; FRIES, P.; WOELFFLE, S. Vision and challenges for realising the internet of things. CERP-IoT Cluster of European Research Projects on the Internet of Things, 2013.

TAN, H.; YEOA, Z.; NGA, R.; TJANDRAA, T.B.; SONG, B. A sustainability indicator framework for Singapore small and medium-sized manufacturing enterprises. ProcediaCIRP, vol.29, pp.132-137, 2015.

TRACEY, M; VONDEREMBSE, M.A.; LIM, J.S. Manufacturing technology and strategy formulation: keys to enhancing competitiveness and improving performance. Journal of Operations Management, vol.17, no. 4, pp.411-428, 1999.

VELEVA, V.; HART, M.; GREINER, T.A. Indicators of sustainable production. Journal of Cleaner Production, vol.9, pp.447-452, 2001.

VELEVA, V.; ELLENBECKER, M. Indicators of sustainable production: framework and methodology. Journal of Cleaner Production, vol. 9, no.6, pp. 519-49, 2001.

VERRIER, B.; ROSE, B.; CAILLAUD, E.; REMITA, H. Combining organizational performance with sustainable development issues the lean and green project benchmarking repository. Journal of Clean Production, vol.85, pp.83-93, 2013.

YOO, T.; JEONG, B.; CHO, H. A Petri nets based functional validation for services composition. Expert Systems with Applications, vol. 37, no. 5, pp. 3768-3776, 2010. DOI: 10.1016/j.eswa.2009.11.046

YUSOF, N.M.; SAMAN, M.Z.M.; KASAVA, N.K. A conceptual sustainable domain value stream mapping framework for manufacturing. In: 11th Global Conference on Sustainable Manufacturing. Berlin, Germany, 2013.

WCED. Our Commom Future. Oxford University, 1987.

WOLLSCHAEGER, M.; SAUTER, T.; JASPERNEITE, J. The future of industrial communication: automation networks in the era of the internet of things and Industry 4.0. IEEE Industrial Electronics Magazine, vol.11, no.1, pp. 17-27, 2017. DOI: 10.1109/MIE.2017.2649104, ISSN: 1932-4529.

WU, D.; ROSEN, D.; WANG, L.; SCHAREFER, D. Cloud-based design and manufacturing: A new paradigm in digital manufacturing and design innovation. Computer-Aided Design, vol.59, pp. 1-14, 2015. 
ZHANG, X.; BADURDEEN, F.; ROUCH, K.; JAWAHIR, I. On improving the product sustainability of metallic automotive components by using the total life-cycle approach and the 6R methodology. 11th Global Conf. on Sustainable Manufacturing Innovative Solutions. Berlin, Germany, 2013. 


\section{ANEXO}

São listados aqui os trabalhos derivados da presente tese e que foram aceitos em congressos e a sua relação com a pesquisa desenvolvida.

\section{AN1. TRABALHOS}

Segue uma lista de trabalhos desenvolvidos ao longo do curso, os quais foram submetidos a congressos nacionais e internacionais e aceitos para publicações em seus anais.

\section{AN1.1 ACEITOS E APRESENTADOS EM EVENTOS TÉCNICO- CIENTÍFICOS}

Watanabe, E.H.; da Silva, R.M.; Junqueira, F.; Santos Filho, D.J.; Miyagi, P.E. (2014), Indicadores de Desempenho em Sistemas Produtivos Sustentáveis - Abordagem com a Ferramenta PFS - ENEGEP 2014 XXXIV Encontro Nacional da Engenharia de Produção. Este foi o primeiro manuscrito produzido, após estudar sobre desempenho de sustentabilidade em sistemas produtivos, e após pesquisas sobre o estado da arte dos indicadores de sustentabilidade na indústria, definiuse o tema para se trabalhar na tese.

Watanabe, E.H.; da Silva, R.M.; Blos, M.F.; Junqueira, F.; Santos Filho, D.J.; Miyagi P.E. (2014), Modelagem de Processos para Avaliação de Desempenho em Sistemas Produtivos Sustentávies - INDUSCON 2014, XI International Conference on Industry Applications. Após pesquisas observou-se gaps na área da avaliação de sustentabilidade em sistemas produtivos como a falta de uma abordagem sistemática. Assim neste segundo manuscrito tratou-se de incluir técnicas de modelagem para explorar a sistematização no processo de avaliação.

Watanabe, E.H.; da Silva, R.M.; Blos, M.F.; Junqueira, F.; Santos Filho, D.J.; Miyagi, P.E. (2015), A Framework to Evaluate Performance of Disperse Productive System through the Sustainability Performance Indicators, INCOM $2015-15^{\text {th }}$ IFAC/IEEE/IFIP/IFORS Symposium of Information Control Problems in Manufacturing, 
Ottawa Canada. Para dar uma solução abrangente de avaliar desempenho de um sistema desenvolveu-se uma estrutura, framework, considerando uma reinterpretação da norma ANSI/ISA 95 e técnicas de modelagem, o qual foi desenvolvido neste manuscrito.

Watanabe, E.H.; da Silva, R.M.; Blos, M.F.; Junqueira, F.; Santos Filho, D.J.; Miyagi, P.E. (2015), Key Performance Indicators for Disperse Productive System to Evaluate Performance Sustainability. COBEM 2015 - 23rd ABCM International Congress of Mechanical Engineering- Rio de Janeiro-RJ. Investigou-se indicadores utilizados em indústrias e classificou-se e reorganizou-se em listas conforme os aspectos de sustentabilidade e criou-se uma lista com indicadores de tecnologia onde monitora o desempenho através do uso de tecnologias inovadoras. Estas listas de indicadores foram publicadas neste manuscrito.

Watanabe, E.H.; da Silva, R.M; Junqueira, F.; Santos Filho, D.J.; Miyagi, P.E. (2016), An Emerging Industrial Business Model considering Sustainability Evaluation and using Cyber Physical System Technology and Modelling Techniques. CPHS 2016 - 1st IFAC Conference on Cyber-Physical e Human-Systems. Florianópolis Brazil.Para propor uma idéia de fazer nogócio utilizando ferramenta como Rede de Petri e sistemas computacionais baseados na Internet, este assunto foi apresentado neste manuscrito, onde a sustentabilidade é o condutor de mudanças nas atividades das empresas.

Watanabe, E.H.; da Silva, R.M.; Tsuzuki, M.S.G, Junqueira, F.; Santos Filho, D.J.; Miyagi, P.E. (2016), A Framework to Evaluate the Performance of a New Industrial Business Model. IMS $2016-12^{\text {th }}$ IFAC Workshop on Intelligent Manufacturing Systems. Austin, Texas - USA. Aplicação do framework proposto para avaliar a sustentabilidade de cada departamento de uma empresa e assim avaliar a eficiência de suas atividades. Este foi $o$ assunto deste manuscrito.

Watanabe, E.H.; da Silva, R.M.; Tsuzuki, M.S.G, Junqueira, F.; Santos Filho, D.J.; Miyagi, P.E. (2017),A Methodology to Evaluate Sustainability Performance in Productive System considering Modelling Techniques. IFAC 2017 - The $29^{\text {th }}$ World Congress of the International Federation of Automatic Control. Toulouse - 
France. O estudo das técnicas de modelagem como ferramenta de avaliação online dos indicadores de sustentabilidade foi o assunto deste manuscrito.

AN1.2. Trabalhos publicados em periódicos científicos

Watanabe, E.H.; da Silva, R.M.; Junqueira, F.; Santos Filho, D.J.; Miyagi, P.E. (2016), Systematization Performance Evaluation Process for Industrial Productive Systems considering Sustainability Indicators. IFIP Advances in Information and Communication Technology, vol. 470, pp. 77-85. Os conceitos de Sistema Ciber físico foram utilizados para mostrar a possibilidade de implementação de meios computacionais na avaliação da sustentabilidade. Este foi o assunto para este manuscrito.

Watanabe, E.H.; da Silva, R.M.; Blos, M.F.; Junqueira, F.; Santos Filho, D.J.; Miyagi, P.E. (2018), Framework to Evaluate Performance and Sustainability of Disperse Productive Systems. Springer JBSMSE - Journal of the Brazilian Society of Mechanical Sciences and Engineering. (no prelo) $O$ framework foi detalhado em todos as suas funcionalidades, este é o resultado de todo estudo desenvolvido e publicado em cada manuscrito ao longo do período de pesquisa que teve como meta a elaboração da tese.

\section{AN2. REDE DE PETRI (RDP)}

A rede de Petri (RdP), como uma ferramenta gráfica e matemática, provê um ambiente uniforme para modelagem, análise formal e projeto de SEDs (ZURAWSKI e ZHOU, 1994; ADAM et al., 1998) e, é comprovadamente efetiva como técnica de descrição e especificação de processos (MORALES; MELO e MIYAGI, 2007; YOO et al., 2010; HAMADI e BENATALLAH, 2003). É uma representação que pode ser usada tanto no nível conceitual quanto no nível funcional de um sistema e que pode assim ser analisado e validado antes de prosseguir sua conversão para um programa de controle (ADAM et al., 1998). A RdP é uma ferramenta de comunicação entre pessoas relacionadas ao projeto e análise de sistemas, permitindo uma fácil interpretação e clara identificação dos estados e ações. Possui a vantagem de que um mesmo modelo pode ser usado para análise das propriedades comportamentais e para validação de 
desempenho, assim como para o desenvolvimento sistemático de modelos para simulação e para programação de controladores (ZURAWSKI e ZHOU, 1994). Possibilita a representação da dinâmica do sistema e sua estrutura em diferentes níveis de abstração. Pode ser usada para modelar propriedades de sistemas como sincronização de processos, eventos assíncronos, operações concorrentes e conflitos ou compartilhamento de recursos (ZURAWSK e ZHOU, 1994; ADAM et al., 1998). Como ferramenta gráfica, provê um meio de comunicação entre os usuários, como o engenheiro de requisitos, e o cliente (ZURAWSKI e ZHOU, 1994). Matematicamente, a RdP pode ser descrita por um conjunto de equações algébricas lineares e, por isso, pode ser usada para a verificação formal de relações de precedência entre eventos, operações concorrentes, sincronização de atividades, inexistência de deadlocks, atividades repetitivas e de exclusão mútua de recursos compartilhados (ZURAWSKI e ZHOU, 1994).

Desde sua apresentação por Carl Adam Petri (BRAUER e REISIG, 2006), a RdP tem sido usada na modelagem e análise de diferentes tipos de sistemas e aplicações tais como: protocolos distribuídos (KANESHIRO et al., 2008), aplicações industriais (ZURAWSKI e ZHOU, 1994), tratamento de falhas (MORALES, MELO e MIYAGI, 2007; LIRA et al., 2008), fluxo de processos (KIEPUSZEWSKI et al., 2003), controle supervisório (LEE et al., 2005; GARCIA et al., 2008), entre outras.

A RdP é um grafo composto de lugares (neste texto os termos reservados da RdP estão sublinhados), representados por círculos, transições, representado por barras, arcos orientados interligando os componentes anteriores e marcas, que são utilizadas para definir o estado de uma RdP. Também são consideradas multigrafos direcionados bipartidos (Figura A1), pois vários arcos orientados podem sair de um nó, lugar ou transição, para os demais, existindo a restrição de que os arcos só interligam elementos de natureza diferente (PETERSON, 1981; MURATA, 1989; SILVA, 2013; SRINIVASAN e VENKATASUBRAMANIAN, 1998).

Matematicamente, a RdP pode ser descrita por um conjunto de equações algébricas lineares (ZURAWSKI e ZHOU, 1994). 
Figura A1 - Exemplo de multigrafos em uma rede de Petri (RdP).

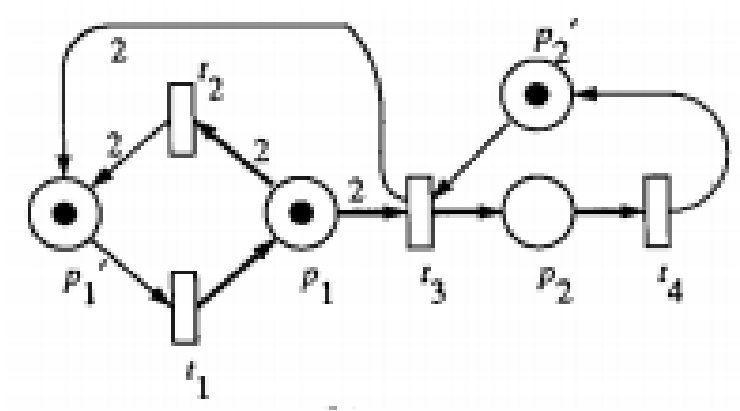

Fonte: Adaptado de Murata (1989).

\section{AN3.1 FORMALIZAÇÃO}

Existem atualmente vários tipos de $\mathrm{RdP}$, sendo que aqui apresenta-se inicialmente a chamada de rede de Petri Condição-Evento (C/E net) que, matematicamente é descrita como uma 4-tupla:

$$
P N_{C E}=(P, T, F, M)
$$

onde:

$P$ é o conjunto de elementos passivos chamados de lugares,

$T$ é o conjunto de elementos ativos chamados de transições,

$F_{C E}$ é o conjunto de relacionamentos entre os elementos passivos e os elementos ativos chamados de arcos orientados e $M_{C E}$ é um vetor de números binários em que cada elemento $m_{i}$ indica o número de marcas no lugar $p_{i} \mathrm{e}, m_{i} \in(0,1)$, onde, $P$ e $T$ são conjuntos finitos, não nulos $(P \cup T \neq \emptyset)$ e disjuntos $(P \cap T=\emptyset)$, e

$$
F_{C E} \underline{C}(P \times T) \cup(T \times P)
$$

Os estados do sistema ou processo e sua evolução são representados pela distribuição das marcas (marcação) nos lugares da rede. A dinâmica da RdP depende de seus elementos ativos, isto é, as transições, e de como as marcas estão distribuídas entre os elementos passivos, os lugares da rede. Pode-se assim adotar a ideia de que as marcas fluem pela rede direcionada pelos arcos orientados, isto é, fluem de um lugar para uma transição e de uma transição para um lugar. 
Para que uma marca flua de um lugar $p \in P$ para uma transiçãot $t \in T$ por um arco orientado $f \in F_{C E}$, esse lugar deve possuir uma marca, ou seja, $m_{p}=1$. Esse lugarp é dito então uma pré-condição da transição $t$ e sua representação é $p \in \bullet t$, em que, $\bullet t$ é um conjunto de pré-condições da transição $t$.

Para que uma marca flua de uma transição $t \in T$ para um lugar $p \in P$ por um arco orientado $f \in F_{C E}$, esse lugar não deve possuir marcas, ou seja, $m_{p}=0$. Esse lugar $p$ é dito então uma pós-condição da transição $t$ e sua representação é $p \in t \bullet$, em que $t$ • é um conjunto de pós-condições da transição $t$.

Quando uma transição possui todas as suas pré-condições e pós-condições atendidas essa transição é dita habilitada para o disparo. Uma transição habilitada para o disparo pode realizar o fluxo de marcas e, caso esse ocorra (num certo instante denominado passo), todo lugar $p_{i}$ tal que $p_{i} \in \bullet t$ tem sua marcação alterada entre 0 passo $k$ e o passo $k+1$ da seguinte maneira $m_{p_{i, k+1}}=0$, e todo lugar $p_{j}$ tal que $p_{j} \in$ $t \bullet$ tem sua marcação alterada entre o passo $k$ e o passo $k+1$ da seguinte maneira $m_{p_{j, k+1}}=1$.

\section{AN3.2 CARACTERÍSTICAS DOS SEDS MODELADOS EM RDP}

O comportamento dinâmico de SEDs pode ser entendido pela evolução de seus processos que possuem características especificas. Estes processos por sua vez são compostos por um conjunto de atividades. Algumas das características mais importantes dos processos em SEDs são:

Sequência: a sequência é a característica mais frequente em processos e indica uma ordem de realização das atividades envolvidas, isto é, qual processo ou conjunto de atividades deve ser concluído para que outro seja iniciado. Em RdP, atividades são representados por transições. Assim, a relação de sequência de duas atividades $t_{1}$ e $t_{2}$, pode ser representada adicionando-se num lugar $p_{1}$ e $\underline{\operatorname{arcos}}$ orientados de modo que $p_{1} \in \bullet t_{2}$ e $p_{1} \in t_{1} \bullet$. Assim para que a transição $t_{2}$ seja habilitada é necessário que a transição $t_{1}$ tenha sido anteriormente disparada. A Figura A2 mostra duas atividades numa relação de sequência. 
Figura A2 - Representação em RdP de duas atividades em sequência.

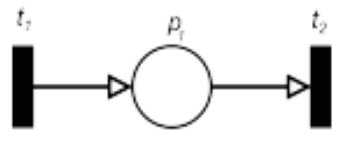

Fonte: Adaptado de Murata (1989).

Paralelismo: o paralelismo é uma característica das atividades que podem ser executados ao mesmo tempo, isto é, concomitantemente sem que haja interferência da execução de um em outro, mas ambos com a mesma origem, isto é, uma única condição (estado) inicial. Em RdP, o paralelismo de duas atividades pode ser modelado por duas transições $t_{2}$ e $t_{3}$ e dois lugares $p_{1}$ e $p_{2}$ e arcos orientados de modo que $p_{1} \in \bullet t_{2}, p_{2} \in \bullet t_{3}$. Para representar a mesma condição inicail, adiciona-se mais uma transição $t_{1} \mathrm{e}$ arcos orientados para que, $p_{1} \in t_{1} \bullet, p_{2} \in t_{1} \bullet$. Assim, quando ocorre 0 disparo da transição $t_{1}$ tanto a transição $t_{2}$ quanto a transição $t_{3}$ ficam habilitadas, mas 0 disparo de um independe da outra. A Figura A3 mostra um paralelismo de duas atividades.

Figura A3 - Representação do paralelismo em RdP de duas atividades com a mesma condição inicial.

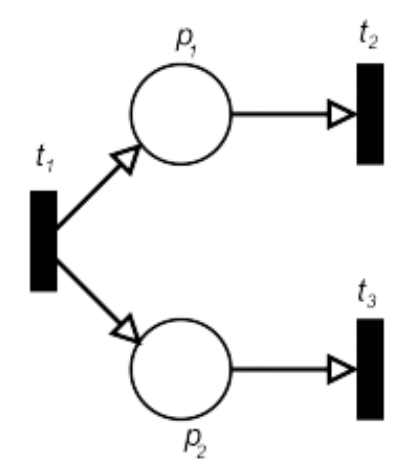

Fonte: Adaptado de Murata (1989).

Sincronização: a sincronização é uma característica de sistemas em que uma atividade depende da execução de outras atividades. Em geral, a sincronização é feita entre atividades em paralelo, mas também pode ocorrer entre duas atividades com origens (processos) totalmente independentes. Em RdP, a sincronização de duas atividades pode ser modelada por três transições $t_{1}, t_{2} \mathrm{e} t_{3} \mathrm{e}$ dois lugares $p_{1} e p_{2} \mathrm{e}$ 
arcos orientados de modo que $p_{1} \in \bullet t_{3}, p_{2} \in \bullet t_{3,}, p_{1} \in t_{1} \bullet, p_{2} \in t_{2} \bullet$. Assim, é necessário que tanto a transição $t_{1}$ como a transição $t_{2}$ sejam anteriormente disparadas para que a transição $t_{3}$ seja habilitada. A Figura A4 mostra uma sincronização de duas atividades.

Figura 34 - Representação em RdP da sincronização de duas atividades.

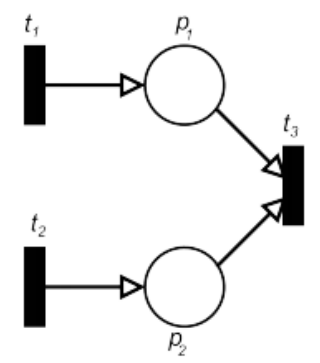

Fonte: Adaptado de Murata (1989).

Conflito: o conflito é uma característica de sistemas associada a escolha. Quando as atividades estão em conflito, significa que apenas uma delas pode ser executada e, a execução de uma dessas atividades inibe a execução das outras atividades que estavam em conflito. Em RdP, o conflito de duas atividades pode ser modelada por três transições $t_{1}, t_{2}$ e $t_{3} \mathrm{e}$ um lugar $p_{1}$ em que $p_{1} \in \bullet t_{2}, p_{1} \in \bullet t_{3} \mathrm{e}$ $p_{1} \in t_{1} \cdot$. Assim, após o disparo da transição $t_{1}$, tanto a transição $t_{2}$ quanto a transição $t_{3}$ ficam habilitadas, mas apenas uma delas poderá ser disparada. A Figura A5 ilustra este caso.

Figura A5 - Representação em RdP do conflito entre duas atividades.

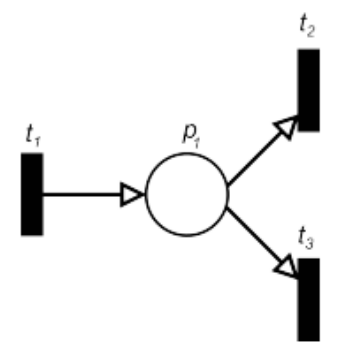

Fonte: Adaptado de Murata (1989). 
Compartilhamento de recursos: o compartilhamento de recursos é uma característica de sistemas em que atividades diferentes dependem de um mesmo recurso para serem executados. Um recurso pode ser um equipamento usado em diferentes atividades em um SP como uma máquina ou ferramenta usada em sistemas de manufatura. Em RdP, o compartilhamento de recursos de duas atividades pode ser modelado por quatro transições $t_{1}, t_{2}, t_{3}$ e $t_{4}$ e, três lugares $p_{1}, p_{2}$ e $p_{3}$ em que $p_{1} \in \bullet$ $t_{1}, p_{1} \in \bullet t_{2}, p_{2} \in \bullet t_{3}, p_{3} \in \bullet t_{4}, p_{2} \in t_{1} \bullet, p_{3} \in t_{2} \bullet, p_{1} \in t_{3} \bullet$ e $p_{1} \in t_{4} \bullet$ e $m_{p_{1}}=1$. Assim, tanto a sequencia $t_{1}, t_{3}$ quanto a sequencia $t_{2}, t_{4}$ dependem de um recurso presente em $p_{1}$, mas por ser um recurso único, apenas uma das sequencias pode ocorrer de cada vez e apenas após essa sequencia ser finalizada, o recurso volta a ficar disponível. A Figura A6 mostra um compartilhamento de recurso de dois processos.

Figura A6 - Represetnação em RdP do compartilhamento de recursos entre atividades de dois processos distintos.

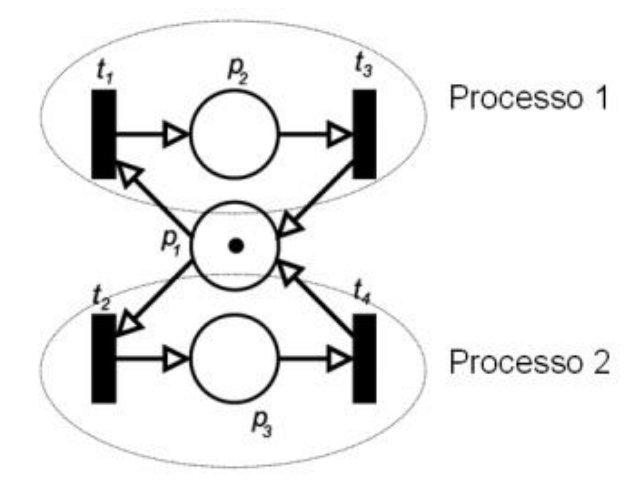

Fonte: Adaptado de Murata (1989).

A representação de sistemas complexos, isto é, com grande número de elementos e/ou interações entre estes elementos, por meio de RdP pode gerar um grafo cuja dimensões pode ser de difícil manipulação, entendimento a análise. Como consequência, muitos usuários de RdP desenvolveram extensões para suprir suas necessidades, incluindo atributos adicionais, relações de tempo e comportamento estocásticos porém mantendo na medida do possível a simplicidade conceitual do grafo JENSEN, 1981; JENSEN et al., 2007; GUSTAVSON e TOERN, 1995). 


\section{AN4. Production Flow Schema (PFS)}

Baseado nas características de SEDs e nas implicações sobre os requisitos para especificação de seu controle foi desenvolvido o Production Flow Schema (PFS) que é associado a uma metodologia de modelagem de sistemas. Nesta metodologia o PFS é usado para a modelagem de processos no nível conceitual do sistema (MIYAGI, 1996) e a partir desse modelo, representado por um grafo PFS, realiza-se o detalhamento dos processos produtivos até a especificação dos comandos e sinais de controle envolvidos. Neste nível o sistema é modelado em RdP ou alguma outra extensão ou interpretação da RdP como o SFC, GRAFCET ou MFG (HASEGAWA e OHNO, 1985) que são técnicas próprias para a programação de controladores industriais.

O PFS consiste num modelo baseado numa abordagem top-down que assegura um procedimento sistemático, racional que é baseado na interpretação da propriedade de hierarquia da RdP. Utiliza a técnica de refinamentos sucessivos, explorando o conceito de macro eventos, ou seja, atividades que podem incluir vários outros eventos e estados organizados hierarquicamente (VILLANI, 2004; ARAKAKI et al., 1996). O modelo conceitual representando um alto nível de abstração do sistema e sem consideração de sua dinâmica do sistema visa descrever as principais características das funções que são consideradas no sistema, isto é, a ênfase está na identificação das partes que representam atividades e das partes que são consideradas passivas, assim como no fluxo de itens (pessoas, material e/ou informação) entre estes elementos. Segundo REISIG, (1992) o PFS é uma interpretação da RdP do tipo canal-agência.

O objetivo do PFS é identificar as atividades e o fluxo (informação, material, outros) envolvido em um nível de abstração relativamente alto. Este fluxo pode ser considerado como primário ou secundário conforme a interpretação adotada. O PFS é composto pelos seguintes elementos (Figura A7):

- $\quad$ atividade (neste texto os elementos do PFS também estão sublinhados): executa ações e modificações de itens;

- $\quad$ inter-atividade ou distribuidor: não executa nenhuma transformação, mas é capaz de armazenar e distribuir itens. Entre duas atividades deve sempre ter um elemento inter-atividade; $\mathrm{e}$

- $\quad$ arco: representa relacionamento entre os elementos. 
Figura A7 - Representação dos elementos do PFS.

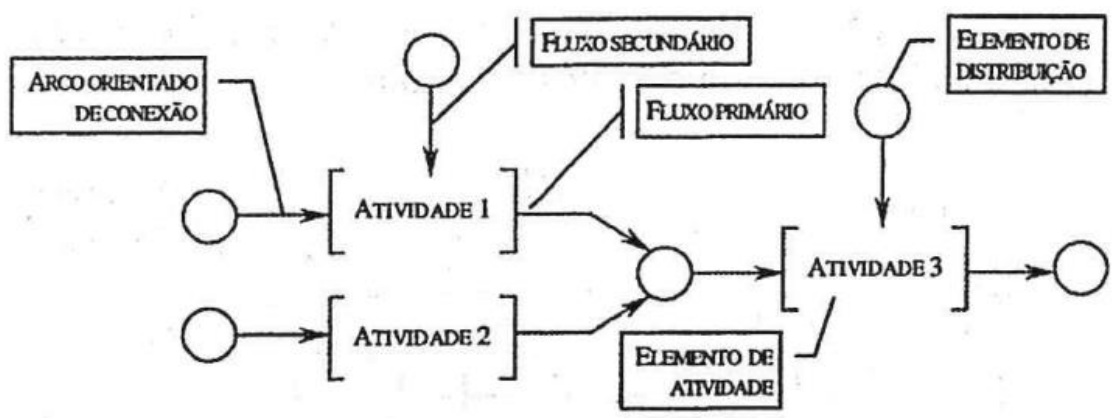

Fonte: $\mathrm{O}$ autor

No PFS, diferentemente da RdP não se tem o conceito de fluxo de marcas, isto é, não existe nenhuma representação explicita de evolução dinâmica.

Conforme Miyagi (2001), de modo geral, a aplicação racional e sistemática do PFS para modelagem de SPs deve seguir as seguintes etapas: (1) identificação das principais atividades de transformação de itens (materiais e/ou informações); (2) detalhamento dos fluxos de itens entre as atividades; (3) detalhamento das atividades, identificando as inter-atividades; (4) introdução dos elementos de controle de recursos e (5) detalhamento dos sinais trocados entre o sistema de controle e a planta.

A Figura A8 é um exemplo de um SP e sua modelagem em PFS.

Figura A8 - (a) Sistema produtivo. (b) Modelo em PFS do processo produtivo.

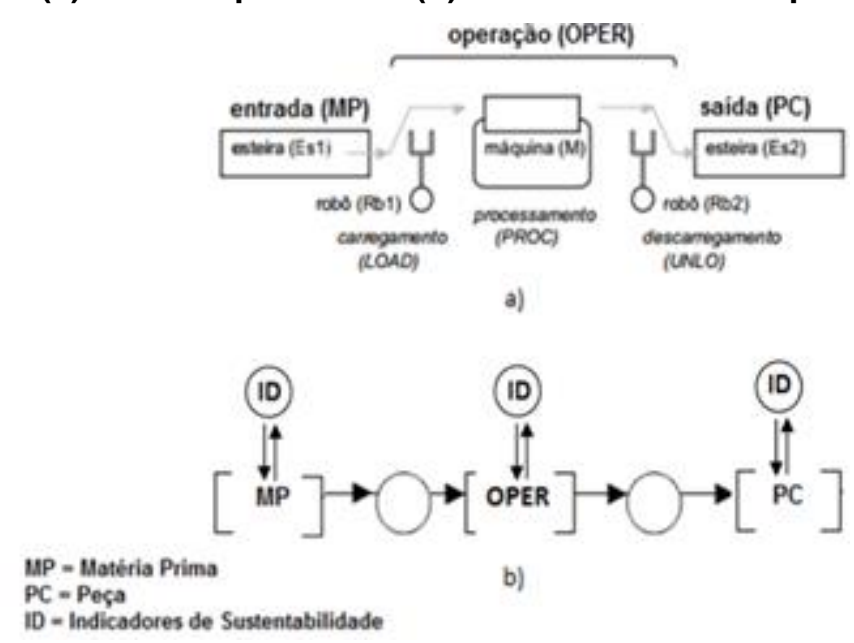

Fonte: Adaptado de Miyagi (1996).

A Figura A9 ilustra o modelo em PFS de um SP, onde as informações dos indicadores de sustentabilidade são requisitadas em uma das atividades da produção. 
Assim quando os modelos em RdP são derivados do PFS as variáveis relacionadas com os indicadores de desempenho são explicitamente descritas.

Figura A9 - Exemplo de modelo em RdP que detalha uma atividade do PFS de um sistema produtivo.

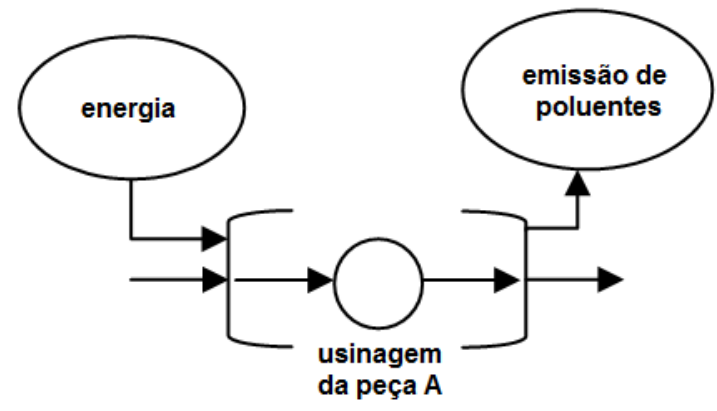

Fonte: $\mathrm{O}$ autor

\section{AN5. SIMULAÇÃO DISCRETA}

Simulação é, em geral, entendida como a "imitação" de uma operação ou de um processo do mundo real. A simulação envolve a geração de uma "história artificial" de um sistema para a análise de suas características operacionais.

O comportamento de um sistema é estudado por meio de um modelo de simulação. Este modelo evidentemente procura reproduzir o comportamento de diversos parâmetros que caracterizam a operação do sistema. Uma vez desenvolvido e validado, o modelo pode ser usado para investigar uma grande variedade de questões sobre o sistema. Mudanças no sistema podem ser simuladas a fim de prever o impacto no seu desempenho. A simulação pode também ser usada para estudar sistemas ainda na fase de concepção, antes que sejam efetivamente implementados. Assim, a simulação pode ser usada como uma ferramenta para predizer os efeitos de uma mudança em sistemas existentes e também como uma ferramenta de projeto para avaliar e validar o desempenho de novos sistemas (JUNQUEIRA e MIYAGI, 2009).

A simulação é vantajosa quando ela "imita" com menor custo ou menos recursos o que acontece num sistema real. Os dados de saída de uma simulação devem corresponder diretamente às saídas que seriam obtidas do sistema real. Em contraste com as técnicas analíticas, a simulação é "executada" ao invés de ser resolvida. Dado um conjunto particular de entradas o modelo é assim executado e o 
comportamento do sistema é gerado. De um processo de alteração de variáveis do modelo tem-se em um conjunto de cenários que podem ser estudados.

As principais vantagens da simulação são:

- Novas políticas, procedimentos operacionais, regras de decisão, fluxos de informação, procedimentos organizacionais, etc. podem ser estudados sem interferência nas operações do sistema real.

- Novos equipamentos, arranjos físicos, sistemas de transporte, etc. podem ser testados antes de se investir recursos com as aquisições envolvidas.

- Hipóteses de como e por que certos fenômenos ocorrem podem ser avaliados.

- $\quad$ O tempo pode ser comprimido ou expandido, permitindo que o fenômeno em estudo possa ser acelerado ou retardado.

- Gargalos onde as informações ou materiais têm seus fluxos comprometidos podem ser identificados.

- $\quad$ As principais desvantagens são:

- A construção de modelos requer um treinamento especializado. Pode ser considerada uma "arte" que se aprende ao longo do tempo e que envolve o "bom" uso da experiência.

- Os resultados da simulação podem ser difíceis de interpretar. Como as saídas da simulação podem incluir variáveis aleatórias, não é trivial determinar se os resultados observados resultam de inter-relações efetivas das partes do sistema ou se é fruto da aleatoriedade do sistema.

- A modelagem do sistema e a análise dos dados podem consumir muito tempo e muitos recursos. Por outro lado, economizar tempo e recursos na modelagem e na análise pode resultar em cenários insuficientes para atender os objetivos.

$\mathrm{Na}$ defesa do uso da simulação, as desvantagens acima citadas têm sido minimizadas por meio dos seguintes argumentos:

- Fornecedores de softwares de simulação têm continuamente desenvolvido pacotes que contêm um tipo de template de modelos préconcebidos nos quais é necessário somente definir os dados da operação.

- Muitos fornecedores de softwares também têm desenvolvido pacotes com ferramentas que facilitam a análise dos dados de saída da simulação. 
- $\quad$ Os avanços nas plataformas computacionais permitem que a simulação seja realizada cada vez mais rapidamente.

Os modelos de simulação neste caso são analisados por métodos numéricos ao invés de métodos analíticos. Isto é, em vez de métodos analíticos que empregam o raciocínio dedutivo/matemático para resolver um modelo, consideram-se métodos numéricos que empregam procedimentos computacionais para executar os modelos matemáticos.

Os modelos quando executados geram uma história artificial do sistema baseada nas suposições assumidas. Resultados e observações são então colhidos para serem analisadas e estimar o desempenho do sistema real. Como os modelos de simulação do mundo real são relativamente complexos, e a quantidade de informações manipuladas é muito grande, geralmente utilizam-se computadores para executar a sua simulação.

Em geral, a metodologia para a análise via simulação é dividido em quatro passos principais. (Figura A10)

Figura A10 - Passos da metodologia para análise via simulação.

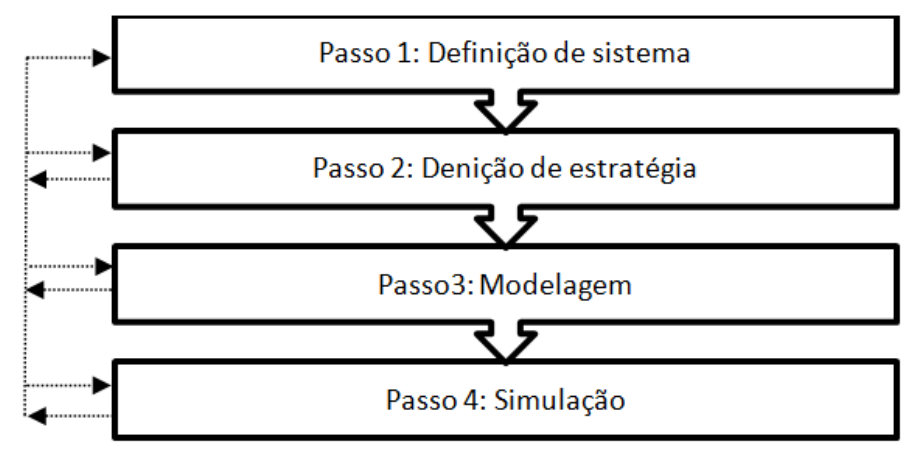

Fonte: Adaptado de Miyagi (1996)

Passo 1: Definição do sistema - A principal atividade deste passo é obter as informações necessárias sobre o sistema e construção do modelo a ser simulado. Todos os requisitos de sistema devem ser considerados.

Passo 2: Definição de estratégias - De acordo com a informação adquiridos no passo 1, são definidas as estratégias de controle da simulação, isto é, quais os cenários a serem testados.

Passo 3: Modelagem - Por exemplo considerando a modelagem baseada em RdP conforme descrito anteriormente, primeiramente, um modelo conceitual é obtido 
usando a técnica de PFS. Em seguida, o modelo é refinado até um modelo funcional que pode ser uma RdP devidamente interpretada.

Passo 4: Simulação - Uma vez que os modelos são construídos, a simulação é executada para numa primeira fase verificar e validar o modelo e depois disso, fornecer informações sobre o comportamento do sistema, permitindo, por exemplo, a detecção de ocorrência de bloqueios (deadlocks), de estados não desejados, etc. A partir de dados de simulação a avaliação de desempenho também pode ser obtida.

A simulação de SEDs é própria para a análise de sistemas no qual o estado (discreto) das variáveis muda apenas com a ocorrência de eventos (considerados instantâneos). Neste sentido, têm sido desenvolvidas uma série de ferramentas para edição, simulação e análise de RdPs. Um levantamento sobre as ferramentas mais importantes pode ser encontrado em Störrle (1998), onde são destacadas suas principais características e os seus prós e contras. 